Argonne

ANL/DIS-13/18

\title{
Integrating Solar PV in Utility System Operations
}

Decision and Information Sciences Division 


\begin{abstract}
About Argonne National Laboratory
Argonne is a U.S. Department of Energy laboratory managed by UChicago Argonne, LLC under contract DE-AC02-06CH11357. The Laboratory's main facility is outside Chicago, at 9700 South Cass Avenue, Argonne, Illinois 60439. For information about Argonne and its pioneering science and technology programs, see www.anl.gov.
\end{abstract}

\title{
Availability of This Report
}

This report is available, at no cost, at http://www.osti.gov/bridge. It is also available on paper to the U.S. Department of Energy and its contractors, for a processing fee, from:

U.S. Department of Energy

Office of Scientific and Technical Information

P.O. Box 62

Oak Ridge, TN 37831-0062

phone (865) 576-8401

fax (865) 576-5728

reports@adonis.osti.gov

\section{Disclaimer}

This report was prepared as an account of work sponsored by an agency of the United States Government. Neither the United States Government nor any agency thereof, nor UChicago Argonne, LLC, nor any of their employees or officers, makes any warranty, express or implied, or assumes any legal liability or responsibility for the accuracy, completeness, or usefulness of any information, apparatus, product, or process disclosed, or represents that its use would not infringe privately owned rights. Reference herein to any specific commercial product, process, or service by trade name, trademark, manufacturer, or otherwise, does not necessarily constitute or imply its endorsement, recommendation, or favoring by the United States Government or any agency thereof. The views and opinions of document authors expressed herein do not necessarily state or reflect those of the United States Government or any agency thereof, Argonne National Laboratory, or UChicago Argonne, LLC. 


\section{Integrating Solar PV in Utility System Operations}

by

A. Mills, ${ }^{2}$ A. Botterud, ${ }^{1}$ J. Wu,,${ }^{1,4}$ Z. Zhou, ${ }^{1}$ B-M. Hodge,${ }^{3}$ M. Heaney ${ }^{3}$ ${ }^{1}$ Argonne National Laboratory

${ }^{2}$ Lawrence Berkeley National Laboratory

${ }^{3}$ National Renewable Energy Laboratory

${ }^{4}$ University of Chicago

October 2013 



\section{Contents}

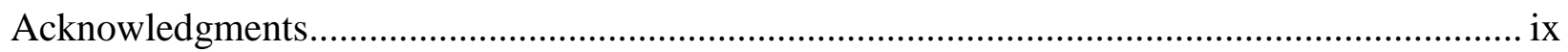

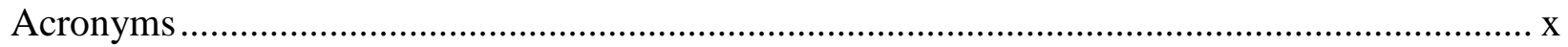

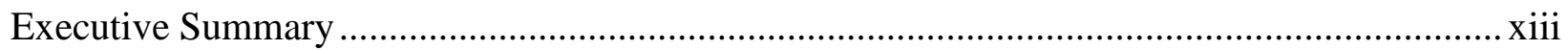

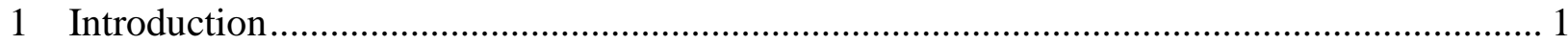

2 Background: Existing Utility Practices and Changes to Those Practices with Increased PV Deployment ................................................................................. 5

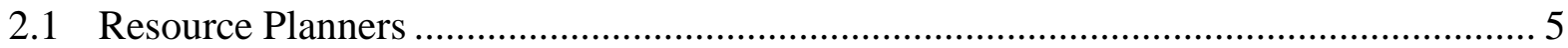

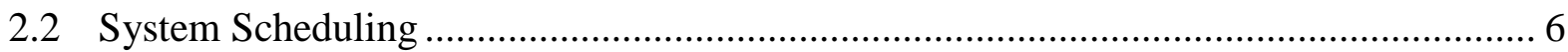

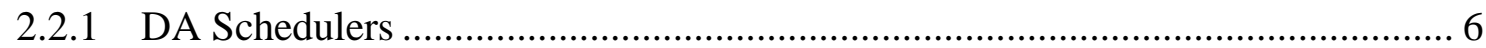

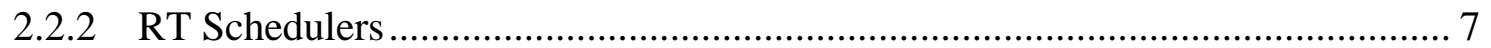

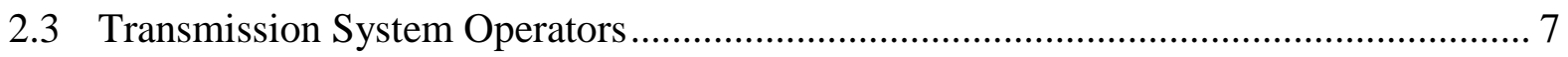

2.4 Expected Changes with Increased PV Generation ................................................ 8

3 Analytical Framework for Modeling the Impact of Increased PV ................................... 9

3.1 Operating Reserve Requirements ................................................................... 10

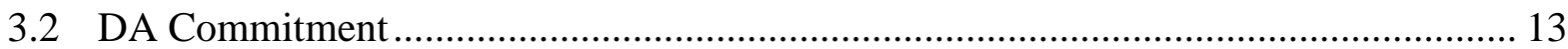

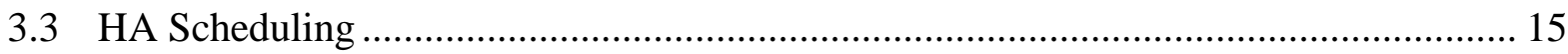

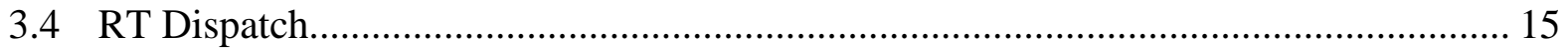

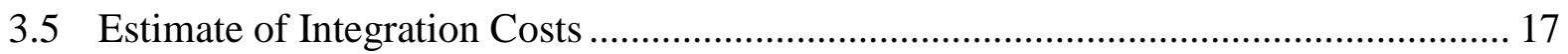

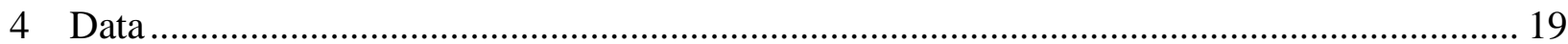

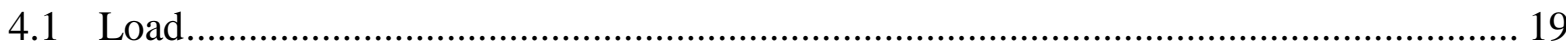

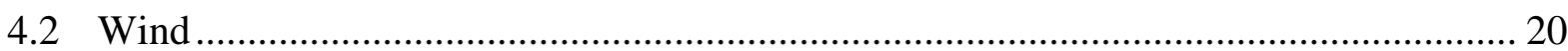

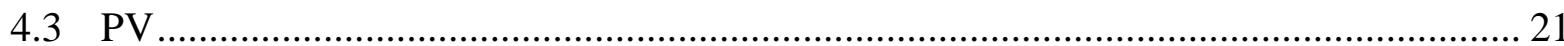

4.4 Forecasting Errors ............................................................................................... 23

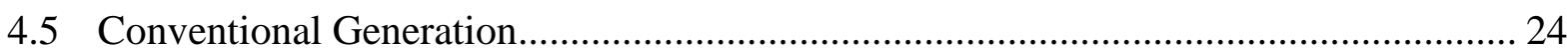

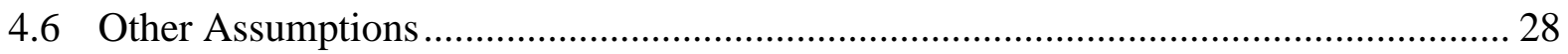

5 Impact of PV with Base Assumptions ........................................................................ 29

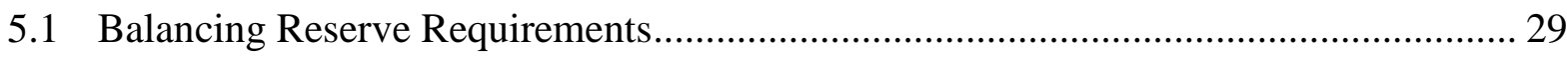

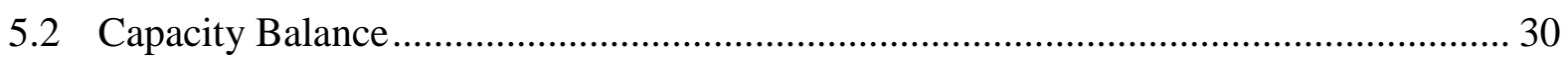

5.3 DA Commitment and HA Schedules ..................................................................... 33

5.4 Detailed Thermal Generation Dispatch and Rescheduling between DA and HA......... 40

5.5 RT Deployment of Balancing Reserves and CPS2 Performance................................ 44

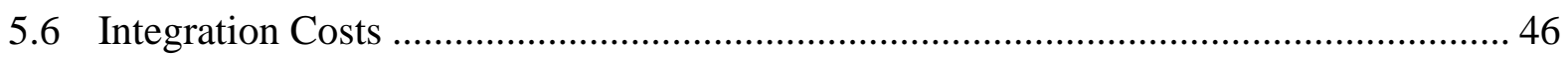




\section{Contents (Cont.)}

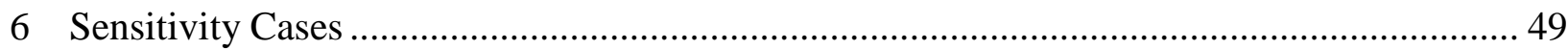

6.1 Sensitivity to Change in Historical Weather Year in the Low-PV Scenario .................. 49

6.2 Sensitivity to Change in Individual Parameters in the High-PV

(Flex. Nucl.) Scenario ........................................................................................ 50

6.2.1 Change in Balancing Reserves and CPS2 Score............................................. 51

6.2.2 Impact of Changes in Flexibility................................................................... 54

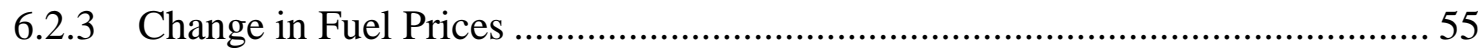

6.2.4 Removing Load and Wind DA Forecast Errors............................................... 56

6.2.5 Summary of Single-Parameter Sensitivity Cases Based on the High-PV (Flex. Nucl.) Scenario..................................................................... 57

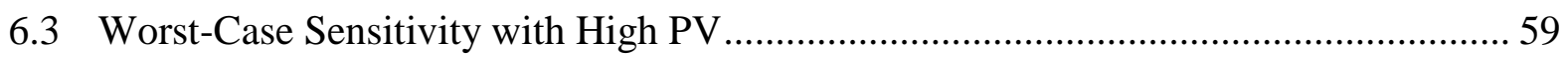

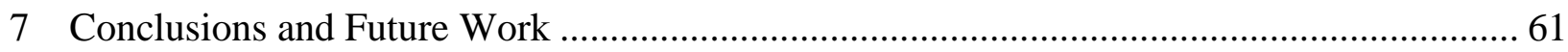

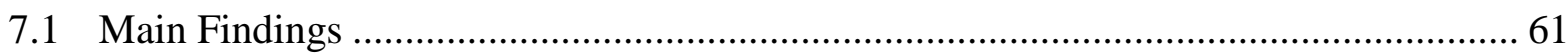

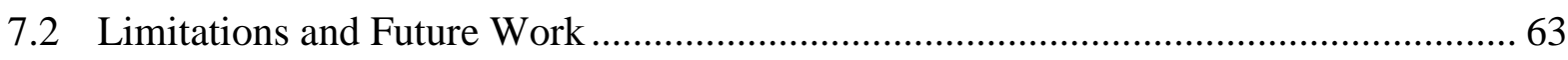

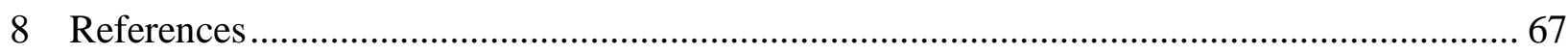

Appendix A Approach for Simulation of 1-min PV Data …………………………............. 71

Appendix B Balancing Reserve Calculations and Simulation of CPS2 Score ........................... 81

Appendix C DA/HA Commitment and Dispatch Model Formulation ...................................... 109

Appendix D Additional HA Scheduling Results ................................................................. 115

Appendix E Location of Wind and Solar Sites................................................................. 119 


\section{Tables}

ES-1 Impact of PV in 2027 Using Base Assumptions .......................................................

1 Method Used to Create Balancing Reserve Rules for Load and Wind and

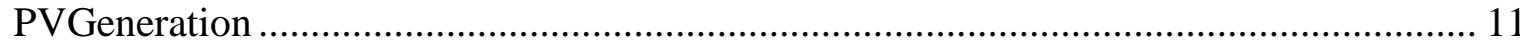

2 Operating Reserve Categories Used in DA and HA Scheduling ..................................... 12

3 Description of Scenarios Used to Evaluate the Impacts of PV (2027) ............................. 19

$4 \quad$ Normalized Forecasting Error Statistics for Load, Wind, and Solar PV in 2027 .............. 23

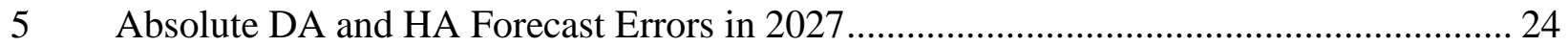

$6 \quad$ Generator Capacity and Fuel Price by Technology ……….............................................. 25

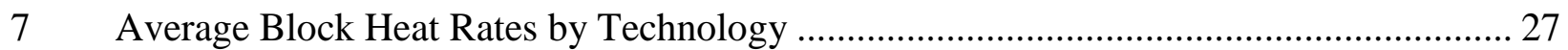

$8 \quad$ Start-up Cost, and Variable Cost Assumptions by Technology ……................................. 27

9 Minimum on, Minimum off, and Cold Start-up Times by Technology ……….................. 27

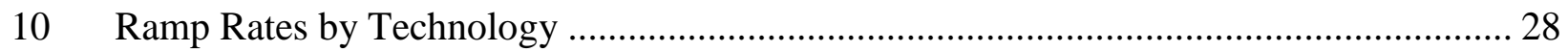

11 Balancing Reserve Requirements in HA for the Load-Wind and Net Load in the Low-PV and High-PV Scenarios ..................................................................... 30

12 Summary of HA Energy Scheduling Results for Low-PV Scenario.................................... 36

13 Summary of HA Reserve Scheduling Results for Low-PV Scenario .................................. 36

14 Summary of HA Energy Scheduling Results for High-PV Scenarios ................................ 37

15 Summary of HA Reserve Up Scheduling Results for High-PV Scenarios ......................... 37

16 Summary of HA Reserve Down Scheduling Results for High-PV Scenarios .................... 38

17 Unmet Spinning Reserves in HA Schedule for Low-PV and High-PV Scenarios.............. 38

18 Total Curtailment of Renewable Energy in HA Schedule for Low-PV and

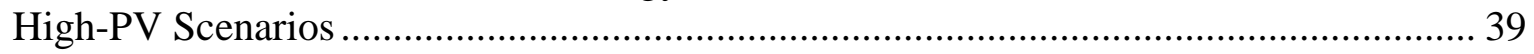

19 Natural Gas Consumption and DA vs. HA Schedule Deviations in the Low-PV and High-PV Scenarios ................................................................................ 44

20 Resulting CPS2 Score for the Load-Wind and Net Load in the Low-PV and

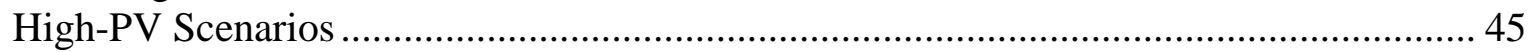

21 Total Costs and Solar PV Integration Costs for Low-PV and High-PV Scenarios............. 46

22 Sensitivity of Balancing Reserve Rules to Choice of Historical Weather Year ................. 49

23 Total Cost and Estimates of Integration Costs for the Low-PV Scenario and 2004 Weather Sensitivity Case.................................................................................... 50

24 Overview of Sensitivity Cases for High-PV 2027 Scenario …………………………....... 51

25 BR Requirements and CPS2 Score in Sensitivity Cases for the High-PV Scenario .......... 52

26 Total Cost and Estimated Integration Costs in BR Sensitivity Cases of the

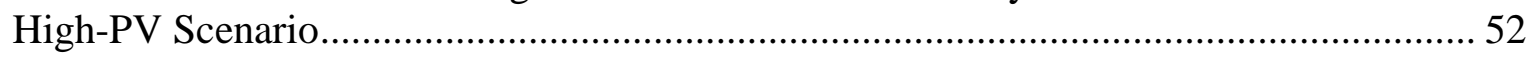




\section{Tables (Cont.)}

27 Renewable Curtailment in the BR Sensitivities to the High-PV Scenario 53

28 Total Cost and Estimated Integration Costs in Balancing Reserve Sensitivity Cases of the High-PV Scenario ............................................................................ 55

29 Renewable Curtailment in the Flexibility Sensitivities to the High-PV Scenario ............. 55

30 Total Cost and Estimated Integration Costs in Fuel Price Sensitivity Cases

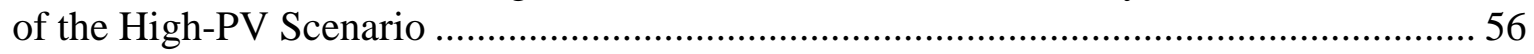

31 Renewables Curtailment in the Fuel Price sensitivities to the High-PV Scenario ............ 56

32 Total Cost and Estimated Integration Costs in Forecast Sensitivity Cases

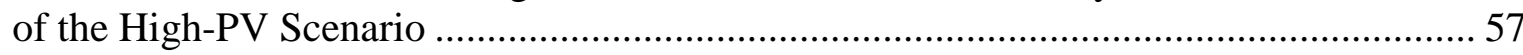

33 Total Cost and Estimated Integration Costs in the Worst-Case Sensitivity of the High-PV Scenario 60

34 Renewable Curtailment in the Worst-Case Sensitivity to the High-PV Scenario............. 60

B-1 HA Forecast Methods for Different Resources ......................................................... 83

B-2 Assumptions Used to Estimate BR Rules in the Low-PV Case and Evaluate Their

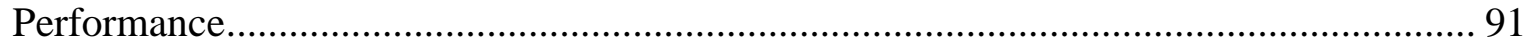

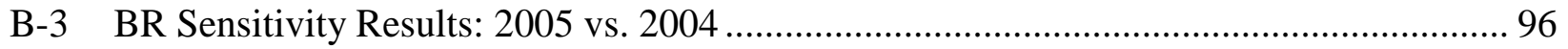

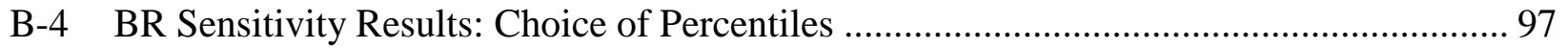

B-5 BR Sensitivity Results: ACE Smoothing Filter ..................................................... 98

B-6 BR Sensitivity Results: BR Ramp Rates .................................................................. 99

B-7 BR Sensitivity Results: Forecast Lead Time.............................................................. 100

B-8 BR Sensitivity Results: Inter-Hour Ramps ............................................................. 101

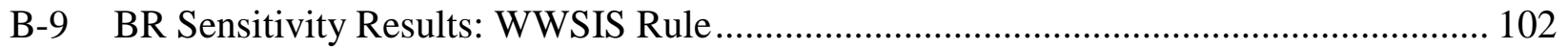

B-10 Summary of BR Sensitivity Results .................................................................... 102

B-11 Overview of Operating Reserve Methods .............................................................. 105

D-1 Summary of HA Energy Scheduling Results for the Low-PV Scenario........................ 115

D-2 Summary of HA Energy Scheduling Results for the High-PV Scenario (2027) ............ 115

D-3 Summary of HA Energy Scheduling Results for the High-PV (Flex. Nucl). Scenario ... 116

D-4 Summary of HA Reserve Scheduling Results for the Low-PV Scenario ....................... 116

D-5 Summary of HA Reserve Scheduling Results for the High-PV Scenario...................... 117

D-6 Summary of HA Reserve Scheduling Results for the High-PV Scenario...................... 117

E-1 Location and Configuration of PV Systems for APS .............................................. 119

E-2 Location of Expected APS Wind Sites.............................................................. 120 


\section{Figures}

ES-1 PV Integration Cost Estimates for Sensitivity Cases Using the High-PV Scenario with Flexible Nuclear Operations as a Benchmark ......................................... xvi

ES-2 Tradeoff Between Balancing Performance and Integration Cost of PV ........................ xvii

1 Overview of Main Steps in Analytical Framework........................................................ 9

2 Illustration of Method Used To Simulate Deployment of Balancing

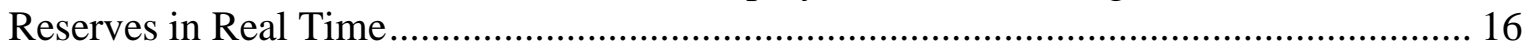

3 Estimated HA Load Schedule for 2027, Chronological and Sorted in Descending Order ........................................................................................... 20

4 Estimated HA Wind Schedule for 2027, Chronological and Sorted in Descending Order.

5 Estimated HA Solar PV Schedule for 2027, Chronological and Sorted in

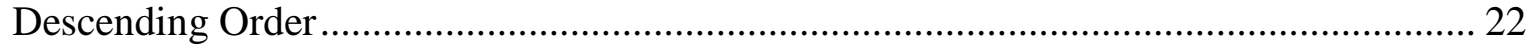

6 Aggregate Supply Curve for Thermal Generators in APS System for 2027 .................. 26

7 Balancing Reserve Requirements for Load-Wind and for Net Load over the Year in the Low-PV Scenario and High-PV Scenario ............................................... 29

8 Capacity Balance for Low-PV and High-PV Scenario in 2027 .................................... 31

$9 \quad$ Net Load and Must Run Capacity for Low-PV and High-PV Scenarios in 2027 ............. 33

10 HA Energy Schedule in Peak-Load Week, July 18-24, under the Low-PV and High-PV Scenarios

11 HA Energy Schedule in Minimum-Load Week, March 7-13, under the Low-PV and High-PV Scenarios

12 Daily Deviation between HA and DA Energy Schedules for Main Thermal Technologies in Low-PV and High-PV Scenarios

13 ACE Resulting from a Mismatch between Deviations from the HA Schedule and Deployment of Balancing Reserves in RT in the Low-PV Scenario and the High-PV Scenario.

14 Daily Increases in Total Costs due to HA BR Increase and DA Forecast

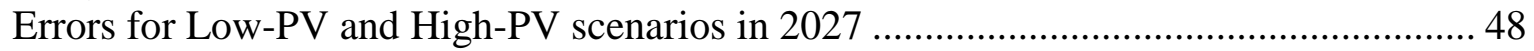

15 Tradeoff Between Balancing Performance and Integration Cost of PV ........................ 54

16 Renewable Energy Curtailment as a Percentage of Total Available Resources for High-PV Sensitivity Cases

17 PV Integration Cost Estimates for High-PV Sensitivity Cases ..................................... 58

18 Total Cost Estimates for High-PV Sensitivity Cases .................................................. 59

A-1 Simulation Approach to Generate a Time Series of Aggregate PV Production with 1-min Resolution 


\section{Figures (Cont.)}

A-2 Cumulative Probability Distribution Function of the 1-min Clear Sky Index for Different Hourly Average Clear Sky Index Values Derived from the DOE ARM Network

A-3 Power Spectral Density of Normalized Sub-hourly Variability for Different Values of the Hourly Average Clear Sky Index ..................................................... 74

A-4 Coherence of Normalized Clear sky Index as a Function of Distance between Sites Based on a Best Fit to Equation 1 ............................................................... 75

A-5 Simulated PV Production Data at Each Individual Site and Aggregated for a Clear and Cloudy Day in April ..... 77

A-6 Evaluation of Large Ramps in Aggregate PV Production Depending on the Clock Minute of the Hour 78

B-1 Process Used to Establish and Validate Balancing Reserve Rules ................................ 81

B-2 Illustration of Method Used to Create Wind Power Forecasts ...................................... 83

B-3 Illustration of Conversion of Flat Hourly Forecast into HA Schedule with Ramps ......... 83

B-4 Illustration of 1-min Deviations from the HA Schedule .............................................. 84

B-5 Illustration of Balancing Reserves Rules Derived from Analysis of 1-min Deviations .... 84

B-6 BR Rules for Wind Conditioned on HA Wind Schedule ............................................... 85

B-7 BR rule for PV Conditioned on the Clear Sky Production............................................. 86

B-8 BR rules for the Load Conditioned on the Hour of the Day .......................................... 87

B-9 Balancing Reserves Rules over the Full Year for 2005 for the Load, Wind, PV, and Net Load

B-10 Illustration of Reserves Deployment Based on Deviations and Limited by BR Rules 89

B-11 Illustration of ACE Based on Deviations Not Met by Deployment of BR .................... 89

B-12 CPS2 Violations Occur Only When 10-min Average of ACE Exceeds L10................... 90

B-13 BR Rules can be Revised to Reduce ACE, Reduce Violations, and Ensure Compliance with NERC Balancing Standards

B-14 Schedules, Deviations from the Schedule, and ACE for an April Day in 2005 along with the Annual ACE, All Based on the Load ....

B-15 Schedules, Deviations from the Schedules, and ACE for the Same April 2005 Day along with the Annual ACE, All Based on the Wind.

B-16 Schedules, Deviations from the Schedules, and ACE for the Same April 2005 Day along with the ACE, All Based on the PV

B-17 Schedules, Deviations from the Schedules, and ACE for the same April 2005 Day along with the ACE, All Based on the Net Load 


\section{Acknowledgments}

This report has been prepared by Argonne National Laboratory (Argonne), Lawrence Berkeley National Laboratory (LBNL), and National Renewable Energy Laboratory (NREL). Argonne, LBNL, and NREL are U.S. Department of Energy laboratories operated under contracts DE-AC02-06CH11357, DE-AC02-05CH11231, and DE-AC02-05CH11231.

The authors acknowledge the U.S. Department of Energy SunShot Initiative for funding the research presented in this report. We also thank Arizona Public Service Company (APS) for providing data and important guidance to our analysis. We are also grateful to the reviewers of a draft version of this document, including Ron Flood (APS), Brendan Kirby, Jan Kleissl (University of California, San Diego), Venkat Banunarayanan (U.S. Department of Energy), Tim Mason (Black \& Veatch Energy), Canan Uckun (Argonne), and Brett Bethke (Argonne).

The authors are solely responsible for the content of this report and any omissions or errors contained herein. 


\section{Acronyms}

$\mathrm{AC}$

$\mathrm{ACE}$

AGC

APS

ARM

Bcf

BA

BR

CAISO

CC

CPS

CT

DA

DC

DCS

DOE

ED

EIM

EWITS

EMS

FERC

FFT

GW

GWh

HA

$\mathrm{hr}$

ICE

IRP

ISO

$\mathrm{L}_{10}$

$\min$

MILP

MW

MWh alternating current

area control error

automatic generation control

Arizona Public Service Company

Atmospheric Radiation Measurement

billion cubic feet

balancing authority

balancing reserve

California Independent System Operator

combined cycle

Control Performance Standard

combustion turbine

day-ahead

direct current

Disturbance Control Standard

U.S. Department of Energy

economic dispatch

energy imbalance market

Eastern Wind Integration and Transmission Study

energy management system

Federal Energy Regulatory Commission

Fast-Fourier Transform

gigawatt(s)

gigawatt-hour(s)

hour-ahead

hour(s)

Intercontinental Exchange

Integrated Resource Plan

independent system operator

a threshold parameter used in estimating CSP2

minute(s)

mixed integer linear program

megawatt(s)

megawatt-hour(s) 
NERC North American Electric Reliability Corporation

NREL National Renewable Energy Laboratory

NSRDB National Solar Radiation Database

O\&M operations and maintenance

PSD power spectral density

PV photovoltaic

RPS Renewable Portfolio Standard

RT real time

ST steam turbine

UC unit commitment

WECC Western Electricity Coordinating Council

WWSIS Western Wind and Solar Integration Study 
This page intentionally left blank. 


\section{Executive Summary}

Deployment of solar photovoltaic (PV) power generation is growing rapidly in the United States. Utilities and system operators are increasingly conducting studies of the impact of PV on operations, including assessments of short-term variability and uncertainty. Consideration of the complex issues surrounding sub-hourly variability and forecasting of PV power output has still been somewhat limited because of the difficulty of creating realistic sub-hourly PV datasets and forecast errors for future scenarios with increased PV production. How utility operations should be changed to more economically integrate large amounts of solar PV power is an open question currently being considered by many utilities. This study develops a systematic framework for estimating the increase in operating costs due to uncertainty and variability in renewable resources, uses the framework to quantify the integration costs associated with sub-hourly solar power variability and uncertainty, and shows how changes in system operations may affect these costs. Toward this end, we present a statistical method for estimating the required balancing reserves to maintain system reliability along with a model for commitment and dispatch of the portfolio of thermal and renewable resources at different stages of system operations. We estimate the costs of sub-hourly solar variability, short-term forecast errors, and day-ahead (DA) forecast errors as the difference in production costs between a case with "realistic" PV (i.e., subhourly solar variability and uncertainty are fully included in the modeling) and a case with "well behaved" PV (i.e., PV is assumed to have no sub-hourly variability and can be perfectly forecasted). In addition, we highlight current practices that allow utilities to compensate for the issues encountered at the sub-hourly time frame with increased levels of PV penetration.

In this analysis we use the analytical framework to simulate utility operations with increasing deployment of PV in a case study of Arizona Public Service Company (APS), a utility in the southwestern United States. In our analysis, we focus on three processes that are important in understanding the management of PV variability and uncertainty in power system operations. First, we represent the decisions made the day before the operating day through a DA commitment model that relies on imperfect DA forecasts of load and wind as well as PV generation. Second, we represent the decisions made by schedulers in the operating day through hour-ahead (HA) scheduling. Peaking units can be committed or decommitted in the HA schedules and online units can be redispatched using forecasts that are improved relative to DA forecasts, but still imperfect. Finally, we represent decisions within the operating hour by schedulers and transmission system operators as real-time (RT) balancing. We simulate the DA and HA scheduling processes with a detailed unit-commitment (UC) and economic dispatch (ED) optimization model. This model creates a least-cost dispatch and commitment plan for the conventional generating units using forecasts and reserve requirements as inputs. We consider only the generation units and load of the utility in this analysis; we do not consider opportunities to trade power with neighboring utilities. We also do not consider provision of reserves from renewables or from demand-side options.

We estimate dynamic reserve requirements in order to meet reliability requirements in the RT operations, considering the uncertainty and variability in load, solar PV, and wind resources. Balancing reserve requirements are based on the $2.5^{\text {th }}$ and $97.5^{\text {th }}$ percentile of 1-min deviations from the HA schedule in a previous year. We then simulate RT deployment of balancing reserves 
using a separate minute-by-minute simulation of deviations from the HA schedules in the operating year. In the simulations we assume that balancing reserves can be fully deployed in $10 \mathrm{~min}$. The minute-by-minute deviations account for HA forecasting errors and the actual variability of the load, wind, and solar generation. Using these minute-by-minute deviations and deployment of balancing reserves, we evaluate the impact of PV on system reliability through the calculation of the standard reliability metric called Control Performance Standard 2 (CPS2). Broadly speaking, the CPS2 score measures the percentage of 10-min periods in which a balancing area is able to balance supply and demand within a specific threshold. Compliance with the North American Electric Reliability Corporation (NERC) reliability standards requires that the CPS2 score must exceed $90 \%$ (i.e., the balancing area must maintain adequate balance for $90 \%$ of the 10-min periods). The combination of representing DA forecast errors in the DA commitments, using 1-min PV data to simulate RT balancing, and estimates of reliability performance through the CPS2 metric, all factors that are important to operating systems with increasing amounts of PV, makes this study unique in its scope.

\section{Results}

We analyze the impact of distributed and utility-scale PV on the APS system based on projected conventional generation, load, and wind and PV resources in 2027. Two PV deployment levels are considered: low PV is based on the PV that APS includes in its 2012 Integrated Resource Plan (IRP) base case, and high PV is based on the PV penetration that APS includes in the expanded renewables case of the IRP. The low-PV case includes sufficient PV to meet $8.8 \%$ of the annual energy, and the high-PV case includes enough PV to meet $17.0 \%$ of the annual energy (prior to any curtailment of renewables). Both cases also consider wind penetration of $4.9 \%$ of annual energy. Based on existing practices at APS five of the eight coal plants are treated as must-run units that can dispatch between minimum and maximum generation, but they cannot be turned off. Similarly, nuclear units are always operated at full nameplate capacity. We find that the combination of must-run generation, inflexible nuclear operations, and large amounts of solar in the high-PV case leads to severe operational challenges during low-load and high solar periods under the assumption that the utility cannot trade power with neighboring utilities. For a high-PV case to be practical, some solution to these challenges will be necessary. We included a "flexible nuclear" case as one option for introducing flexibility during low-load and high solar periods. The impacts of this level of PV deployment under the assumption of constant nuclear operation in the low-PV and high-PV cases and the alternative flexible nuclear operation in the high-PV case are summarized in Table ES-1.

The assumption of flexible nuclear operation in the high-PV flexible nuclear case (where all the nuclear units can operate below maximum output and can provide reserves) decreases the integration cost and greatly reduces the need to curtail renewables from almost $18 \%$ down to $3.4 \%$ of available renewables. 
Table ES-1. Impact of PV in 2027 Using Base Assumptions

\begin{tabular}{|c|c|c|c|c|}
\hline & \multirow{2}{*}{$\begin{array}{l}\text { Load-Wind } \\
\text { No PV }\end{array}$} & \multicolumn{3}{|c|}{ Net Load } \\
\hline & & Low PV & $\begin{array}{c}\text { High PV } \\
\text { (Const. Nucl.) }\end{array}$ & $\begin{array}{c}\text { High PV } \\
\text { (Flex. Nucl.) }\end{array}$ \\
\hline PV nameplate capacity (MW-ac) & 0 & 1,674 & 2,974 & 2,974 \\
\hline Energy from $\mathrm{PV}$ (\% annual demand) & $0 \%$ & $8.8 \%$ & $14.3 \%$ & $16.8 \%$ \\
\hline Renewable curtailment (\% renewable energy) & $0 \%$ & $2.9 \%$ & $17.8 \%$ & $3.4 \%$ \\
\hline Maximum balancing reserve up (MW) & 187 & 278 & 556 & 556 \\
\hline Average balancing reserve up (MW) & 132 & 171 & 241 & 241 \\
\hline CPS2 score (must be >90) & 96.1 & 95.8 & 92.6 & 92.6 \\
\hline \multicolumn{5}{|l|}{ Integration Cost } \\
\hline Balancing reserve cost (\$/MWh-PV) & $\mathrm{N} / \mathrm{A}$ & 1.61 & 3.56 & 1.11 \\
\hline DA forecast error cost ( $\$$ MWh-PV) & $\mathrm{N} / \mathrm{A}$ & 0.27 & 0.21 & 0.63 \\
\hline Total PV integration cost ( $\$ / M W h-P V)$ & $\mathrm{N} / \mathrm{A}$ & 1.88 & 3.77 & 1.74 \\
\hline
\end{tabular}

The addition of PV increases the variability and uncertainty between HA scheduling and RT operations. Additional balancing reserves are added in both the up and down direction to manage this uncertainty and variability. The peak and average requirement for balancing reserves in the up direction without PV, with low PV, and with high PV are summarized in Table ES-1, along with the estimated integration costs for low PV, high PV with constant nuclear operation, and high PV with flexible nuclear operation. The total integration cost is primarily due to the cost of holding resources in reserve during the HA scheduling that can then be deployed in RT to manage remaining uncertainty and variability (balancing reserve cost). The remaining portion of the costs (DA forecast error cost) is from redispatch of online generation, changes in UC within the operating day for peaking units, and imperfect UC decisions for other units based on imperfect forecasts between the DA and HA scheduling.

On the basis of the RT simulations of minute-by-minute deviations from the HA schedule, we find that the balancing reserves based on the $2.5^{\text {th }}$ to $97.5^{\text {th }}$ percentile of deviations are sufficient to achieve a CPS2 score that exceeds NERC minimum standards of a CPS2 score of $90 \%$ (Table ES-1), though none of the cases achieve APS's current practice of aiming to maintain a 99\% CPS2 score. The decrease in the CPS2 score, particularly in the high-PV scenario, indicates there is some degradation of CPS2 performance when balancing reserves requirements are based on the $2.5^{\text {th }}$ to $97.5^{\text {th }}$ percentile of deviations, an issue we address through sensitivity studies.

We conduct an extensive sensitivity analysis of system cost and reliability, using the high-PV (Flex. Nucl.) scenario as a benchmark, under different assumptions about balancing reserves, system flexibility, fuel prices, and forecasting errors. For these sensitivities we find integration costs vary within the range of $\$ 1.0$ to $\$ 4.4 / \mathrm{MWh}-\mathrm{PV}$ (Figure ES-1). The majority of the integration cost is due to an increase in the cost of balancing reserves held during HA scheduling, whereas DA forecast errors continue to be a smaller contributor to integration costs. Figure ES-1 shows that changes in fuel prices and forecast assumptions for wind and load do 
have an effect on integration costs, but the impacts are less pronounced compared to those for the other sensitivities, which are discussed in more detail below.

In the sensitivities related to balancing reserves, we examine two options for increasing the CPS2 performance with high PV penetration: (1) increase the amount of balancing reserve held in the HA or (2) increase the maximum rate of deployment (change from our initial assumption of full deployment in $10 \mathrm{~min}$ to full deployment in $5 \mathrm{~min}$ ). Either option increases the CPS2 score to more than $95 \%$, but both also increase the integration costs. There is clearly a trade-off between integration costs and the utility's reliability level (Figure ES-2); the proper balance between the two will depend on the priorities of the utility.

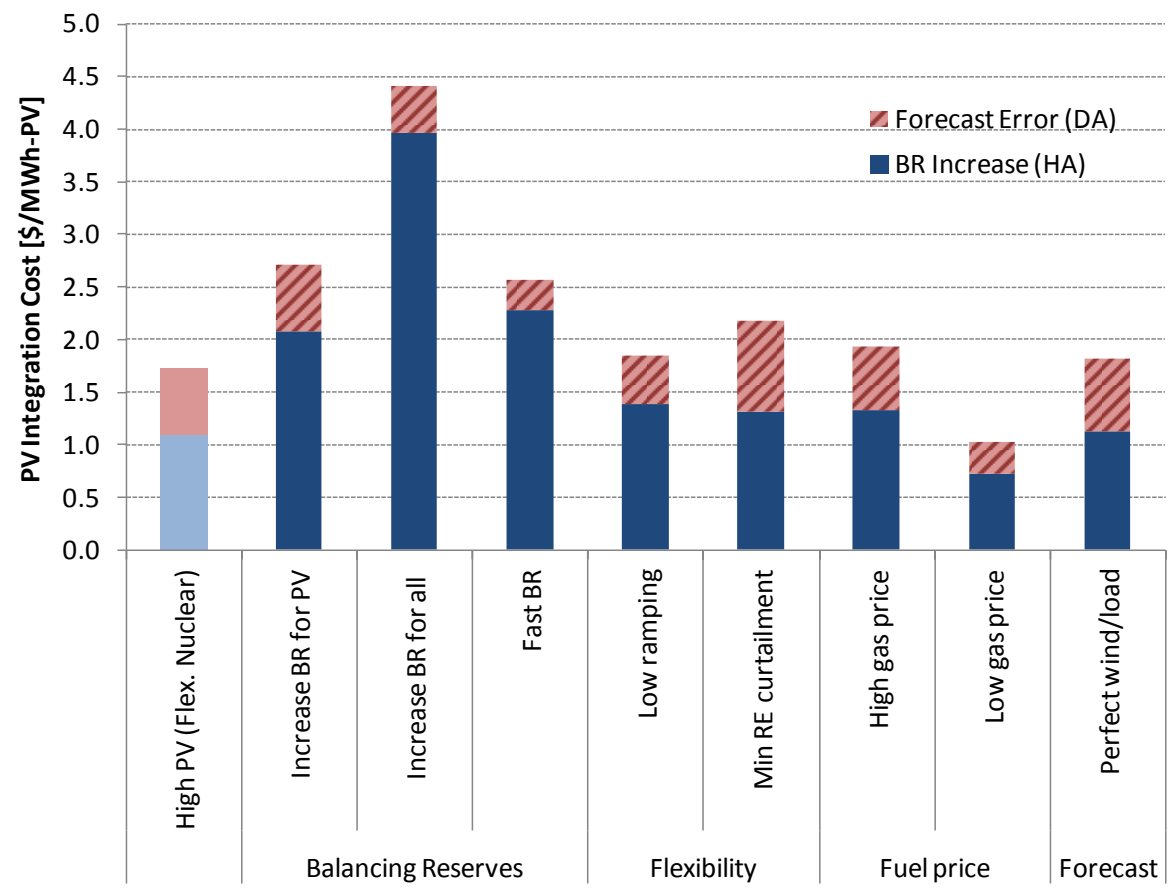

Figure ES-1. PV Integration Cost Estimates for Sensitivity Cases Using the High-PV (2027) Scenario with Flexible Nuclear Operations as a Benchmark 


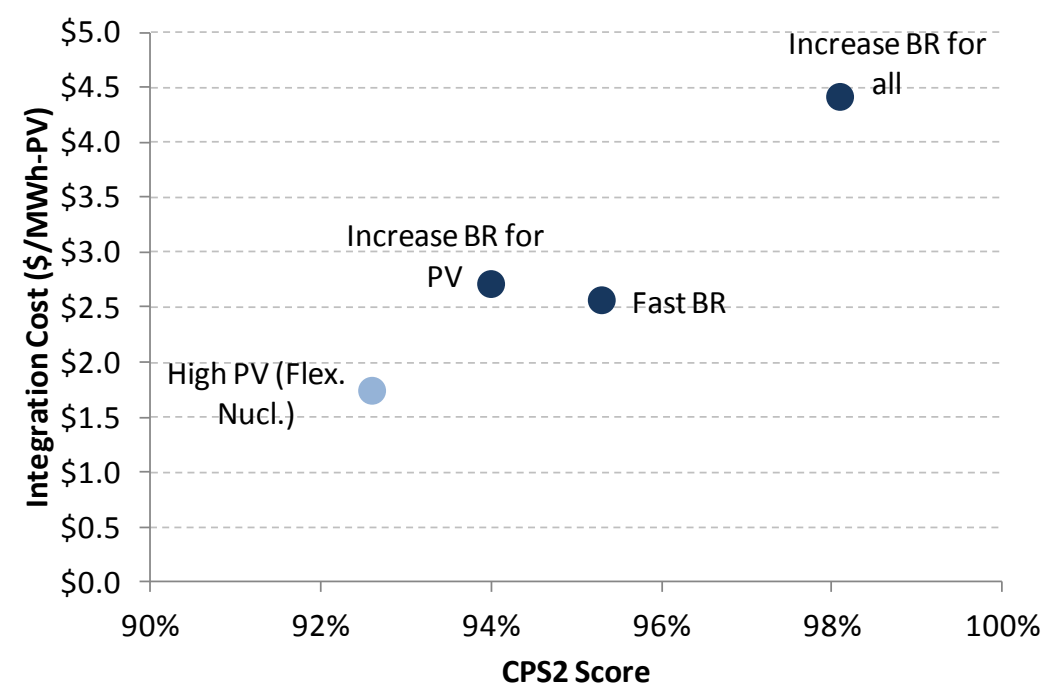

Figure ES-2. Tradeoff Between Balancing Performance (CPS2 Score for Net Load) and Integration Cost of PV

On the basis of the sensitivities related to flexibility, we find that system flexibility is essential for minimizing integration costs. Flexibility is particularly important in this analysis because we assume that the utility absorbs all generation within its service territory (i.e., we assume that there are no opportunities to trade with neighboring utilities). In addition to the comparison of constant and flexible nuclear operations with high PV mentioned earlier, we show the impact of reduced system flexibility by reducing the capabilities of thermal generators to ramp from one hour to the next and minimizing curtailment of renewable energy. Renewables curtailment can be reduced to less than $1 \%$ by artificially introducing a large penalty for renewable curtailment into the UC/ED model. However, minimizing this curtailment changes the dispatch of thermal units and also results in an increase in the integration cost (Figure ES-1). Lower ramp rates of thermal units also increase the integration costs.

To further highlight the importance of flexibility, we constructed a worst-case scenario in which limits to flexibility (including constant nuclear output, low ramp rates for other thermal generators, and penalties on renewables curtailment) and increased balancing reserve requirements were simultaneously assumed. In this worst case, the integration cost increases to $\$ 9.6 / \mathrm{MWh}$ and renewables curtailment exceeds $10 \%$ of available renewable generation (despite the penalties for renewable curtailment), and it also becomes challenging to meet the balancing reserve requirements with frequent occurrences of reserve shortfalls. This case is unrealistic given the combination of several conservative assumptions regarding system flexibility and the actual ability of the utility to trade with other utilities. However, the results do highlight the importance of finding buyers for excess power during times with high PV production or the need to increase flexibility from existing thermal power plants or other resources. 


\section{Limitations and Future Work}

This case study does have a number of limitations that should be considered in the examination of these conclusions. Simulations of future deployments of variable generation are always challenging because of the need to synthesize high-time resolution production and forecasts that reflect geographic diversity. The methods used in this study to synthesize 1-min PV production data are based on existing methods applied for wind power, but not otherwise applied to power from solar PV. Anomalies in the data may overstate short-term PV variability. Furthermore, the thermal plant characteristics were developed from publicly available datasets and likely differ from true plant performance.

There are also limitations based on the simplifications used to model actual strategies and procedures used by utilities. For instance, the model does not fully reflect the flexibility to make recommitment decisions at any time between DA and HA scheduling. This may understate the flexibility available from the thermal generators. On the other hand, the revised dispatch and commitments in the HA were made with a single run of the optimization model over a 24-hr period based on the assumption that the HA forecasts are known. This modeling assumption may understate the costs of managing variability and uncertainty. We also did not include transmission constraints within the utility footprint.

Another important limitation of this case study is that we did not model exchange with the broader Western Electricity Coordinating Council (WECC) area outside of the utility boundaries, an assumption that is likely to overstate the challenges with low-net-load periods, particularly if neighboring utilities are adding less renewables to their systems. These impacts could also be mitigated with the inclusion of APS in any of the proposed Energy Imbalance Markets (EIM) currently being examined in the Western Interconnection. This new sub-hourly real time energy market would provide access to more flexibility that might prevent significant amounts of renewables curtailment, and also reduce the costs associated with sub-hourly solar variability. In addition, the NERC Board of Trustees recently approved a new balancing standard that would replace the CPS2 with an alternative reliability metric. This new balancing standard may also alter the balancing reserve requirements in scenarios with high PV. Last, we did not remove any thermal generation capacity from the low-PV portfolio when the amount of PV was increased in the high-PV scenario, although PV is likely to have some capacity value. If refined estimates of the impact of PV on system operations, cost, and reliability are required, these limitations should be addressed.

Overall, we only investigated a small subset of the potential future sources of system flexibility in this study. Additional sources for flexibility include demand side programs that shift load into low net-load periods or energy storage. Demand resources can also contribute to the provision of operating reserves. Another important source of flexibility not considered in this study is the potential provision of reserves from wind and utility-scale solar resources. As long as the utility can send a control signal to these resources they can provide operating reserves, particularly in the down direction. Contributions to system flexibility from demand resources and renewables may very well be easier to implement than flexible nuclear operations as investigated in this analysis. In future work, we therefore recommend exploring these additional sources of system flexibility. 
In this study, we did not consider dynamic balancing reserves that change based on expected weather conditions. In particular, if probabilistic forecasts are available they could be used to ensure that there was low probability of clouds before reserves would be reduced. This would potentially decrease the balancing reserve requirements for PV and lower integration costs accordingly. Factoring weather forecasts into the dynamic estimation of balancing reserves represents an interesting direction for future work. Finally, the potential use of stochastic scheduling strategies that make direct use of probabilistic forecasts to commit and dispatch system resources is also an area of active research. In this case, the mathematical objective of the scheduling problem is to minimize operating cost over a range of forecast scenarios for renewable generation. Hence, balancing reserves are scheduled implicitly rather than imposed as explicit reserve requirements. The potential benefits of stochastic scheduling for system cost and reliability is also an area we want to explore in future work. 
This page intentionally left blank. 


\section{Introduction}

Solar power is increasingly becoming an important contributor to global electricity systems, with more than $95 \mathrm{GW}$ of photovoltaic (PV) power installed globally at the end of 2012 (IEA 2013). This growth in PV capacity is expected to be sustained in the United States through compliance with state Renewables Portfolio Standards (RPS) that mandate a certain percentage of electricity be produced from renewable sources and growth in customer-sited PV. Because solar PV power output is both variable and uncertain, there are concerns about how its inclusion in system operations in significant amounts affects traditional power systems operations. Solar PV power follows a very clear diurnal cycle because of the changing position of the sun and, with no intrinsic storage capability, is not available to supply power during hours of darkness. While the expected power output during the day, assuming a clear sky, can be accurately calculated in advance, instances of clouds moving over a PV array lead to short-term variability in power output and imperfect forecasts. Large solar installations on the megawatt scale are currently being added to the transmission system; however, a large number of solar installations are also being introduced at the distribution level, on residential and commercial rooftops. The impact of this difference in PV siting can be seen in both the expected variability and uncertainty. In general, aggregated distributed PV is less variable than utility-scale installations for the same capacity (Marcos et al. 2011a; Mills et al. 2011). This is because the same amount of capacity is spread over a larger geographic area, and thus localized weather conditions cannot affect as much of the installed capacity simultaneously. However, most distributed PV is "behind the meter" in that the utility is unaware of its output and sees its impact only through reduced demand. This can cause issues with the integration of distributed PV because of increased loadforecasting errors caused by the utility being unaware of the magnitude of the distributed PV presence.

To understand the impacts of this increase in solar PV power production on electricity systems, simulations of power system operations with high penetrations, or grid integration studies, are often conducted by utilities and independent system operators (ISOs). The number of grid integration studies that include solar PV power is growing (GE Energy 2010; Ma et al. 2011; Black \& Veatch 2012a; CAISO 2010; Navigant Consulting et al. 2011). However, consideration of the complex issues surrounding sub-hourly variability and forecasting of PV power output has still been somewhat limited because of the difficulty of creating realistic sub-hourly PV datasets and forecast errors for future scenarios with increased PV production. Important parts of power system operations affected by sub-hourly variability and uncertainty include regulation reserves requirements and sub-hourly dispatch. How these operations can be changed to more economically integrate large amounts of solar PV power is an open question currently being considered by many utilities.

The goals of this work are to (1) develop a systematic framework for analyzing implications for operating procedures and corresponding increases in operating costs due to uncertainty and variability in renewable resources and (2) use the framework to quantify the integration costs and reliability implications associated with sub-hourly solar power variability and uncertainty and to show how changes in system operations may affect these costs. We estimate the costs of subhourly solar variability, short-term forecast errors, and day-ahead (DA) forecast errors as the 
difference in production costs between a case in which sub-hourly solar variability and uncertainty are fully integrated into the analysis, and the case in which these factors are ignored. In addition, we highlight current practices that allow utilities to compensate for the issues encountered at the sub-hourly time frame with increased levels of PV penetration. Throughout the report, we highlight instances in which the approach used in this study differs from or is similar to those in previous studies.

We chose Arizona Public Service Company (APS) as an example utility for a case study. APS is an affiliate of Pinnacle West Capital Corporation and the largest utility in the state of Arizona. APS serves more than 1.1 million customers covering a service territory of almost 35,000 square miles. As a vertically integrated utility, APS has more than 8,600 MW of generation, 5,300 miles of transmission lines, and 28,000 miles of distribution lines. APS has excellent solar resources located within its service territory and is expecting a large increase in solar power installations in the near future, making it a natural choice for a test system.

In order to analyze the impact of solar variability and uncertainty, we utilize a unit commitment (UC) and economic dispatch (ED) model of power system operations with renewable energy (Wang et al. 2011; Zhou et al. 2012; Botterud et al. 2013). The load and wind and solar generation datasets for the APS system consist of time series of the electricity demand, wind power output, and solar power output at a 1-min level for the area and time period under study. In order to separate the impacts of the solar variability and uncertainty, this analysis also includes forecasts of the wind and solar power output at different time frames relevant for system operations, here assumed to be DA and hour-ahead (HA). These datasets rely heavily on wind and solar profiles developed as part of the Western Wind and Solar Integration Study (WWSIS) (Potter et al. 2008), ${ }^{1}$ with selected locations chosen to model expected installations in the APS service territory. In addition, 1-min solar data were synthesized by using an approach that starts with hourly satellite-derived solar data for each site and then adds sub-hourly variability. The method of synthesizing sub-hourly variability accounts for the correlation of variability between sites on sub-hourly time scales and the amount of sub-hourly variability that would be expected for a particular level of cloudiness.

Using the models and data described above, we then identify changes to existing procedures that could allow APS to maintain compliance with reliability standards while increasing the amount of solar PV installed in its system. The primary changes we focus on in this analysis are increases in balancing reserves and revised dispatch within the operating day.

The analysis quantifies the amount of additional balancing reserves that should be held in the DA and HA scheduling to ensure that adequate resources are available to be deployed in real time (RT), even with increased forecast errors and increased variability. We also simulate the redispatch of generating units between DA and HA scheduling; a method of managing forecast errors as the uncertainty in the forecasts is reduced closer to the operating hour. We assess the

1 The WWSIS Phase 1 wind dataset uses a common method to join together individual 3-day simulations for each wind site. This method does not have a severe effect on a small number of sites, but may lead to an overstatement of wind variability every 3 days at 16:00 MST. Since this study uses only 21 wind sites, we do not expect this problem to have a significant impact on the sub-hour variability of wind. Additional details on this issue are described at www.nrel.gov/electricity/transmission/pdfs/western_dataset_irregularity.pdf. 
cost implications of these changes to the APS procedures by comparing the costs of operating the system with all these changes with the costs that would have been incurred had these factors been ignored. We rely on various sensitivity scenarios to examine how sensitive these costs and the performance of the APS system is to various assumptions about balancing reserves, capabilities of thermal generating units, and the level of solar PV power deployment.

The remainder of this report is structured as follows. Section 2 provides a high-level overview of the current practices at APS based on discussions between the authors and representatives from the utility. Section 3 describes the analytical framework developed in this study to create a more simplified model of APS operations to quantitatively examine the impacts of increased solar PV and the effectiveness of various responses available to APS. Section 4 describes the dataset and assumptions used to simulate the APS system. The results of the case study of the APS system using this model and dataset are presented in Section 5. In Section 6 several sensitivity cases are presented to better understand the potential impacts of PV on utility system operations. Section 7 discusses the implications of the results and the sensitivity cases and provides conclusions and recommendations for additional research. The appendices describe the model, datasets, and intermediate results in more detail. 
This page intentionally left blank. 


\section{Background: Existing Utility Practices and Changes to Those Practices with Increased PV Deployment}

In order to better understand current utility practices, the authors met with APS representatives from functional areas, including resource planning, generation scheduling, and transmission system operations. Although our case study focus is on the APS system, other vertically integrated utilities with a large expansion of renewable energy are likely to use similar utility practices and face the same types of operational challenges related to the uncertainty and variability in renewable resources.

\subsection{Resource Planners}

APS recently completed an integrated resource plan (APS 2012) that forecasted needs out to 2027 and examined several candidate portfolios to meet its generation needs. Based in part on satisfying the Arizona RPS requirement, the base case resource portfolio includes more than 1,400 MW of utility-owned and customer-sited PV by 2020 and more than 1,600 MW by 2027 (roughly a 9\% PV penetration by 2027 on an energy basis). An expanded renewables portfolio also examined by APS would include a further 1,300 MW of utility-owned PV by 2027 for a total of more than 2,900 MW of PV on the APS system (roughly a 17\% PV penetration by 2027 on an energy basis). These portfolios would also include more than $250 \mathrm{MW}$ of wind in 2020 and more than $650 \mathrm{MW}$ of wind by 2027 (roughly a 5\% penetration of wind by 2027). The total resources in each candidate portfolio are sufficient to meet the forecasted peak demand accounting for the relatively low peak capacity contribution of PV and wind. The future capacity plan provided in the integrated resource plan (APS 2012) includes the company's projections of both capacity retirements and capacity additions between 2012 and 2027.

The resource planners examined the performance of each candidate portfolio using a detailed production cost model called PROMOD IV (from Ventyx), which simulates the dispatch of the APS portfolio along with the broader Western Electricity Coordinating Council (WECC) market. The production cost model used in the analysis accounts for hourly variation in load and wind and solar generation profiles along with the operational cost related to starting and stopping power plants when needed (though not the wear-and-tear costs associated with starting and stopping units). The production cost model does not directly account for DA or short-term uncertainty or sub-hourly variability of load, wind, and PV. To compensate for the lack of representation of those factors in the production cost model results, APS adds an integration cost to the cost of portfolios depending on the amount of renewable energy included in the portfolio. Our analysis of integration costs is structured to provide more detail into the magnitude and drivers of this type of integration cost. One factor that will make integration relatively easier in the future is that APS expects portfolios to include a significant amount of new, flexible aeroderivative gas turbine power plants (GE LMS 100 units). 


\subsection{System Scheduling}

APS schedulers create generation plans for generating units available to APS to meet expected load and operating reserves less the amount of energy expected from nondispatchable renewables generation. In addition, these schedulers try to identify opportunities to buy power from and sell power to neighboring utilities when economically advantageous. The scheduling is split between a DA trading desk and a RT trading desk. The DA desk completes the plan for the next operating day by 3 p.m., at which time scheduling is transitioned to the RT desk for the remainder of the day through the operating day. Since PV power output is considered to be nondispatchable it is not currently considered in the DA scheduling process. This is especially true for distributed solar PV, since there is little visibility into its output available to the system operator.

\subsubsection{DA Schedulers}

The DA plan is used to make commitments of generation, particularly large thermal units with long start-up times, and to nominate the amount of natural gas that is expected to be consumed by the gas-fired generators. The DA desk uses forecasts of load to estimate how much demand needs to be served. Currently, APS receives wind forecasts for the wind generation assets owned by APS from an external wind forecast vendor. The planned solar thermal plant with thermal storage will also provide APS with forecasts. APS does not yet use a solar PV forecast in its DA scheduling. In addition, APS uses computer asset optimization software that includes the operating characteristics of its power plants to assist in the creation of DA plans.

Trades for power occur through bilateral agreements with power marketers, other generators, or other utilities in the WECC. These trades occur over the Intercontinental Exchange (ICE) trading platform. In addition, APS is increasingly participating in the California Independent System Operator (CAISO) DA market, which has a pricing node at Palo Verde in Arizona.

Before the DA plan is finalized, the DA schedulers are provided an estimate of the amount of contingency reserves that APS is required to maintain during the operating day. This amount is determined per agreement with the Southwest Reserve Sharing Group using a formula that accounts for each member's hourly loads, purchase and sale transactions, and thermal generation, at least $50 \%$ of which must be held as spinning reserve. APS also maintains a relatively constant amount of regulating reserves, no less than $1.5 \%$ of anticipated load, and usually between $30-80 \mathrm{MW}$. Aside from these operating reserves, the DA desk factors in a slight buffer of additional generating capacity that is not otherwise committed in case it is needed during RT. Normally APS includes a reserve margin of $7 \%$ of demand, or a reserve margin of $9 \%$ on warm days, in the DA schedule. This amount is equivalent to the amount of contingency reserve plus the regulating reserve, though it is adjusted based on experience and operator judgment. 


\subsubsection{RT Schedulers}

At the close of the DA plan, responsibility for implementation and adjustment to the plan is transitioned to the RT schedulers. The RT desk uses the obligations from the DA plan and assessments of the conditions throughout the operating day to make adjustments. These adjustments may include making additional bilateral trades with other utilities, changing the timing or need for APS power plants being turned on or off, and changing the power plant dispatch. The RT desk is constantly monitoring the actual load, generating unit capacity and dispatch levels, reserve amounts and obligations, and renewable production throughout the operating day.

Because WECC scheduling rules between balancing areas are currently based on hourly schedules, the RT desk finalizes schedules over the APS interties at $30 \mathrm{~min}$ prior to the start of the operating hour. Hourly schedules in WECC include a ramp between hours that begins $10 \mathrm{~min}$ prior to the start of the operating hour and ends after the first $10 \mathrm{~min}$ in the operating hour. The RT desk can continue to call on resources internal to APS within the operating hour as needed (including starting quick-start units), but trades between APS and other regions are effectively unavailable except for under more extreme circumstances.

\subsection{Transmission System Operators}

The transmission system operators ensure the APS grid is operated in a reliable manner by monitoring power flows on the transmission system, voltages, and reserve levels. In addition, the system operators use an automated energy management system (EMS) to send signals to generation enabled with automatic generation control (AGC) to correct for any remaining imbalances between the generation levels set by the RT desk and the actual load (i.e., regulation). APS indicates that nearly all its generation assets can participate in AGC except for large inflexible power plants that are manually scheduled.

In case of an unexpected loss of generation or transmission (i.e., a contingency), the system operators deploy contingency reserves from APS and call on available resources from a contingency reserve sharing group if needed. The system operators try to ensure that contingency reserves are not used unless an event occurs. APS faces penalties from the reserve sharing group if the APS contingency reserve obligation is not maintained on average over each operating hour.

APS operators are obligated to meet several North American Electric Reliability Corporation (NERC) reliability standards including three related to balancing the APS system. ${ }^{2}$ At any instant, the Area Control Error (ACE) measures the degree to which APS system operators are able to maintain a balance between load and generation. The NERC standards rely in part on the

2 The NERC Board of Trustees recently approved a new balancing standard (BAL-001-2 - Real Power Balancing Control Standard) which replaces the CPS2 score mentioned here with a new metric based on the Balancing Authority ACE Limit or BAAL). The new standard changes the balancing requirements in a way that makes it more important for a BA to correct deviations that contribute to interconnection-wide imbalances and less important to correct for deviations that help mitigate interconnection-wide imbalances. It also expands the averaging period from 10 minutes in the CPS2 metric to 30 minutes. 
ACE and are known as Control Performance Standard (CPS) 1, CPS2, and Disturbance Control Standard (DCS). CPS1 monitors the degree to which ACE at APS coincides (both in terms of timing and the direction of imbalance) with aggregate imbalances in the larger interconnection on a minute-by-minute basis. CPS2 monitors how frequently the 10-min average ACE at APS exceeds a threshold called the utility's $\mathrm{L}_{10}$ parameter, which is currently about $46 \mathrm{MW}$ for APS. DCS sets the rate by which APS needs to recover from a large event such as the sudden loss of a generator and return the system to normal operation. NERC standards specify minimum performance standards, and APS tries to consistently exceed these minimum standards. For instance, APS aims to keep the 10-min average ACE within the minimum $\mathrm{L}_{10}$ threshold $99 \%$ of the time within the month, even though the NERC CPS2 standard requires that the ACE must be within $\mathrm{L}_{10}$ at least $90 \%$ of the time within a month. Similarly, other balancing areas in WECC maintained their ACE to within their respective minimum $\mathrm{L}_{10}$ threshold level 96 to $98 \%$ of the time between 2004 and 2009 (Neve 2013).

\subsection{Expected Changes with Increased PV Generation}

The introduction of large amounts of variable renewable generation (here defined as wind and solar power) will require changes in the procedures and processes used to operate the system. In particular, current practices account for the uncertainty and variability of the load; as solar and wind output is increasingly added to the portfolio, the uncertainty and variability from the variable generators will also need to be managed. Forecasts of wind and solar output will need to be integrated into the DA planning along with the load forecasts. Because these forecasts are not perfect, the economic dispatch process used by the RT desk will need to increasingly adjust the output levels of plants during the operating day. These adjustments will also need to rely on a combination of the short-term forecasts of wind and solar power output and the short-term load forecasts. With increased PV, schedulers will likely need to increase the amount of generation available within the operating hour to adequately compensate for deviations from the HA schedules (GE 2010; Ma et al. 2011; Black \& Veatch 2012a; CAISO 2010; Navigant 2011). Increased regulation reserves that are used to account for variability around the schedule in the 4-sec to 5-min time scale will be increasingly deployed and may also need to be increased (CAISO 2010; Navigant 2011; Ma et al. 2011). 


\section{Analytical Framework for Modeling the Impact of Increased PV}

We develop a simplified model of the process described in the previous section to simulate the utility operations with increasing deployment of PV. In our analysis, we focus on three processes that are important to understanding the management of PV variability and uncertainty in power system operations (Figure 1). First, we represent the decisions made by the DA desk as the DA commitment. Second, we represent the decisions made by the RT desk prior to the close of the RT dispatch as the HA scheduling. Finally, we represent decisions made by the RT desk and transmission system operators after the close of the RT market as RT balancing. We simulate the DA and HA scheduling processes with a detailed unit-commitment (UC) and economic dispatch (ED) optimization model. This model creates a least-cost dispatch and commitment plan for the conventional generating units using forecasts and reserve requirements as inputs. Like system schedulers must do, we develop a method to estimate requirements for reserves that are held in the DA and HA scheduling process. These reserve requirements are chosen with the aim of maintaining sufficient reliability to meet NERC requirements during RT operations. We simulate RT balancing using a separate minute-by-minute simulation based on deviations from the HA schedules. The minute-by-minute deviations account for HA forecasting errors and the actual variability of the load, and wind and solar generation. Using these minute-by-minute deviations, we calculate the resulting CPS2 performance for each scenario to evaluate the impact of PV and the choice of reserve requirements on system reliability. The different parts of the analytical framework are discussed in further detail in the sections below.

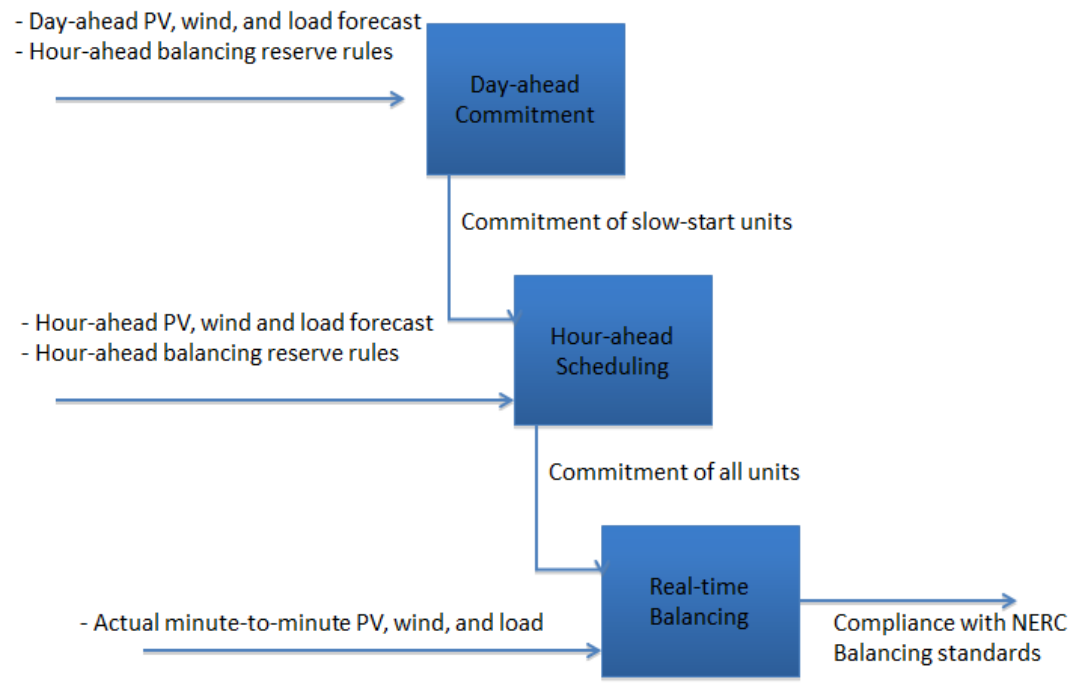

1. Overview of Main Steps in Analytical Framework 


\subsection{Operating Reserve Requirements}

In addition to balancing supply and demand in each hour during the DA and HA scheduling, the model must also meet operating reserve requirements. The operating reserves in the model comprise two types of reserves: contingency reserves and balancing reserves. The deployment of contingency reserves to recover from unexpected events, such as the sudden loss of a large conventional power plant, is not explicitly modeled in this analysis. Instead, we require that the contingency reserve requirement must be met at all times (DA, HA, and RT). As in common utility practice, half of the contingency reserve requirement can be met by non-spinning resources, while the remaining contingency reserves must be met by spinning resources.

The balancing reserves are constraints that must be met in the DA and HA scheduling. In contrast to contingency reserves, we assume that balancing reserves are deployed in RT to manage minute-by-minute deviations from the HA schedule, as described further in the section on RT dispatch. ${ }^{3}$ The amount of balancing reserves available in each hour is based on a set of rules that dynamically change the balancing reserves depending on conditions. ${ }^{4} \mathrm{We}$ use these rules to determine how much to increase the balancing reserves beyond what is needed for the load alone as more wind and PV generation is added to the mix of generating resources. We develop the rules by examining the magnitude of 1-min deviations from the HA schedule, conditioned on either the hour of the day (in the case of load), the scheduled wind generation level (in the case of wind), or the clear sky solar production level (in the case of PV). We determine the amount of balancing reserves required in the up direction and the down direction based on the magnitude of the 2.5th percentile and 97.5th percentile of deviations for the particular conditions, as described in Table 1. These percentiles are an initial starting point for the balancing reserve rules that are informed by similar assumptions used in a wind integration study for the Southwest Power Pool (CRA 2010). Based on the results, we evaluate alternative choices of percentiles and the tradeoffs between increased balancing reserves and increased operating costs. Our approach of establishing balancing reserve rules based on 1-min deviations from schedules is somewhat similar to the approach developed by PNNL and used in a variety of wind and solar integration studies (e.g., Makarov et al. 2009; Navigant Consulting et al. 2011). The solar integration study conducted by Black \& Veatch (2012a) focused on CPS2 compliance and was therefore able to use 10-min data to estimate reserve requirements. The reserve

3 Throughout this document we use the generic term balancing reserves to refer to resources held in the HA to manage deviations from the HA schedule. These reserves can be deployed within the operating hour through a combination of manual instructions from schedulers/operators or through automatic generation control. In this way balancing reserves encompasses the more technical and specific function called regulating reserves (which generally refers to the resources that are dispatched based on automatic generation control to manage very short term deviations). But balancing reserves and regulating reserves are not identical, since we expect that much of the within-hour deployment of balancing reserves could be done through manual dispatch instructions. Similarly, balancing reserves encompasses load following within the operating hour.

4 Balancing reserves used in this study are called dynamic because the amount held in the DA and HA processes depends on expected conditions. In particular, the amount of balancing reserves varies depending on the hour of day (for the contribution of load to the balancing reserve requirement), the position of the sun and the expected solar production, and the expected wind production level. Other solar integration studies vary reserve requirements by the season and whether it is night or day (Black \& Veatch, 2012a) or by the season and hour of day (Navigant Consulting et al. 2011). Dynamic balancing reserves requirements are commonly used in wind integration studies (e.g., EnerNex Corp. 2010). 
requirements in the Black \& Veatch study vary depending on whether it is daytime and the month of the year. ${ }^{5}$

After setting these rules, we make a further adjustment to the balancing reserve requirements called the feasibility check, as detailed in Table 1. This feasibility check ensures that reserves are held to prepare only for situations that might actually occur. For example, if the HA schedule for wind is $75 \mathrm{MW}$ and the 2.5th percentile deviation (i.e., a large drop in wind production relative to the HA schedule) is $100 \mathrm{MW}$, then it only makes sense to hold at most $75 \mathrm{MW}$ of balancing reserves for wind. While the initial balancing reserve level would be $100 \mathrm{MW}$, we revise the balancing reserve for that particular hour downward to $75 \mathrm{MW}$ after the feasibility check. We apply this feasibility check to both PV and wind generation. The feasibility check accounts for the minimum feasible generation levels (0 MW) and the maximum feasible generation level (the wind nameplate capacity in the case of wind and the highest PV output that could occur given the time of day in the case of PV).

Table 1. Method Used to Create Balancing Reserve Rules for Load and Wind and PVGeneration

\begin{tabular}{|c|c|c|c|c|}
\hline \multirow[b]{2}{*}{ Resource } & \multirow[b]{2}{*}{ Conditional } & \multirow{2}{*}{$\begin{array}{c}\text { Magnitude of Balancing } \\
\text { Reserves for Each } \\
\text { Condition }\end{array}$} & \multicolumn{2}{|c|}{ Adjustments from Feasibility Check } \\
\hline & & & Maximum Increase & Maximum Decrease \\
\hline Load & Hour of the day & $\begin{array}{l}2.5 \text { th to } 97.5 \text { th } \\
\text { percentile of minute-by- } \\
\text { minute deviations from } \\
\text { HA load schedule by } \\
\text { hour of day }\end{array}$ & None & None \\
\hline Wind & $\begin{array}{l}\text { HA schedule for } \\
\text { wind as a fraction } \\
\text { of wind nameplate } \\
\text { capacity (divided } \\
\text { into } 20 \text { equal } \\
\text { segments) }\end{array}$ & $\begin{array}{l}2.5 \text { th to } 97.5 \text { th } \\
\text { percentile of minute-by- } \\
\text { minute deviations from } \\
\text { HA wind schedule for } \\
\text { particular wind } \\
\text { production level } \\
\text { segment }\end{array}$ & $\begin{array}{l}\text { HA schedule for wind } \\
\text { plus the balancing } \\
\text { reserve up for wind must } \\
\text { be less than wind } \\
\text { nameplate capacity. }\end{array}$ & $\begin{array}{l}\text { HA schedule for wind } \\
\text { less the balancing } \\
\text { reserve down for wind } \\
\text { must be greater than } 0 \\
\text { MW. }\end{array}$ \\
\hline PV & $\begin{array}{l}\text { Clear sky } \\
\text { production as } \\
\text { fraction of } \\
\text { nameplate capacity } \\
\text { (divided into } 20 \\
\text { equal segments) }\end{array}$ & $\begin{array}{l}2.5 \text { th to } 97.5 \text { th } \\
\text { percentile of minute-by- } \\
\text { minute deviations from } \\
\text { HA PV schedule for } \\
\text { clear sky PV production } \\
\text { segment }\end{array}$ & $\begin{array}{l}\text { HA schedule for PV plus } \\
\text { balancing reserve up for } \\
\text { PV must be less than the } \\
\text { highest expected output } \\
\text { for current clear sky } \\
\text { conditions. }\end{array}$ & $\begin{array}{l}\text { HA PV schedule less } \\
\text { the balancing reserve } \\
\text { down must be greater } \\
\text { than } 0 \mathrm{MW} \text {. }\end{array}$ \\
\hline
\end{tabular}

We first develop these balancing rules based on the datasets from a 2004 weather year. We then apply these balancing rules to simulations using datasets from a 2005 weather year. This approach accounts for the fact that the utility will not know ahead of time what sort of deviations to expect in RT from the HA schedules, but it can use observed deviations from the previous

5 In addition, the Black \& Veatch study defines the HA schedule as flat through the hour without a 20-min ramp between hours (starting $10 \mathrm{~min}$ before the start of the operating hour and ending $10 \mathrm{~min}$ after the start of the operating hour). 
year to develop rules that can be applied in the current year. The Electricity Reliability Council of Texas (ERCOT) uses a similar approach of measuring deviations of wind generation from the schedule based on a previous time period to set the regulation reserve and non-spinning reserve rules for the current time period (ERCOT 2011). ${ }^{6}$

We assume that the balancing reserves for the HA schedule are also held during the DA scheduling. ${ }^{7}$ In any particular hour we calculate the total balancing reserves as the on the root mean square of the load and wind balancing reserves or the load, wind, and PV reserves. ${ }^{8} \mathrm{We}$ assume the balancing reserves are met with spinning resources that can be fully deployed in 10 min. ${ }^{9}$ The operating reserves imposed on the DA and HA scheduling in this study are summarized in Table 2.

Table 2. Operating Reserve Categories Used in DA and HA Scheduling

\begin{tabular}{lllll}
$\begin{array}{l}\text { Reserves in } \\
\text { Scheduling }\end{array}$ & Spinning (upward) & $\begin{array}{c}\text { Non-spinning } \\
\text { (upward) }\end{array}$ & $\begin{array}{c}\text { Spinning } \\
\text { (downward) }\end{array}$ & Notes \\
\hline Balancing & $B R S_{t}^{+}$ & $B R N_{t}^{+}$ & $B R S_{t}^{-}$ & $\begin{array}{c}\text { Values picked to maintain CPS2 score } \\
\text { with or without PV }\end{array}$ \\
Contingency & $C R S_{t}$ & $C R N_{t}$ & $\begin{array}{c}\text { Values do not change in this study, } \\
\text { depend only on current rules. }\end{array}$ \\
Total & $B R S_{t}^{+}+C R S_{t}$ & $B R N_{t}^{+}+C R N_{t}$ & $B R S_{t}^{-}$ & \\
\hline
\end{tabular}

6 As discussed later, we similarly recommend that APS and other utilities begin, if they are already not doing so, measuring and recording the actual deviations experienced in their systems in order to develop and refine balancing reserve rules that can help manage increased wind and PV penetration.

7 This implies that the balancing reserves used in the HA will be known for the same hour during the DA commitment, which in some cases is not possible. It is not an issue with regard to the estimate of the balancing reserves needed for load because the balancing reserve rules for load only depend on the hour of the day. It is also not much of a simplification for PV because PV balancing reserve rules are based on the clear sky solar production (which is known a day ahead). We do, however, make one modification to the reserve rules for PV: we ensure the reserves for PV never assume negative PV production or PV production far above the clear sky production. The adjustments that are made to the reserve rules for PV in HA scheduling are similarly assumed to be known in the DA scheduling. Finally, the assumption that the HA reserves requirements are known in the DA scheduling is a simplification for wind because the reserve requirements are contingent on the HA schedule for wind generation. We assume these reserves will be known in the DA scheduling even though the DA forecast for wind may differ from the HA forecast.

8 The use of the root mean square of the load and wind and PV reserves is based on the assumption that deviations are independent. This assumption is used to generate the total balancing reserves for the net load and is then validated with a minute-by-minute simulation of the total balancing reserves to manage the net-load.

9 Analysis of 1-min deviations indicated that many of the deployments of balancing reserves required full deployment in a short amount of time. However, in one of the cases in Section 6 balancing reserves were increases such that they could manage more of the extreme deviations. In this case, analysis of the more extreme 1-min deviations found not all of the reserves needed to be deployed in 10-min so a portion of the balancing reserves was met by non-spinning reserves. Non-spinning reserves are assumed to be available only after 10-min. This particular case is described further in Section 6. 


\subsection{DA Commitment}

Earlier we described how schedulers at APS need to determine which thermal units will be turned on or off for the next operating day. We simulate these DA commitment decisions using a UC model with unit-specific constraints. These decisions are based on imperfect DA forecasts of PV and wind generation, load, and operating reserve requirements (Table 2). The objective of the DA commitment is to minimize the total cost of meeting the demand and operating reserves for the next day. The UC model is based on previous work on system operations with a large penetration of wind power, which was conducted at Argonne National Laboratory (Wang et al. 2011; Zhou et al. 2012; Botterud et al. 2013). The UC problem is a mixed-integer-linear program (MILP) problem, which we solve with the CPLEX solver. A brief overview of the model is provided below, and a full mathematical description is given in Appendix C.

One of the largest simplifications in this analysis is that we assume that the utility uses its generation to meet its loads and does not trade with other suppliers in WECC. Using this assumption we effectively treat the utility as an isolated system that must have the capabilities to manage all the uncertainty and variability imposed by the load and wind and solar generation without being able to utilize flexibility from elsewhere in the WECC system. As compared to the actual operation of APS today, described earlier, this is a very conservative assumption that tends to overstate the challenges and costs with integrating PV into the system. A further simplification in the model relative to actual practices for APS is that we assume that this commitment decision is binding at the DA scheduling stage for all units except the ones designated to be peaking plants (mainly combustion turbines). Again, this is a conservative assumption relative to current practices at APS, because the RT desk is constantly monitoring the need for units to be started or stopped within the operating day, well before the actual operating hour. This rescheduling may also involve units with longer start-up times such as combined cycle plants. However, we do not have access to intra-day forecasts and do therefore only consider re-scheduling of peaking plants based on HA forecasts in this study.

The objective of the optimization model is to minimize the total cost of meeting the demand for the next day. The operating costs consist of fuel costs and start-up costs for thermal generators. The model has an hourly time resolution, and the optimization is done over a 24-hr time period. Solar PV, wind, and load are represented in the UC model with their predicted values. The subhourly impact of PV is captured by the balancing reserve portion of the operating reserve requirements described above, and imposed as reserve constraints in the UC model. At a high level, the objective function and main constraints can be expressed as follows:

\section{Objective Function}

Minimize (total cost over $24 \mathrm{hr})=$

$$
\sum_{t=1}^{24}\{\text { fuel costs }+ \text { startup costs }+ \text { penalty unserved load }+ \text { penalty unserved reserve }\}_{t}
$$




\section{Main Constraints}

(1) Load-generation balance for all hours, $t$ :

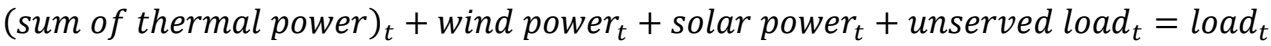

(2) PV dispatch for all hours, $t$ :

Available distribued $P V_{t} \leq$ solar power $r_{t} \leq$ available distributed $P V_{t}+$ available utilityscale $P V_{t}$

(3) Wind dispatch for all hours, $t$ :

$0 \leq$ wind $_{\text {power }} \leq$ available wind power $_{t}$

(4) Spinning and non-spinning reserve up balance for all hours, $t$ :

$(\text { sum of spin res up from thermal plants })_{t}+(\text { unserved spin res up })_{t} \geq C R S_{t}+B R S_{t}^{+}$

(sum of nonspin res from thermal plants $)_{t}+(\text { unserved nonspin res })_{t} \geq C R N_{t}+B R N_{t}^{+}$

(5) Spinning reserve down balance

(sum of spin res down from thermal plants) $)_{t}+(\text { unserved spin res down })_{t} \geq B R S_{t}^{-} \forall t$

(6) Other UC constraints for thermal plants include

min and max generation, block-wise heat rate curves, max ramp rates, and min up and down times.

The objective function contains penalties for unserved load and unmet operating reserve targets. In the case study, we set these penalties to high levels to avoid a situation in which the model finds the costs to be lower if the load was not served or operating reserve targets were not met and instead a penalty was paid. We want to avoid this situation because the RT dispatch simulation assumes that contingency and balancing reserves are fully met in the DA and HA scheduling. As a result of the high penalties, the load is always met in this study and the unserved load in constraint (1) is therefore always zero. Furthermore, the load is considered inflexible and does not respond to prices. This is a conservative assumption, since it is not unlikely that in a future scenario with a smarter grid the demand-side would become more flexible and capable or responding to price signals in the market. However, this important source of system flexibility is not considered in this study.

Constraints (2) and (3) reflect our assumption that solar PV and wind generation can be curtailed, if this is the least-cost solution for the system. However, curtailment of variable generation is limited to wind and utility-scale PV installations, because we assume that system operators have no ability to control or communicate with customer-sited distributed PV.

The operating reserves are split into spinning and non-spinning reserves, as shown in constraints (4) and (5), and are a function of the contingency and balancing reserve requirements (Table 2). 
The model currently assumes that all operating reserves have to be provided by thermal units within the system. In other words, we do not consider potential contributions to operating reserves from responsive demand resources, solar PV, wind, and imports from outside the balancing authority (BA). Demand resources already provide operating reserves in several markets, and renewable resources could also provide reserves, particularly in the down direction. These alternative resources may be able to provide reserves in a more cost-efficient manner, but a requirement is that they can respond continuously to the dispatch of BR in real-time to balance the renewables in the system, which is different from current contingency reserves which are rarely called upon. We have left for future work a more thorough investigation of these important issues, which may enlarge the pool of reserves and increase system flexibility. Hence, the assumption that only thermal resources can provide reserves is also conservative and is likely to underestimate the availability of reserves in a future system. However, in the case study we do consider in some simulations the possibility that nuclear plants can be dispatched down and provide reserves in both directions. Flexible dispatch and reserve provision from nuclear plants would increase the system flexibility substantially, as discussed in the case study, but deviates from current operational procedures at APS. Another limitation is that we do not consider the impact of transmission constraints internal to the utility system in scheduling and dispatch. After discussions with APS, it was clear that current transmission expansion plans are likely to resolve current and potential future bottlenecks in the system. The transmission network internal to the APS system should therefore have limited impact on the optimal scheduling and dispatch. We assume the same is true for this case study.

\subsection{HA Scheduling}

After the DA commitment decisions are made, we assume that the utility will update its schedule in the HA time frame based on the updated HA forecasts of PV, wind, and load. The HA forecast is generally more accurate than the DA forecast. The HA schedule makes adjustments in the commitment decisions for peaking units as needed. We use the same optimization model as in the DA stage to re-commit these quick-start units at the HA stage. In this HA run the commitment status of all units except the quick-start units is fixed from the DA stage. The final HA schedules will end up being more costly than they would have been if load, wind, and PV forecasts were the same at the DA stage as at the HA stage. The higher costs will be due to HA decisions that include re-dispatching generation, turning on quick-start units that would have otherwise not be needed, or in extreme cases not meeting reserve requirements. The implications for RT reliability are investigated through the analysis of CPS2 scores in the RT dispatch, as discussed below.

\subsection{RT Dispatch}

The unit-by-unit commitment and dispatch simulation in the previously described model stops with the HA scheduling. From there, we developed a program (written in the Python language) to simulate the minute-by-minute RT operation of the utility. The program deploys the balancing reserves held in the HA scheduling to meet minute-by-minute deviations from the HA schedules 
(Figure 2). The deployment of the balancing reserves is constrained at any time by the capacity of the balancing reserves that are available in the up or down direction and by the rate at which balancing reserves can be fully deployed, assumed to be $10 \mathrm{~min}$, though we later test other maximum deployment rates. Furthermore, a 5-min moving average filter is applied to the 1-min deviations to set the deployment of balancing reserves because it is not necessary to chase each and every deviation in order to maintain compliance with the NERC CPS2 standard. We assume that a combination of instructions from the RT schedulers and AGC would be able to provide the deployment of balancing reserves modeled with this program. This RT simulation of the deployment of balancing reserves does not account for unit-by-unit specific characteristics and does not use economic optimization to prioritize the deployment of specific units. Instead it simply accounts for the aggregate deployment of all the available balancing reserves.

Any minute-by-minute deviation from the HA schedules that is not met by deployment of balancing reserves leads to a non-zero ACE. The resulting CPS2 score is calculated by examining the number of 10-min periods in which the average ACE over the 10-min period remains within the minimum threshold for the utility specified by the $\mathrm{L}_{10}$ parameter. A CSP2 score of $95 \%$ reported here, for instance, indicates that within $95 \%$ of the 10 -min periods examined over the year, the 10-min average of the ACE was less than $\mathrm{L}_{10}$. For each scenario we simulate the deployment of the balancing reserves and calculate the CPS2 score first for the load and small amount of wind (without any PV) and then again for the load, wind, and PV (what we call the net load).

One important item to note regarding this approach is that reserve requirement rules are determined based on past observations of deviations from schedules. The performance of those reserve rules is then simulated in order to calculate the resulting CPS2 score. In this way, the reserve rules are an input to the simulations and the CPS2 score is an outcome of the actual deployment of reserves. This approach somewhat mimics the information that would be available to schedulers and the outcome of their choices. An alternative simulation approach would be to specify a CPS2 target and determine reserve rules necessary to meet that target

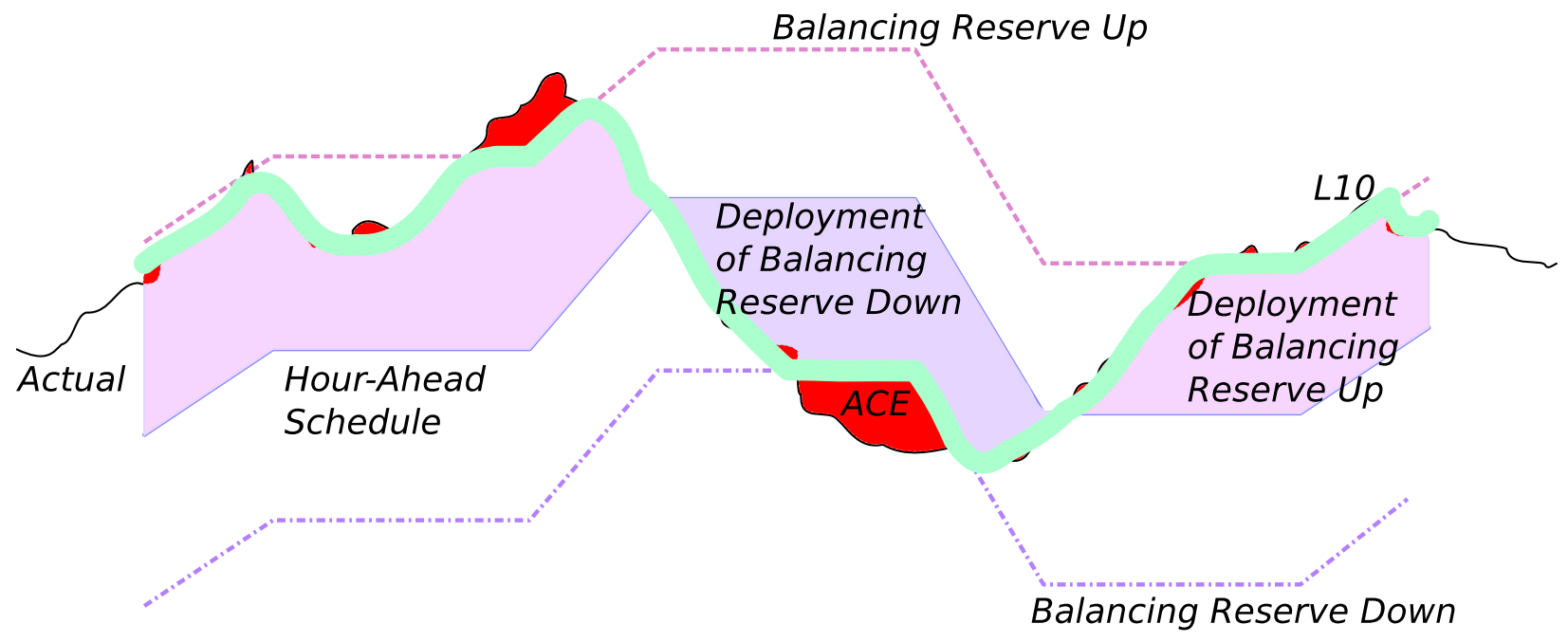

Figure 2. Illustration of Method Used To Simulate Deployment of Balancing Reserves in Real Time 
(i.e. treat the CPS2 score as an input and the reserve rules as an outcome). This allows better control over CSP2 scores across scenarios, but is not, in our opinion, as realistic of a representation of the actual situation faced by system schedulers.

\subsection{Estimate of Integration Costs}

In addition to evaluating the changes in operational practices that utilities will need to consider in order to successfully integrate PV into their power system, we are also interested in understanding the costs associated with DA forecast errors and additional balancing reserves held in the HA scheduling. Utilities like APS can already capture some of the impact of PV on the dispatch of their system by simulating PV in an hourly production cost model without changing balancing reserve requirements and without accounting for DA forecast errors (as in the production cost model runs used by APS resource planners described earlier). We can refer to this as a simulation of "well behaved" PV where hourly variability of PV is captured in the model, but sub-hourly variability and uncertainty in both the DA an HA are not captured. A simulation of "well behaved" PV will account for the smoother changes in PV production from one hour to the next that impact ramping and dispatch of other power plants on an hourly basis. In contrast, we are interested in estimating the magnitude of the costs that are "left out" when utilities assume PV is "well behaved" in a production cost model. In particular we want to estimate the difference in costs between a case in which PV leads to an increase in HA balancing reserves and revised dispatch to manage DA forecast errors and a case in which PV does not require increased balancing reserves and is perfectly forecasted in the DA. We refer to this difference in costs as the "integration costs" of PV. However, we recognize that there is no single accepted definition of the term "integration costs" and no agreed-upon way to correctly calculate such costs (Milligan et al. 2011). That said, we focus on a very specific definition of this cost, which is useful for understanding the magnitude of the costs that would be ignored if we were to instead assume that PV generation was able to be perfectly forecasted in the DA and to not increase the balancing reserve requirement in the HA scheduling. Such an assumption is implicitly made when production cost models are used to simulate the impact of PV without accounting for imperfect forecastability or sub-hourly variability.

In order to estimate this integration cost, we run three simulations and calculate the resulting total production cost (TC) for each case as follows:

1. Perfect, $\boldsymbol{T} \boldsymbol{C}_{\boldsymbol{P}}$. Calculate the total production cost for scenario in which PV is perfectly forecasted in the DA and does not increase balancing requirements for the HA scheduling.

2. HA balancing with no DA forecast errors, $\boldsymbol{T} \boldsymbol{C}_{\boldsymbol{H} \boldsymbol{A}}$. Calculate the total cost for scenario in which the balancing requirement is increased to accommodate PV for the HA scheduling. Maintain the assumption that the DA commitment is based on a perfect DA forecast. 
3. HA balancing and DA forecast errors, $\boldsymbol{T} \boldsymbol{C}_{\boldsymbol{D A}}$. Calculate the total cost for a scenario with both increased balancing requirements in for the HA scheduling and imperfect DA forecasts.

Based on the total production costs estimated in these three cases, we estimate the integration costs as follows:

Cost of the balancing requirement in the HA scheduling (\$/MWh-PV)

$$
\left(T C_{H A}-T C_{P}\right) / E_{p v}
$$

Cost of DA uncertainty (\$/MWh-PV)

$$
\left(T C_{D A}-T C_{H A}\right) / E_{p v}
$$

Cost of uncertainty and balancing reserves

$$
\left(T C_{D A}-T C_{P}\right) / E_{p v}
$$

$=$ Cost of DA uncertainty + cost of balancing reserves $=$ "integration cost" $(\$ / \mathrm{MWh}-\mathrm{PV})^{10}$

10 This definition of "integration cost" is similar to the method used to calculate the integration cost of wind in the Eastern Wind and Transmission Integration Study (EWITS) (EnerNex Corp., 2010):

"The study team computed the cost of managing the delivery of wind energy (i.e., the integration cost) by running a set of comparative production simulations. In these cases, analysts assumed that wind energy did not require carrying additional regulating reserves for managing variability and short-term uncertainty. They also assumed that the hourly wind energy delivery was known perfectly in the unit-commitment step of the simulation $\left[T C_{P}\right]$. The differences in production costs among these cases and the corresponding cases where wind generation is not ideal $\left[T C_{D A}\right]$ can be attributed to the incremental variability and uncertainty introduced by the wind resource."

One difference is that EWITS defines the cost of DA uncertainty as the difference in the cost of the system with DA forecast errors and no additional balancing reserves to the cost of the system with no DA forecast errors and no additional balancing reserves. We define the DA uncertainty as the difference in the cost of the system with DA forecast errors and additional balancing reserves to the cost of the system with no DA forecast errors and additional balancing reserves.

Our approach and the EWITS approach are not the same as the approach used by Black \& Veatch (2012a) in the previous solar integration study. They account only for incremental reserve requirements and do not include a cost associated with DA forecast errors. Further, Black \& Veatch rely on one case in which the load is increased according to the incremental reserve requirements and another in which the load is decreased according to the incremental reserve requirements. The approach used in this study does not change the load based on the reserve requirements; instead, reserves are directly modeled as a constraints in the unit commitment/economic dispatch model. 


\section{Data}

We simulate a case study of the APS system based on projections of the load, renewables, and generation for the year 2027. In the simulations, we maintain relationships between load, wind and PV (at least at an hourly level) using historical data from the same weather year (2005). We develop two scenarios (described in Table 3): one using the 2012 APS Integrated Resources Plan (IRP) base case (low PV) and the other using the expanded renewables case (high PV).

Table 3. Description of Scenarios Used to Evaluate the Impacts of PV (2027)

\begin{tabular}{lccc}
\hline Scenario & $\begin{array}{c}\text { Load } \\
\text { (peak load) }\end{array}$ & $\begin{array}{c}\text { Wind } \\
\text { (nameplate capacity) }\end{array}$ & $\begin{array}{c}\text { PV } \\
\text { (nameplate capacity) }\end{array}$ \\
\hline Low PV & $9,151 \mathrm{MW}$ & $630 \mathrm{MW}$ & $1,674 \mathrm{MW}$ \\
High PV & $9,151 \mathrm{MW}$ & $630 \mathrm{MW}$ & $2,974 \mathrm{MW}$ \\
\hline
\end{tabular}

\subsection{Load}

The load data in this analysis include hourly DA schedules (forecasts), hourly HA schedules (forecasts), and 1-min actual load. To estimate the 2027 load, we scale the historical hourly load from APS by a constant scaling factor of 1.384. The scaling factor is such that the scaled load data matches the projected annual demand for future years in the APS 2012 IRP. Due to data limitations, we did not have access to the DA and HA load schedules from the 2005 weather year, but we did have access to DA and HA load forecast errors recorded by APS in 2010. We therefore create DA load schedules for 2027 by assuming that the historical DA forecast errors that were recorded by APS in 2010 occur with the same magnitude and on the same hour of the year in 2027. We similarly create HA schedules by assuming that historical HA forecast errors recorded by APS in 2010 occur with the same magnitude and on the same hour in 2027 . We do not apply any scaling to the magnitude of DA and HA forecast errors for load. Figure 3 shows the resulting HA load schedule for 2027.

Again due to data limitations, we do not have 1-min load data from the historical 2005 weather year. Instead, we create a 1-min time series of the load by adding 1-min variability recorded over a 44-day period by APS (February 2, 2007 to April 4, 2007) to the hourly load time series. We isolate the 1-min load variability by taking the difference between the 1-min time series and a 1-min interpolation between the hourly averages of the time series based on a cubic spline fit. We then add the 1-min variability to a 1-min cubic spline interpolation of the projected hourly average load in 2027. In order to have a full year of 1-min load data for 2027, we repeat the 44-day series of 1-min variability over and over again throughout the year of 2007 hourly load. We identified and removed five anomalous events in which the ramp rate of the 1-min load appeared to far exceed the ramp rate observed over the remainder of the 44-day period. No scaling was applied to the historical 1-min variability when moving from the historical variability recorded in 2007 and the projected load for 2027. 


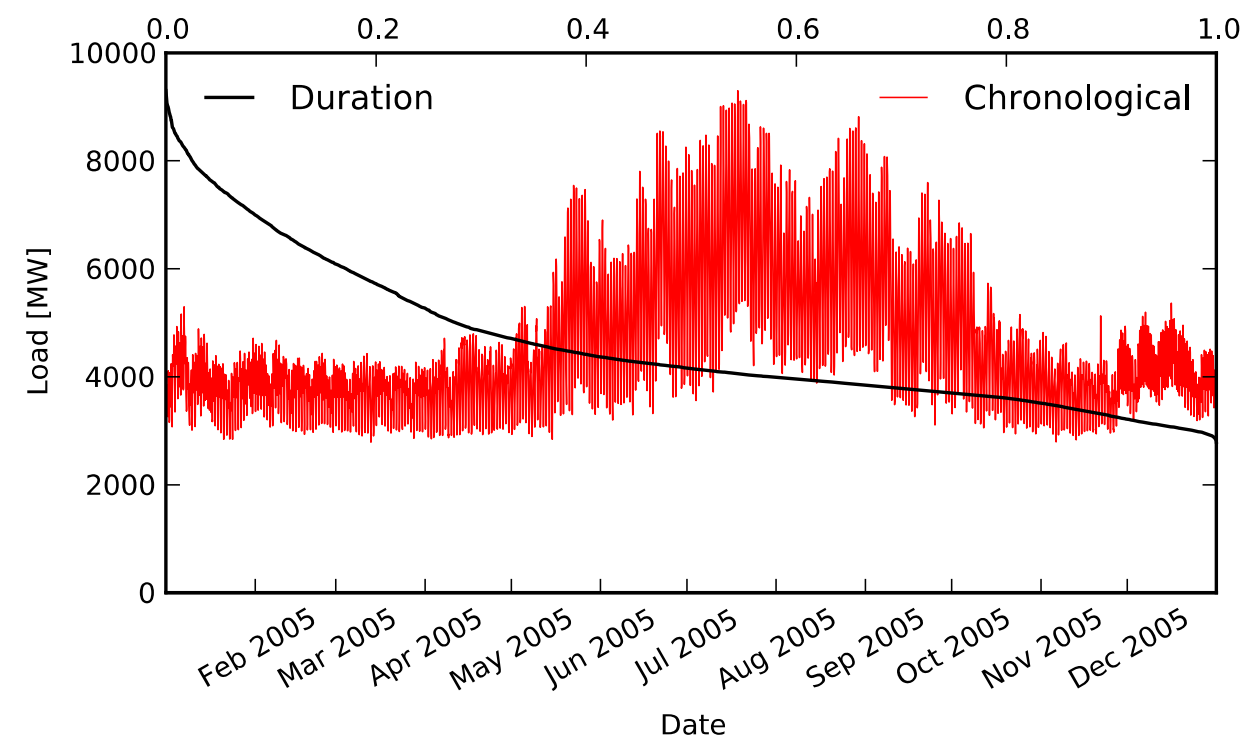

Figure 3. Estimated HA Load Schedule for 2027, Chronological and Sorted in Descending Order (Load Duration Curve)

The lack of scaling for 1-min load variability, HA load forecast errors, and DA load forecast errors between the historical measured value and the projected level in 2027 is a conservative assumption in the sense that it may understate future needs for load variability and uncertainty. In effect, we are assuming that the load variability and uncertainty that APS has experienced in the past is the same as what they will experience in the future, even though the average load levels is expected to grow. This results is a relative improvement in load variability and uncertainty in percent of peak load terms (since the 2027 peak load is higher than historical levels but load variability and uncertainty are not assumed to be higher). It may be that future loads will have more variability and more uncertainty in the future, such that variability and uncertainty will increase in proportion to load growth. If that does occur, the integration costs attributable to PV may by lower (more of the aggregate variability and uncertainty will be attributable to loads) or it could be higher (resources may already be strained managing load uncertainty and variability, making it more difficult to also manage PV variability and uncertainty).

\subsection{Wind}

The wind data used in this analysis are based on wind data and DA forecasts developed for the WWSIS (Potter et al. 2008). The 2027 wind sites include current wind plants that APS has online today in New Mexico and Arizona, and new wind sites also located in New Mexico and Arizona, as described in Appendix E. The existing wind was approximated by $930-\mathrm{MW}$ sites (270-MW nameplate capacity), and the new wind sites were approximated by 12 additional 30-MW sites (360-MW nameplate capacity). The DA schedules generated in the WWSIS were scaled by a factor of 0.9 because of a tendency for DA wind forecasts to otherwise exceed the actual wind output (i.e., we removed the DA wind forecast bias). 
HA schedules for wind were created based on the 1-min actual wind output recorded 30 min prior to the start of the operating hour. The HA forecast for wind was therefore based on an assumption of a 30-min persistence of wind. This is a conservative assumption because advanced wind forecasting techniques available now and in the future should be able to perform better than persistence. Figure 4 shows the resulting HA schedule for wind power.

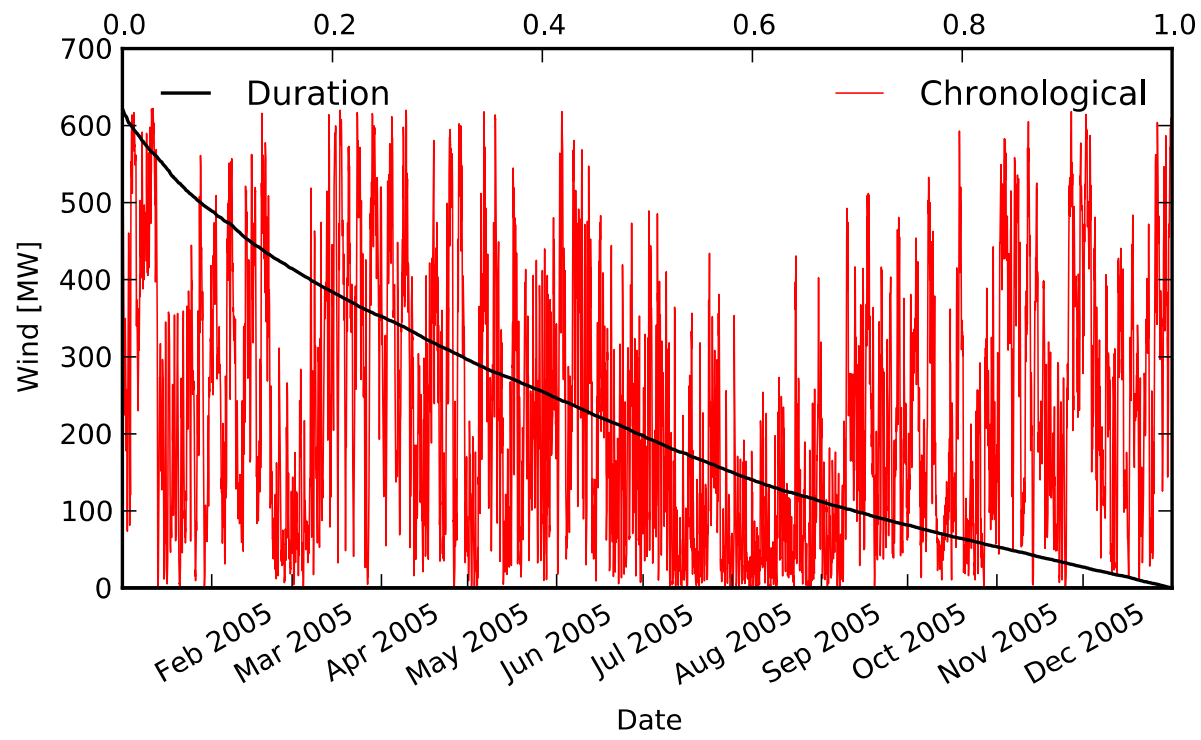

Figure 4. Estimated HA Wind Schedule for 2027, Chronological and Sorted in Descending Order (Wind Duration Curve)

The 1-min time series of actual wind outputs was created by interpolating between the 10-min average wind outputs from the original WWSIS dataset using a cubic spline fit. No additional sub-10-min variability was added to the wind time series.

\subsection{PV}

PV was modeled as a mixture of different PV configurations (e.g., tracking or fixed, horizontal or tilted) and a mixture of distributed and utility scale, all located in Arizona. The locations of the PV sites are described in Appendix E. In all cases, DA schedules were based on hourly DA insolation forecasts developed for the WWSIS (Potter et al. 2008) and then run through the National Renewable Energy Laboratory (NREL) PVWatts program to estimate DA schedules for PV. PVWatts converts insolation into PV production based on the PV plant capacity, PV plant configuration, an assumed DC-to-AC derate factor (assumed to be 0.83 in this case), and ambient temperature. Ambient temperature for a nearby weather station (depending on the location of the modeled PV site) in the same weather year (2005) was used in PVWatts to generate PV production data. 
HA schedules, as shown in Figure 5 for the high-PV scenario, were based on assuming that the 1-min clear sky index 30 min prior to the start of the operating hour would be the clear sky index for the operating hour, where the clear sky index is defined as the ratio of the actual PV production to the PV production if the sky were clear. The HA forecast of PV is therefore represented by a 30-min persistence-of-cloudiness forecast. The resulting forecast is a conservative assumption in that the persistence of cloudiness forecast can be used today without utilizing forecasting techniques that are more advanced than persistence of cloudiness. Actual HA forecasts using techniques that are available today, such as motion-vector forecasts based on satellite images (Hamill and Nehrkom 1993), or using techniques available in the future should be improvements on persistence of cloudiness forecasts (Hammer et al. 1999).

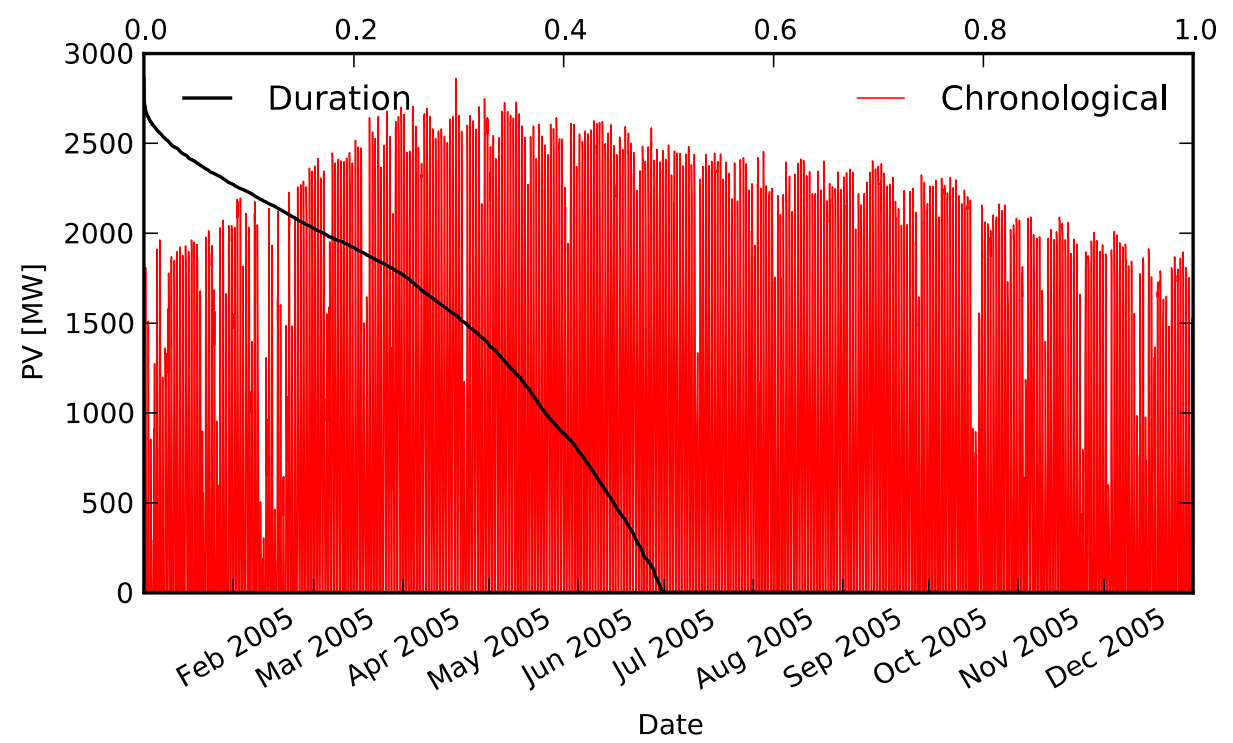

Figure 5. Estimated HA Solar PV Schedule for 2027 (high-PV scenario), Chronological and Sorted in Descending Order (PV duration curve)

The 1-min PV data were synthesized based on an approach detailed in Appendix A. In general, 1-min variability was synthesized for each of the individual PV sites based on the hourly average clear sky index derived from historical satellite data for each site from 2005. The 1-min variability was synthesized in such a way that the energy content in each sub-hourly frequency and the correlation of 1-min variability based on frequency and distance between sites matches characteristics derived from a network of 1-min solar insolation data at the U.S. Department of Energy (DOE) Atmospheric Radiation Measurement (ARM) Network in the Southern Great Plains (described further by Mills and Wiser 2010). The 1-min clear sky production is based on the BIRD clear-sky model (Bird and Holstrom 1981). The 1-min time series that were synthesized based on a point estimate of insolation were further smoothed to represent withinplant smoothing in the case of utility-scale PV or smoothing between small PV installations for distributed PV. In the case of utility-scale PV, the smoothing parameter was based on empirical analysis PV plant data in Spain that show the smoothing is related to the PV plant area (Marcos et al. 2011b). In the case of distributed PV, the same smoothing algorithm was applied, 
but the effective area of the distributed PV was increased to roughly the size of a single cell for the satellite data (roughly $11 \mathrm{~km}$ by $11 \mathrm{~km}$ ) for calculating the smoothing parameter. Insolation data were again converted to PV production data using PVWatts. This synthesized 1-min PV data was not validated through comparisons to actual PV plant data, though this is recommended in future research.

\subsection{Forecasting Errors}

DA forecasting errors affect the degree to which resources need to be re-dispatched or committed in the HA scheduling and HA forecasting errors contribute to the deployment of balancing reserves in RT. Forecast error statistics for load and wind and PV generation are summarized in Tables 4 and 5. Not surprisingly, load, wind, and PV forecast errors are all consistently larger in DA scheduling than in HA scheduling. When normalized to peak load or nameplate capacity, the load is easier to forecast than wind or PV and PV is considerably easier to forecast than wind (Table 4). The normalized forecast errors for PV are larger in the high-PV case because of the greater amount of large utility-scale PV plants added in this scenario. These large utility-scale PV plants have less geographic diversity and therefore somewhat larger forecast errors relative to the nameplate capacity compared to the distributed PV resources. One way to measure the skill of the DA forecasts used in this analysis is to compare the normalized forecast errors to persistence forecasts based on the same hour of the previous day (herby referred to as DA persistence forecasts). The DA wind forecasts provide the greatest improvement relative to DA persistence of $35-37 \%$ (depending on whether the comparison is made using the NMAE or NMSE error metric), followed by DA load forecasts (16-18\% improvement over DA persistence). The DA PV forecasts, however, provide only 2-8\% improvement over DA persistence, suggesting there is room for improvement of DA PV forecasts used in this analysis. Alternative PV forecasting methods are evaluated by Perez et al. (2010).

Table 4. Normalized Forecasting Error Statistics for Load, Wind, and Solar PV in 2027 (Load is normalized by peak HA load and wind and solar PV by nameplate capacity)

\begin{tabular}{|c|c|c|c|c|c|c|c|c|}
\hline \multirow[b]{2}{*}{ Forecast } & \multicolumn{4}{|c|}{ Normalized Mean Absolute Error (NMAE) } & \multicolumn{4}{|c|}{ Normalized Mean Square Error (NMSE) } \\
\hline & Load & Wind & Low PV & High PV & Load & Wind & Low PV & High PV \\
\hline DA & $1.9 \%$ & $12.7 \%$ & $3.2 \%$ & $3.5 \%$ & $2.7 \%$ & $17.2 \%$ & $7.7 \%$ & $8.4 \%$ \\
\hline $\mathrm{HA}$ & $0.2 \%$ & $4.4 \%$ & $1.3 \%$ & $1.6 \%$ & $0.3 \%$ & $6.4 \%$ & $2.8 \%$ & $3.4 \%$ \\
\hline
\end{tabular}

The absolute forecast errors depend on the amount of load, wind, and PV in each scenario. In absolute terms, the magnitude of DA and HA forecast errors for wind are smaller than those for load or PV due to the small amount of wind in each scenario (Table 5). Similarly in the low-PV case, the DA and HA forecast errors for PV are smaller than those for load. In the high-PV case, however, the maximum absolute DA and HA forecast errors for PV exceed the load forecast errors and the mean absolute HA forecast error is also higher for PV than for load. 
Table 5. Absolute DA and HA Forecast Errors in 2027

\begin{tabular}{llcccc}
\hline \multirow{2}{*}{ Absolute Forecast Error [MW] } & Load & Wind & Low PV & High PV \\
\hline \multirow{5}{*}{ DA forecasts } & & & & & \\
& Maximum & 1,945 & 581 & 1,215 & 2,199 \\
& Minimum & 0.0 & 0.0 & 0.0 & 0.0 \\
HA forecasts & Average & 173 & 80.2 & 53.2 & 103 \\
& Maximum & 755 & 267 & 507 & 976 \\
& Minimum & 0.0 & 0.0 & 0.0 & 0.0 \\
& Average & 17.6 & 27.8 & 21.5 & 47.2 \\
\hline
\end{tabular}

\subsection{Conventional Generation}

We derive the data characteristics of the thermal generation systems based on the APS IRP (APS 2012) and the Ventyx database (Ventyx 2012). The IRP document describes the current generator portfolio, as well as the generation expansion and retirement plans until the year 2027 (APS 2012, Attachment D.1(a)(1)). The Ventyx Generator Database provides estimates of several generator parameters, such as capacities, unit blocks, and heat rates. Based on the Ventyx database, ${ }^{11}$ each unit is modeled with a minimum block and three equally sized dispatch blocks between minimum generation and full output. The EIA Annual Energy Outlook (EIA 2012) gives the projection of fuel prices into the future year of 2027. From these sources we are able to build the generator portfolio for the year 2027. We do not model any long-term contracts or market purchases, and also ignore the impacts of transmission constraints in this analysis. These simplifying assumptions must be kept in mind in interpreting the results from our study. In general, market purchases and exchanges of power with neighboring regions may increase the level of flexibility in the system, whereas binding transmission constraints will likely have the opposite effect.

The company has its supply from both conventional resources and renewable resources. The projected conventional resource in 2027 includes 67 generation units that can be independently committed and dispatched. These units include 3 nuclear units in a single plant, 8 coal units, 54 gas-fired power plants (4 steam turbines, 9 combined cycle, and 41 combustion turbines), and 2 small oil units. Eight units are only partly owned by the company (i.e. the three nuclear units and five coal units), and we reduced the capacity, ramp rates, start-up costs, and other relevant parameters according to the ownership percentage. The eight jointly owned units are also assumed to be must-run units, based on the information in APS IRP (APS 2012). The oil units make up less than $1 \%$ of the total capacity, and they are seldom committed in our results because of the high projected oil price. Therefore, we mainly discuss the results for the nuclear, coal, and gas units. Table 6 shows the conventional resource capacity contribution and the fuel prices used in our study. The resulting aggregate supply curve from thermal generators is shown in Figure 6.

${ }^{11}$ We made our own estimates for generators in instances for which Ventyx did not provide data. 
For the given fuel price assumptions, nuclear is the technology with the lowest operating costs, followed by coal, different types of gas-fired generation, and finally the two oil units with very high fuel price. In the case study, we use the same portfolio of thermal generators in all simulated cases. We do conduct sensitivity analysis on the fuel prices for coal and gas.

Based on current utility practices, we at first restrict the nuclear plant to constant operation at full capacity. As is explained later, this assumption (along with other assumptions such as that the utility is unable to sell excess power to neighboring utilities) contributes to the need for curtailment of relatively large amounts of renewables. We therefore relax the constant nuclear constraint in some of the cases as a way to introduce more flexibility in system resources and therefore reduce renewable curtailment. The assumptions used to simulate this hypothetical flexible nuclear plant are described in the tables. Although actual nuclear flexibility parameters for nuclear plants are not available for the nuclear plant operated by APS (since it is operated with constant output), nuclear plants are operated in a flexible manner in France and Germany (OECD 2012). The parameters used in to model flexible nuclear in this study match the capabilities of these flexible nuclear plants in other countries. In addition, the utility currently requires five of the coal units to always remain online, though these can be dispatched between minimum generation and full capacity. The minimum generation level of these online units plus the fixed output of the nuclear capacity, a total minimum generation level of 1,798 MW, has significant implications for the amount of renewable curtailment under a high PV penetration, as evident from the case study results presented in the next section. We refer to the aggregate minimum generation level as the "must-run" capacity.

Table 6. Generator Capacity and Fuel Price by Technology (ST-Steam, CC-Combined Cycle, CT-Combustion Turbine)

\begin{tabular}{lccccc}
\hline \multicolumn{1}{c}{ Technology } & $\begin{array}{c}\text { No. of } \\
\text { Units }\end{array}$ & $\begin{array}{c}\text { Maximum Capacity } \\
{[\mathrm{MW}]}\end{array}$ & $\begin{array}{c}\text { Minimum Capacity } \\
{[\% \text { of max] }}\end{array}$ & $\begin{array}{c}\text { Total Capacity } \\
{[\mathrm{MW}]}\end{array}$ & $\begin{array}{c}\text { Fuel Price } \\
\text { [\$/MMBtu] }\end{array}$ \\
\hline Nuclear $^{*}$ (ST) & 3 & 387 & $100(50$ if flex. $)$ & 1,162 & 0.50 \\
Coal $^{*}$ (ST) & 8 & $108-488$ & $45-55$ & 1,982 & 1.96 \\
Gas (ST) & 4 & $70-100$ & $25-48$ & 361 & 5.85 \\
Gas (CC) & 9 & $88-672$ & $25-30$ & 3,206 & 5.85 \\
Gas (CT) & 41 & $19-103$ & $25-50$ & 2,945 & 5.85 \\
Oil (CT) & 2 & $16-54$ & 50 & 70 & 27.40 \\
\hline
\end{tabular}

* The three nuclear units and 5 of the coal units are partly owned and must-run. 


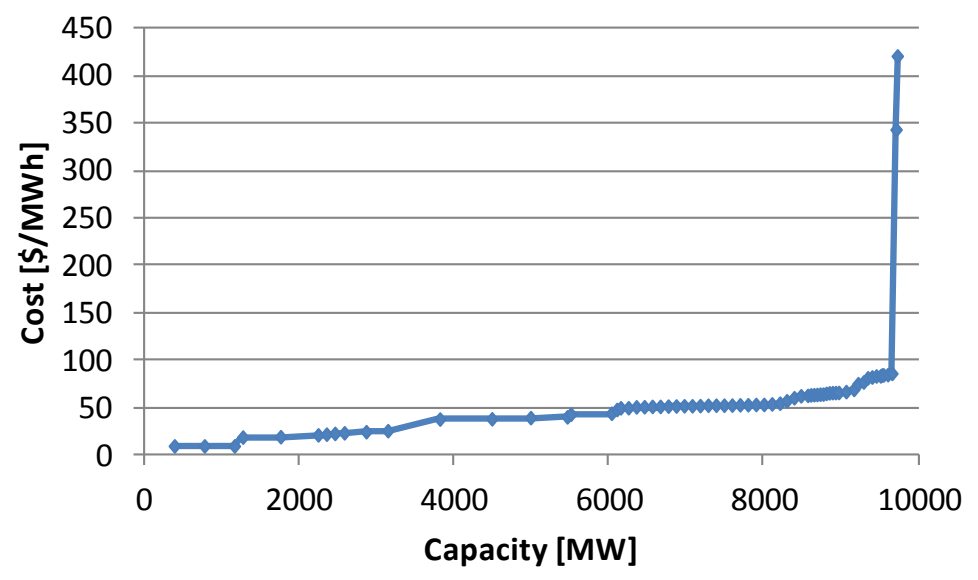

Figure 6. Aggregate Supply Curve for Thermal Generators in APS System for 2027

An accurate representation of unit commitment and other operational constraints is obviously important to investigate the impact of forecasting errors and variability in renewable resources on operating cost and system reliability. To the extent possible, we based the unit-level data for operational constraints and costs, such as hourly ramp rates, minimum up- and down-times, startup costs (calculated from median start-up fuel use), and heat rates on information in the Ventyx database. However, for some of the required parameters for the commitment/dispatch model, we had to use generic assumptions derived from other sources (Black \& Veatch 2012b; Intertek APtech 2012; Cirillo et al. 2006). The most important assumptions are summarized in Table 7 through Table 10. Note that the warm start-up costs (Table 8) considers median start-up fuel use, as reported in Ventyx (2012), and do not consider other costs such as increased maintenance and capital expenditures. The resulting start-up costs are in the lower range of what is reported in Intertek Aptech (2012), particularly for the coal units. ${ }^{12}$

Because we use several sources from industry and to some extent our own assumptions in building the dataset, we emphasize that the values of many parameters are likely to deviate from the true values in the APS system. This should be kept in mind in evaluating the results presented in the next section. The purpose of the study is not to calculate operating costs with high accuracy, but rather to present a consistent methodological framework for estimation of integration costs and investigate how such costs, system reliability, and scheduling decisions change under different assumptions about reserve requirements, operational flexibility, fuel costs, etc., as further discussed in the next chapter.

\footnotetext{
12 Note that 5 out of 8 coal units are considered must-run, as discussed above, so that the start-up costs do not impact their schedules in any case.
} 
Table 7. Average Block Heat Rates by Technology (ST-steam, CC-combined cycle, CT-combustion turbine). (Blocks 1, 2, 3 have the same size, i.e., $\left(P_{\max }-P_{\min }\right) / 3$, for each plant)

\begin{tabular}{lcccc}
\hline & \multicolumn{4}{c}{ Heat Rates [MMBtu/MWh] } \\
\cline { 2 - 5 } Technology & $\mathrm{P}_{\min }$ & Block 1 & Block 2 & Block 3 \\
\hline \multirow{2}{*}{ Nuclear (ST) } & 10.5 & 10.5 & 10.5 & 10.5 \\
Coal (ST) & $9.6-13.4$ & $9.5-12.7$ & $9.0-11.9$ & $8.8-11.8$ \\
Gas (ST) & $14.0-17.8$ & $12.4-16.0$ & $11.6-14.4$ & $11.0-13.6$ \\
Gas (CC) & $8.4-16.1$ & $7.5-12.6$ & $7.0-11.2$ & $6.7-10.8$ \\
Gas (CT) & $12.2-19.3$ & $11.0-17.0$ & $9.5-15.4$ & $8.7-15.0$ \\
Oil (CT) & $17.0-19.8$ & $15.0-17.9$ & $12.9-15.7$ & $12.7-15.5$ \\
\hline
\end{tabular}

Table 8. Start-up Cost, and Variable Cost Assumptions by Technology (ST-Steam, CC-Combined Cycle, CT-Combustion Turbine)

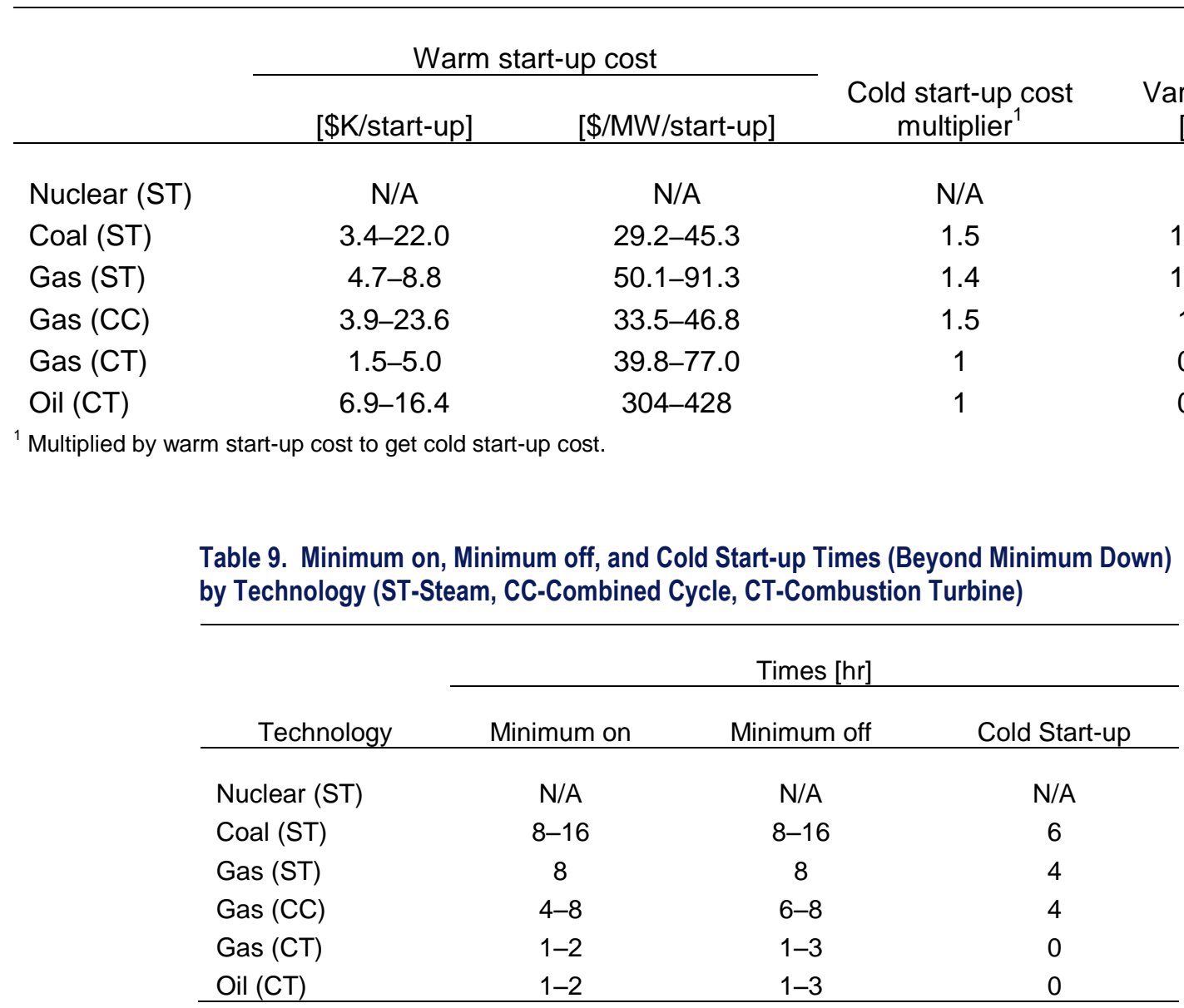


Table 10. Ramp Rates by Technology (ST-Steam, CC-Combined Cycle, CT-Combustion Turbine)

\begin{tabular}{|c|c|c|c|c|c|c|}
\hline & \multicolumn{2}{|c|}{ Ramp rate down } & \multicolumn{2}{|c|}{ Ramp rate up } & \multicolumn{2}{|c|}{ Instant ramp rate up } \\
\hline & {$[\% / h r]$} & {$[\mathrm{MW} / \mathrm{hr}]$} & {$[\% / h r]$} & [MW/hr] & {$[\% / \min ]$} & {$[\mathrm{MW} / \mathrm{min}]$} \\
\hline Nuclear* (ST) & 35.7 & 138 & 35.7 & 138 & 5 & 19 \\
\hline Coal (ST) & $31.1-39.4$ & $35-184$ & $26.2-44.3$ & $28-146$ & 2 & $2.2-10$ \\
\hline Gas (ST) & $73.7-81.4$ & $57-77$ & $47.0-61.4$ & $43-47$ & 2 & $1.4-2.0$ \\
\hline Gas (CC) & $43.4-83.0$ & $44-336$ & $29.7-50.0$ & $42-336$ & 5 & $4.4-34$ \\
\hline Gas (CT) & $81.3-100$ & $19-103$ & $70.0-100.0$ & $19-103$ & 8.33 & $1.6-8.6$ \\
\hline Oil (CT) & 100 & $16-54$ & 100.0 & $16-54$ & 8.33 & $1.3-4.5$ \\
\hline
\end{tabular}

* These parameters only apply in cases with flexible nuclear operations.

\subsection{Other Assumptions}

In this study, we model two categories of operating reserves, as discussed in Section 3.1 and summarized in Table 2. The balancing reserves are calculated dynamically based on forecasting errors and variability in solar power, wind power, and load. The results are presented in Section 5. In contrast, the contingency reserves are kept constant throughout the simulation period and do not change between DA and RT. On the basis of projections in the APS IRP (APS 2012), we assume a contingency reserve of $410 \mathrm{MW}$, half of which is spinning. This estimate takes into account that APS is part of the Southwest Reserve Sharing Group, which effectively reduces the required amount of contingency reserves for the utility because of reserve sharing with neighboring utilities.

In the system simulations, we do not model contingencies. However, forecasting errors and subhourly variations are accounted for in the RT dispatch and corresponding estimation of DA and HA balancing reserves to meet certain reliability standards. In the modeling of DA and HA scheduling, we therefore want to avoid reserve shortfalls. This is done by imposing a high penalty on unserved reserve in the objective function of the unit commitment/dispatch model. We used a penalty of $\$ 9,900 / \mathrm{MW}$-h for unserved reserves, applying the same penalty for all reserve categories and types in Table 2 . This is just below the assumed penalty for unserved load of $\$ 10,000 / \mathrm{MWh}$. The results show that in most cases the resulting curtailment of reserves is very small, as further discussed in Section 6. 


\section{Impact of PV with Base Assumptions}

\subsection{Balancing Reserve Requirements}

The balancing reserve requirements in each scenario were found by examining the 1-min deviations from the HA schedule. As described earlier in Section 3.1, the balancing reserve rules were then chosen to be able to cover deviations within the 2.5 th and 97.5 th percentile in the down and up direction, respectively. In a real system, it is not possible to know ahead of time what the 1-min deviations will be from HA schedules. What is possible, on the other hand, is to examine the 1-min deviations from HA schedules from the previous year then utilize that information to develop balancing reserve rules for the operating year. We simulate this situation by analyzing 1-min deviations from HA schedules based on a 2004 weather year ${ }^{13}$ to develop balancing reserve rules that are applied in our simulation using the 2005 weather year date. The resulting balancing reserve requirements for the HA schedules are shown in Figure 7. The requirements are shown for the case in which balancing reserves are required just for the load and wind followed by the case in which balancing reserves are required for the net load (load, wind, and PV). The balancing reserve requirements are dynamic and change on an hour-to-hour basis, depending on system conditions. The maximum balancing reserve and the average balancing reserve in the up direction are summarized for the load-wind and net load in each scenario in Table 11.

(a)

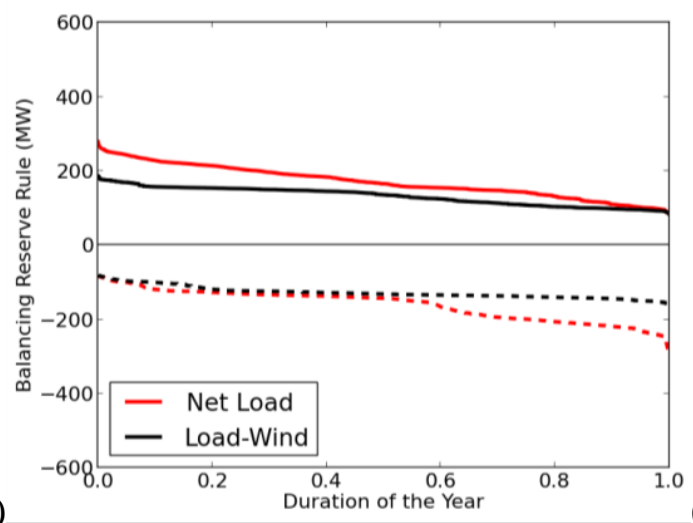

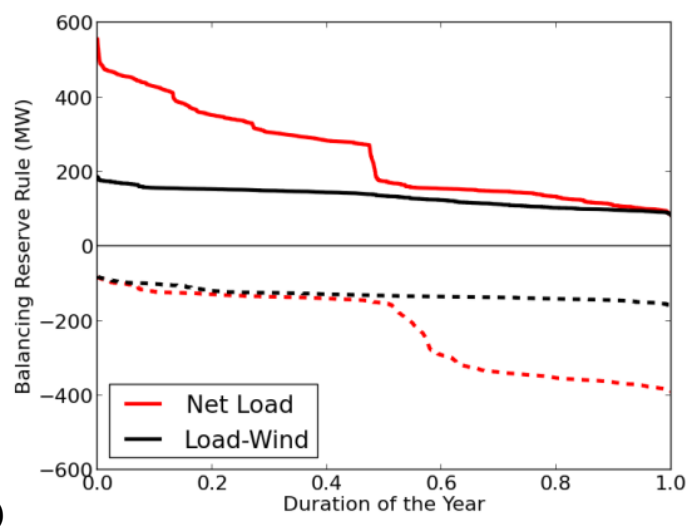

Note: Solid line is the balancing reserve requirement in the up direction; dashed line is the balancing reserve requirement in the down direction. Hourly balancing reserve requirements in each direction are sorted from highest to lowest to create an exceedance curve.

Figure 7. Balancing Reserve Requirements for Load-Wind and for Net Load (load, wind, and PV) over the Year in the Low-PV Scenario (a) and High-PV Scenario (b)

${ }^{13}$ The 2004 weather year data for load, wind, and PV were created in the same manner as the 2005 weather year, described in Section 4. In addition to hourly averages of wind and PV production for 2004 we also had DA forecasts for wind and PV based on the 2004 weather year. For load, we had hourly load from 2004 but had to again rely on other historical years for DA forecast errors (2010), HA forecast errors (2010), and 1-min load variability (2007). 
The addition of PV to the utility system leads to an increase in the balancing reserve requirement in both the up and down directions. Adding 1,674 MW of PV in the low-PV scenario increases the maximum balancing reserve requirement by $92 \mathrm{MW}$ (5.5\% of PV nameplate capacity) beyond the maximum balancing requirement for the load and wind alone. ${ }^{14}$ In the high-PV scenario large, utility-scale PV plants are added to the PV already in the low-PV scenario, leading to a total nameplate capacity of 2,974 MW of PV. The maximum balancing reserve requirement for the net load in the high-PV case is now $369 \mathrm{MW}$ larger $(12.4 \%$ of the PV nameplate capacity) than the maximum balancing reserve requirement for the load and wind alone. Note, however, that the maximum balancing reserve requirement occurs only over a very small portion of the year, as illustrated in Figure 7. This figure also highlights that increases in the balancing reserves due to only occur in roughly half of the hours of the year since balancing reserves do not need to be increased for PV in night-time hours.

Table 11. Balancing Reserve Requirements in HA for the Load-Wind and Net Load (load, wind, and PV) in the Low-PV and High-PV Scenarios

\begin{tabular}{|c|c|c|c|c|c|c|}
\hline \multirow[b]{2}{*}{ Scenario } & \multicolumn{2}{|c|}{$\begin{array}{l}\text { Maximum Balancing } \\
\text { Reserve up (MW) }\end{array}$} & \multicolumn{2}{|c|}{$\begin{array}{c}\text { Average Balancing Reserve } \\
\text { up (MW) }\end{array}$} & \multicolumn{2}{|c|}{$\begin{array}{c}\text { Maximum Balancing Reserve } \\
\text { down (MW) }\end{array}$} \\
\hline & Load-Wind & Net Load & Load-Wind & Net Load & Load-Wind & Net Load \\
\hline Low PV & 187 & 278 & 132 & 171 & 159 & 234 \\
\hline High PV & 187 & 556 & 132 & 241 & 159 & 390 \\
\hline
\end{tabular}

\subsection{Capacity Balance}

The overall balance between supply (thermal and renewable) and demand (load and operating reserves) over a year is illustrated in Figure 8 for the low-PV and high-PV scenarios. There is clearly a large spike in demand during the summer months. In fact, the sum of load and operating reserves up (balancing and contingency) exceeds the installed thermal capacity for some hours in the summer. However, because of the contributions from wind and solar PV, there is always a positive capacity surplus in the system. The minimum capacity surplus is $646 \mathrm{MW}$ and occurs at 4 p.m. July 18 in the low PV scenario. ${ }^{15}$ In the high-PV scenario, the capacity balance is improved, compared to the low-PV scenario, because the high-PV scenario contains 1,300 MW more PV capacity, while the thermal capacity and the load are the same. However, the balancing reserves increase because of the additional PV. The minimum capacity surplus is now $727 \mathrm{MW}$

\footnotetext{
14 A similar scenario in the Black \& Veatch (2012a) solar integration study found an incremental increase in reserves of up to $229 \mathrm{MW}$ (13.7\% of PV nameplate) in order to maintain a CPS2 score of $95 \%$. The Black \& Veatch study used a slightly different approach for calculating reserves (including the use of a 70-min persistence-of-cloudiness forecast for PV compared to the 30-min persistence-of-cloudiness used in this study) and also did not account for reserves for wind. These differences may in part explain why Black \& Veatch found larger incremental reserve requirements than reported in this study.

15 Note that forced and planned outages are not reflected in this figure. We do not consider outages explicitly in system commitment and dispatch simulations, but the model ensures that the operating reserve requirements are always met, to the extent possible, in the HA schedule.
} 
and occurs at 5 p.m. on July 12. The average capacity surplus is $314 \mathrm{MW}$ higher than that in the low-PV scenario.
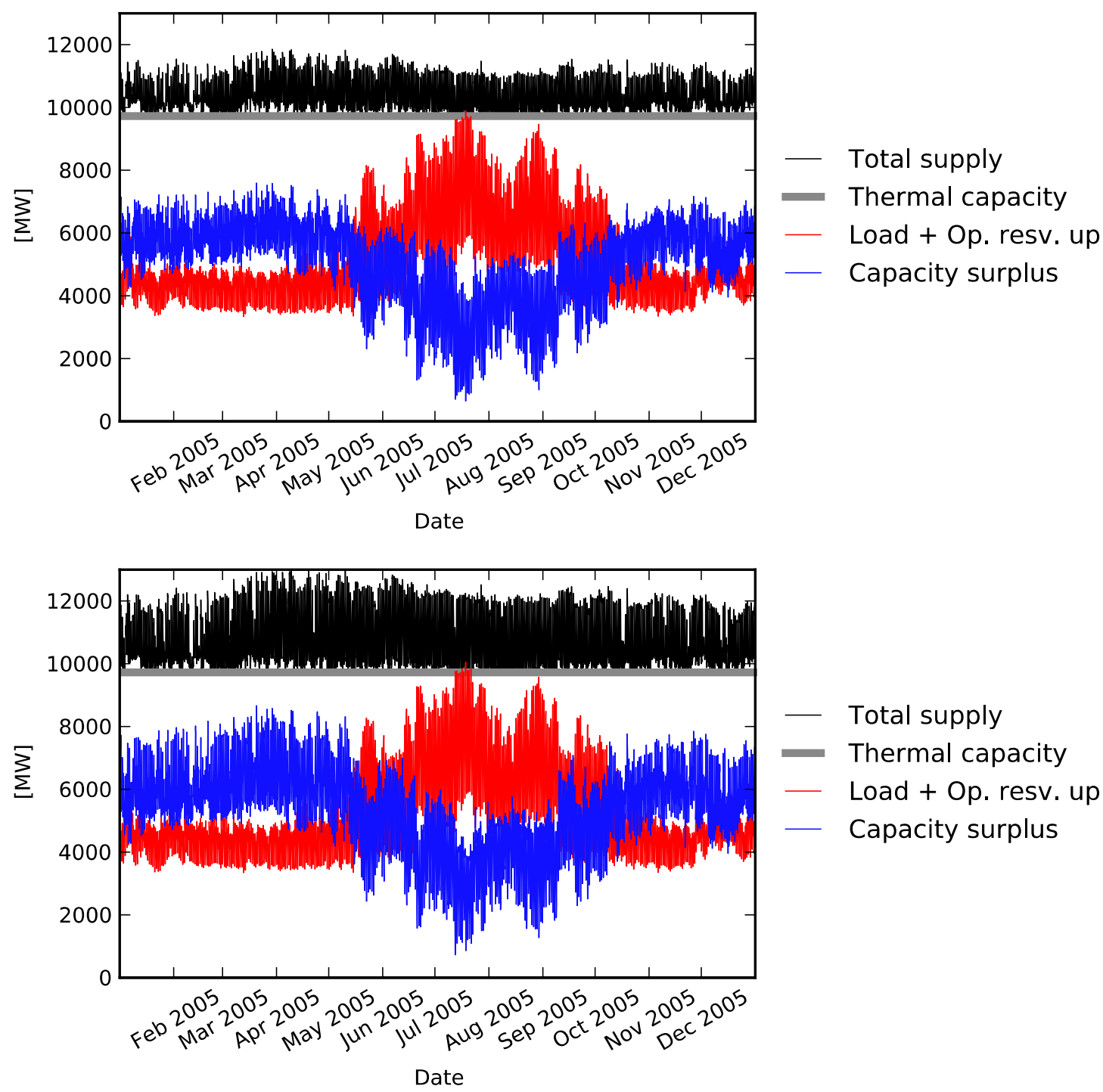

Figure 8. Capacity Balance for Low-PV (top) and High-PV Scenario (bottom) in 2027

Because we assume that the utility does not trade power with neighboring utilities, another important factor is the minimum net load compared to the must-run capacity (based on the minimum generation of five coal units and the full capacity of the nuclear units). Curtailment of renewables will be necessary when the minimum net load is lower than the must-run capacity. The actual curtailment will be even larger due to the requirement that thermal generators must provide balancing down reserves only. Enabling renewables to provide balancing down reserves when they would otherwise be curtailed is one way to reduce overall curtailment. Some renewables can already provide reserves in the down direction (by curtailing output when called 
on), but we do not include this option in the current analysis. We highlight this limitation here and propose this as an area for future analysis in Section 7.

We compare the HA schedule of the net load plus the operating reserves down to the must-run capacity for both the low-PV and high-PV scenarios (see Figure 9). Periods of low net load occurs primarily in spring months. In some hours the minimum net load is lower than the mustrun capacity, suggesting that renewables curtailment will be necessary when it is assumed that the utility is unable to sell excess power to neighboring utilities, that five of the coal units must always remain online, that renewables are unable to provide balancing down reserves, and that the nuclear units must remain at full capacity. The potential for renewable curtailment is particularly acute in the high-PV scenario under these assumptions. In fact, by comparing the net load and balancing reserve down requirements for each hour of the year with the must run capacity, we find that more than $8 \%$ of the available renewable resources over the year must be curtailed due to surplus situations. This is a simple calculation of the minimum required curtailment of renewable energy, which does not account for economic considerations and operational constraints in the power plants. The same calculation for the low-PV scenario gives a minimum renewable curtailment of less than $0.4 \%$ under the same assumptions, indicating that curtailment due to generation surplus is a much smaller problem under a lower PV penetration.

Based on this simple analysis, we suggest that the utility in a future scenario with high penetration of solar PV must find some solution to manage generation in low net load periods, particularly in the winter and spring months. These solutions could involve some combination of finding willing buyers for excess power outside of the utility, identifying ways to maintain reliability while allowing the five must-run coal plants to periodically shut down, requiring renewable generators to have the capability to provide balancing down reserves, or enabling the power output from the nuclear plant to be dispatched down in response to system needs. We model the latter option as an alternative to the base case with constant nuclear output in the highPV scenario. In this "flexible nuclear" case we allow the nuclear plants to operate between the nameplate capacity and a 50\% minimum generation level (while still requiring the nuclear plants to always remain online). Some curtailment will still be necessary in the high-PV scenario even with flexible nuclear. We explore the consequences of the minimum net load in more detail later by calculating the actual curtailment of renewables during the HA scheduling in both the low-PV and high-PV scenarios. 

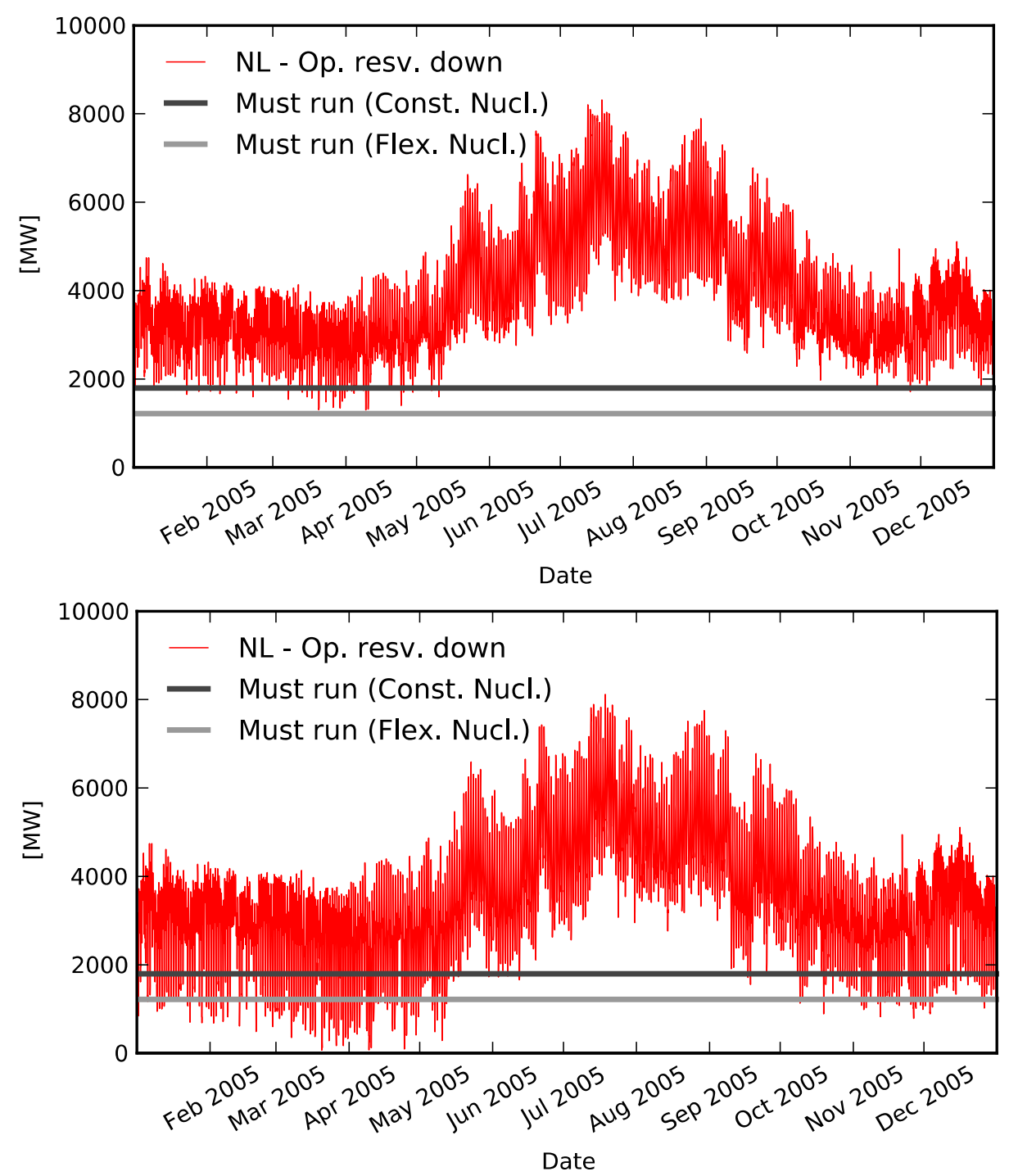

Figure 9. Net Load and Must Run Capacity for Low-PV (top) and High-PV (bottom) Scenarios in 2027

\subsection{DA Commitment and HA Schedules}

Below we present results from the scheduling model for the low-PV and high-PV scenarios for 2027. In all cases, commitment and dispatch simulations were done for a full year. The low-PV scenario is analyzed under the assumption of constant nuclear plant output. In contrast, we analyze the high-PV scenario under two assumptions: fixed and flexible nuclear plant operations. This is motivated by the initial finding that a large amount of renewable curtailment would be required in the high-PV scenario with the assumptions about limited trade with neighbors, mustrun coal plants, no balancing down reserves from renewables, and fixed nuclear output. Therefore, in the high-PV scenario we introduce a case where those issues have been mitigated to some degree by assuming that the nuclear plant can be operated in a flexible manner. With the flexible nuclear assumption in the high-PV scenario, nuclear plants can be dispatched down, and 
therefore provide spinning reserves up and down, when this is optimal from an economic perspective. This assumption deviates from current operational practices for most nuclear power plants, including nuclear plants owned and operated by APS. That said, the operators of the Columbia Generating Station in the Northwest US sometimes dispatch the nuclear plant below full capacity due to "economic dispatch" requests (automatic dispatch of a nuclear plant by signals from the power system is not permitted in the US by the nuclear regulator, but it is possible for the nuclear plant operators to change the plant dispatch). Nuclear plants in France and Germany often change the output of their nuclear plants in response to system conditions (OECD 2012). ${ }^{16}$

Without further research, we cannot judge the best way to manage low net-load periods in a high PV scenario, but we can use the flexible nuclear case as a proxy for the solution that would be implemented by the utility. Where necessary, we distinguish between the high-PV scenario with inflexible nuclear and the high-PV scenario with flexible nuclear by calling them high-PV (Const. Nucl.) and high-PV (Flex. Nucl.), respectively. Additional results for the high-PV case with constant nuclear are reported in the Appendix D. As the constant nuclear assumption is not as limiting in the low-PV scenario, we maintain the constant nuclear assumption throughout the discussion of the low-PV scenario.

An overview of the HA scheduling results for energy and reserves is presented in Table 12 through Table 17. In both the low-PV and high-PV scenarios (Const. Nucl and Flex. Nucl.), the majority of energy is provided by three sources: nuclear, coal, and combined cycle (CC) natural gas plants. In the low-PV scenario, nuclear, coal, and CC plants provide more than $84 \%$ of the annual energy (Table 12). $8.6 \%$ of the annual energy is provided by the combination of utilityscale and distributed PV and $4.7 \%$ by wind, so that the renewable energy penetration is $13.3 \%$ in the low-PV scenario. In contrast, less energy is provided by nuclear, coal, and CC plants in the high-PV scenario due to the additional energy from PV. The high-PV scenario increases the share of delivered PV to $14.3 \%$ or $16.8 \%$ of the annual demand, depending on whether the nuclear plants are operated as a constant or flexible resource (Table 14). Wind decreases slightly due to more curtailment, particularly with the constant nuclear assumption. The additional PV in the high-PV scenario primarily displaces energy from $\mathrm{CC}$ and coal plants (Table 14). In the flexible nuclear case, PV also reduces production by nuclear plants because solar PV has zero marginal costs while nuclear marginal costs are non-zero. The decrease in the load factors of the thermal plants indicates that these plants are increasingly part-loaded with higher PV penetration. Oil-fired units are not dispatched at all, except in the high-PV case with constant nuclear, and the dispatch of gas-fired steam units is also very limited.

\footnotetext{
16 "Based on the experience in France and Germany, this study finds that in terms of short-run load following, the technical capabilities of nuclear energy are comparable to those of large coal-fired units, are only slightly below those of combined cycle gas plants, but remain inferior to those of open cycle gas or oil turbines. Such short-run load following may constitute not only an essential contribution at the system-level but also an economically useful tool at the level of the plant and the electricity market. As prices in the day-ahead market become increasingly volatile, drop more frequently below the variable costs of nuclear power production and occasionally turn negative, the ability to stop production at constant levels becomes a vital part of an operator's financial viability" (OECD 2012).
} 
In the low-PV scenario, virtually all spinning reserves up (i.e., the combined need for spinning balancing and contingency reserves) are provided by coal, $\mathrm{CC}$, and combustion turbine (CT) plants (Table 13). CTs do not contribute significantly to meeting the spinning reserves down. Nuclear plants cannot provide reserves in either direction in the low-PV scenario since they are assumed to operate at constant output. In the high-PV scenario, there is a similar pattern in the case with constant nuclear operation, i.e. coal, CC, and CT provide spinning reserves up, whereas coal and CC provide almost all the down reserves (Table 15). Allowing flexible nuclear operations changes the reserve scheduling significantly, particularly in the down direction, as nuclear plants now provide $9.3 \%$ of up reserves and as much as $33.1 \%$ of the reserves in the down direction (Table 15).

The total unmet spinning reserves are insignificant in the low-PV scenario, as shown in Table 17. This result indicates that the commitment and dispatch model was able to meet more than $99.999 \%$ of the required operating reserve targets. ${ }^{17}$ The periods with low net load in the highPV scenario with constant nuclear lead to some challenges with meeting spinning reserve requirements (Table 17). The unmet spinning reserves down in the high-PV (Const. Nucl.) scenario amounts to $551 \mathrm{MW}-\mathrm{h} / \mathrm{yr}$, meaning that the commitment and dispatch model was able to meet $99.97 \%$ of the required operating reserve target. The instances where the system has difficulty meeting the spinning reserve down requirement are still rare and only happen in 9 out of the 8,760 hours in a year. Allowing nuclear to be flexible in the high-PV (Flex. Nucl.) scenario resolves the challenge of meeting the spinning reserve down requirement, with no reserve shortfall in the down direction (Table 17).

More detailed analysis of the results indicate that the provision of spinning reserves down is less challenging and costly than provision of spinning reserve up. In fact, the spinning reserve down constraint is much less frequently binding than the spinning reserve up constraint. On average there is considerably more spinning reserve down capability compared to the balancing reserve down requirement, especially in the high-PV (Flex. Nucl.) scenario. ${ }^{18}$ This is another indication that flexible nuclear operations would make the system much more flexible and it becomes less costly to provide the required balancing reserves.

More detailed summary statistics of the HA scheduling results for energy and reserves are presented in Appendix D.

17 As discussed in Section 3, the objective function of the scheduling model includes a high penalty for curtailment of reserves $(\$ 9,990 / \mathrm{MW}-\mathrm{h})$. Small amounts of curtailment may still occur, e.g., if this is cheaper than starting an additional unit or if the corresponding cost is within the mixed integer programming (MIP) gap of the MIP model (which was set to $0.5 \%$ ).

18 The average shadow price of the spinning reserve down constraint is $\$ 1.6 / \mathrm{MW}-\mathrm{h}$ in the low-PV scenario and on average there is twice as much down reserve available compared to the requirement. In the high-PV scenario the average shadow price for down reserves is $\$ 15.4 / \mathrm{MW}-\mathrm{h}$ and $\$ 1.3 / \mathrm{MW}-\mathrm{h}$ with constant and flexible nuclear operations, with 1.5 and 3 times as much available down reserves on average compared to the requirement. In comparison, the average shadow prices of the spinning reserve up constraint are $\$ 24.3 / \mathrm{MW}-\mathrm{h}, \$ 25.6 / \mathrm{MW}-\mathrm{h}$, and $\$ 20.5 / \mathrm{MW}$-h for the low-PV, high-PV (Const. Nucl.), and high-PV (Flex. Nucl.), and surplus reserve up capability constraint is almost always binding in each of the cases. 
Table 12. Summary of HA Energy Scheduling Results for Low-PV Scenario (2027)

\begin{tabular}{|c|c|c|c|}
\hline \multirow[b]{2}{*}{ Category } & \multicolumn{3}{|c|}{ Energy } \\
\hline & $\begin{array}{l}\text { Load Factor }^{\mathrm{a}} \\
{[\% \text { nameplate] }}\end{array}$ & $\begin{array}{c}\text { Capacity Factor } \\
{[\% \text { nameplate }]}\end{array}$ & $\begin{array}{l}\text { Energy } \\
{[\% \text { total] }}\end{array}$ \\
\hline Nuclear (ST) & 100.0 & 100.0 & 25.2 \\
\hline Coal (ST) & 89.5 & 89.6 & 38.5 \\
\hline Gas (ST) & 30.6 & 0.0 & 0.0 \\
\hline Gas (CC) & 58.5 & 29.9 & 20.7 \\
\hline Gas (CT) & 62.0 & 3.6 & 2.3 \\
\hline Oil (CT) & $\mathrm{N} / \mathrm{A}$ & 0.0 & 0.0 \\
\hline Solar & $\mathrm{N} / \mathrm{A}$ & 23.7 & 8.6 \\
\hline Wind & $\mathrm{N} / \mathrm{A}$ & 34.3 & 4.7 \\
\hline Total & & & 100.0 \\
\hline \multicolumn{4}{|c|}{$\begin{array}{l}\text { Load factor is the ratio of the average energy from a unit when it is on to the } \\
\text { unit nameplate capacity (average of individual unit load factors, not considering } \\
\text { units that are never dispatched). }\end{array}$} \\
\hline \multicolumn{4}{|c|}{$\begin{array}{l}\text { b Capacity factor is the ratio of average energy to the total nameplate capacity } \\
\text { for all units in a category. }\end{array}$} \\
\hline
\end{tabular}

Table 13. Summary of HA Reserve Scheduling Results for Low-PV Scenario (2027)

\begin{tabular}{|c|c|c|c|c|}
\hline \multirow[b]{2}{*}{ Category } & \multicolumn{2}{|c|}{ Spinning Reserve up } & \multicolumn{2}{|c|}{ Spinning Reserve down } \\
\hline & $\begin{array}{l}\text { Average if on }{ }^{\mathrm{a}} \\
\text { [\% nameplate] }\end{array}$ & $\begin{array}{l}\text { Reserve } \\
{[\% \text { total] }}\end{array}$ & $\begin{array}{l}\text { Average if on }{ }^{\mathrm{a}} \\
\text { [\% nameplate] }\end{array}$ & $\begin{array}{l}\text { Reserve } \\
\text { [\% total] }\end{array}$ \\
\hline Nuclear (ST) & 0.0 & 0.0 & 0.0 & 0.0 \\
\hline Coal (ST) & 5.5 & 28.0 & 8.7 & 54.1 \\
\hline Gas (ST) & 19.8 & 0.0 & 0.0 & 0.0 \\
\hline Gas (CC) & 16.6 & 55.8 & 8.6 & 45.9 \\
\hline Gas (CT) & 32.0 & 16.2 & 0.2 & 0.1 \\
\hline Oil (CT) & $\mathrm{N} / \mathrm{A}$ & 0 & $\mathrm{~N} / \mathrm{A}$ & 0 \\
\hline Solar & $\mathrm{N} / \mathrm{A}$ & $N / A$ & $N / A$ & $\mathrm{~N} / \mathrm{A}$ \\
\hline Wind & $\mathrm{N} / \mathrm{A}$ & $\mathrm{N} / \mathrm{A}$ & $N / A$ & $\mathrm{~N} / \mathrm{A}$ \\
\hline Total & & 100.0 & & 100.0 \\
\hline
\end{tabular}

a Average of individual unit reserve provisions, not considering units that are never dispatched. 
Table 14. Summary of HA Energy Scheduling Results for High-PV Scenarios (2027)

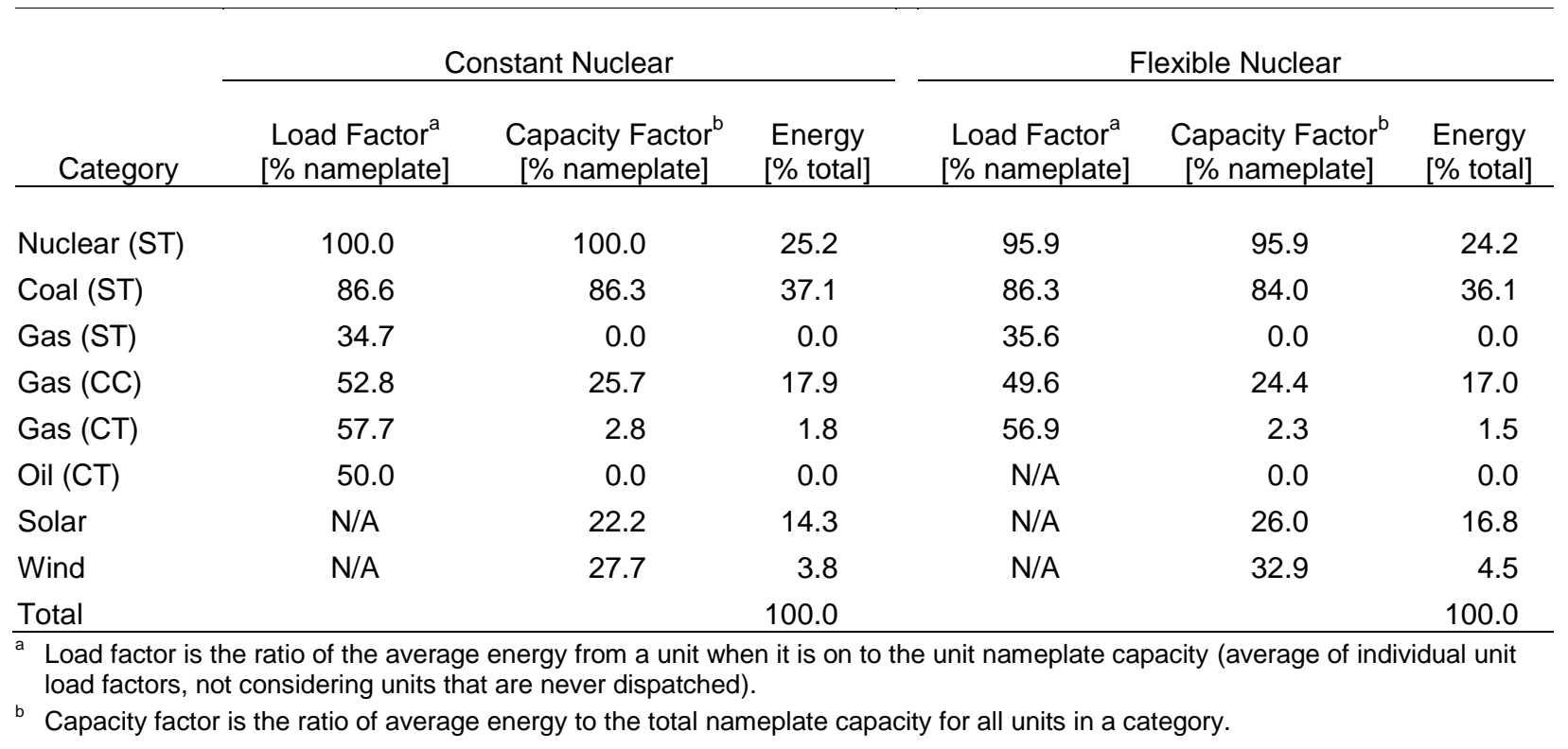

Table 15. Summary of HA Reserve Up Scheduling Results for High-PV Scenarios (2027)

\begin{tabular}{|c|c|c|c|c|}
\hline \multirow[b]{2}{*}{ Category } & \multicolumn{2}{|c|}{ Constant Nuclear } & \multicolumn{2}{|c|}{ Flexible Nuclear } \\
\hline & $\begin{array}{l}\text { Average if on }{ }^{\mathrm{a}} \\
\text { [\% nameplate] }\end{array}$ & $\begin{array}{l}\text { Reserve } \\
{[\% \text { total] }}\end{array}$ & $\begin{array}{l}\text { Average if on }{ }^{\mathrm{a}} \\
{[\% \text { nameplate }]}\end{array}$ & $\begin{array}{l}\text { Reserve } \\
\text { [\% total] }\end{array}$ \\
\hline Nuclear (ST) & 0.00 & 0.0 & 3.7 & 9.3 \\
\hline Coal (ST) & 7.8 & 33.9 & 6.1 & 25.7 \\
\hline Gas (ST) & 17.8 & 0.0 & 20.0 & 0.0 \\
\hline Gas (CC) & 18.8 & 52.1 & 25.9 & 52.1 \\
\hline Gas (CT) & 35.9 & 14.0 & 39.4 & 12.9 \\
\hline Oil (CT) & 50.0 & 0.0 & $\mathrm{~N} / \mathrm{A}$ & 0 \\
\hline Solar & $\mathrm{N} / \mathrm{A}$ & $\mathrm{N} / \mathrm{A}$ & $\mathrm{N} / \mathrm{A}$ & $\mathrm{N} / \mathrm{A}$ \\
\hline Wind & $N / A$ & $\mathrm{~N} / \mathrm{A}$ & $\mathrm{N} / \mathrm{A}$ & $\mathrm{N} / \mathrm{A}$ \\
\hline Total & & 100.0 & & 100.0 \\
\hline
\end{tabular}

${ }^{a}$ Average of individual unit reserve provisions, not considering units that are never dispatched. 
Table 16. Summary of HA Reserve Down Scheduling Results for High-PV Scenarios (2027)

\begin{tabular}{|c|c|c|c|c|}
\hline \multirow[b]{2}{*}{ Category } & \multicolumn{2}{|c|}{ Constant Nuclear } & \multicolumn{2}{|c|}{ Flexible Nuclear } \\
\hline & $\begin{array}{l}\text { Average if on }{ }^{\mathrm{a}} \\
\text { [\% nameplate] }\end{array}$ & $\begin{array}{l}\text { Reserve } \\
{[\% \text { total] }}\end{array}$ & $\begin{array}{l}\text { Average if on }{ }^{a} \\
{[\% \text { nameplate] }}\end{array}$ & $\begin{array}{l}\text { Reserve } \\
{[\% \text { total] }}\end{array}$ \\
\hline Nuclear (ST) & 0.00 & 0.0 & 19.3 & 33.1 \\
\hline Coal (ST) & 10.4 & 60.8 & 13.5 & 36.8 \\
\hline Gas (ST) & 0.0 & 0.0 & 0.0 & 0.0 \\
\hline Gas (CC) & 8.1 & 39.1 & 12.0 & 30.0 \\
\hline Gas (CT) & 0.2 & 0.0 & 0.4 & 0.0 \\
\hline Oil (CT) & 0.0 & 0.0 & $\mathrm{~N} / \mathrm{A}$ & 0 \\
\hline Solar & $N / A$ & $N / A$ & $\mathrm{~N} / \mathrm{A}$ & $N / A$ \\
\hline Wind & $\mathrm{N} / \mathrm{A}$ & $N / A$ & $\mathrm{~N} / \mathrm{A}$ & $N / A$ \\
\hline Total & & 100.0 & & 100.0 \\
\hline
\end{tabular}

Table 17. Unmet Spinning Reserves in HA Schedule for Low-PV and High-PV Scenarios (2027)

\begin{tabular}{|c|c|c|c|c|c|c|}
\hline & \multicolumn{2}{|c|}{ Low-PV Scenario } & \multicolumn{2}{|c|}{$\begin{array}{l}\text { High-PV Scenario } \\
\text { (Const. Nucl.) }\end{array}$} & \multicolumn{2}{|c|}{$\begin{array}{l}\text { High-PV Scenario } \\
\text { (Flex. Nucl.) }\end{array}$} \\
\hline & $\begin{array}{l}\text { Spinning } \\
\text { Reserve up }\end{array}$ & $\begin{array}{c}\text { Spinning } \\
\text { Reserve } \\
\text { down }\end{array}$ & $\begin{array}{l}\text { Spinning } \\
\text { Reserve up }\end{array}$ & $\begin{array}{c}\text { Spinning } \\
\text { Reserve } \\
\text { down }\end{array}$ & $\begin{array}{l}\text { Spinning } \\
\text { Reserve up }\end{array}$ & $\begin{array}{c}\text { Spinning } \\
\text { Reserve } \\
\text { down }\end{array}$ \\
\hline Reserve target [GW-h/yr] & 1,493 & 1,410 & 2,110 & 1,972 & 2,110 & 1,972 \\
\hline Unmet reserves [MWh/yr] & 9.3 & 0.0 & 4.0 & 551.2 & 5.7 & 0.0 \\
\hline Percentage of reserve req. & 0.0 & 0.0 & 0.0 & 0.0 & 0.0 & 0.0 \\
\hline
\end{tabular}

Table 18 shows that the total curtailment of renewable energy (wind and solar PV) is significant in the low-PV scenario, with almost $3 \%$ of the available renewable resources curtailed. Hence, in some situations the model finds it optimal to curtail renewable energy for economic reasons in the low-PV scenario, although APS does not currently practice curtailment of renewables based on economics. The renewable curtailment indicates that the system will face some challenges absorbing the wind and solar penetration levels identified in the APS 2012 IRP base case (13.7\% of the load in total) under the assumptions of no trade with neighbors, must-run coal units, no balancing reserves down from renewables, and constant nuclear output.

Under the same assumptions, a large amount of curtailment (17.8\% of the available renewable energy) occurs in the high-PV (Const Nucl.) scenario. The high curtailment found by the model can be explained in part by the fixed nuclear output and the minimum generation levels of other units that remain online during low net-load events. The minimum amount of curtailment expected based on the net load and balancing reserve in the down direction is $8.3 \%$ of the total renewables potential in the high-PV (Const. Nucl.) scenario, as discussed in the previous section. The remaining curtailment is likely due to economic factors and possibly also physical 
constraints such as minimum up- and downtimes, ramp rates, and the resulting minimum generation of other online thermal capacity during low net-load periods. The curtailments occur mainly in the months between October and May and during daytime hours between 7 a.m. and 6 p.m. MST. In fact, more than $99 \%$ of the total renewables curtailment occurs between 7 a.m. and 6 p.m. MST, making PV the primary driver of the renewables curtailment. Moreover, if neighboring utilities had less PV in their systems it is likely that some of the curtailed energy could be sold since curtailment occurs when loads are high. However, we do not consider exchange with other entities in this study and under a scenario with limited flexibility, challenges during low net-load times may be more noticeable with inflexible nuclear and coal units and high PV than challenges with forecastability and short-term variability.

Assuming that nuclear can be operated in a flexible manner dramatically reduces renewable curtailment in the high-PV (Flex. Nucl.) scenario, bringing it close to the same percentage as in the low-PV scenario (Table 18). This result shows that with a high PV penetration, it is very important with more flexibility in the rest of the system, in order to absorb the available renewable generation and avoid high levels of curtailments. We model flexible operation of the nuclear power plants as one such source of flexibility. Other sources of flexibility, such as trading with neighboring utilities/markets, relaxing must-run requirements for some coal units, provision of down reserves by renewables, and price response from consumers can also contribute to more system flexibility, but are not considered in this study.

In all the results presented in this chapter the model curtails renewable energy whenever this is optimal from an economic perspective while also considering all the physical constraints of the power plants. In a later sensitivity scenario investigates the implications of minimizing the renewable curtailments for economic reasons by placing a very high penalty on renewable curtailments in the commitment and dispatch model. Potential reductions in curtailments from letting renewables provide down reserves are left for future work.

Table 18. Total Curtailment of Renewable Energy (wind and solar) in HA Schedule for Low-PV and High-PV Scenarios (2027)

\begin{tabular}{lccc}
\hline & Low-PV Scenario & $\begin{array}{c}\text { High-PV (Const. } \\
\text { Nucl.) }\end{array}$ & $\begin{array}{c}\text { High-PV (Flex. } \\
\text { Nucl.) Scenario }\end{array}$ \\
\hline Curtailment [GWh/yr] & 162 & 1,587 & 299 \\
Percentage of renewable energy & 2.9 & 17.8 & 3.4 \\
\hline
\end{tabular}




\subsection{Detailed Thermal Generation Dispatch and Rescheduling between DA and HA}

We now take a closer look at some of the results from the UC/ED model. For the high-PV scenario, we limit the discussion to the scenario with flexible nuclear operations, as the preceding results illustrate that with fixed nuclear operations, along with assumptions of mustrun coal units, no trading with neighboring utilities, and all reserves provided by thermal units, operational challenges arise in terms of very high curtailments of renewable energy as well as difficulties in meeting BR requirements in some hours. As previously pointed out, the additional system flexibility could come from other resources than the nuclear power plants.

A detailed illustration of the energy scheduling results at the HA stage for the low-PV and highPV (Flex. Nucl.) scenarios is presented in Figure 10 and Figure 11. During the peak load period, coal and nuclear units are scheduled as baseload units, i.e., primarily operating at their maximum output levels, in both scenarios (Figure 10). Gas-fired plants (both CC and CT) are used to follow the daily fluctuations in net load. CT plants operate only during peaking hours, whereas CC plants also operate at low-load hours. Figure 10 shows that the solar PV generation peaks before the load and that CT plants to a large extent make up for the declining solar PV toward the end of the days while loads are still high. Furthermore, the amount of generation by CT plants is considerably higher in the low-PV scenario. The wind generation is the same in both scenarios, because there is no curtailment of renewable energy (wind or solar) during the peak load week in these two scenarios.

Figure 11 illustrates that the dispatch schedule deviates much more from the conventional pattern in the minimum-load week. The coal plants' dispatch varies more frequently because the coalfired units are dispatched up and down to follow the fluctuations in net load. In the high-PV (Flex. Nucl.) scenario the nuclear plants also are dispatched down during daytime to make room for solar generation. Gas-fired power plants (CCs and CTs) are still being scheduled in both scenarios, although coal and nuclear are frequently the only thermal technologies operating. In those hours spinning reserves are provided entirely from coal (low-PV with fixed nuclear) or from coal and nuclear (high-PV (Flex. Nucl.) scenario). There is substantial curtailment of renewable energy in the high-PV (Flex. Nucl.) scenario during the daytime. Curtailment levels in individual hours are as high as $30 \%$, whereas $10 \%$ of the total available renewable energy is curtailed in this week in the high-PV scenario, despite the assumption of flexible nuclear operations. In the low-PV scenario, the curtailment of wind and solar generation is also significant with $8 \%$ of the available renewable resources spilled during the low-load week. The less flexible system with fixed nuclear operations contributes in large part to the renewable curtailment. Still, the curtailment in absolute terms is lower in the low-PV scenario than in the high-PV (Flex. Nucl.) scenario since it has a much lower solar PV penetration level. In both cases, allowing wind and solar to provide reserves could contribute to reduce the curtailment of renewables and the overall cost of operation. However, we do not consider reserve provision from renewables or demand response in this case study, as pointed out above. 

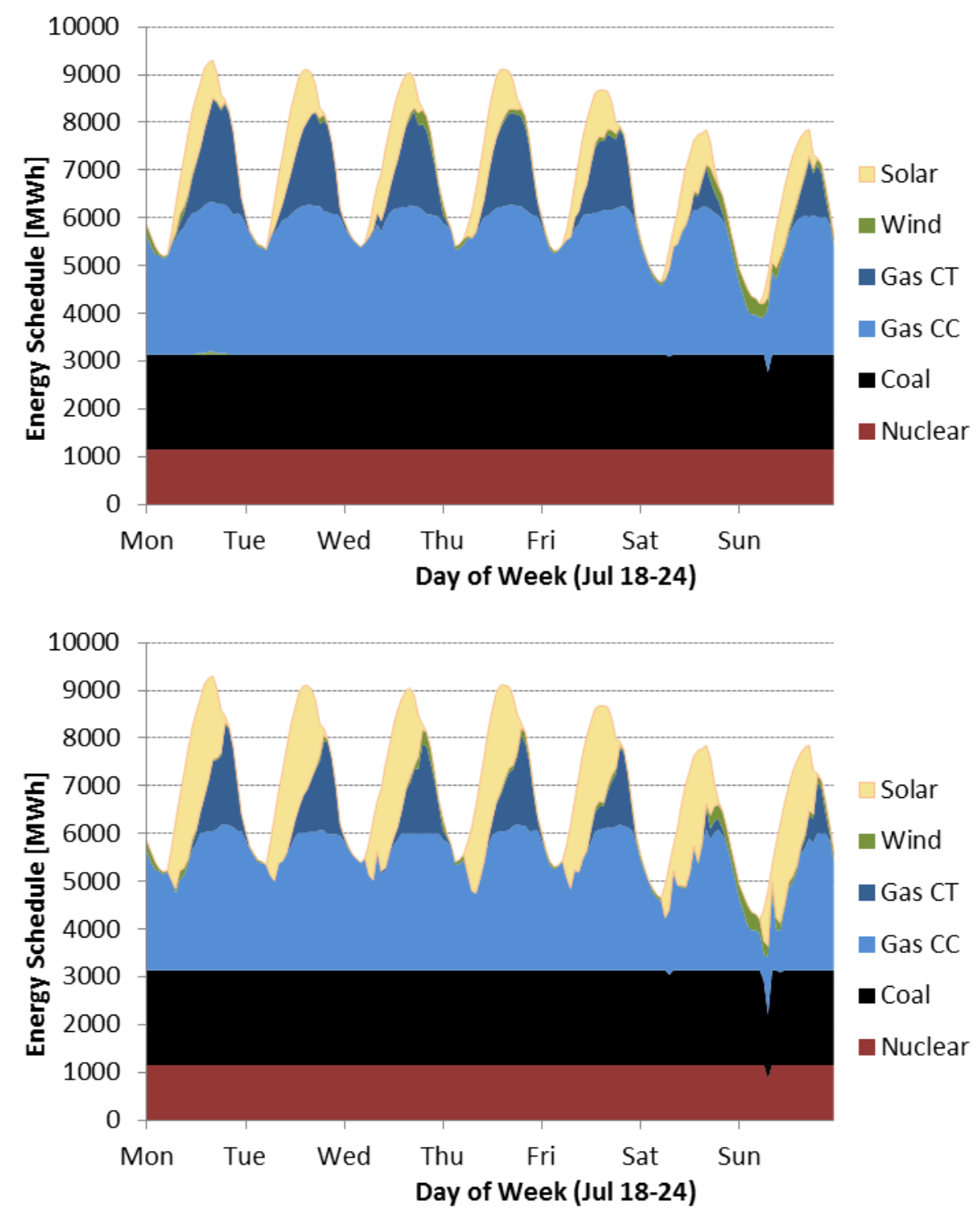

Figure 10. HA Energy Schedule in Peak-Load Week, July 18-24, under the Low-PV (top) and High-PV (Flex. Nucl.) (bottom) Scenarios 

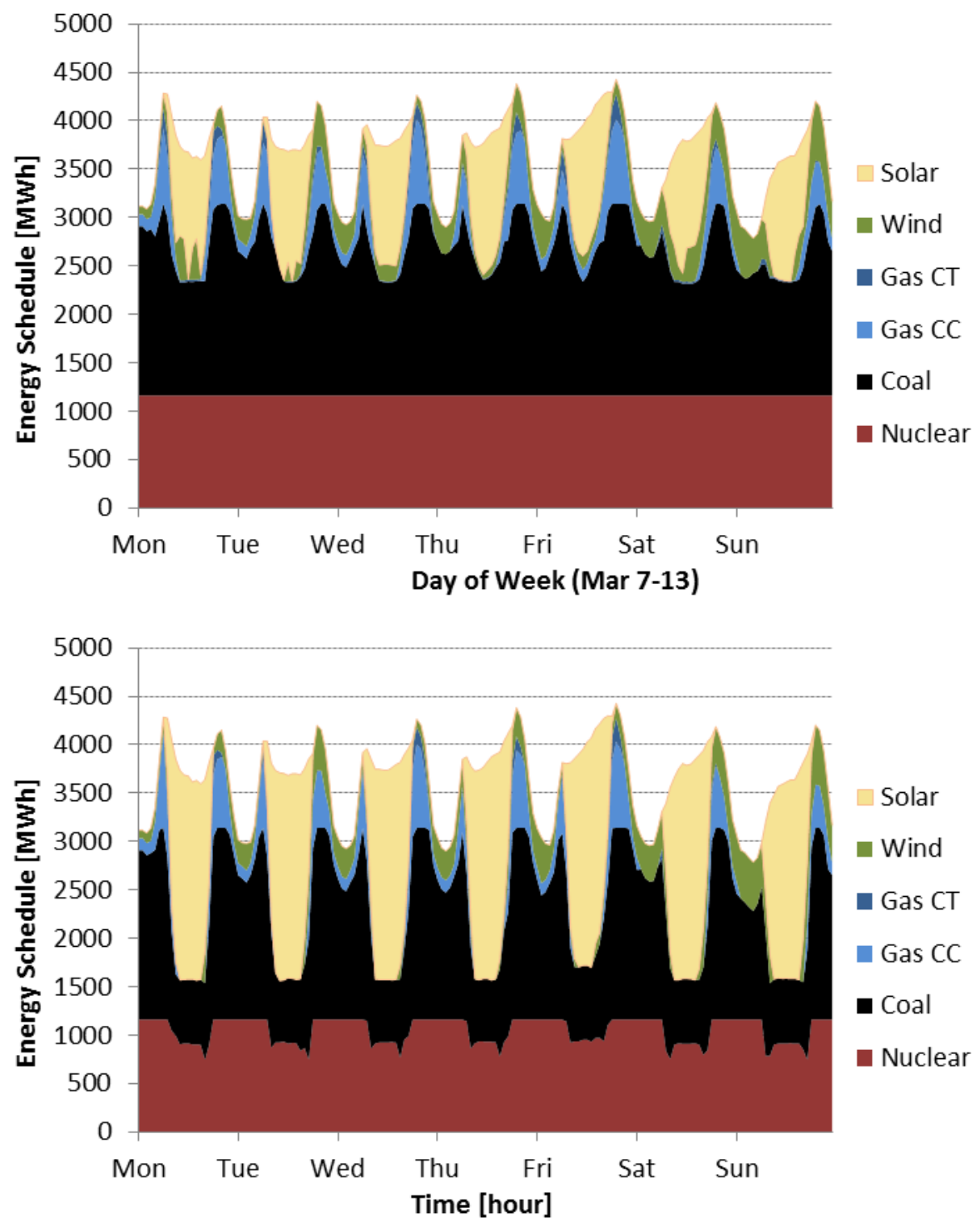

Figure 11. HA Energy Schedule in Minimum-Load Week, March 7-13, under the Low-PV (top) and High-PV (Flex. Nucl.) (bottom) Scenarios

We also investigate the rescheduling of thermal generation between the DA and HA based on daily scheduling deviations (calculated as the HA schedule less the DA schedule in each hour, summed over a day). In total, there is a slight reduction in the thermal generation between DA and HA. This reduction is due to a bias in the load forecast, which is higher for DA compared to HA. For the individual technologies, Figure 12 shows that nuclear generation sees no change in the low-PV scenario since its dispatch is constant and only limited scheduling deviations in the high-PV (Flex. Nucl.) since nuclear is first in the dispatch order because of its low fuel cost. The coal and gas fired plants all see significant variations between the DA and HA schedules. In particular, CC and CT plants experience large negative deviations (i.e., HA schedule is lower than DA schedule) a few days of the year. Overall, the differences between the lowPV and highPV (Flex. Nucl.) scenarios are relatively small. A possible explanation is that the load- 
forecasting error on average is higher than the wind- and solar-forecasting errors on an absolute basis (Table 5). Hence, load-forecasting errors, which are the same in both scenarios, may be the main driver for re-dispatching needs between DA and HA in both scenarios.
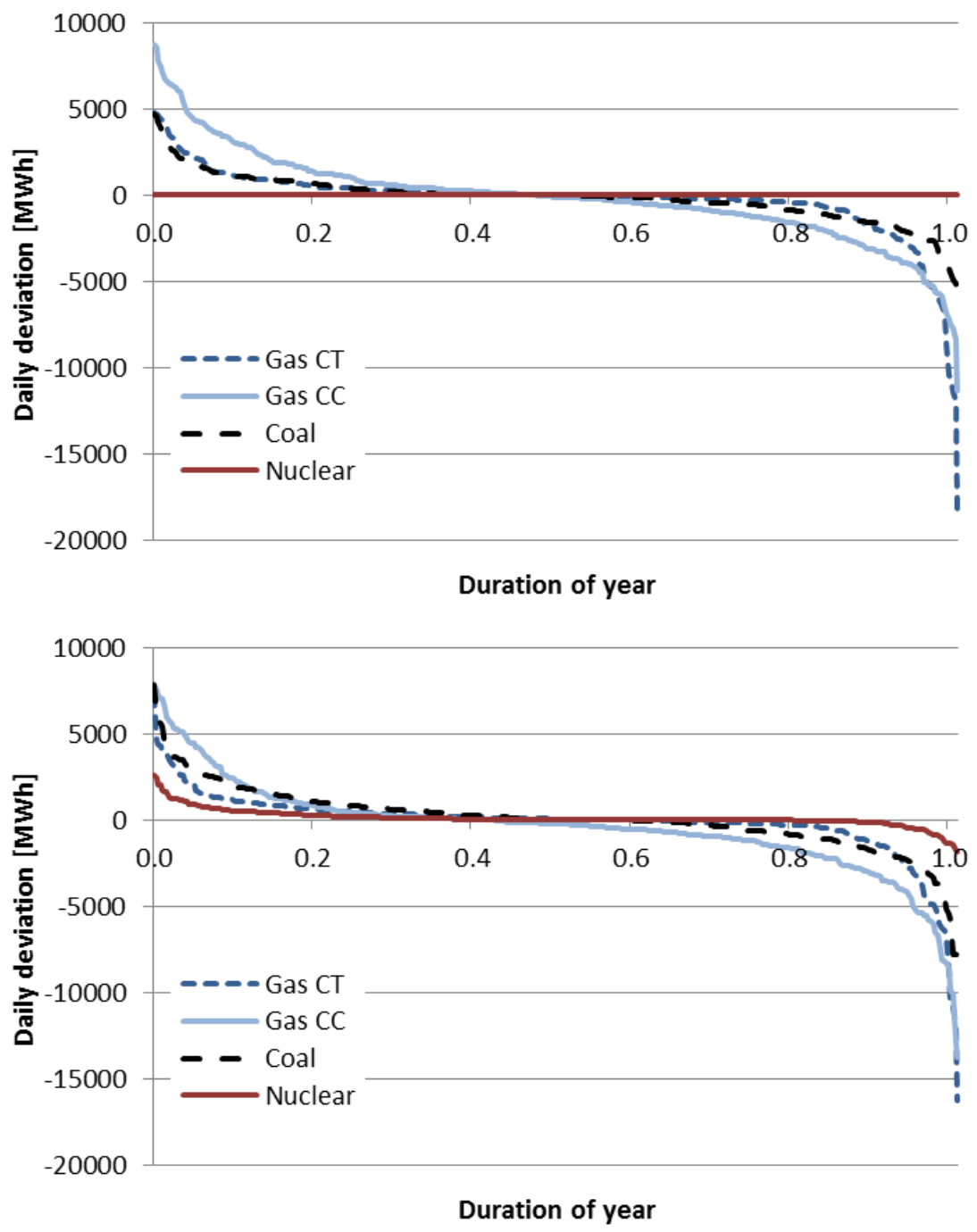

Figure 12. Daily Deviation between HA and DA Energy Schedules for Main Thermal Technologies in Low-PV (top) and High-PV (Flex. Nucl.) (bottom) Scenarios

The aggregate deviation between the DA and HA schedules is particularly important for understanding the impact of DA forecast errors on natural gas contracting and delivery. Natural gas purchases are made at the DA stage and only consumed in power plants during the operating day, as discussed in Section 2. Additional gas can be extracted from natural gas storage when the actual natural gas consumption over the day is larger than purchased or scheduled in the DA. Conversely, excess gas can be sent to storage when actual natural gas consumption is less than expected DA. Balancing natural gas using storage requires that adequate storage capacity is 
available. The maximum daily withdrawals from natural gas storage or maximum daily injections into storage based on aggregate natural gas deviations between the DA and HA schedules are summarized in Table 19. These figures assume all the gas that is nominated on the DA but then not consumed in the HA is injected into storage or all excess gas consumption in the operating day is withdrawn from storage. For reference, the maximum daily natural gas consumption and average natural gas consumption are also shown. Note that EIA records show $1.3 \mathrm{Bcf} /$ day of maximum daily delivery capacity from natural gas storage facilities in the nearby states of New Mexico and Utah as of September 2012 (though none in Arizona) (EIA, 2013). The maximum storage injection and withdrawal both increase slightly between the low-PV and high-PV (Flex. Nucl.) scenarios although less gas is burned overall in the high-PV (Flex. Nucl.) scenario. These results indicate that the ratio of natural gas storage capacity to natural gas delivery capacity (and utilization) increases with a higher PV penetration.

Table 19. Natural Gas Consumption and DA vs. HA Schedule Deviations in the Low-PV and High-PV Scenarios

\begin{tabular}{|c|c|c|}
\hline Natural Gas Consumption & Low-PV Scenario & $\begin{array}{c}\text { High-PV (Flex. Nucl.) } \\
\text { Scenario }\end{array}$ \\
\hline Maximum daily natural gas consumption [Bcf/day] & 0.69 & 0.58 \\
\hline Average daily natural gas consumption [Bcf/day] & 0.19 & 0.15 \\
\hline Maximum daily withdrawal from storage [Bcf/day] & 0.10 & 0.12 \\
\hline Maximum daily injection to storage [Bcf/day] & 0.27 & 0.28 \\
\hline
\end{tabular}

\subsection{RT Deployment of Balancing Reserves and CPS2 Performance}

The additional balancing reserves held in the HA scheduling are available for deployment in RT to maintain a balance between supply and demand on a minute-by-minute basis (though contingency reserves must still be held in reserve during normal operations). Any deviations from the HA schedule not met by deployment of balancing reserves in RT lead to ACE. The ACE for the load-wind and the net load for the low-PV and high-PV scenarios are shown in Figure 13.

(a)

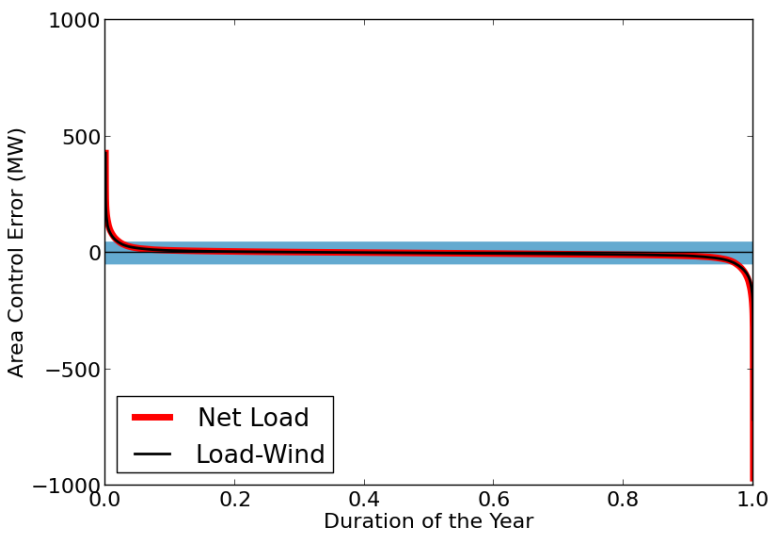

(b)

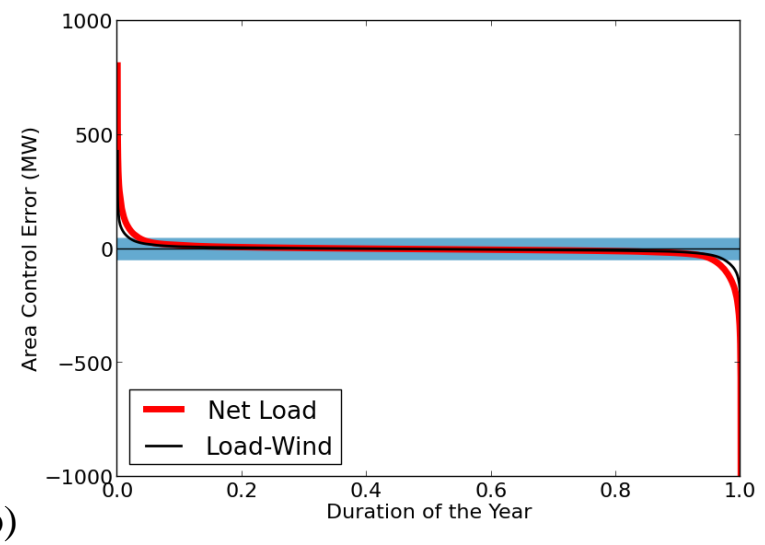

Note: Blue bar represents the $\mathrm{L}_{10}$ parameter for APS, which is assumed to be $46 \mathrm{MW}$

Figure 13. ACE Resulting from a Mismatch between Deviations from the HA Schedule and Deployment of Balancing Reserves in RT in the Low-PV Scenario (a) and the High-PV Scenario (b) 
In the low-PV scenario, the HA balancing reserves are sufficient to maintain a similar distribution of the ACE in the case with load and wind only and the case with the net load (load, wind, and PV). As a result, the final CPS2 score, which is based on the number of 10-min periods in which the ACE is within the tolerance band defined by the utilities $\mathrm{L}_{10}$ parameter, is similar for the case with the load-wind (a CPS2 score of 96.1\%) and the case with the net load (a CPS2 score of 95.8\%), as shown in Table 20. We also approximated the CPS1 score using several simplifying assumptions ${ }^{19}$ described in Appendix B. The approximated CPS1 score is well above the minimum required for compliance with NERC balancing standards (a minimum CPS1 score of 100) in both the low-PV and high-PV scenarios. From the perspective of the NERC balancing standard, the utility is just as reliable with PV as it is without PV in the low-PV scenario, as long as the additional balancing reserves identified in Figure 7 are provided during the HA scheduling.

Table 20. Resulting CPS2 Score for the Load-Wind and Net Load (load, wind, and PV) in the Low-PV and High-PV Scenarios

\begin{tabular}{lccccc}
\hline & \multicolumn{2}{c}{$\begin{array}{c}\text { CPS2 } \\
\text { (must be }>90 \%)\end{array}$} & & \multicolumn{2}{c}{$\begin{array}{c}\text { Approximate CPS1 } \\
\text { (must be }>100)\end{array}$} \\
\cline { 2 - 3 } Scenario & Load-Wind & Net Load & & Load-Wind & Net Load \\
\cline { 2 - 3 } Low PV & $96.1 \%$ & $95.8 \%$ & & 184 & 182 \\
High PV & $96.1 \%$ & $92.6 \%$ & & 184 & 169 \\
\hline
\end{tabular}

In the high-PV scenario, the ACE appears to be slightly greater in magnitude for the net load compared to the load-wind alone, as shown in Figure 13. As a result, the CPS2 score in the highPV scenario for the net load is only $92.6 \%$, compared to the CPS2 score of $96.1 \%$ for the loadwind alone (Table 20). ${ }^{20}$ While the CPS2 score of $92.6 \%$ still exceeds the minimum score for the NERC balancing standard, the decrease does indicate that the system is somewhat less reliable in the high-PV scenario. In this case, we assumed the balancing reserves are set based on the $2.5^{\text {th }}$ and $97.5^{\text {th }}$ percentile in of 1 -min deviations and balancing reserves are assumed to be able to be fully deployed in 10-min. The use of these percentiles in developing balancing reserve rules appears to be adequate in the case of load and wind or load, wind, and low PV. However, the degradation of the CPS2 score in the high PV case may not be acceptable to a system operator that desires a larger buffer from the CPS2 score that would violate NERC reliability standards. We address this issue in Section 6 by changing assumptions regarding balancing reserves (both

19 The CPS1 score is more difficult to estimate than CSP2 since CPS1 depends in part on the degree to which the overall interconnection is in balance. Overall balance of the interconnection is measured by the difference between the actual interconnection frequency and the target frequency (usually $60 \mathrm{~Hz}$ ), also known as the frequency error. The CPS1 score only penalizes imbalances that worsen the overall interconnection-wide imbalance. We simplify the CPS1 score calculation by assuming that the historical correlation between imbalances at APS and the overall interconnection-wide imbalance is the same with or without PV. Using this assumption and estimates of various other parameters, we can approximate the CPS1 score using our estimate of the 1-min ACE.

${ }^{20}$ Note that the same CPS2 score applies with both constant and fixed nuclear operations, since the same HA balancing reserve requirements are imposed in both cases. 
in terms of the percentiles used to set the magnitude of balancing reserves and the rate of deployment of balancing reserves) in order to maintain a high CPS2 score with an without PV.

\subsection{Integration Costs}

The integration costs are estimated as the difference in the total cost in cases that account for DA uncertainty and the increase in balancing reserves in the HA scheduling and in cases that ignore those factors. In order to calculate the integration costs of PV, we simulate the system under three different assumptions, as explained in Section 3.5. Total costs under perfect conditions, $T C_{p}$, assumes a perfect forecast for solar PV and no increase in HA balancing reserves. In contrast, $T C_{H A}$ refers to simulations with increased $\mathrm{HA}$ balancing reserves, and $T C_{D A}$ is the case that considers both increased HA balancing reserves and DA forecasting errors for solar PV. Total costs are primarily fuel and variable O\&M costs, whereas start-up costs make up between $3.0 \%$ and $4.5 \%$ of the total costs in these scenarios. Integration costs and the respective contributions from increased balancing reserves and DA forecast errors are then calculated from the differences among the three cases, divided by the total potential PV generation, as shown in Table 21. One caveat to note regarding these integration costs: the balancing reserves are sufficient to ensure that the CPS2 score is above the minimum threshold of $90 \%$ both with and without PV, but the CPS2 score is low compared to APS target levels and more importantly the CPS2 score does decrease with PV relative to the level for load and wind alone. The impact on the integration cost of increasing balancing reserves in order to maintain the CPS2 score with PV is explored in Section 6.

Table 21. Total Costs and Solar PV Integration Costs for Low-PV and High-PV Scenarios

\begin{tabular}{|c|c|c|c|c|c|c|}
\hline \multirow[b]{2}{*}{ Scenario } & \multicolumn{3}{|c|}{ Total Cost, $T C(\$ M / y r)$} & \multicolumn{3}{|c|}{ Integration Cost (\$/MWh-PV) } \\
\hline & $T C_{p}$ & $T C_{H A}$ & $T C_{D A}$ & $\begin{array}{c}\text { BR Increase (HA) } \\
\left(T C_{H A}-T C_{p}\right) / E_{p v} \\
\end{array}$ & $\begin{array}{c}\text { Forecast Error (DA) } \\
\left(T C_{D A}-T C_{H A}\right) / E_{p v}\end{array}$ & $\begin{array}{c}\text { Total } \\
\left(T C_{D A}-T C_{p}\right) / \mathrm{E}_{\mathrm{pv}} \\
\end{array}$ \\
\hline Low PV & 888.4 & 894.1 & 895.1 & 1.61 & 0.27 & 1.88 \\
\hline $\begin{array}{l}\text { High PV } \\
\text { (Const. Nucl) }\end{array}$ & 797.8 & 822.5 & 823.9 & 3.56 & 0.21 & 3.77 \\
\hline $\begin{array}{l}\text { High PV } \\
\text { (Flex. Nucl.) }\end{array}$ & 777.9 & 785.6 & 790.0 & 1.11 & 0.63 & 1.74 \\
\hline
\end{tabular}

The estimated integration costs of PV are \$1.88/MWh-PV in the low-PV scenario under the assumptions used in this study. Increasing the PV penetration in the high-PV (Const. Nucl.) scenario nearly doubles the integration cost to \$3.77/MWh-PV. In both the high-PV and low-PV scenarios, the increased balancing reserves requirement is responsible for most of the integration cost, while the forecasting error plays a less significant role on average.

Assuming that nuclear plants are flexible has a significant impact on the integration costs. The integration cost in the high-PV (Flex. Nucl.) scenario is only $\$ 1.74 / \mathrm{MWh}$, less than half of the cost with constant nuclear under high-PV assumptions and also lower than in the Low-PV 
scenario (which also assumes constant nuclear). This decrease in the integration cost is due to less costly provision of balancing reserves with flexible nuclear operations, resulting in a much lower balancing reserve portion of the integration costs. The forecast error costs actually increase with flexible nuclear compared to constant nuclear with high PV.

Furthermore, the overall total operational costs are lower with flexible nuclear than the total costs with constant nuclear in the high-PV scenario partly because of the large decrease in curtailment of renewable energy, leading to more displacement of thermal generation. Based on the difference in costs for the constant nuclear scenario and the flexible nuclear scenario, the economic value of increased nuclear flexibility to the utility would be nearly $\$ 34$ million per year with high PV penetration.

The increase in operating costs from the increased balancing reserves and DA forecast errors do not occur uniformly on all days of the year. We further examine the two sources contributing to the total integration cost by looking at the daily increases in the total operating costs due to the BR increase and the DA forecasting errors in the low-PV and high-PV (Flex. Nucl.) scenarios (Figure 14). Higher BR increases operating costs on almost all days of the year, and the variability in the daily cost increase across the year is relatively small in both scenarios. The average increase in operating costs from the DA forecasting errors is smaller than the increase in costs from the BR, as previously noted. DA forecast errors even reduce operating costs on $40 \%$ and $34 \%$ of the days of the year in the low-PV and high-PV (Flex. Nucl.) scenarios respectively. ${ }^{21}$ However, in contrast to the relatively uniform increase in costs from $\mathrm{BR}$, the increase in total cost due to the DA forecast error is more volatile. This is particularly noticeable in the high-PV (Flex. Nucl.) scenario where the cost increase due to the DA forecast error is very large for a few days. In fact, the maximum daily increase in costs from DA forecast errors is about four times as high as for the increased costs from BR, as shown in Figure 14. In contrast, the maximum costs due to BR and DA forecasting errors are at about the same level for the lowPV scenario. These results indicate that even though the increased BR makes up the majority of the integration cost over the year, the impact of forecasting errors may pose a higher risk for the utility because it is unpredictable and can be very high for some days.

21 A likely explanation for the cost reduction is that solar PV forecasting errors sometimes will counter the windand load-forecasting errors and therefore lead to a reduction in net-load forecasting error. 

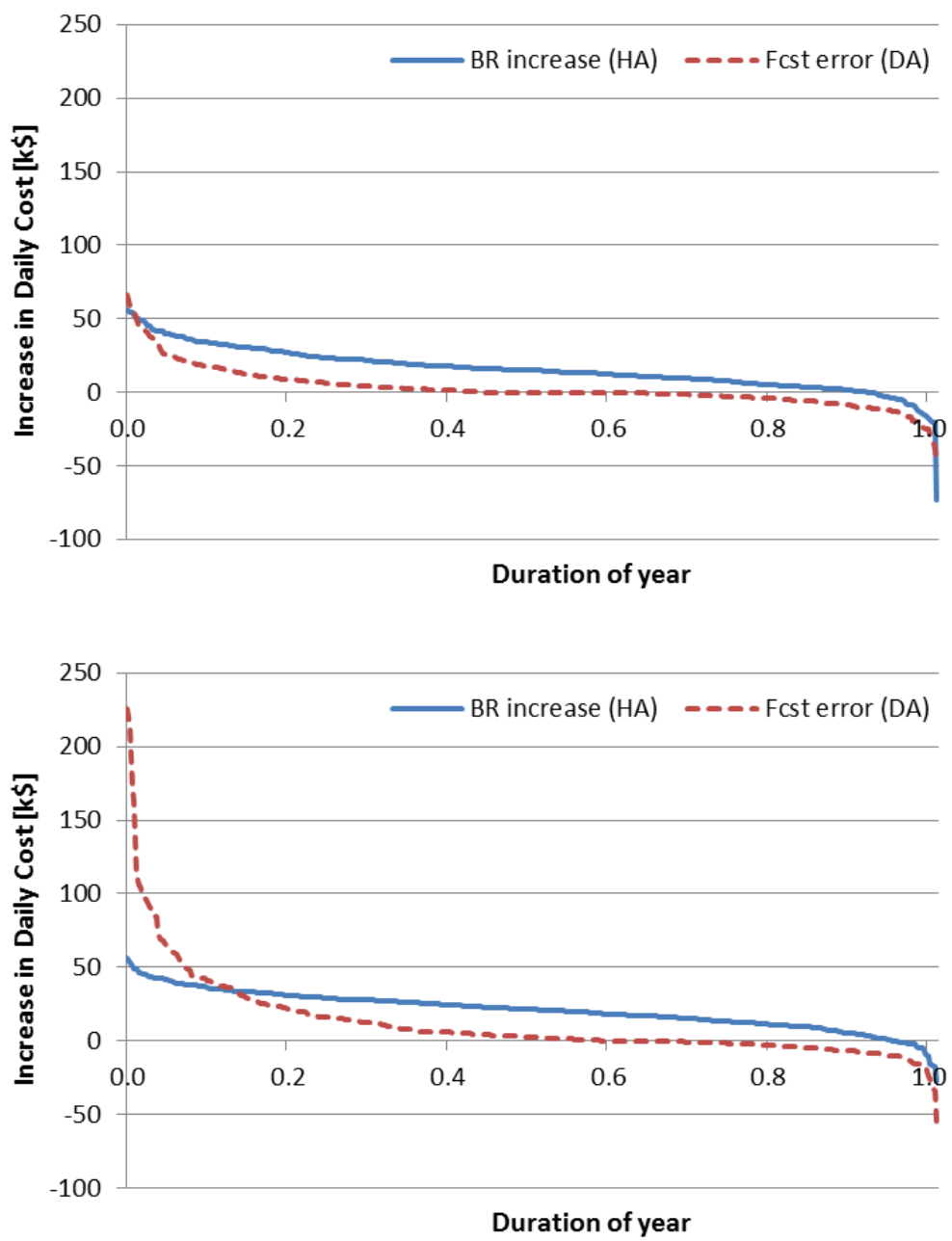

Figure 14. Daily Increases in Total Costs due to HA BR Increase and DA Forecast Errors for Low-PV (top) and High-PV (Flex. Nucl.) (bottom) scenarios in 2027 


\section{Sensitivity Cases}

We conduct a number of sensitivity cases to understand the degree to which the findings in the previous section change if some of the current practices at APS (e.g., avoidance of economic curtailment of renewables) are reflected in the integration cost estimates, and also to ascertain the robustness of the estimates to changes in various uncertain parameters. The sensitivities are separated into three groups. The first group simply examines the impact of changing the historical weather year from 2005 to 2004 in the low-PV scenario. The second group explores a wide range of different parameters, one at a time, using the high-PV (Flex. Nucl.) scenario as the benchmark. Finally, the third contemplates a worst-case scenario in which several parameters are changed at the same time in the high-PV (Const. Nucl.) scenario to further restrict the flexibility of the system. The purpose of this worst-case scenario is to develop an upper bound to potential integration costs and further highlight the potential economic costs associated with restrictions on flexibility.

\subsection{Sensitivity to Change in Historical Weather Year in the Low-PV Scenario}

We test the sensitivity of the results to the choice of historical weather year by re-creating the low-PV scenario with historical weather data from 2004 instead of 2005. Changing the weather year has no significant impact on the maximum and average balancing reserve requirement, as shown in Table 22. Similarly, changing the weather year has no significant impact on renewable curtailment, unmet spinning reserve requirements, and CPS2 performance. The annual curtailment of renewables remains at around 3\% of the potential renewables with 2004 weather data whereas the unmet spinning reserve requirement decreases with 2004 weather data. The CPS2 score for the net load increases in the low-PV scenario from $95.8 \%$ with 2005 weather data to $96.1 \%$ with 2004 weather data.

Table 22. Sensitivity of Balancing Reserve Rules to Choice of Historical Weather Year

\begin{tabular}{|c|c|c|c|c|c|c|}
\hline \multirow[b]{2}{*}{ Case } & \multicolumn{2}{|c|}{$\begin{array}{c}\text { Maximum Balancing Reserve } \\
\text { up in HA (MW) }\end{array}$} & \multicolumn{2}{|c|}{$\begin{array}{c}\text { Average Balancing Reserve } \\
\text { up in } \mathrm{HA}(\mathrm{MW})\end{array}$} & \multicolumn{2}{|c|}{$\begin{array}{c}\text { Maximum Balancing Reserve } \\
\text { down in } \mathrm{HA}(\mathrm{MW})\end{array}$} \\
\hline & Load-Wind & Net Load & Load-Wind & Net Load & Load-Wind & Net Load \\
\hline Low-PV & 187 & 278 & 132 & 171 & 132 & 171 \\
\hline 2004 weather & 187 & 275 & 130 & 170 & 130 & 170 \\
\hline
\end{tabular}

The choice of historical weather year (and hence historical load conditions) has a large impact on total costs. The use of 2004 weather conditions instead of the historical 2005 weather year leads to a large drop in total costs (Table 23), mainly because of lower loads in 2004. The estimated integration costs decline by $\$ 0.21 / \mathrm{MWh}-\mathrm{PV}$ with 2004 conditions. The lower load with 2004 conditions reduces the cost of providing additional reserves, and does not change the cost of making up for DA forecast errors. 
Table 23. Total Cost and Estimates of Integration Costs for the Low-PV Scenario and 2004 Weather Sensitivity Case

\begin{tabular}{|c|c|c|c|c|c|c|}
\hline \multirow[b]{2}{*}{ Case } & \multicolumn{3}{|c|}{ Total Cost $(T C)(\$ M / y r)$} & \multicolumn{3}{|c|}{ Integration Cost (\$/MWh-PV) } \\
\hline & $T C_{p}$ & $T C_{H A}$ & $T C_{D A}$ & BR Increase (HA) & Forecast Error (DA) & Total \\
\hline Low-PV & 888.4 & 894.2 & 895.2 & 1.61 & 0.27 & 1.88 \\
\hline 2004 weather & 804.8 & 809.9 & 810.8 & 1.40 & 0.27 & 1.67 \\
\hline
\end{tabular}

\subsection{Sensitivity to Change in Individual Parameters in the High-PV (Flex. Nucl.) Scenario}

While operations with PV in the low-PV scenario were found to be relatively similar to the operations for load and wind alone, the high-PV scenario highlighted potential challenges. The most dramatic impact occurred in the high-PV (Const. Nucl.) case where we found large curtailment of renewable energy during low net-load periods and also challenges in meeting the required BR in a few hours. These operational challenges need to be addressed for a scenario with high PV. One possible approach is to allow nuclear units to be dispatched down and provide spinning reserves, as discussed in the previous chapter. We leave exploration of other options to increase system flexibility to future research, and restrict the sensitivity analysis in this section to cases based on the high-PV (Flex. Nucl.) scenario. To some extent, we can expect that if other solutions provide system flexibility of the same magnitude, the other solutions should have similar impacts on the results as flexible nuclear.

Even after addressing the large curtailment with constant nuclear operation, several additional issues remain to be examined. One important issue is the decrease in the CPS2 score with highPV. A second concern is the remaining curtailment of renewables even with flexible nuclear. A third issue is that several parameters, such as fuel prices, are uncertain. In this section, we address these remaining issues by examining several sensitivities that vary BR rules, thermal plant flexibility, and penalties for renewable curtailment. We also examine the impact of different fossil fuel prices and the degree to which including load and wind variability and forecast errors affects the costs of managing PV variability and forecast errors. The sensitivity scenarios are categorized and summarized in Table 24. The assumption of flexible nuclear plant operations apply to all these cases in Table 24. 
Table 24. Overview of Sensitivity Cases for High-PV (Flex. Nucl.) 2027 Scenario

\begin{tabular}{|c|c|c|}
\hline Category & Case & Description \\
\hline Flexible nuclear & High-PV (Flex. Nucl.) & Base assumptions for high-PV (Flex. Nucl.) 2027 scenario \\
\hline \multirow[t]{3}{*}{$\begin{array}{l}\text { Balancing reserves } \\
(\mathrm{BR})\end{array}$} & Increase $\mathrm{BR}$ for $\mathrm{PV}$ & $\begin{array}{l}\text { Use 1st and 99th percentiles of deviations from PV HA } \\
\text { schedules to set BR (but continue to use 2.5th to 97.5th } \\
\text { percentiles for load and wind deviations. }\end{array}$ \\
\hline & Increase BR for all & $\begin{array}{l}\text { Greatly increase BR for all by using } 0.1 \text { st and } 99.9 \text { st } \\
\text { percentiles of deviations from PV, wind, and load HA } \\
\text { schedules to set BR rules. }\end{array}$ \\
\hline & Fast BR & $\begin{array}{l}\text { Require faster deployment rate of BR (5-min instead of } \\
10 \text {-min response time). }\end{array}$ \\
\hline \multirow[t]{2}{*}{ Flexibility } & Low ramping & $\begin{array}{l}\text { Assume ramp rates for thermal generators are lower (use } \\
\text { average ramp rates instead of maximum block ramp rates). }\end{array}$ \\
\hline & $\begin{array}{l}\text { Minimum renewables } \\
\text { curtailment }\end{array}$ & $\begin{array}{l}\text { Minimize curtailment of renewable energy by adding a high } \\
\text { curtailment penalty ( } \$ 10,000 / \mathrm{MWh}) \text { in objective function of } \\
\text { commitment and dispatch model. }\end{array}$ \\
\hline \multirow[t]{2}{*}{ Fuel prices } & High gas price & $\begin{array}{l}\text { Assume natural gas price increases by } 25 \% \text { from } \\
\$ 5.85 / \mathrm{MMBtu} \text { to } \$ 7.31 / \mathrm{MMBtu} \text {. }\end{array}$ \\
\hline & Low gas price & $\begin{array}{l}\text { Assume natural gas price decreases to } \$ 4.00 / \mathrm{MMBtu} \text { and } \\
\text { coal price increases from } \$ 1.96 / \mathrm{MMBtu} \text { to } \$ 3.00 / \mathrm{MMBtu} \text {. }\end{array}$ \\
\hline Forecasting & Perfect wind/load & $\begin{array}{l}\text { Assume perfect DA and HA forecasts for wind power and } \\
\text { load in commitment and dispatch model. }\end{array}$ \\
\hline
\end{tabular}

\subsubsection{Change in Balancing Reserves and CPS2 Score}

Among the sensitivity cases in Table 24, only the ones in the balancing reserves category change the BR rules and CPS2 scores. We investigate three sensitivity cases that are designed to maintain a higher CPS2 score in the high-PV (Flex. Nucl.) scenario for the net load:

(1) moderately increase balancing reserve requirements related only to PV deviations from the HA schedule; (2) greatly increase balancing reserves for PV, wind, and load; and (3) require a higher rate of deployment of the original high-PV scenario balancing reserves.

By increasing the percentiles of the deviations used to establish the BR rules to the 1st and 99th percentiles for PV, the maximum and average balancing reserve requirement in the up direction are increased by $15 \%$ and $21 \%$, respectively. As a result, the CPS2 score for the net load increases to $94.0 \%$ (Table 25), a score that again meets minimum standards for NERC but is still below the historical performance for APS.

Further increasing the balancing reserves by using the 0.1 th and 99.9th percentiles for deviations of PV, load, and wind increases the CPS2 score to $99.6 \%$ for load-wind and $98.1 \%$ for the net load with high PV. The reserves required to manage this high CPS2 score, however, are significantly greater than the reserves required in the benchmark high-PV (Flex. Nucl.) scenario, as the maximum and average balancing-up requirement increase by $82 \%$ and $89 \%$, respectively. 
However, if we assume that non-spinning reserves are capable of deployment after $10 \mathrm{~min}$ and that spinning reserves therefore are needed only for deviations that occur within 10 min, then the balancing-up reserve that needs to be met by spinning reserves is only a portion of this maximum balancing reserve up requirement - the remainder can be met with non-spinning reserves. Examination of the deviations shows that spinning reserves must be used for the first $737 \mathrm{MW}$ balancing-up reserves and that any of the remaining $276 \mathrm{MW}$ of balancing-up reserves can be non-spinning resources that are only available after $10 \mathrm{~min}$. These sensitivities show that the reliability of the utility system can be maintained with high PV penetration in part by increasing the amount of balancing reserves held in the HA scheduling.

The disadvantage of increasing the balancing reserve requirements is that it increases the integration costs associated with PV (Table 26) and increases renewable curtailment (Table 27). In particular, increasing the balancing reserve requirements for load, wind, and PV in order to achieve a $98.1 \%$ CPS 2 score doubles the integration cost to $\$ 4.41 / \mathrm{MWh}$ and also increases the total operating cost by $\$ 25 \mathrm{M} / \mathrm{yr}$. The increase in the integration cost is entirely due to the balancing reserve portion of the integration costs (the DA forecast error component slightly declines). Increasing the balancing reserve requirement for load, wind, and PV also almost triples the renewables curtailment to more than $9 \%$ annual curtailment of renewables. Increasing reserves for PV only also significantly increase integration costs and renewable curtailments, although to a much lesser extent.

Table 25. BR Requirements and CPS2 Score in Sensitivity Cases for the High-PV Scenario

\begin{tabular}{|c|c|c|c|c|c|c|}
\hline \multirow{2}{*}{$\begin{array}{c}\text { Sensitivity for High-PV } \\
\text { Scenario }\end{array}$} & \multicolumn{2}{|c|}{ CPS2 Score } & \multicolumn{2}{|c|}{$\begin{array}{c}\text { Maximum Balancing Reserve } \\
\text { up in } \mathrm{HA}(\mathrm{MW})\end{array}$} & \multicolumn{2}{|c|}{$\begin{array}{c}\text { Average Balancing } \\
\text { Reserve up in HA (MW) }\end{array}$} \\
\hline & Load-Wind & Net Load & Load-Wind & Net Load & Load-Wind & Net Load \\
\hline High PV (Flex. Nucl.) & $96.1 \%$ & $92.6 \%$ & 187 & 556 & 132 & 241 \\
\hline Increase BR for PV & $96.1 \%$ & $94.0 \%$ & 187 & 641 & 132 & 292 \\
\hline Increase BR for all & $99.6 \%$ & $98.1 \%$ & 359 & 1014 & 223 & 456 \\
\hline Fast BR & $97.8 \%$ & $95.3 \%$ & 187 & 556 & 132 & 241 \\
\hline
\end{tabular}

Table 26. Total Cost and Estimated Integration Costs in BR Sensitivity Cases of the High-PV (Flex. Nucl.) Scenario

\begin{tabular}{|c|c|c|c|c|c|c|}
\hline \multirow[b]{2}{*}{ Case } & \multicolumn{3}{|c|}{ Total Cost $(T C)(\$ \mathrm{M} / \mathrm{yr})$} & \multicolumn{3}{|c|}{ Integration Cost (\$/MWh-PV) } \\
\hline & $T C_{p}$ & $T C_{H A}$ & $T C_{D A}$ & BR Increase (HA) & Forecast Error (DA) & Total \\
\hline High PV (Flex. Nucl.) & 777.9 & 785.6 & 790.0 & 1.11 & 0.63 & 1.74 \\
\hline Increase BR for PV & 777.9 & 792.3 & 796.7 & 2.08 & 0.63 & 2.71 \\
\hline Increase BR for all & 784.2 & 811.7 & 814.8 & 3.96 & 0.45 & 4.41 \\
\hline Fast BR & 782.6 & 798.4 & 800.4 & 2.27 & 0.29 & 2.56 \\
\hline
\end{tabular}


Table 27. Renewable Curtailment in the BR Sensitivities to the High-PV(Flex. Nucl.) Scenario

\begin{tabular}{lcc}
\hline & \multicolumn{2}{c}{ Renewables Curtailment } \\
\cline { 2 - 3 } $\begin{array}{c}\text { Sensitivity for High-PV } \\
\text { Scenario }\end{array}$ & [GWh/yr] & Percentage of Potential \\
\hline High PV (Flex. Nucl.) & 299 & 3.4 \\
Increase BR for PV & 424 & 4.8 \\
Increase BR for all & 810 & 9.1 \\
Fast BR & 420 & 4.7 \\
\hline
\end{tabular}

An alternative option is to increase the rate of deployment of the balancing reserves. In the benchmark high-PV (Flex Nucl.) scenario, we assumed balancing reserves are primarily met by spinning resources that could be fully deployed in $10 \mathrm{~min}$. In this sensitivity case we assume that the balancing reserves are met by resources that can be fully deployed in $5 \mathrm{~min}$. As in the benchmark high-PV scenario, we use the 2.5th and 97.5th percentile of deviations for load, wind, and PV to define the magnitude of the balancing reserves held in the HA scheduling. The maximum and average balancing reserve requirement in the up direction remains similar to the requirements in the high-PV scenario (Table 25). The CPS2 score for the net load increases to $95.3 \%$ in the case with a faster rate of deployment of balancing reserves. The increase in CPS2 score indicates that the ACE in the high-PV case is not primarily due to insufficient balancing reserve capacity but to insufficient ability for the balancing reserves to keep up with deviations from the HA schedules. Increasing the rate at which balancing reserves can be deployed results in a lower ACE and a higher CPS2 score.

The disadvantage of the requirement that balancing reserves be able to be deployed rapidly is that it reduces the pool of generation resources that can contribute to the balancing reserves in the HA scheduling. Similar to the two cases with increased BR, the fast BR case also increases the integration cost (up to $\$ 2.56 / \mathrm{MWh}$ ) by increasing the BR portion, as shown in Table 26. However, while comparing the fast BR case with the increase BR for PV case, note that the fast BR case obtains a higher CPS2 score whereas the estimated integration cost is lower than in the increase BR for PV case. Overall it appears that there are several options that can increase the CPS2 score, but each at the cost of increasing the integration cost for PV, as shown in Figure 15. 


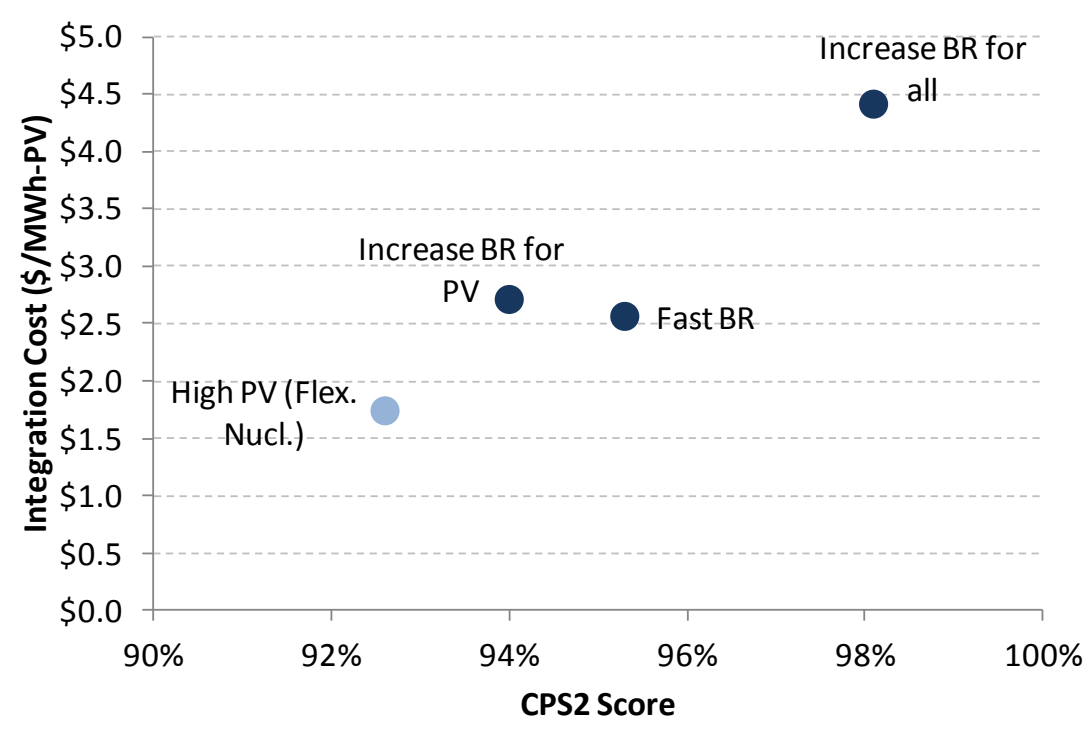

Figure 15. Tradeoff Between Balancing Performance (CPS2 Score for Net Load) and Integration Cost of PV

The detailed results show that the utility system is sufficiently flexible (in terms of high ramp rates of generation capacity) that more than $99.999 \%$ of the spinning reserve requirement continues to be met in the HA scheduling, even after increasing the rate at which balancing reserves are deployed in the high-PV (Flex. Nucl.) scenario. The curtailment of spinning reserve up also remains insignificant in the two cases with increased BR. Curtailment of spinning reserve down does not occur in any of the three cases related to balancing reserves.

\subsubsection{Impact of Changes in Flexibility}

The sensitivity cases in the flexibility category test the impact of assuming lower ramp rates for thermal generators and the inclusion of a high penalty for renewables curtailment in the commitment and dispatch model.

Decreasing the assumed ramp rates for thermal generators increases the integration cost only slightly (Table 28), but gives a more significant increase in the renewables curtailment (Table 29). Decreasing the ramp rate of thermal generators has no significant impact on the amount of unmet spinning reserves. The minimum renewables curtailment sensitivity introduces a large penalty for renewables curtailment in the commitment and dispatch model. This penalty ensures that renewables curtailment occurs only when it would otherwise cost the system more than $\$ 10,000 / \mathrm{MWh}$ to prevent the curtailment of renewables. Introducing this penalty does decrease curtailment relative to the benchmark high-PV (Flex. Nuclear) scenario (Table 29), but curtailment still occurs. The estimated integration cost increases to $\$ 1.85 / \mathrm{MWh}$ in this case with lower renewables curtailment. Overall, the case with the minimum renewables curtailment has higher operating costs than the benchmark high-PV (Flex. Nucl.) case, indicating that economic curtailment of such resources make sense during surplus conditions. Some renewables 
curtailment is still necessary with high PV penetration and flexible nuclear with the other assumptions that the utility is not connected to a broader market, some coal plants are must-run, and renewables cannot provide balancing down reserves. In reality, APS is connected to other utilities, and it may be prudent to find other buyers for its power during low-net-load periods with high PV if possible or examine other potential sources of flexibility. Another observation is that there is a significant amount of spinning reserve down curtailment in the minimum renewables curtailment case, that is, the reserve-down constraint is violated as much as 707 hours of the year and the total annual curtailment is $8 \%$ of the down-reserve requirement. This is explained by the very high penalty assigned to renewables curtailment, which is actually higher than the penalty of $\$ 9,900 / \mathrm{MW}$-h for violating the reserve requirements. Hence, in this case the model prioritizes using renewable energy ahead of maintaining sufficient balancing reserves.

Table 28. Total Cost and Estimated Integration Costs in Balancing Reserve Sensitivity Cases of the High-PV (Flex. Nucl.) Scenario

\begin{tabular}{|c|c|c|c|c|c|c|}
\hline \multirow[b]{2}{*}{ Case } & \multicolumn{3}{|c|}{ Total Cost $(T C)(\$ \mathrm{M} / \mathrm{yr})$} & \multicolumn{3}{|c|}{ Integration Cost (\$/MWh-PV) } \\
\hline & $T C_{p}$ & $T C_{H A}$ & $T C_{D A}$ & BR Increase (HA) & Forecast Error (DA) & Total \\
\hline High PV (Flex. Nucl.) & 777.9 & 785.6 & 790.0 & 1.11 & 0.63 & 1.74 \\
\hline Low ramping & 786.3 & 795.9 & 799.1 & 1.39 & 0.46 & 1.85 \\
\hline $\begin{array}{l}\text { Min renewables } \\
\text { curtailment }\end{array}$ & 779.1 & 788.2 & 794.1 & 1.32 & 0.86 & 2.18 \\
\hline
\end{tabular}

Table 29. Renewable Curtailment in the Flexibility Sensitivities to the High-PV (Flex. Nucl.) Scenario

\begin{tabular}{lcc}
\hline & \multicolumn{2}{c}{ Renewables Curtailment } \\
\cline { 2 - 3 } $\begin{array}{c}\text { Sensitivity for } \\
\text { High-PV Scenario }\end{array}$ & \multicolumn{2}{c}{$\begin{array}{c}\text { Percentage of } \\
\text { Renewable Energy }\end{array}$} \\
\hline High PV (Flex. Nucl.) & 299 & 3.4 \\
Low ramping & 351 & 4.6 \\
Min renewables curtailment & 82 & 0.9 \\
\hline
\end{tabular}

\subsubsection{Change in Fuel Prices}

The fuel price sensitivity cases examine the impact of increasing the assumed natural gas price by $25 \%$ (bringing it in line with APS projections of natural gas prices in 2027) and decreasing the natural gas price by $25 \%$ while simultaneously increasing the price of coal. The price of coal is increased in the low gas price sensitivity to the point that a typical CC plant and a typical coal plant have similar marginal costs. Increasing the natural gas price by $25 \%$ increases the integration cost by $11 \%$ to $\$ 1.93 / \mathrm{MWh}$ (Table 30 ). Decreasing the natural gas price by $25 \%$ (and increasing the cost of coal) lowers the integration cost by $41 \%$ to $\$ 1.02 / \mathrm{MWh}$. The DA forecast 
error cost and the cost of HA balancing reserves change in similar proportions to the overall change in integration costs with lower natural gas prices.

Increasing the natural gas price by $25 \%$ increases the renewables curtailment slightly (Table 31 ). In contrast, decreasing the natural gas price and increasing the cost of coal reduces the renewables curtailment by $12 \%$. Changing the fuel price assumptions had no noticeable impact on the amount of unmet spinning reserves.

Table 30. Total Cost and Estimated Integration Costs in Fuel Price Sensitivity Cases of the High-PV Scenario

\begin{tabular}{|c|c|c|c|c|c|c|}
\hline \multirow[b]{2}{*}{ Case } & \multicolumn{3}{|c|}{ Total Cost $(T C)(\$ M / y r)$} & \multicolumn{3}{|c|}{ Integration Cost (\$/MWh-PV) } \\
\hline & $T C_{p}$ & $T C_{H A}$ & $T C_{D A}$ & BR Increase $(\mathrm{HA})$ & Forecast Error (DA) & Total \\
\hline High PV (Flex. Nucl.) & 777.9 & 785.6 & 790.0 & 1.11 & 0.63 & 1.74 \\
\hline High gas price & 869.7 & 878.9 & 883.1 & 1.32 & 0.61 & 1.93 \\
\hline Low gas price & 785.5 & 790.4 & 792.6 & 0.72 & 0.30 & 1.02 \\
\hline
\end{tabular}

Table 31. Renewables Curtailment in the Fuel Price sensitivities to the High-PV (Flex. Nucl.) Scenario

\begin{tabular}{lcc}
\hline & \multicolumn{2}{c}{ Renewables Curtailment } \\
\cline { 2 - 3 } $\begin{array}{c}\text { Sensitivity for High-PV } \\
\text { Scenario }\end{array}$ & [GWh/yr] & Percentage of Potential \\
\hline High PV (Flex. Nucl.) & 299 & 3.4 \\
High gas price & 311 & 3.5 \\
Low gas price & 264 & 3.0 \\
\hline
\end{tabular}

\subsubsection{Removing Load and Wind DA Forecast Errors}

We examine the degree to which load and wind DA forecast errors affect the results in the highPV (Flex. Nucl.) scenario by including only PV forecast errors in the model. This has no noticeable impact on the renewables curtailment and on the unmet spinning reserves. It does, however, increase the estimated integration cost by $4 \%$ to $\$ 1.81 / \mathrm{MWh}$, mainly due to higher cost from the DA forecast error (Table 32). The increase in the integration costs when load and wind forecast errors are ignored is likely due to situations in which forecast errors for solar PV and wind or load cancel each other out, an effect that disappears when load and wind forecasts are perfect. The result illustrates that it is important to consider forecasting errors for all renewable resources as well as load, in estimating integration costs. 
Table 32. Total Cost and Estimated Integration Costs in Forecast Sensitivity Cases of the High-PV (Flex. Nucl.) Scenario

\begin{tabular}{lcccccccc}
\hline & \multicolumn{3}{c}{ Total Cost $(T C)(\$ \mathrm{M} / \mathrm{yr})$} & & \multicolumn{3}{c}{ Integration Cost $(\$ / \mathrm{MWh}-\mathrm{PV})$} \\
\cline { 2 - 3 } \cline { 7 - 8 } \multicolumn{1}{c}{ Case } & \multicolumn{2}{c}{$T C_{p}$} & $T C_{H A}$ & $T C_{D A}$ & & BR Increase $(\mathrm{HA})$ & Forecast Error (DA) & Total \\
\hline High PV (Flex. Nucl.) & 777.9 & 785.6 & 790.0 & & 1.11 & 0.63 & 1.74 \\
Perfect wind/load & 772.8 & 780.6 & 785.3 & & 1.13 & 0.68 & 1.81 \\
\hline
\end{tabular}

\subsubsection{Summary of Single-Parameter Sensitivity Cases Based on the High-PV (Flex. Nucl.) Scenario}

With flexible nuclear plants and high PV, the renewables curtailment varies with the sensitivity cases between $0.9 \%$ and $9.1 \%$ of the renewable potential (Figure 16). Curtailment is lowest in the case in which there is a penalty in the commitment and dispatch model for curtailing renewables. The fact that curtailment occurs even with a large penalty (and the earlier finding that curtailment greatly increases with inflexible nuclear plants) suggests that APS should prepare to find buyers for its power during low net-load periods, work to increase the flexibility of its coal and nuclear facilities, increase demand response, and/or develop ways to provide balancing down from renewables in scenarios with high PV penetration.

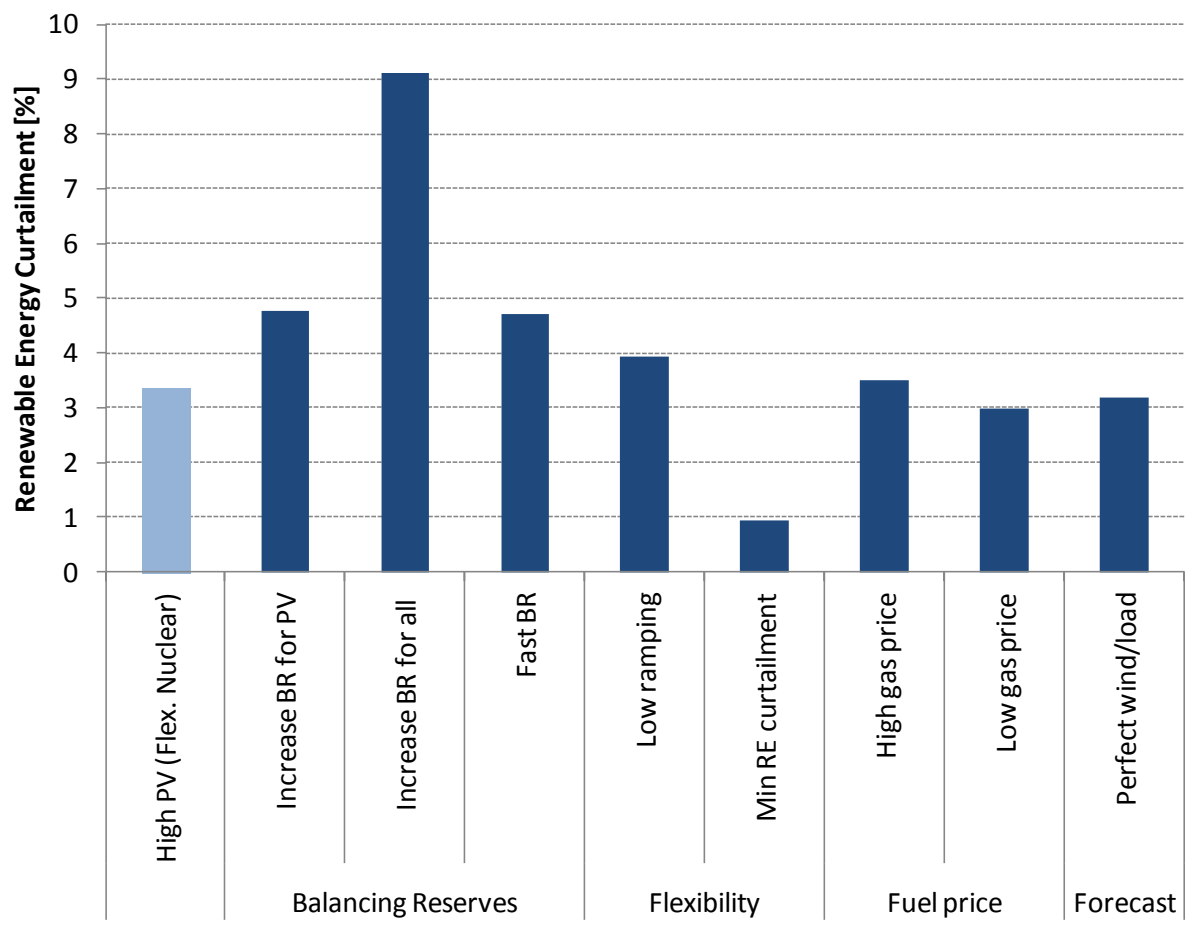

Figure 16. Renewable Energy Curtailment as a Percentage of Total Available Resources for High-PV (2027) Sensitivity Cases 
The integration costs also varied with the sensitivity cases (Figure 17). The lowest integration cost is $\$ 1.02 / \mathrm{MWh}$ with low natural gas prices and higher coal prices, while the highest is $\$ 4.41 / \mathrm{MWh}$ with the assumption of very high balancing reserves. Across all sensitivity cases to the high-PV (Flex. Nucl.) scenario, the integration cost due to DA forecast error is consistently lower than the balancing reserve costs. Finally, Figure 18 summarizes the total operating costs, accounting for both DA forecast errors and increased BR, for the different sensitivity cases. The cases with more stringent BR all lead to higher costs of operation. Less flexibility also contributes to cost increases. Not surprisingly, a higher gas price gives a substantial increase in generation costs, whereas the cost reduction in the low gas-price case is offset by the assumed increase in coal price in that case. Perfect wind and load forecasts give a small reduction in total operating costs, although the integration cost estimate in that case is slightly higher than that in the baseline high-PV (Flex. Nucl.) scenario.

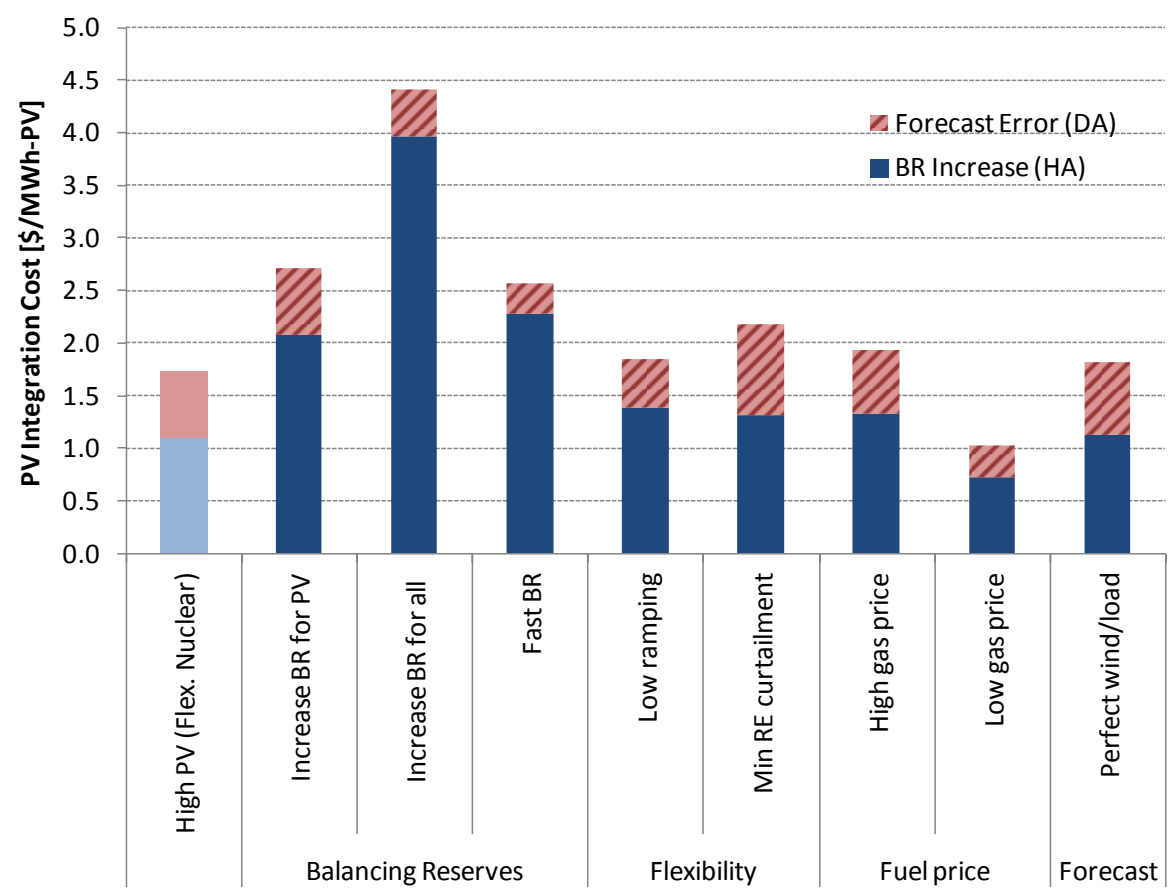

Figure 17. PV Integration Cost Estimates for High-PV (2027) Sensitivity Cases 


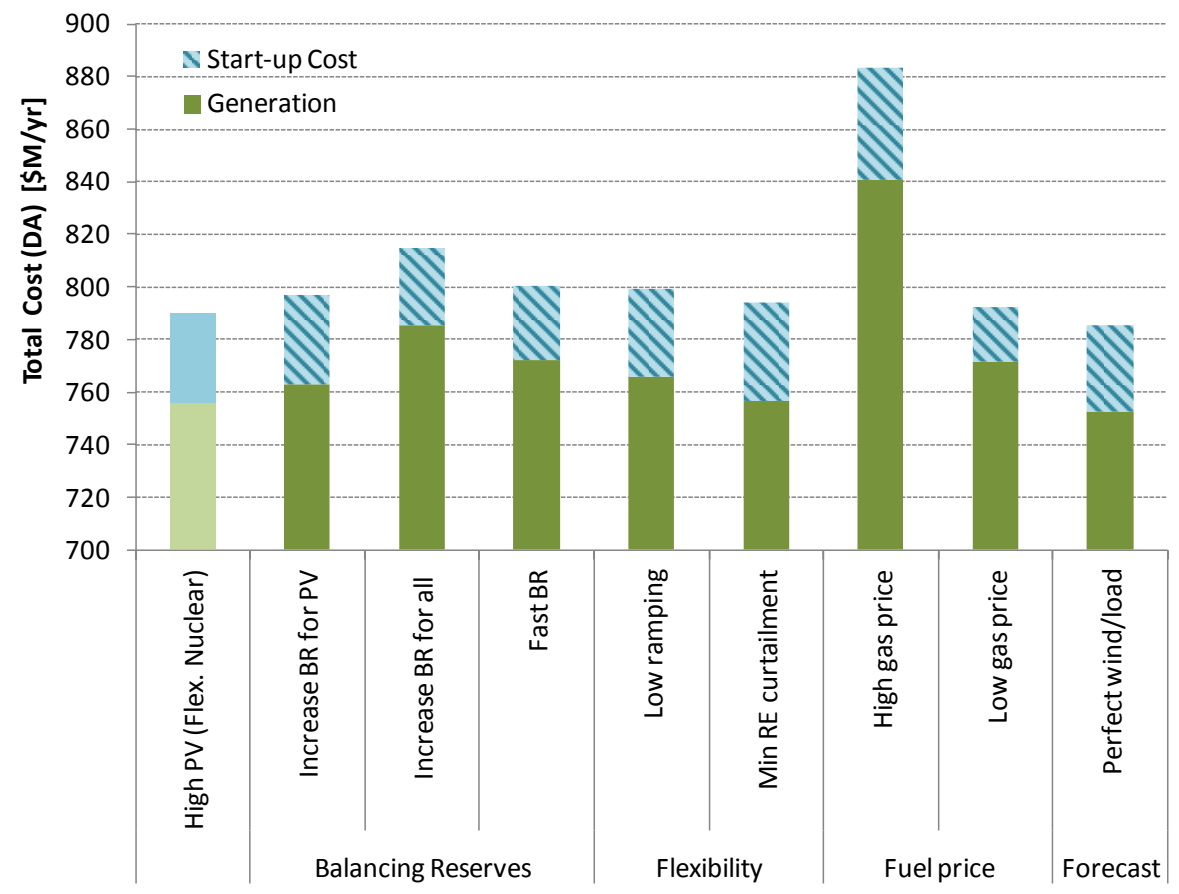

Figure 18. Total Cost Estimates for High-PV (2027) Sensitivity Cases

\subsection{Worst-Case Sensitivity with High PV}

Under the assumption that the utility is not able to buy and sell power with other markets, the results presented so far indicate that flexibility in nuclear plants, other thermal generators, and renewables are all important to managing high PV penetrations. We wanted to establish an upper bound to the integration costs with high PV penetration by evaluating an extreme sensitivity case in which none of this flexibility is available. In this worst-case scenario, we assume constant nuclear operation (without the ability to provide reserves), penalties for renewables curtailment, and low ramp rates of non-nuclear thermal generation. We also use the 0.1th and 99.9th percentile of load, wind, and PV deviations from the HA schedule to set the BR requirements, similar to the increase BR for all sensitivity case. The results are compared to both the high-PV (Flex. Nucl.) and high-PV (Const. Nucl.) scenarios in Table 33 and Table 34.

The combination of these severe constraints on flexibility leads to a greatly increased total cost overall and an increase in the estimated integration cost to more than $\$ 9.5 / \mathrm{MWh}$. The increase in the integration cost is due entirely to an increase in the BR costs, as the DA forecast error costs remains at a relatively modest level. The renewables curtailment is again very high (10.5\%), but still considerably lower than in the high-PV (Const. Nucl.) scenario since there is now a high penalty for curtailment of renewables. Although this penalty increases the utilization of renewable energy it contributes to increase the integration cost, along with the increased BR requirements and lower ramp rates for thermal generators.

Beyond the economic impacts of this inflexibility, the combination of assumptions also affects reliability. The unmet spinning reserves in most previous cases were minimal even with high PV 
penetration, the main exception being the minimum renewables curtailment case, which has a large curtailment of spinning reserve down, as discussed above. In the worst case, however, the unmet spinning reserves up increases to more than $41,000 \mathrm{MW}-\mathrm{h} / \mathrm{yr}(1.5 \%$ of the total requirement). The unmet spinning reserves-down is also significant, at $1,730 \mathrm{MW}-\mathrm{h} / \mathrm{yr}(0.1 \%$ of the total requirement). The spinning reserves-up requirement is not met in $13 \%$ of the hours of the year, and the spinning reserve down requirement is not met in $2 \%$ of the hours of the year. As a result, the CPS2 score could suffer under these extreme assumptions, because the commitment and dispatch model was not able to meet the BR requirement in a nontrivial fraction of the hours.

This worst-case result indicates that a combination of low ramping rates for thermal plants, constant nuclear output, penalties for renewables curtailment, and very high BR, along with the default assumptions of no trading with neighboring utilities and must-run coal units, would result in considerable reduction in system reliability because of the lower amount of flexibility in the system. The worst-case result clearly illustrates the importance of flexibility, from both the reliability and cost perspectives. ${ }^{22}$

Table 33. Total Cost and Estimated Integration Costs in the Worst-Case Sensitivity of the High-PV Scenario

\begin{tabular}{|c|c|c|c|c|c|c|}
\hline \multirow[b]{2}{*}{ Case } & \multicolumn{3}{|c|}{ Total Cost $(T C)(\$ \mathrm{M} / \mathrm{yr})$} & \multicolumn{3}{|c|}{ Integration Cost (\$/MWh-PV) } \\
\hline & $T C_{p}$ & $T C_{H A}$ & $T C_{D A}$ & BR Increase (HA) & Forecast Error (DA) & Total \\
\hline High PV (Flex. Nucl.) & 777.9 & 785.6 & 790.0 & 1.11 & 0.63 & 1.74 \\
\hline High PV (Const. Nucl.) & 797.8 & 822.5 & 823.9 & 3.56 & 0.21 & 3.77 \\
\hline Worst case & 831.5 & 894.1 & 897.6 & 9.05 & 0.50 & 9.55 \\
\hline
\end{tabular}

Table 34. Renewable Curtailment in the Worst-Case Sensitivity to the High-PV Scenario

\begin{tabular}{lcc}
\hline & \multicolumn{2}{c}{ Renewables Curtailment } \\
\cline { 2 - 3 } $\begin{array}{c}\text { Sensitivity for High-PV } \\
\text { Scenario }\end{array}$ & \multicolumn{2}{c}{$\begin{array}{c}\text { Percentage of } \\
\text { Renewable Energy }\end{array}$} \\
\hline High PV (Flex. Nucl.) & 299 & 3.4 \\
High PV (Const. Nucl.) & 1587 & 17.8 \\
Worst case & 934 & 10.5 \\
\hline
\end{tabular}

${ }^{22}$ Note that total costs increase substantially even if the impact of reduced reliability due to the substantial reserve shortfalls is not considered in the total cost calculations. 


\section{Conclusions and Future Work}

Utilities can manage short-term variability and DA forecast uncertainty of PV through several sources of flexibility available in existing operating practices. These practices include re-dispatch of committed generation units, commitment of peaking units within the operating day, and holding additional resources in reserve during HA scheduling to be deployed in RT. Managing variability and uncertainty through these methods is not without cost. In this report, we present a comprehensive analytical framework for measuring the cost and reliability implications of the bulk power system under a high penetration of renewable energy. We also quantify these costs through a case study based on the projected generation portfolio of APS in 2027 with a solar PV resource of $8.8 \%$ of annual demand (low-PV scenario) and $17.0 \%$ of annual demand (high-PV scenario). Both scenarios also consider a wind resource of $4.9 \%$ of annual demand. We conduct a detailed sensitivity analysis of system reliability and cost under different assumptions about balancing reserves, system flexibility, fuel prices, and forecasting errors.

\subsection{Main Findings}

An important criterion for managing increased amounts of PV is to maintain reliability as measured by NERC balancing standards. We develop hourly balancing reserve requirements based on statistical analysis that can be used by utilities in the HA scheduling process to ensure that sufficient resources are available within the operating hour to manage deviations from the HA schedule. Increased variability and uncertainty from PV lead to an increase in these HA balancing reserve requirements. We used simulated minute-by-minute deviations from HA schedules developed from an earlier weather year to create the balancing reserve requirements to use in the simulated operating year. As PV generation in utility systems increases, utilities may similarly find it helpful to begin collecting information on actual deviations from schedules to develop balancing reserve requirements that match their system conditions.

As long as low net-load events are managed and the HA balancing requirements are available, the CPS2 score of the utility continues to exceed the minimum NERC requirement in all cases examined. In cases with low PV penetration and HA balancing reserves based on the $2.5^{\text {th }}$ and $97.5^{\text {th }}$ percentile of deviations from the HA schedule, CPS2 performance is similar with or without PV. Maintaining equivalent CPS2 performance in the high-PV scenario (which introduces several additional large utility-scale PV plants) is found to be more challenging. In order to maintain CPS2 performance with high PV, either the rate at which balancing reserves are deployed needs to be increased or the amount of balancing reserves held needs to be further increased. Both options increase operating costs significantly relative to simply allowing CPS2 performance to be reduced to below its level without PV (though still above the NERC minimum requirement of $90 \%$ ).

In the low-PV scenario we found that the operational challenges are relatively modest and estimate the integration cost to be $\$ 1.88 / \mathrm{MWh}-\mathrm{PV}$ at a CPS2 score of $95.8 \%$. In the high-PV scenario, however, we find the operational challenges more substantial and we estimate the integration cost to be $\$ 3.77 / \mathrm{MWh}-\mathrm{PV}$ at a lower CPS2 score of $92.6 \%$. In the high-PV scenario, 
curtailments of renewable energy reach a very high level (17.8\% of the total resource) and it also becomes challenging to meet the increased BR requirements in a few hours of the year. These results rely on several conservative assumptions about system flexibility, including no trading with neighboring utilities, no demand response, all operating reserves (both up and down) provided by thermal power plants, several must-run coal plants, and constant output from all nuclear plants. In the high-PV scenario we relax the latter assumption and find that with flexible nuclear plants providing both energy and reserves the integration cost drops substantially to $\$ 1.74 / \mathrm{MWh}-\mathrm{PV}$. Flexible nuclear dispatch also reduces the curtailment of renewables to $3.4 \%$ of the total resource, indicating that the increased system flexibility makes it much easier to absorb high solar PV penetration levels. Other sources of system flexibility, not investigated in this study, are also likely to reduce the integration cost and mitigate operational challenges.

For the low-PV scenario, our sensitivity analysis shows that the choice of reference year may have significant impact on total costs as well as integration costs. Using historical data from 2004 instead of 2005 gave a reduction in the integration cost by $\$ 0.21 / \mathrm{MWh}-\mathrm{PV}$ to $\$ 1.67 / \mathrm{MWh}$ PV due to lower loads in 2004.

For the high-PV scenario we mainly focused the sensitivity analysis on the case with flexible nuclear operations. We found that system reliability can be improved either by increasing the balancing reserves or by requesting that they respond faster. However, this comes at the expense of higher integration costs and also more curtailment of renewable energy. In the case with the highest reserve requirements, the CPS2 score improved to $98.1 \%$, but both the integration cost and the curtailment of renewable almost tripled to $\$ 4.41 / \mathrm{MWh}-\mathrm{PV}$ and $9.1 \%$ respectively. We also investigated reductions in system flexibility. A case with lower hourly ramp rates for thermal generators saw only a small increase in the estimated integration costs. In another case we minimized the amount of renewable curtailment by adding a high curtailment penalty to the objective function of the UC/ED model. We found that the renewable curtailment dropped to less than $1 \%$, but this came at an increase in the integration cost from $\$ 1.74 / \mathrm{MWh}-\mathrm{PV}$ in the high-PV (Flex. Nuclear) case to $\$ 2.14 / \mathrm{MWh}-\mathrm{PV}$. Hence, we conclude that some economic curtailment of renewables during challenging periods make sense from a cost perspective. In other sensitivity cases we found that a higher gas price increases the integration costs, and vice versa for a lower gas price. We also found that if a perfect forecast for load and wind is assumed the total operating cost decreases slightly, but the estimated PV integration cost actually increases since the possibility of wind, load, and solar PV forecasts cancelling each other out is not considered. Across all the sensitivity cases the primary contributor to the integration cost is the increase in balancing reserves due to short-term variability and forecast uncertainty, whereas the cost from DA forecast errors plays a less significant role.

We also constructed a case with several severe constraints on system flexibility, including constant nuclear operation (without the ability to provide reserves), penalties for renewables curtailment, low ramp rates of non-nuclear thermal generation, along with the highest balancing reserve requirements. In this worst-case scenario we found that the integration cost did not exceed \$10/MWh-PV, although the case did highlight the severe challenges with absorbing all the PV generation with limited flexibility and without the ability to sell excess power to nearby utilities. 
From the dispatch results, we found that the most challenging conditions identified with high PV penetration occur during periods of low net load. Low net load occurs during winter and spring months in daytime hours with high PV penetration. Under the assumption that the utility is not able to sell surplus power to neighboring utilities during these periods, managing the low netload periods requires increased flexibility beyond what is available through current practices. We find that both economic curtailment of renewables and flexibility of nuclear plant operations are valuable.

Under the default assumption of fixed nuclear operation, all operating reserves are provided by the other thermal generators. The dispatch results shows that the gas $\mathrm{CC}$ plants are the largest contributor to spinning reserve up, whereas coal plants are the largest contributor to spinning reserves down. Under the relaxed case with flexible nuclear, the nuclear plants also make significant contributions to reserves, particularly in the down direction with $33 \%$ of the HA down reserves coming from nuclear plants with high-PV. Even with an increase in the balancing reserve requirement, the utility system is always found to have a capacity surplus (before accounting for outages of thermal plants). This ample supply of generation capacity is likely to explain in part the relatively low range of integration costs found in this study.

\subsection{Limitations and Future Work}

This case study does have a number of limitations that should be considered when these conclusions are examined. Simulations of future deployments of variable generation are always challenging because of the need to synthesize high-time resolution production and forecasts that reflect geographic diversity. The methods used in this study to synthesize 1-min PV production data are based on existing methods described elsewhere for wind, but not otherwise applied to PV. This dataset was not validated in the current project, though this is recommended for future work. Anomalies in the data that may overstate short-term PV variability are noted and described in Appendix A.

There are also limitations based on the simplifications used in this study to model actual strategies and procedures used by utilities. One such limitation is that unit commitment decisions are made only in the DA schedule based on DA forecasts and again in the HA schedule for peaking units based on HA forecasts. In reality utilities can commit or decommit units during the operating day in response to changing conditions and updated forecast information. Hence, the modeling approach in this study likely understates the intra-day flexibility available from the thermal generators. On the other hand, the revised dispatch and commitments in the HA schedule were made with a single run of the optimization model over a 24 -hr period. In reality, a utility does not know what will happen in hour 2 when making dispatch and quick-start commitment decisions for hour 1 . This modeling assumption may understate the costs of managing variability and uncertainty. Finally, the RT simulation only considered the available HA reserves without actually conducting a RT dispatch of the individual plants. Representation of intra-day commitment and more detailed HA and RT processes would all contribute to better reflect actual utility operations. 
Transmission constraints within the utility footprint also were not included in this analysis. This limitation may overstate the ability of resources within the APS system to provide the required energy and reserves to meet the load within the system. Another limitation is that the thermal plant characteristics were developed from publicly available datasets and likely differ from true plant performance. Moreover, we did not remove any thermal generation capacity from the lowPV portfolio when increasing the amount of PV in the high-PV scenario. If the utility assigns a non-zero capacity credit to the incremental PV additions, some of the thermal generation capacity may not be available. Moreover, the optimal mix of thermal technologies may also change as flexible resources become more desirable with higher renewable penetration levels. These limitations should be addressed when refining the estimates of the impact of PV on system operations, cost, and reliability.

Another large limitation of this case study is not modeling the potential for trading and exchange outside of the utility boundaries with other entities in WECC. The lack of a representing outside exchange may overstate the challenges with low net-load periods, particularly if neighboring utilities are adding less PV to their systems. In fact, since most curtailment of renewables happen during day-time and sunlight, it may be possible to sell surplus power to other utilities with higher net loads during those hours. This is in contrast to the situation with high wind penetration levels, since it is likely more challenging to sell excess nightly energy. Considering outside power exchange, ideally by modeling a wider geographic footprint or by introducing a representative market node in the UC/ED model, should lead to better estimates of operating and integration costs.

For APS, inclusion in any of the proposed Energy Imbalance Markets (EIM) currently being examined in the Western Interconnection could provide access to more outside flexibility that might prevent significant amounts of renewables curtailment, and also reduce the costs associated with sub-hourly solar variability. Another interesting industry development is that the NERC Board of Trustees recently approved a new balancing standard that would replace the CPS2 with an alternative reliability metric. This new balancing standard may also alter the balancing reserve requirements in scenarios with high PV.

Overall, we only investigated a small subset of the potential future sources of system flexibility in this study. Additional sources for flexibility include demand side programs that shift load into low net-load periods or energy storage. Denholm and Margolis (2007a,b) highlighted challenges of managing low net-load periods with increased PV penetration and the potential role for curtailment, load shifting, and storage. Botterud et al. (2013) showed that price responsive demand for energy could contribute to lower operating costs and less curtailment of renewable energy, as shown in Botterud et al. (2013). Demand resources can also contribute to provision of operating reserves, and this is already current practice for several system operators in the United States. Another important source of flexibility not considered in this study is the potential provision of reserves from wind and utility-scale solar resources. As long as the utility can control these resources they can provide operating reserves, particularly in the down direction. Contributions to system flexibility from demand resources and renewables may very well be easier to implement than flexible nuclear operations as investigated in this analysis. In future work, we therefore recommend exploring these additional sources of system flexibility. 
The balancing reserve rules for PV developed in this study did not account for forecasts of how clear it was expected to be. The reserves might be able to be lower during hours where it is expected that there will be little clouds. In particular, if probabilistic forecasts are available they could be used to ensure that there was low probability of clouds before reserves would be reduced. This would potentially decrease the balancing reserve requirements for PV and lower integration costs accordingly. Factoring weather forecasts into the dynamic estimation of balancing reserves represent an interesting direction for future work. Finally, the potential use of stochastic scheduling strategies that make direct use of probabilistic forecasts to commit and dispatch system resources is also an area of active research. In this case, the mathematical objective of the scheduling problem is to minimize operating cost over a range of forecast scenarios. Hence, balancing reserves are scheduled implicitly rather than imposed as explicit reserve requirements. Although several challenges, including a high computational burden, need to be addressed before stochastic methods can be used directly in utility operations, several studies show potential benefits in terms of reduced system cost and improved reliability (e.g., Wang et al. 2011; Zhou et al. 2013). However, most of the work on stochastic scheduling so far has been done in the context of wind power, and more work is needed to analyze the potential operational benefits for integration of solar power. 
This page intentionally left blank. 


\section{$8 \quad$ References}

APS (Arizona Public Service Company), 2012, 2012 Integrated Resource Plan, March.

Black \& Veatch, 2012a, Integrated Photovoltaic (PV) Integration Cost Study, prepared for Arizona Public Service Company, Nov.

Black \& Veatch, 2012b, Cost Report: Cost and Performance Data for Power Generation Technologies, prepared for the National Renewable Energy Laboratory, Feb.

Bird, R., and R. Hulstrom, 1981, Simplified Clear Sky Model for Direct and Diffuse Insolation on Horizontal Surface, Technical Report No. SERI/TR-642-761, Solar Energy Research Institute, Golden, Colo. [http://rredc.nrel.gov/solar/pubs/PDFs/TR-642-761.pdf].

Botterud, A., Z. Zhou, J. Wang, J. Sumaili, H. Keko, J. Mendes, R.J. Bessa, and V. Miranda, 2013, "Demand Dispatch and Probabilistic Wind Power Forecasting in Unit Commitment and Economic Dispatch: A Case Study of Illinois," IEEE Transactions on Sustainable Energy $4(1): 250-261$.

CAISO (California Independent System Operator). 2010. Integration of Renewable Resources at 20\% RPS. Folsom, CA: California Independent System Operator.

[http://www.caiso.com/2804/2804d036401f0.pdf]

Cirillo R.R., P. Thimmapuram, T. Veselka, V. Koritarov, G. Conzelmann, C. Macal, G. Boyd, M. North, T. Overbye, and X. Cheng, 2006, Evaluating the Potential Impact of Transmission Constraints on the Operation of a Competitive Electricity Market in Illinois, Report ANL-06/16, Argonne National Laboratory, April.

CRA (Charles River Associates), 2010, SPP WITF Wind Integration Study, prepared for Southwest Power Pool, Little Rock, Ark. [http://www.spp.org/publications/2010.zip].

Denholm, P., and R. M. Margolis, 2007a, "Evaluating the Limits of Solar Photovoltaics (PV) in Traditional Electric Power Systems,” Energy Policy 35(5):2852-2861.

doi:10.1016/j.enpol.2006.10.014.

Denholm, P., and R. M. Margolis, 2007b, "Evaluating the Limits of Solar Photovoltaics (PV) in Electric Power Systems Utilizing Energy Storage and Other Enabling Technologies." Energy Policy 35(9): 4424-4433. doi:10.1016/j.enpol.2007.03.004.

E3 (Energy and Environmental Economics, Inc.), 2013, PacifiCorp-ISO Energy Imbalance Market Benefits, San Francisco, Calif. [http://www.caiso.com/Documents/PacifiCorpISOEnergyImbalanceMarketBenefits.pdf].

EIA (U.S. Energy Information Administration), 2012, Annual Energy Outlook 2012 [http://www.eia.gov/]. 
EIA, 2013, Natural Gas Annual Respondent Query System (EIA-191 Data through 2012) [http://www.eia.gov/cfapps/ngqs/ngqs.cfm?f_report=RP7].

ERCOT (Electricity Reliability Council of Texas), 2011, 2011-2012 ERCOT Methodologies for Determining Ancillary Service Requirements, Austin, Tex.

EnerNex Corp., 2010, Eastern Wind Integration and Transmission Study, NREL/SR-550-47078, National Renewable Energy Laboratory, Golden, Colo.

[www.nrel.gov/wind/systemsintegration/pdfs/2010/ewits_final_report.pdf].

GE, 2010, Western Wind and Solar Integration Study.

IEA (International Energy Agency), 2013, PVPS Report A Shanpshot of Global PV 1992-2012, Report IEA-PVPS T1-22:2013.

Intertek Aptech, 2012, Power Plant Cycling Costs, Intertek Aptech report AES 12047831-2-1, April.

Hamill, T. M., and T. Nehrkorn, 1993, "A Short-Term Cloud Forecast Scheme Using Cross Correlations," Weather and Forecasting 8(4):401-411.

Hammer, A., D. Heinemann, E. Lorenz, and B. Lückehe, 1999, "Short-term forecasting of solar radiation: a statistical approach using satellite data," Solar Energy 67(1-3):139-150. doi:10.1016/S0038-092X(00)00038-4.

Ma, J., Y. Makarov, C. Loutan, and Z. Xie, 2011, "Impact of Wind and Solar Generation on the California ISO's Intra-hour Balancing Needs,"presented at the IEEE Power \& Energy Society General Meeting, Detroit, Mich.

Makarov, Y. V, C. Loutan, J. Ma, and P. de Mello, 2009, "Operational Impacts of Wind Generation on California Power Systems,” IEEE Transactions on Power Systems 24(2):10391050 .

Marcos, J., L. Marroyo, E. Lorenzo, D. Alvira, and E. Izco, 2011a, "Power Output Fluctuations in Large Scale PV Plants: One Year Observations with One Second Resolution and a Derived Analytic Model," Progress in Photovoltaics: Research and Applications 19:218- 227.

Marcos, J., L. Marroyo, E. Lorenzo, D. Alvira, and E. Izco, 2011b, "From Irradiance to Output Power Fluctuations: The PV Plant as a Low Pass Filter," Progress in Photovoltaics: Research and Applications: n/a-n/a. doi:10.1002/pip.1063.

Milligan, M., K. Clark, J. King, B. Kriby, T. Guo, and G. Liu, 2013, Examination of Potential Benefits of an Energy Imbalance Market in the Western Interconnection, NREL/TP-5500-57115, National Renewable Energy Laboratory, Golden, Colo. 
Milligan, M., E. Ela, B. Hodge, B. Kirby, D. Lew, C. Clark, J. DeCesaro, and K. Lynn, 2011, "Integration of Variable Generation, Cost-Causation, and Integration Costs," The Electricity Journal 24(9):51-63. doi:10.1016/j.tej.2011.10.011.

Mills, A., and R. Wiser, 2010, Implications of Wide-Area Geographic Diversity for Short-Term Variability of Solar Power. Lawrence Berkeley National Laboratory, Berkeley, Calif. [http://eetd.lbl.gov/ea/emp/reports/lbnl-3884e.pdf].

Mills, A., M. Ahlstrom, M. Brower, A. Ellis, R. George, T. Hoff, B. Kroposki, C. Lenox, N. Miller, M. Milligan, J. Stein, and Y.-H Wan, 2011, "Dark Shadows: Understanding Variability and Uncertainty of Photovoltaics for Integration with the Electric Power Systems," IEEE Power \& Energy Magazine. pp. 33-41.

Navigant Consulting, Sandia National Laboratories, Pacific Northwest National Laboratories, and NV Energy, 2011, Large-scale Solar Integration Study, NV Energy. Las Vegas, Nev. [http://www.navigant.com/insights/library/energy/large-scale_pv_integration_study/].

Neve, A., 2013, "Reliability-based Control Field Trial," presented at the Operating Committee Informational Webinar, Feb. 4, Western Electricity Coordinating Council [http://www.wecc.biz/OC\%20Informational\%20Webinar02042013/Lists/Presentations/1/RBC\% 20Field\%20Trial\%20Presentation\%20-\%20Anitha\%20Neve.pdf].

OECD/Nuclear Energy Agency. 2012. Nuclear Energy and Renewables: System Effects in Lowcarbon Electricity Systems. Paris: OECD Publishing [http://dx.doi.org/10.1787/9789264188617en].

Perez, R., S. Kivalov, J. Schlemmer, K. Hemker Jr., D. Renné, and T. E. Hoff. 2010. "Validation of Short and Medium Term Operational Solar Radiation Forecasts in the US." Solar Energy 84 (12): 2161-2172.

Potter, C., D. Lew, J. McCaa, S. Cheng, S. Eichelberger, and E. Grimit, 2008, "Creating the Dataset for the Western Wind and Solar Integration Study,". Wind Engineering 32:325-338.

Ventyx, 2012, Ventyx Electric Power Industry Database [https://velocitysuite.ventyx.com/].

Wang J., A. Botterud, R. Bessa, H. Keko, L. Carvalho, D. Issicaba, J. Sumaili, and V. Miranda, 2011, "Wind Power Forecasting Uncertainty and Unit Commitment," Applied Energy 88(11): 4014-4023.

Zhou Z., A. Botterud, J. Wang, R.J. Bessa, H. Keko, J. Sumaili, and V. Miranda, 2013, "Application of Probabilistic Wind Power Forecasting in Electricity Markets," Wind Energy 16(3):321-338. 
This page intentionally left blank. 


\section{Appendix A Approach for Simulation of 1-min PV Data}

\section{A.1 Need for Simulated PV Data}

A primary challenge in simulating the impact of $\mathrm{PV}$ on power system operations is generating high time-resolution PV production data that capture the geographic diversity of the expected deployment of solar PV. Hourly data with high geographic resolution is widely available from historical satellite images. Conversely, historical high time-resolution PV production data are available from individual existing PV sites. But neither of these datasets provide both a large geographic footprint and high time resolution. For this study, we use the historical hourly satellite-derived data for each PV site and then use simulation methods to generate realistic 1min data. In the future these methods for simulating 1-min PV data for planned PV plants may not be necessary if satellite data and ground measurements improve. Clean Power Research, for example, offers 1-km, 1-min resolution data through its SolarAnywhere High resolution product for California and Hawaii. Such a dataset may prove to be a preferred alternative to the methods outlined below if it were available where APS expects PV to be located.

\section{A.2 Objective}

The objective of the simulation approach is to generate 1-min PV production data with the following characteristics:

- Geographic locations are based on where APS expects PV to be installed in future portfolios.

- Data reflect historical hour-to-hour insolation patterns using satellite observations of clouds.

- Sub-hourly variability at a particular site represents the expected variability based on the hourly average level of cloudiness.

- Correlation of sub-hourly variability between sites is a function of the distance between individual sites.

\section{A.3 Data}

The data used to characterize sub-hourly solar insolation and the correlation of sub-hourly variability between sites were from the DOE ARM network in the Southern Great Plains region of the United States. This dataset was used in an earlier analysis of solar variability and is described in more detail in Mills and Wiser (2010). Hourly insolation from historical satellitederived data is from the National Solar Radiation Database (NSRDB). 


\section{A.4 Approach}

An approach to simulating high-resolution data for many sites that was developed and applied for wind energy (Veers 1988; Sørensen et al. 2007, 2008) is adapted in this study for PV simulation. In the case of wind, spectral analysis of wind speeds at an individual site was first used to characterize the magnitude of variability across different time scales. Coherence analysis between wind speeds at multiple sites was then used to characterize the degree to which variability is correlated between sites over each of those same time scales. Analysis of multiple sites at different distances was then used to characterize the relationship between coherence between sites and the distance between sites. This information and the geographic layout of individual sites that were simulated were then used with an advanced Monte Carlo approach to generate time series at each site whose frequency characteristics and coherence characteristics followed patterns similar to the original data. The simulation approach assumed variability within each frequency bin was normally distributed.

\section{Adaptations of the Approach for PV}

In order to adapt this approach for solar power, a few key characteristics of solar power must be taken into account:

- Unlike wind, solar variability can be separated into a deterministic component because of the change of the position of the sun and a stochastic component due to transient phenomena like clouds.

- The deterministic component of solar insolation is called the clear sky insolation and the ratio of the actual insolation to the clear sky insolation at any point of time is called the clear sky index. The clear sky index is equal to 1.0 when the actual insolation is equal to what it would be at that time on a clear day.

- The clear sky index within an hour is not normally distributed; both the magnitude and shape of the clear sky distribution within an hour depend on the hourly clear sky index (Skartveit and Olseth 1992).

The following simulation approach builds on the earlier work by Veers (1988) and Sørensen et al. $(2007,2008)$ by introducing intermediate steps that allow these unique characteristics of solar to be taken into account. The overall simulation approach is illustrated in Figure A-1. The method starts with hourly insolation for each site based on historical satellite data, determines how variable the insolation should be within that hour depending on the relative cloudiness, and then simulates a 1-min time series for each site while accounting for the correlation of fluctuations between sites. Further smoothing is applied to each site based on the size of the plant to account for any "within-plant" smoothing. 


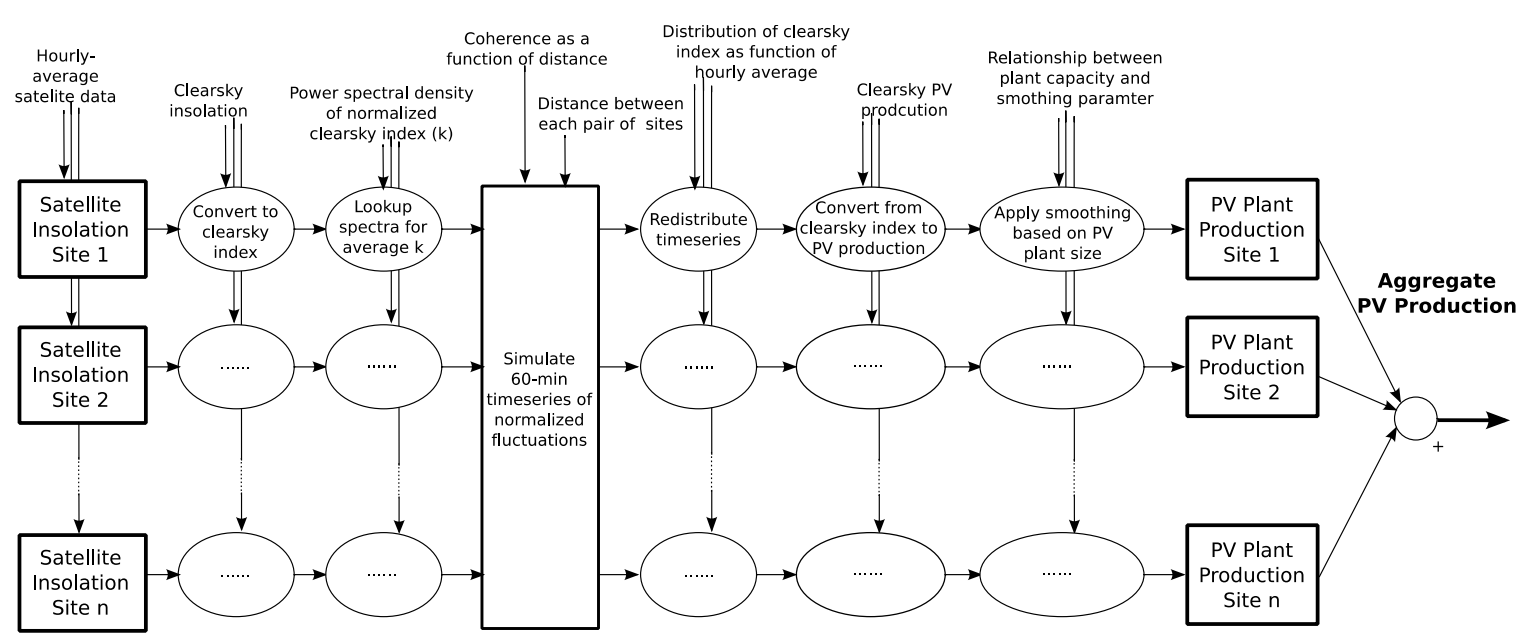

Figure A-1. Simulation Approach to Generate a Time Series of Aggregate PV Production with 1-min Resolution

A key step just prior to the time series simulator in Figure A-1 is using the hourly average clear sky index to look up the normalized power spectral density (PSD) as a function of the clear sky index. This PSD is based on analysis of 1-min solar insolation data from the DOE ARM Network. The PSD is used in the time series simulator to specify the relative magnitude of subhourly fluctuations as a function of the frequency or time scale of the fluctuations. In order to account for the non-normal distribution of the clear sky index within an hour, the PSD is estimated for a normalized time series, described next.

The normalization of the DOE ARM Network time series data can be best explained through a simple example. First, the probability that the 1-min clear sky index is less than a particular value is shown for different levels of the hourly average clear sky index $(\bar{k})$ in Figure A-2. Consider a site where the hourly clear sky index is 0.7 , representing an hour that is partly cloudy. Analysis of hours in which the average clear sky index was 0.7 shows that the probability that the 1-min clear sky index at any point is less than 1.0 is roughly about 0.95 ; in other words, $95 \%$ of the time the 1-min clear sky index is less than 1.0 when the hourly average clear sky index is 0.7 . The normalization of the 1-min clear sky time series is done by looking up the corresponding value in a standard normal distribution that would occur with that same probability. When the hourly average clear sky index is 0.7 and the 1-min clear sky index is 1.0 , then the normalized time series has a value of 1.645 because $95 \%$ of the time a random number pulled from a standard normal distribution is less than 1.644. This same procedure is used for each 1-min value of the clear sky index time series depending on the average clear sky index for that hour. 


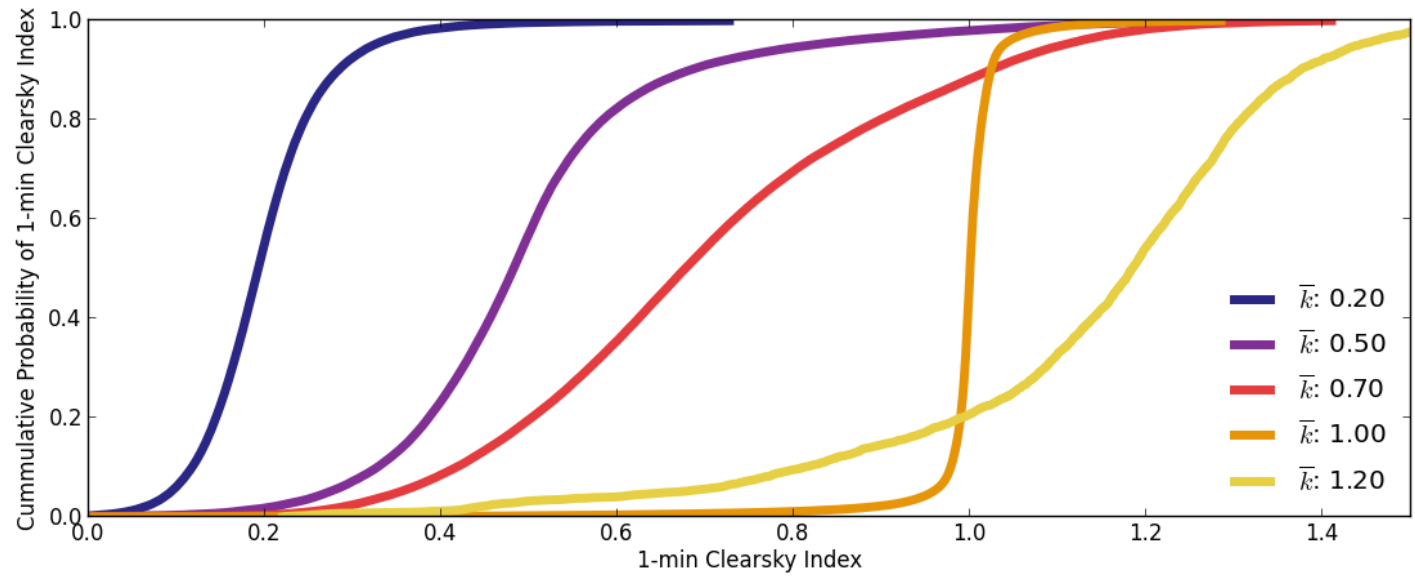

Figure A-2. Cumulative Probability Distribution Function of the 1-min Clear Sky Index for Different Hourly Average Clear Sky Index Values ( $\overline{\mathbf{k}})$ Derived from the DOE ARM Network

Once the 1-min clear sky index time series has been normalized, the PSD is found for the normalized clear sky index using the Fast-Fourier Transform (FFT). The average PSD of the normalized time series for each hourly average clear sky index value $(\bar{k})$ is shown in Figure A-3. Since the temporal resolution of the normalized time series is $1 \mathrm{~min}$, the shortest period fluctuations that can be resolved is $2 \mathrm{~min}$.

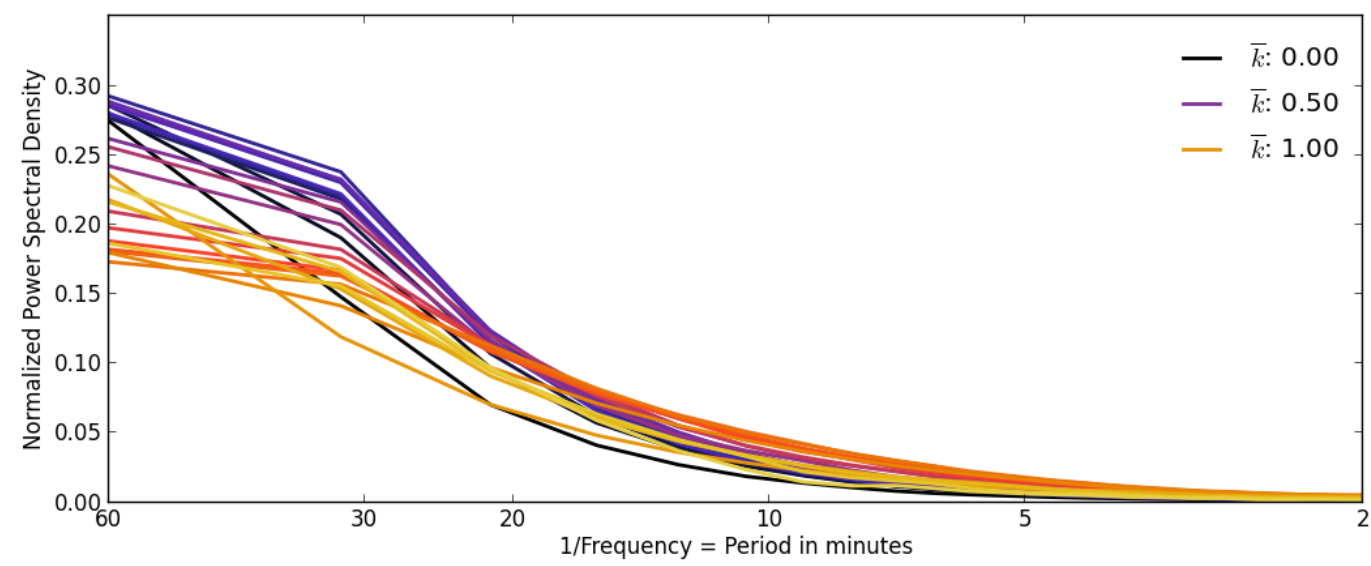

Figure A-3. Power Spectral Density of Normalized Sub-hourly Variability for Different Values of the Hourly Average Clear Sky Index ( $\overline{\mathbf{k}})$

The time series simulator uses the normalized PSD for each site depending on the hourly average clear sky index and information about the geographic distribution of the sites in the creation of the time series. Geographic distribution is accounted for through two parameters: the distance between any pair of sites and coherence of sub-hourly variability as a function of distance. Coherence is a frequency-domain analogue to correlation. Coherence includes information on the correlation of fluctuations for each frequency or time scale. For example, for two sites that are some distance apart, the correlation between longer fluctuations is expected to be greater than the 
correlation between shorter, transient fluctuations. The time series simulator converts information about the magnitude of fluctuations from the frequency domain to the time domain and uses the coherence information to choose the phase of those fluctuations.

To determine this relationship, the coherence of the normalized time series was found for each pair of sites in the DOE ARM Network dataset. The coherence as a function of distance was then fit to the function in Equation 1 to determine the parameters $b, a_{1}$, and $a_{2}$. This relationship was then used to define the coherence as a function of distance between pairs of sites in the timeseries simulator. For the best fit, the parameter $b=0.9011, a_{1}=84.64$, and $a_{2}=0.334$. The relationship using the best-fit parameters from the DOE ARM Network data is shown in

$$
\text { Coherence }=b \cdot e^{-\left(a_{1} \cdot \text { freq } \cdot \text { dist }\right)}+(1-b) \cdot e^{-\left(a_{2} \cdot \text { freq } \cdot \text { dist }\right)}
$$

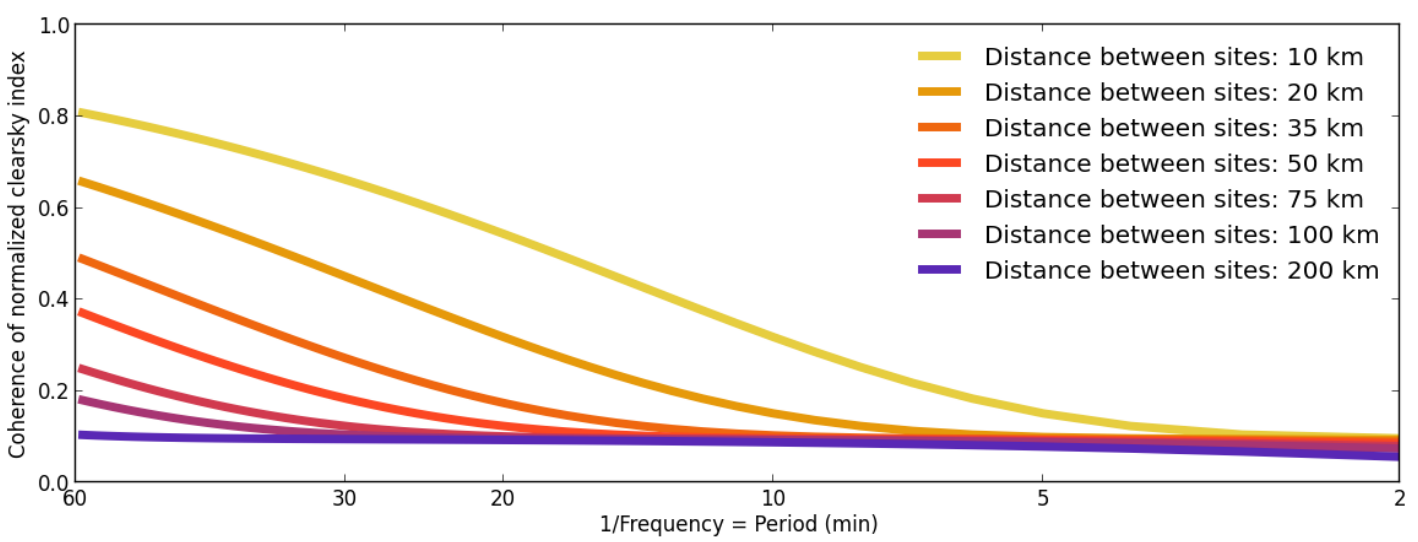

Figure A-4. Coherence of Normalized Clear sky Index as a Function of Distance between Sites Based on a Best Fit to Equation 1

The time series simulator uses the PSD at each site and the coherence between sites to create an hour-long time series of the normalized time series with a temporal resolution of $1 \mathrm{~min}$. Because the PSD and the coherence parameters have been normalized, the core time series simulator (the large rectangular box in Figure A-1) can now be largely based on the method used by Veers (1988) and Sørensen et al. (2007, 2008).

The hourly average clear sky index at each site is then used to redistribute the normalized time series to represent the 1-min clear sky index using the distributions in Figure A-2. Using the earlier example, if the normalized time series has a value of 1.645 for one particular minute when the hourly average clear sky index for the hour was 0.7 , then the 1-min clear sky index is 1.0 .

After the time-series simulator is run for $1 \mathrm{hr}$, new hourly clear sky index data for each site are entered to generate the next 60-min time series of the clear sky index for each site. This process is continued for an entire year with each hour of 1-min simulated data being joined to the previous hour of 1-min simulated data. The year of 1-min clear sky index data for each site is 
then multiplied by a year of 1-min clear sky PV production data to estimate the 1-min PV production data for a point at each site over 1 year.

The final adjustment that needs to be made before aggregating the PV production time series for each site is to account for any within PV plant smoothing. The fluctuations generated by the time-series simulator reflect changes in insolation that would occur at a point. A PV plant, even a small PV plant, generally leads to smoother production than would be expected by just looking at the insolation at a point. To account for this within-plant smoothing, a first-order linear filter is applied to the time series with the smoothing parameter based on the PV plant size. The relationship between plant smoothing and the smoothing filter is based on empirical analysis of within-plant smoothing for several different sized PV plants in Spain (Marcos et al. 2011b). ${ }^{23}$ In addition, it is assumed that distributed PV is spread out over a large area. In the case of distributed PV, it is assumed that the effective plant area is the size of the resolution of the historical satellite data, an area of about $11 \mathrm{~km}$ by $11 \mathrm{~km}$.

The correlated 1-min time series for each PV site is then aggregated to determine the total PV production. The 1-min PV production for each site modeled for this study and the resulting aggregate PV production are shown for two consecutive days in Figure A-5.

The first day is relatively clear, leading to only a few dips in PV production at sites within the day. The second day is partly cloudy at most of the sites, which leads to large changes in output at many of the individual sites. The aggregate PV production on the partly cloudy day is lower on average than on the clear day. The aggregation mitigates the variability, although the partly cloudy day is still more variable than the clear day.

23 An alternative method to a first-order linear filter approach for capturing the within-plant smoothing is a waveletbased variability model proposed by Lave et all (2013). We did not attempt to implement this alternative approach, but leave it as a suggestion for future research. 


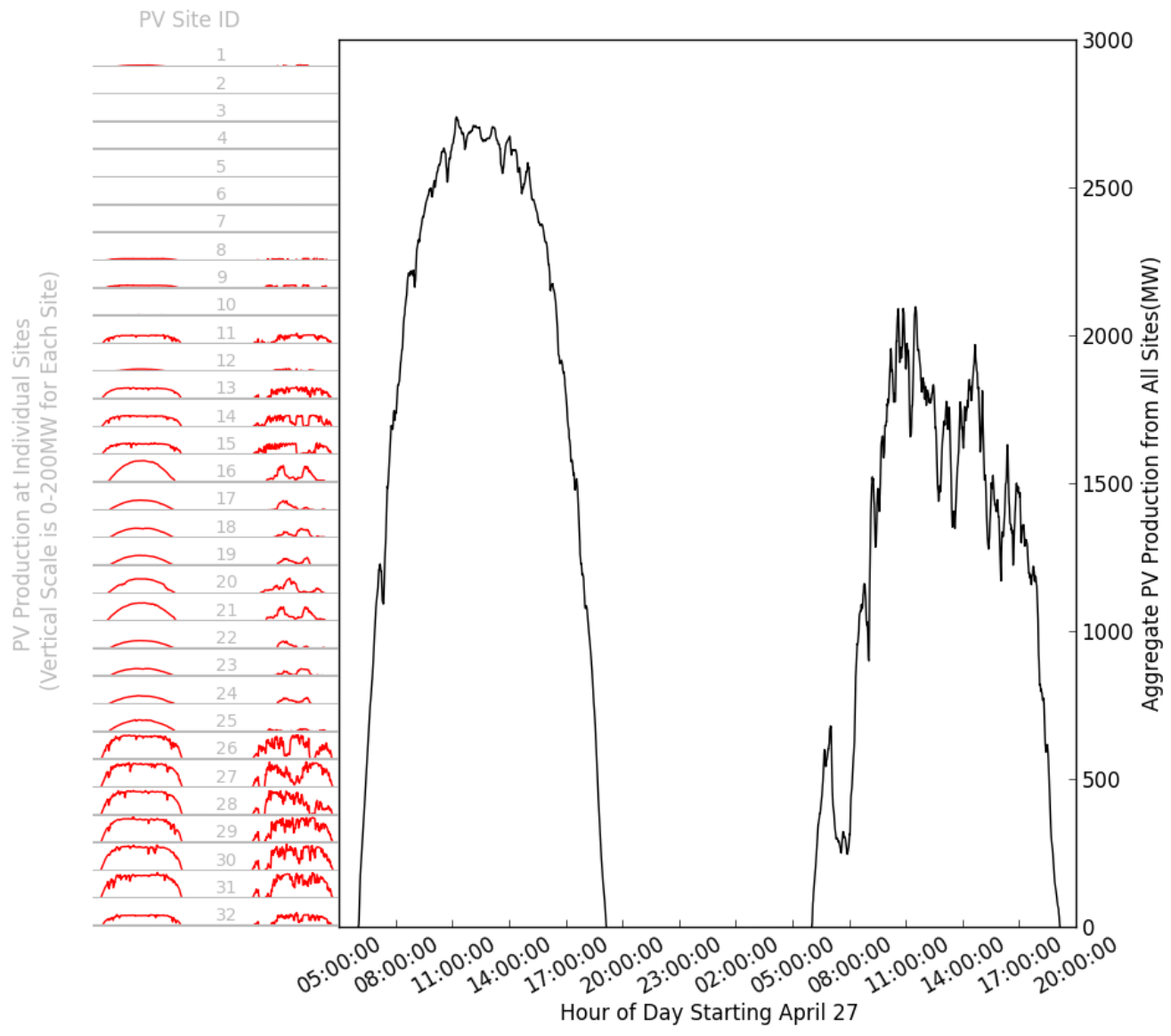

Figure A-5. Simulated PV Production Data at Each Individual Site and Aggregated for a Clear and Cloudy Day in April

\section{A.5 Future Improvements to Methodology}

Two issues deserve attention in future iterations of this time-series simulation tool: anomalies introduced by estimation of the hourly average clear sky index and hour-to-hour seams issues.

First, the data from the historical satellite images did not always line up well with the clear sky insolation data estimated with the Bird Clear Sky Model ${ }^{24}$ (Bird and Hulstrom 1981). In some hours near sunrise and sunset the estimated hourly average clear sky index was well outside of its normal expected range. In those cases the average hourly clear sky index for the anomalous hours was replaced with the daily average clear sky index. It appeared that this mismatch could occur at many of the sites simultaneously. As a result, examination of the simulated 1-min data showed that some days, particularly cloudy days, could show a rise in aggregate PV production with rising of the sun followed by a relatively strong decrease in the following hours. Such behavior is actually apparent in the cloudy day in Figure A-5. It is not always clear whether this behavior during sunset and sunrise hours is realistic or an artifact of the modeling approach.

${ }^{24}$ Available in Excel format at http://rredc.nrel.gov/solar/models/clearsky/. 
Second, the time series simulator generates 60 -min time series for each hour and then stitches these time series together. This approach appears reasonable when joining two hours with similar hourly average clear sky index values. In some cases, however, the hour-to-hour change in the hourly average clear sky index is large. The process of stitching together the two 60-min time series can therefore lead to a large change in PV production at the top of the hour (Figure A-6). This limitation of the simulation method tends to overstate the magnitude of ramps at the top of the hour. Overall, ramp rate validation of the simulated 1-min PV data compared to actual 1-min PV data is desirable and should be a priority for future work.

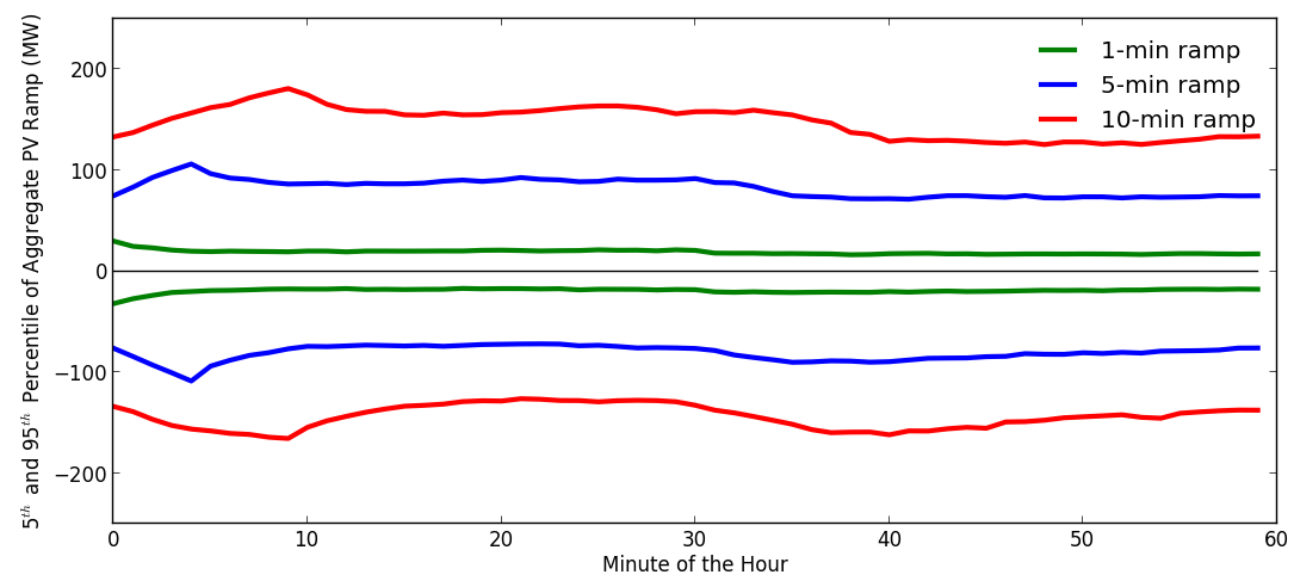

Figure A-6. Evaluation of Large Ramps in Aggregate PV Production Depending on the Clock Minute of the Hour

Finally, additional improvements to this approach could include accounting for wind speed at the cloud height to adjust the within-plant smoothing parameter (e.g., Lave and Kleissl 2013), determining if wind direction should be used to predict coherence between two PV sites (e.g., Hinkelman 2013), improving the variability characterization and coherence function to reflect cloud speeds in the Southwest, tuning the clear sky insolation model, and validation of synthesized data using actual correlated PV plant data at multiple sites.

\section{A.6 References}

Bird, R. E., and R. L. Hulstrom, 1981, Simplified Clear Sky Model for Direct and Diffuse Insolation on Horizontal Surfaces, Technical Report No. SERI/TR-642-761, Solar Energy Research Institute, Golden, Colo.

Hinkelman, L. M. 2013. "Differences Between Along-wind and Cross-wind Solar Irradiance Variability on Small Spatial Scales.” Solar Energy 88: 192-203.

Lave, M., and J. Kleissl. 2013. "Cloud Speed Impact on Solar Variability Scaling - Application to the Wavelet Variability Model." Solar Energy 91: 11-21. 
Lave, M., J. Kleissl, and J.S. Stein. 2013. "A Wavelet-Based Variability Model (WVM) for Solar PV Power Plants.” IEEE Transactions on Sustainable Energy 4 (2): 501-509.

Marcos, J., L. Marroyo, E. Lorenzo, D. Alvira, and E. Izco, 2011, "From Irradiance to Output Power Fluctuations: The PV Plant as a Low Pass Filter," Progress in Photovoltaics: Research and Applications 19(5):505-510. doi:10.1002/pip.1063.

Mills, A., and R. Wiser, 2010,. Implications of Wide-Area Geographic Diversity for Short-Term Variability of Solar Power, LBNL-3884E, Lawrence Berkeley National Laboratory, Berkeley, Calif. [http://eetd.lbl.gov/ea/emp/reports/lbnl-3884e.pdf].

Skartveit, A., and J.A. Olseth, 1992, "The Probability Density and Autocorrelation of Short-term Global and Beam Irradiance," Solar Energy 49(6):477-487. doi:10.1016/0038-092X(92)901554.

Sørensen, P., N. A. Cutululis, A. Vigueras-Rodríguez, H. Madsen, P. Pinson, L.E. Jensen, J. Hjerrild, and M. Donovan. 2008. "Modelling of Power Fluctuations from Large Offshore Wind Farms," Wind Energy 11(1):29-43. doi:10.1002/we.246.

Sørensen, P., N.A. Cutululis, A. Vigueras-Rodriguez, L.E. Jensen, J. Hjerrild, M.H. Donovan, and H. Madsen, 2007, "Power Fluctuations From Large Wind Farms," IEEE Transactions on Power Systems 22(3):958-965. doi:10.1109/TPWRS.2007.901615.

Veers, P.S., 1988, Three-Dimensional Wind Simulation, SAND88-0152, Sandia National Laboratories, Albuquerque, N.M. 
This page intentionally left blank. 


\section{Appendix B Balancing Reserve Calculations and Simulation of CPS2 Score}

\section{B.1 Overview}

We determine the amount of balancing reserves (BR) that need to be set aside during the HA scheduling process in each hour to ensure that the balancing authority (BA) can meet NERC reliability requirements. The particular standard we focus on in this analysis is the NERC balancing standard called Control Performance Standard 2 (CPS2). The BR rules are established based on observations of large minute-by-minute deviations from the HA schedule. We then verify that those rules are sufficient to meet a desired target CPS2 level. If the reserves are insufficient, the BR rules are revised to ensure compliance (Figure B-1).

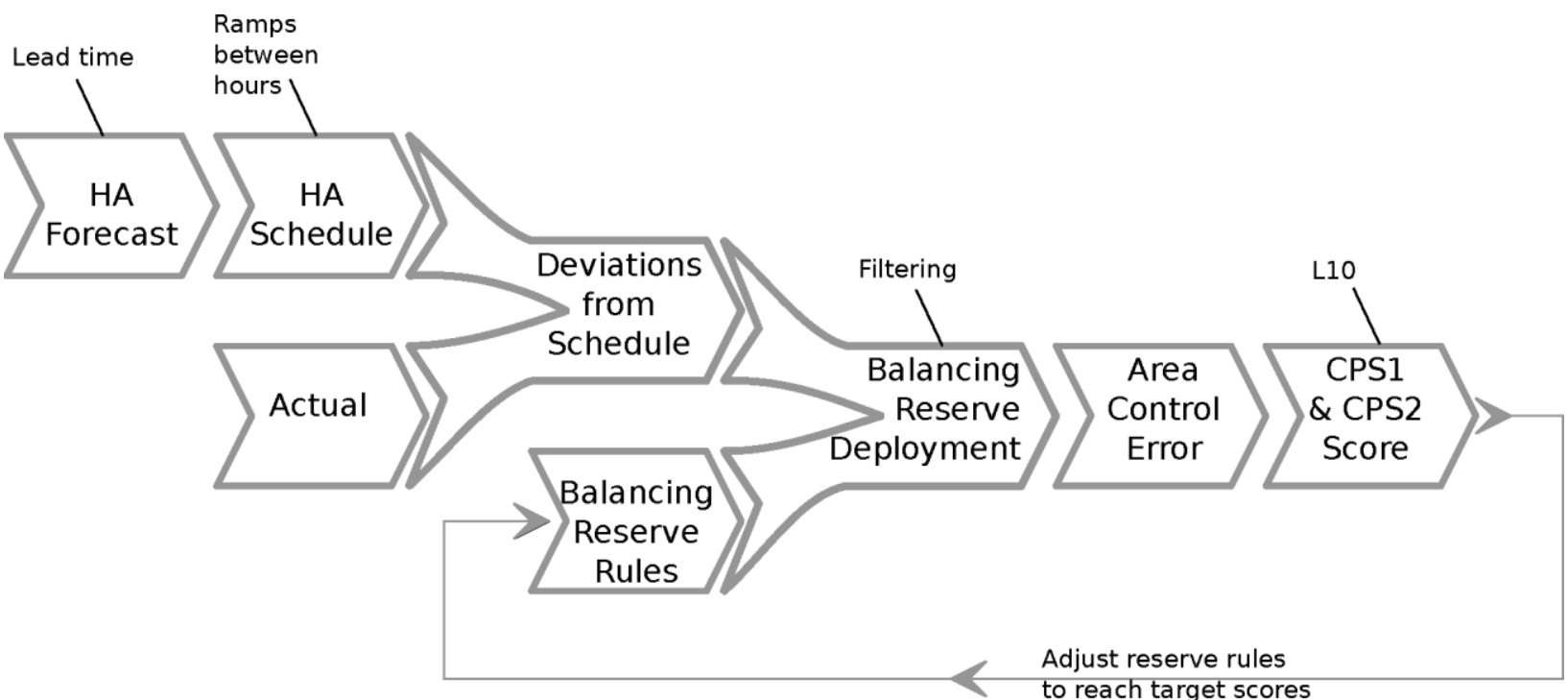

Figure B-1. Process Used to Establish and Validate Balancing Reserve Rules

The HA schedule is a flat hourly schedule with ramps between hours that is determined based on HA forecasts. Deviations from the HA schedule are based on the difference between the actual 1-min production and HA schedule in each minute. Within each operating hour, BR are deployed to meet deviations.

The area control error (ACE) is a measure of the degree to which deviations from the HA schedule are matched by deployment of BR within the operating hour. The ACE can be non-zero if deviations exceed the amount of BR available at that time or if the ramp rate of deviations exceeds the rate at which that the BR can be deployed. A small amount of ACE, within a utilityspecific parameter called $\mathrm{L}_{10}$, is allowable in the NERC CPS2 standard. The deployment of BR is therefore simulated to follow a filtered signal of the deviations from the HA schedule. Small, 
rapid deviations are allowed to pass through to the ACE without the operator having to respond with deployments of BR.

The CPS2 score is based on a comparison of the 10-min average ACE to the utility-specific $\mathrm{L}_{10}$ parameter. If the 10-min average of the ACE exceeds $\mathrm{L}_{10}$, then a violation occurs in that 10-min period. The CPS2 score is the number of periods without a violation as a percentage of the total number of potential periods. The minimum CSP2 score for compliance with NERC balancing standards requires that CSP2 be greater than $90 \%$. In other words, the average ACE must be less than $\mathrm{L}_{10}$ in more than $90 \%$ of the 10 -min periods.

Because holding resources in reserve during the HA scheduling imposes a cost, the BR rules should be kept to the minimum needed to maintain a reasonable CPS2 score. In the extreme, a BA can always maintain an ACE of zero by keeping a very large amount of large BR that could ramp extremely quickly and then deploying those BR to manage every deviation from the HA schedule. The BA would then achieve the highest possible CPS2 score of $100 \%$. In the other extreme, if the BR were to be zero, then every deviation from the HA schedule would result in an ACE. In periods in which the 10-min average ACE was large enough to exceed $\mathrm{L}_{10}$, the $\mathrm{BA}$ would have violations. Because some periods would likely have a small ACE but many more would have an ACE exceeding $\mathrm{L}_{10}$, the CPS2 score would likely be greater than $0 \%$, but far lower than the minimum $90 \%$.

This analysis is used to identify reasonable BR rules that maintain a CPS2 score above the minimum of $90 \%$, without trying to always achieve a perfect $100 \%$ CPS2 score. We examine how the BR rules need to change with the addition of variability and uncertainty from PV, in addition to the variability and uncertainty of the load and wind.

The remainder of this appendix outlines the assumptions and methods used to estimate these BR rules and the resulting CSP2 score. At the end we briefly consider the implications of imbalances on the NERC CPS1 score and compare the analysis method used here to other previous work on balancing reserves for variable generation.

\section{B.2 HA Forecasts}

HA forecasts are used to set the level of the HA schedule. The method used to generate HA forecasts differs by technology (Table B-1). 
Table B-1. HA Forecast Methods for Different Resources

\begin{tabular}{ll}
\hline Resource & \multicolumn{1}{c}{ HA Forecast Method } \\
\hline Wind & The 1-min wind production value 30 min prior to the start of the operating hour (Figure B-2). \\
\hline PV & $\begin{array}{l}\text { The 1-min clear sky index } 30 \text { min prior to the start of the operating hour times the average clear } \\
\text { sky production during the operating hour }\end{array}$ \\
\hline Load & $\begin{array}{l}\text { Historical HA load forecast errors at APS observed in 2010 are assumed to occur for the same day } \\
\text { and hour of the modeled year. }\end{array}$ \\
\hline Net load & The net-load forecast in each hour is the load forecast minus the wind and PV forecasts. \\
\hline
\end{tabular}

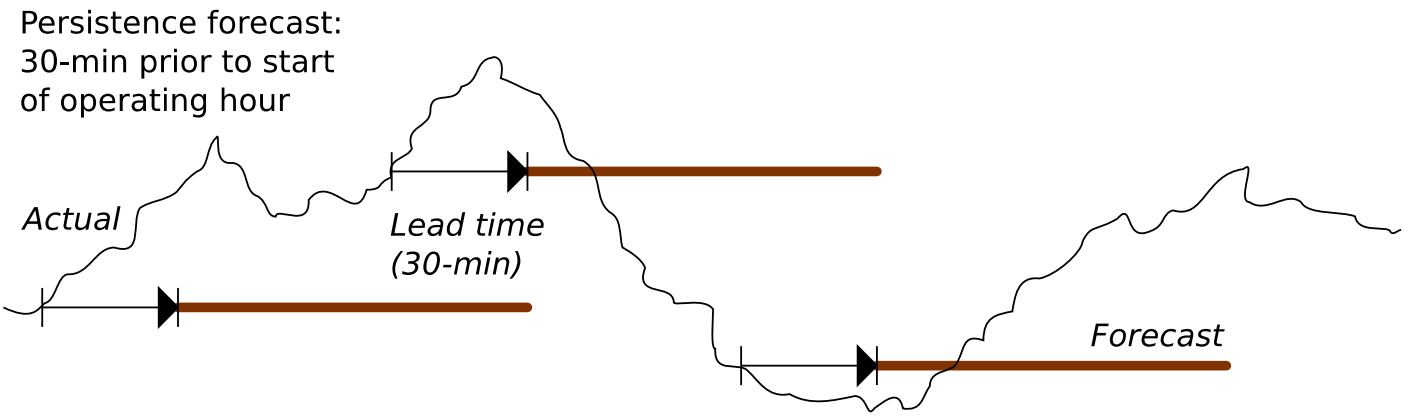

Figure B-2. Illustration of Method Used to Create Wind Power Forecasts

\section{B.3 HA Schedule}

The flat hourly forecast is converted into a minute-by-minute HA schedule by adding ramps at the start (ramping from the previous HA schedule) and end (ramping to the next HA schedule) of the hour (Figure B-3). The ramps start at 10-min prior to the operating hour and end 10-min after the start of the operating hour.

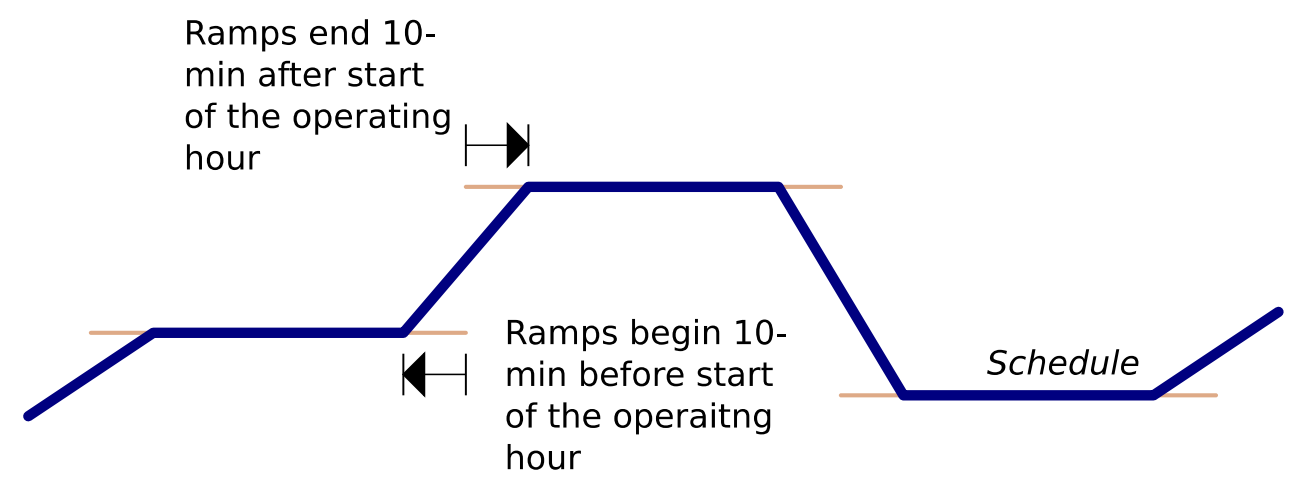

Figure B-3. Illustration of Conversion of Flat Hourly Forecast into HA Schedule with Ramps 


\section{B.4 Deviations}

The 1-min deviations from the HA schedule are calculated by subtracting the actual 1-min output from the minute-by-minute HA schedule (Figure B-4). These deviations are the primary driver for the deployment of BR.

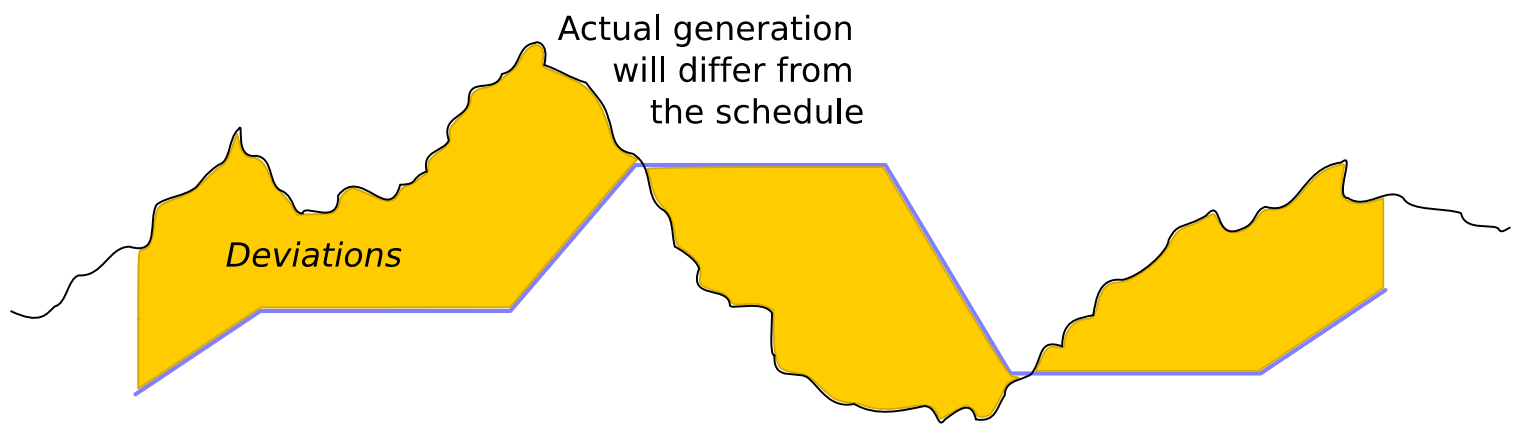

Figure B-4. Illustration of 1-min Deviations from the HA Schedule

\section{B.5 Balancing Reserves Rules}

The amount of BR available in each hour is based on empirical analysis of the 1-min deviations from the HA schedule, contingent on various factors (described for each load, wind, and PV in the following sections). BR levels are set independently for balancing up and balancing down (Figure B-5). The BR rules are set for wind, PV, and load and then combined, as described below, to create the BR rule for the net load.

Going into the operating hour, a certaint amount of operating reserves (BR) are set aside

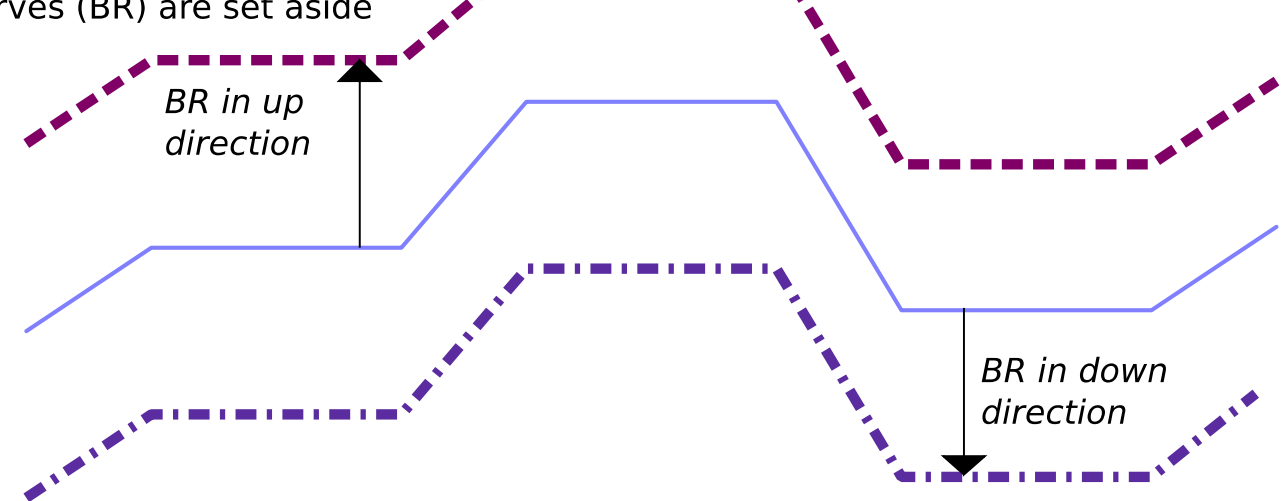

Figure B-5. Illustration of Balancing Reserves Rules Derived from Analysis of 1-min Deviations 


\section{B.5.1 BR Rules for Wind}

The 1-min deviations of the aggregate wind from the HA wind schedule are separated into 20 equal-sized bins depending on the scheduled wind between $0 \mathrm{MW}$ and the maximum wind output. The 2.5th percentile deviation is then used to set the balancing-down reserve rule for that bucket of HA wind forecast. The 97.5th percentile deviation is used to set the balancing-up reserve rule for that bucket of HA forecast wind. The BR rules are then applied to wind based on the HA wind schedule for a particular hour.

The BR rules for wind in the low-PV case using this approach are shown in Figure B-6. The BR rule is conditioned on the HA wind schedule as a fraction of the maximum observed wind output $(627 \mathrm{MW})$. The BR rule in the up direction is greatest when the HA wind schedule is about $40 \%$ of its peak wind output. The BR rule in the down direction is greatest when the HA schedule for wind is about $70 \%$ of its peak output. The BR rule is low both when the HA schedule for wind is close to zero and close to the peak wind production.

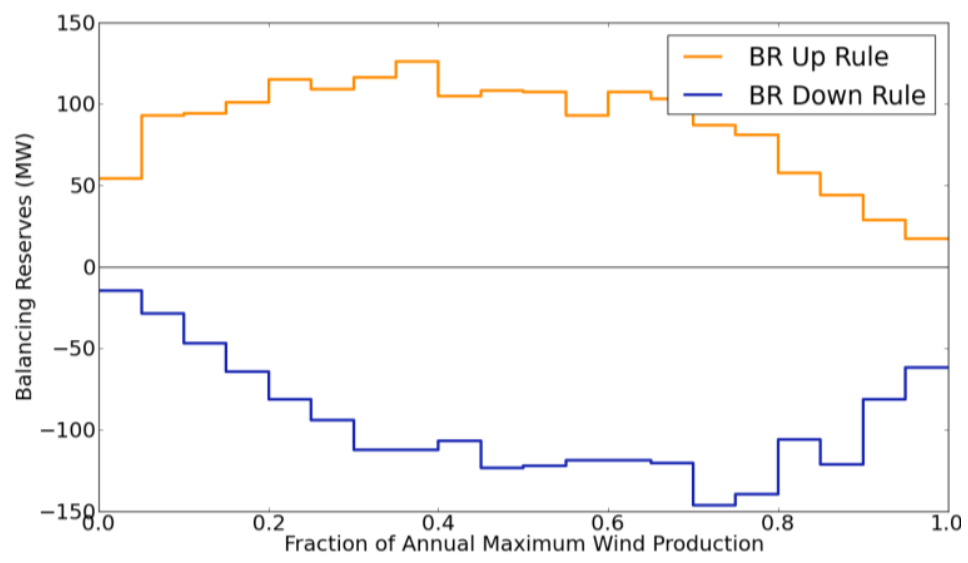

Figure B-6. BR Rules for Wind Conditioned on HA Wind Schedule

A validation pass is used to ensure that the hourly BR rule for wind always represents feasible actual wind output levels. Therefore, the BR requirements are further revised to meet the following criteria:

- $\mathrm{BR}^{+}+\mathrm{HA}$ wind schedule $\leq$ maximum observed 1-min wind over the year

- $\mathrm{BR}^{-}+\mathrm{HA}$ schedule $\geq 0 \mathrm{MW}$

\section{B.5.2 BR Rules for PV}

Similar to the case for wind, the 1-min deviations of aggregate PV from the HA schedule are separated into 20 equal-sized bins. The different bins for PV, however, depend on the hourly clear sky production level, and the bins start at $0 \mathrm{MW}$ and increase to the highest clear sky production level. The 2.5 th percentile deviation is then used to set the BR down for that bucket 
of clear sky production. The 97.5th percentile is used to set the BR up requirement for that bucket of clear sky production. The BR rules are then applied to PV in each hour based on that hour's average clear sky production.

The BR rule for PV based on the low-PV case is shown in Figure B-7. The amount of BR in the up direction is greatest when the clear sky production is near the annual maximum clear sky production $(1,600 \mathrm{MW})$. The requirement is lower when the clear sky production is near zero.

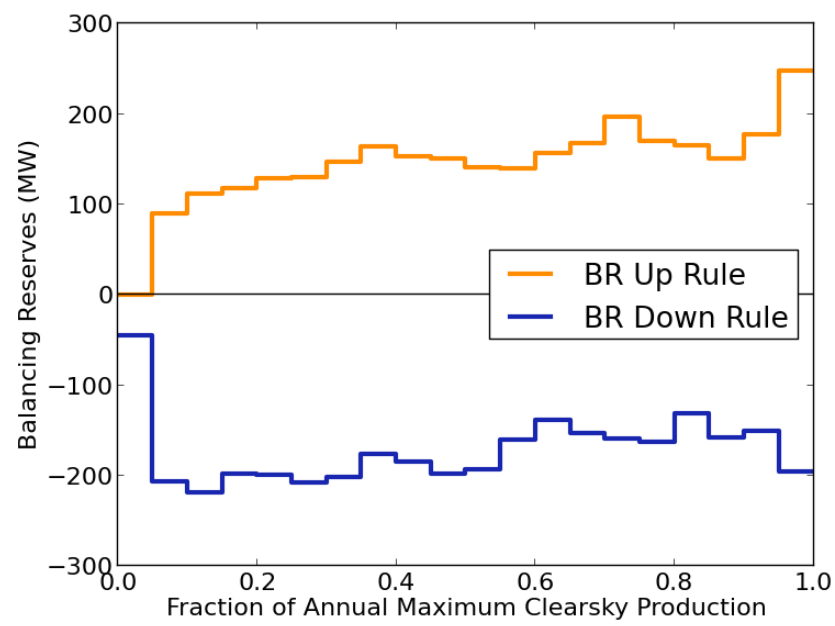

Figure B-7. BR rule for PV Conditioned on the Clear Sky Production

To ensure feasibility, the following adjustments to the BR rules are made for PV in a validation pass:

- $\mathrm{BR}^{+}+\mathrm{HA}$ schedule $\leq$ maximum hourly clear sky index $\times$ hourly clear sky level

- $\mathrm{BR}^{-}+\mathrm{HA}$ schedule $\geq 0 \mathrm{MW}$

\section{B.5.3 BR Rules for Load}

The BR rule is based on the 1-min deviations that occur in each hour of the day (e.g., the deviations that occur between 4:00 a.m. and 4:59 a.m. over the entire year). The 2.5th percentile deviation is then used to set the BR down for that hour of the day. The 97.5th percentile deviation is used to set the BR up requirement for that hour of the day.

The resulting BR rules for the load are shown for each hour of the day in Figure B-8. The BR rule for the load is at most about $115 \mathrm{MW}$ up and $95 \mathrm{MW}$ down and does not vary significantly depending on the hour of the day. 


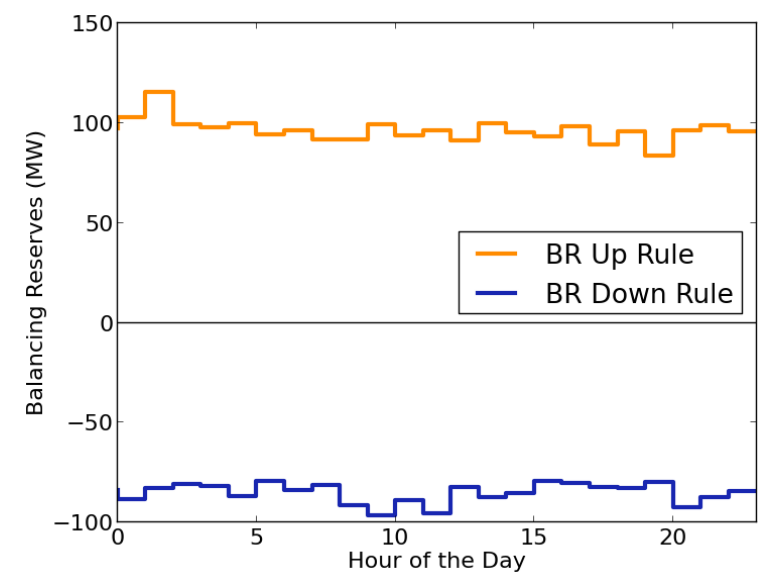

Figure B-8. BR rules for the Load Conditioned on the Hour of the Day

\section{B.5.4 BR Rules for Net Load}

The BR rule for each hour for the net load is simply calculated as the root mean square of the BR rule for the load, PV, and wind in that hour. Because of sign differences, the balancing reserve up for load is combined with the balancing reserve down for PV and wind. The rationale behind this approach is the assumption of uncorrelated deviations in the load, wind, and PV. This assumption is shown to be valid based on the CPS2 score being about the same for the load, wind, PV, and net load when the BR rules for the net load are calculated using this approach.

The BR rules for each hour of the year are shown for the load, wind, PV, and net load based on the 2005 weather year in Figure B-9. The values are shown as a reserve level duration curve and are not chronological (i.e., they are sorted from highest to lowest values). A few points are apparent from this figure:

- The BR rule changes little throughout the year for the load.

- The BR rule for wind is less stable than load and can be larger in magnitude than the reserves for load.

- The BR rule for PV is near zero for half the year, but it then changes dramatically depending on conditions for the other half of the year.

- The net load BR rule also changes significantly throughout the year. Net load BR in the down direction (negative values below) are similar in magnitude to the net load BR in the up direction (positive values). 


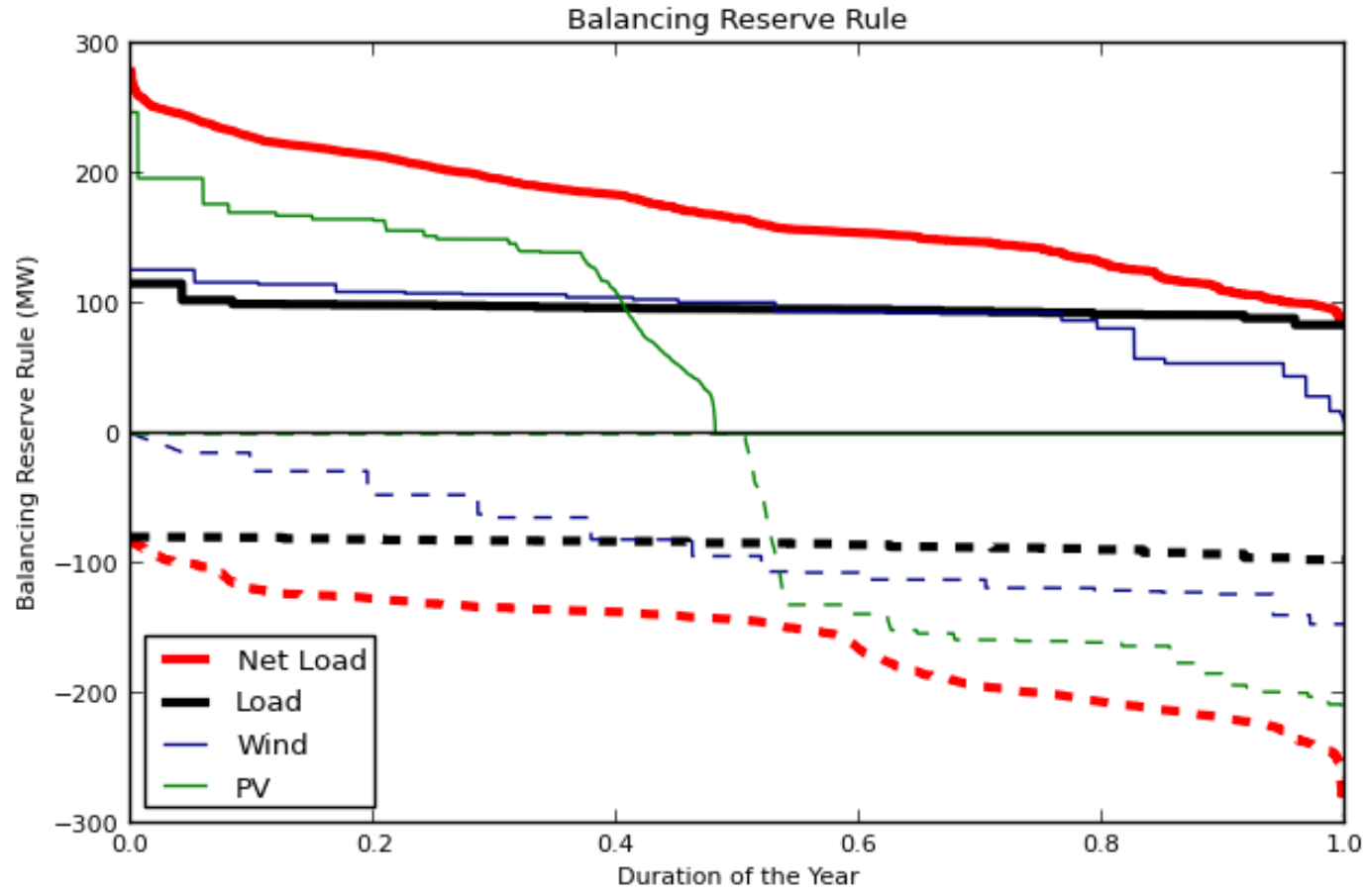

Figure B-9. Balancing Reserves Rules over the Full Year for 2005 for the Load, Wind, PV, and Net Load

\section{B.6 Balancing Reserve Deployment}

The 1-min deviations between the HA schedule and the actual production are used to simulate the deployment of balancing reserves. The BR can be deployed up to the limits imposed by each hour's BR rule. In addition, balancing reserves are assumed to be able to be fully deployed within $10 \mathrm{~min}$, and this sets a maximum ramp rate for the deployment of the balancing reserves. For example, if the BR rule for a particular hour results in $100 \mathrm{MW}$ of balancing reserves being available, then the maximum deployment rate is assumed to be $10 \mathrm{MW} / \mathrm{min}$ (or $100 \mathrm{MW}$ in 10 min assuming the BR can be fully deployed in $10 \mathrm{~min}$ ). Further, if the hourly BR rule were to be increased to $150 \mathrm{MW}$, then the maximum deployment rate would increase to $15 \mathrm{MW} / \mathrm{min}$. This establishes a relationship between the capacity of BR and the maximum ramp rate for deployment of BR. No additional reserves are deployed once the deviations exceed the limit of the BR rule or the maximum ramp rate (Figure B-10). Any excess deviation results in ACE. This simulation is somewhat conservative because some resources used for BR may actually be able to be deployed faster than $10 \mathrm{~min}$. This simulation does not capture these faster resources because it assumes a single ramp rate for all generation used to provide balancing reserves. A simulation that captures unit-by-unit contributions to deployment of balancing reserves would better reflect the capabilities of faster units.

During the initial testing, we found that the BR deployments were often "chasing" small 1-min deviations that if ignored would lead to only small ACEs, often less than the $\mathrm{L}_{10}$ limit for the utility. The deviations were therefore filtered by using an exponentially weighted moving average filter (using only past deviations in each time step). The time constant was set to 5 min 
for the filter. Deviations that are filtered out are not met with BR deployment and therefore also contribute to the ACE. Because these deviations are often very small, this filtering has a minimal impact on the CPS2 score.

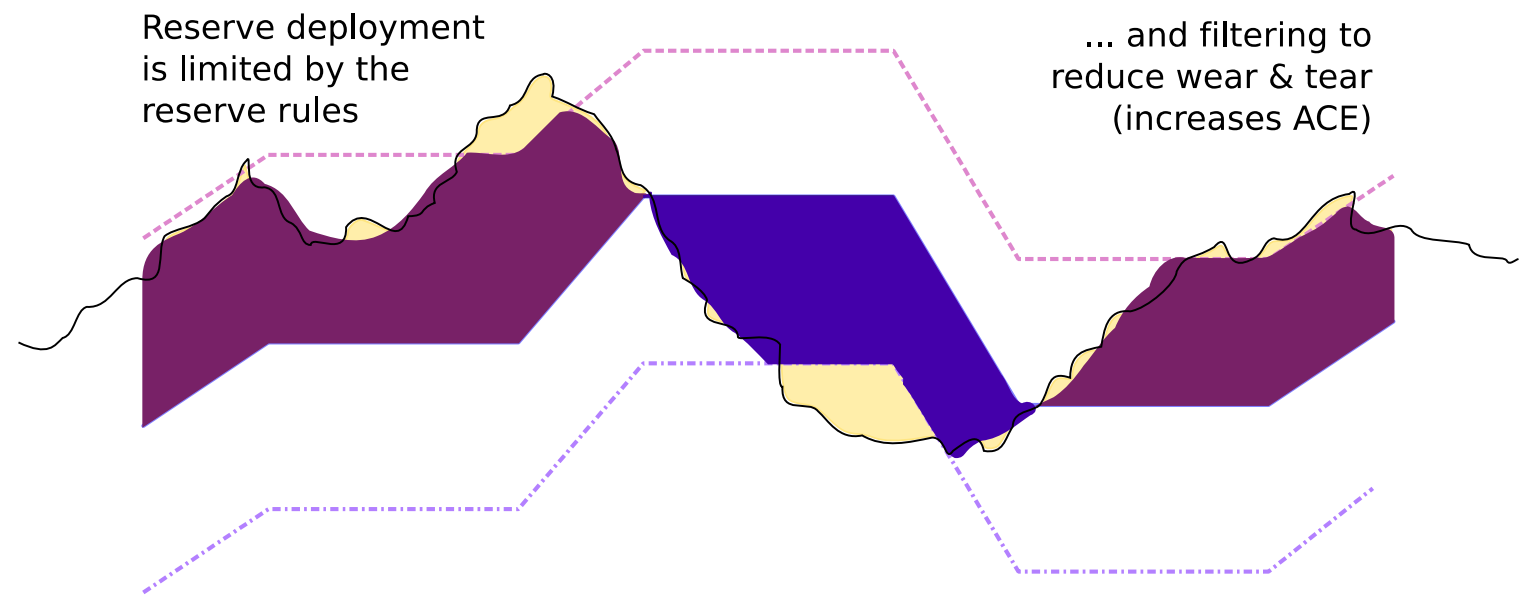

Figure B-10. Illustration of Reserves Deployment Based on Deviations and Limited by BR Rules

\section{B.7 Area Control Error (ACE)}

For each minute, the ACE is calculated as the difference between the 1-min deviation from the HA schedule and the minute-to-minute BR deployment (Figure B-11). ${ }^{25}$

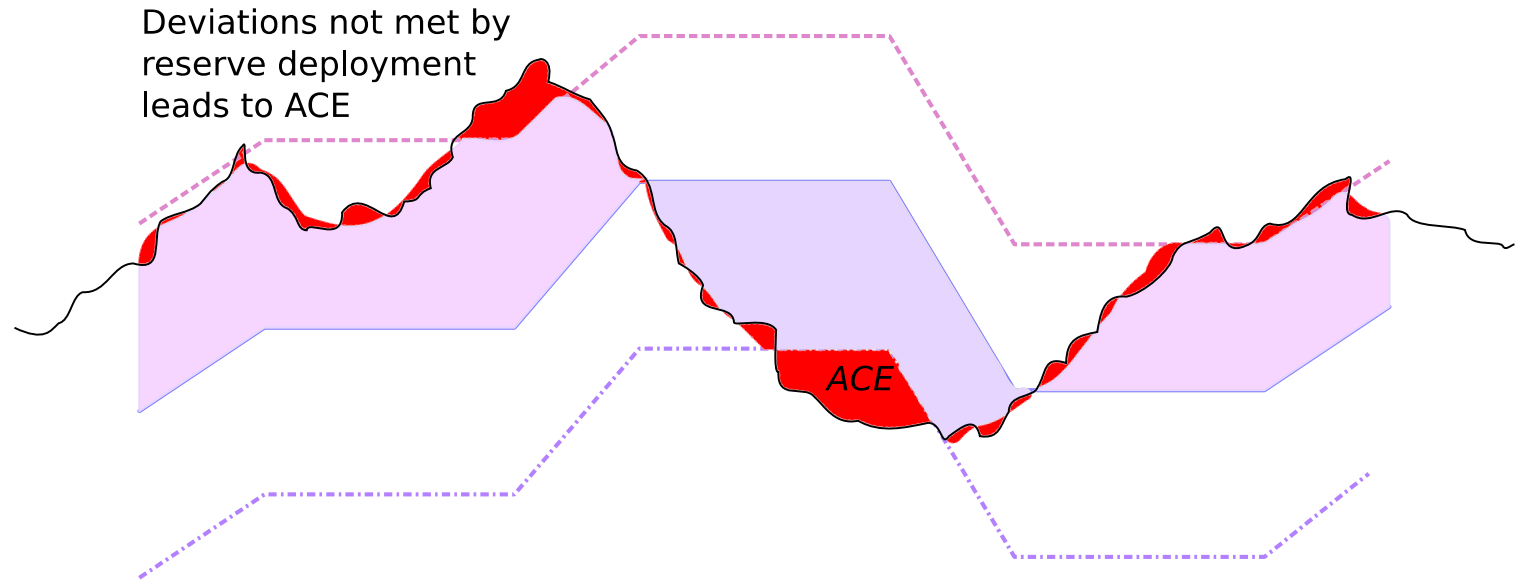

Figure B-11. Illustration of ACE Based on Deviations Not Met by Deployment of BR

${ }^{25}$ The ACE can be calculated by assuming deviations and balancing reserve deployment are based only on a single resource (e.g., wind alone or load alone). Or it can be calculated based on all resources combined (i.e., the net load). 


\section{B.8 CPS2 Score}

The CPS 2 score is calculated based on the utility-specific $\mathrm{L}_{10}$ value provided by NERC and the 10 -min average of the ACE. The CPS2 score is the percentage of 10-min periods in which the 10 -min average ACE does not exceed $\mathrm{L}_{10}$ (Figure B-12). This score must be greater than $90 \%$ for NERC compliance. ${ }^{26}$

Good performance of the BR rules is such that the CPS2 score for the load is greater than $90 \%$ and the CPS2 score for the load and net load are about equal. Typical CPS2 scores for a number of BAs in WECC averaged between $96 \%$ and $98 \%$ between 2002 and $2009 .^{27}$

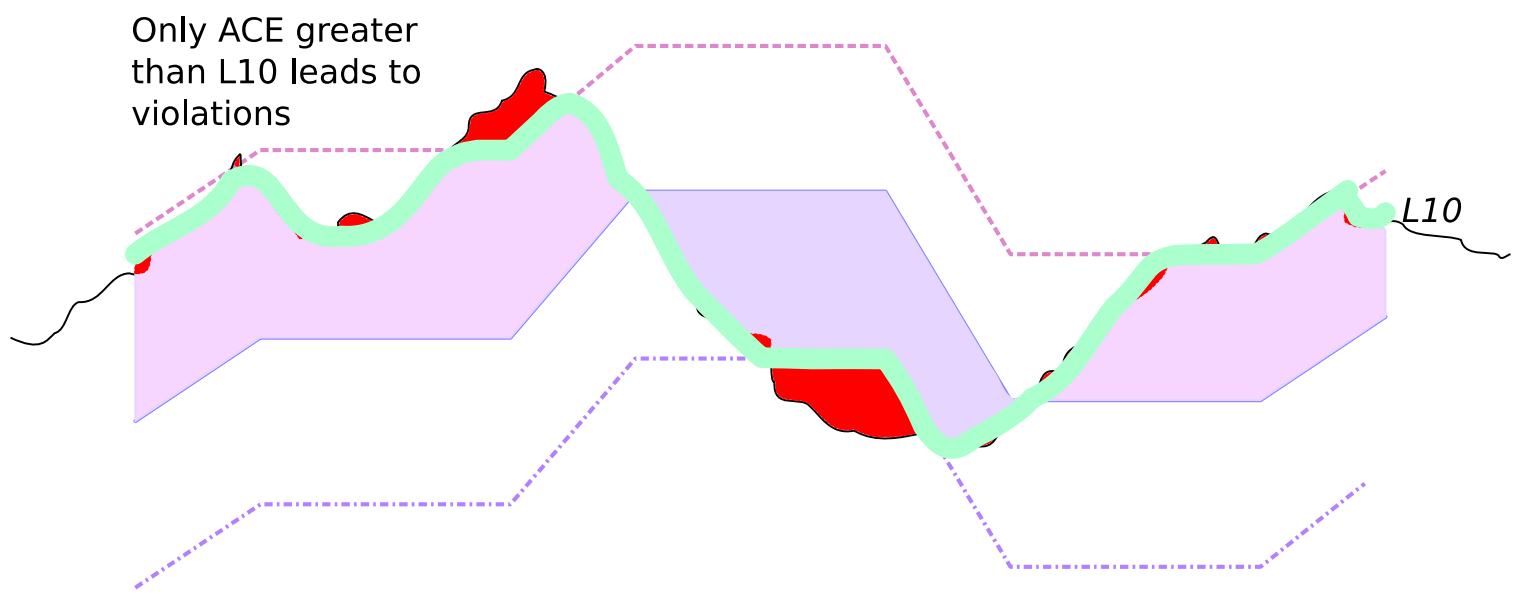

Figure B-12. CPS2 Violations Occur Only When 10-min Average of ACE Exceeds L10 (shown by width of green line)

\section{B.9 Revision of BR Rules}

If it appears that the initial BR rules do not lead to an adequate CPS2 score, then the percentiles of deviations used to set the BR rules can be increased and tested again (Figure B-13). Alternatively, if the CPS2 score is very close to $100 \%$, then the percentiles can be decreased. This process can be repeated until the desired CPS2 score is met.

${ }^{26}$ Because the ACE can be calculated for load, wind, and PV alone or for the net load, the CPS2 score can be found for each of these resources too.

${ }^{27}$ http://www.wecc.biz/OC\%20Informational\%20Webinar02042013/Lists/Presentations/ 1/RBC\%20Field\%20Trial\%20Presentation\%20-\%20Anitha\%20Neve.pdf. 


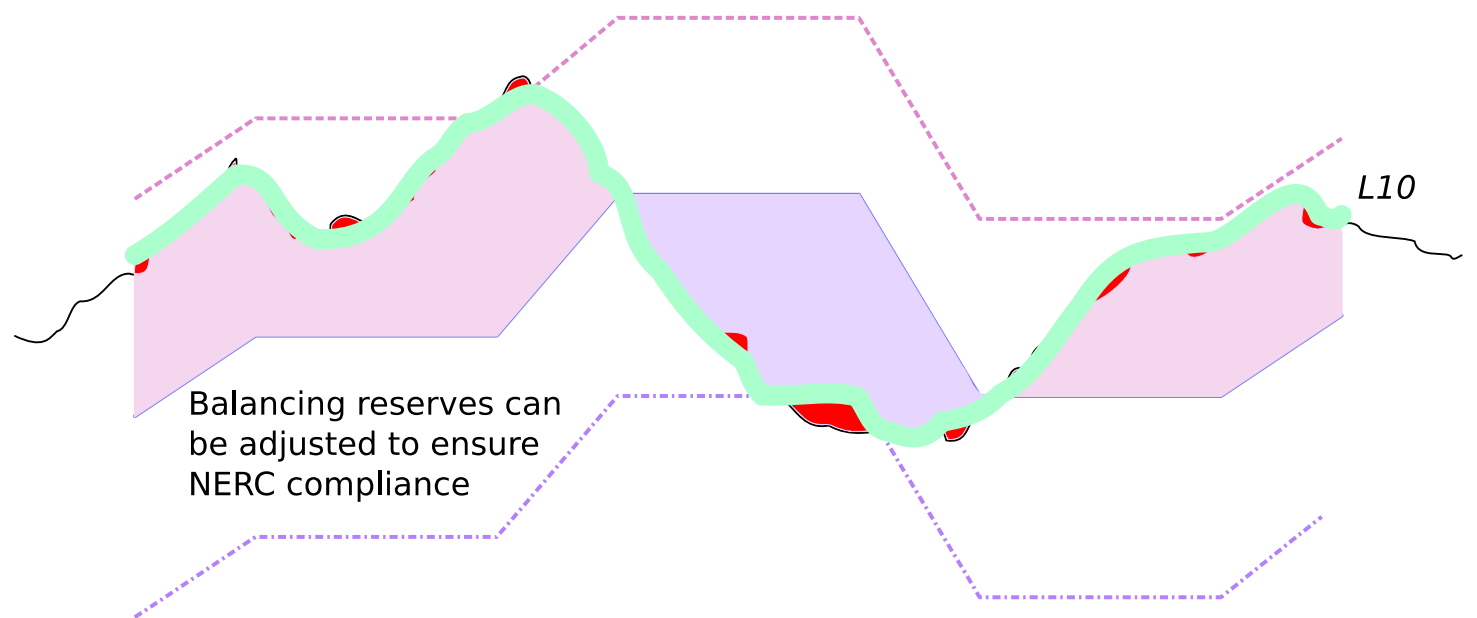

Figure B-13. BR Rules can be Revised to Reduce ACE, Reduce Violations, and Ensure Compliance with NERC Balancing Standards

\section{B.10 Intermediate Results}

Several assumptions were used to estimate the BR rules and CPS2 performance using the load, wind, and PV data for the low-PV case (Table B-2).

Table B-2. Assumptions Used to Estimate BR Rules in the Low-PV Case and Evaluate Their Performance

\begin{tabular}{ll}
\hline \multicolumn{1}{c}{ Assumptions } & \multicolumn{1}{c}{ Value } \\
\hline \hline BR amp rate & Fully deployable in 10 min \\
\hline Percentile of 1-min deviations used for BR & $\begin{array}{l}\text { 2.5th percentile for downward rule; 97.5th percentile for upward } \\
\text { rule }\end{array}$ \\
\hline Schedule ramps & $\begin{array}{l}10 \text { min prior to operating hour and } 10 \text { min before the end of the } \\
\text { operating hour }\end{array}$ \\
\hline Schedule lead time for persistence forecast & 30 min prior to the start of the operating hour \\
\hline APS L 10 value & $\begin{array}{l}\text { 48 MW } \\
\text { Data year }\end{array}$ \\
\hline
\end{tabular}




\section{B.10.1 Load}

By using the assumptions in Table B-2, the HA schedule (black line), the rules for upward balancing (green line) and downward balancing (grey line) in each hour, and the 1-min actual load data (red line) are shown over a full day starting at midnight on April 28, 2005 in the top left of Figure B-14. The deviations from the HA schedule, the deployment of the BR and the resulting ACE for the same time period are all shown in the bottom left of Figure B-14. The deviations from the HA schedule that are met with deployment of BR are shown as the tan area, while deviations that are not met from deployment of BR (and therefore result in ACE) are shown as the red area. The ACE (red line) and $\mathrm{L}_{10}$ for APS (blue area) are shown in the top left. Finally, a cumulative distribution function of the ACE over the entire year is shown in the bottom right. The resulting CPS2 score for the load only is $93.8 \%$, somewhat lower than the historical CPS2 score of $97.3 \%$ reported by APS for the month of March 2007.

Schedules

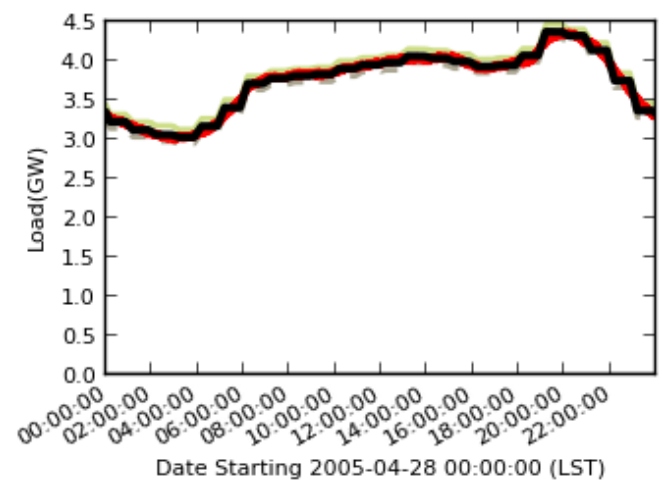

Deviations from the Schedule

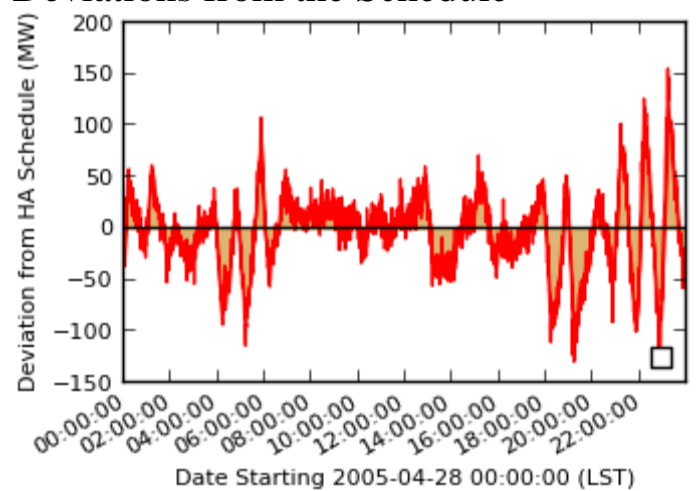

Resulting $\mathrm{ACE}\left(\mathrm{L}_{10}\right.$ in blue)

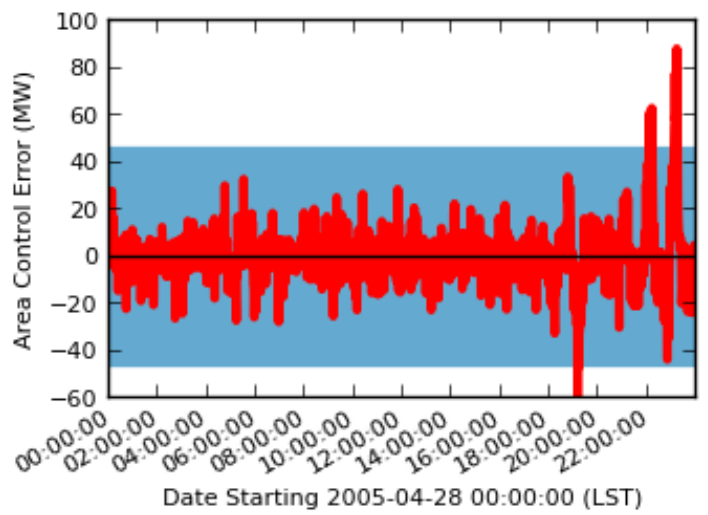

Cumulative ACE over the Full Year

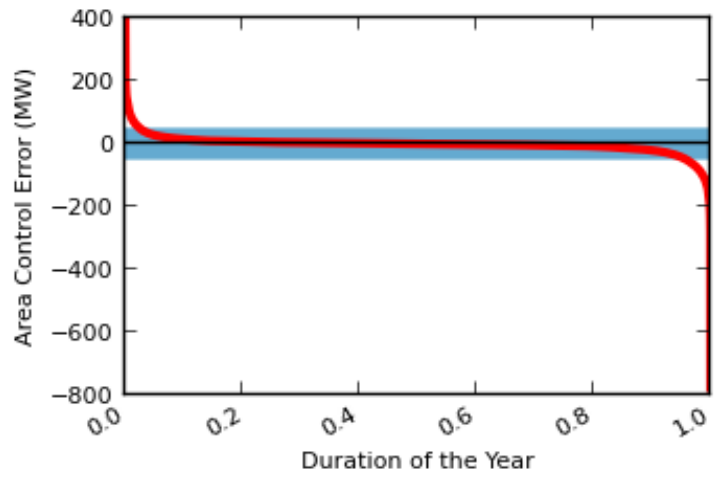

Figure B-14. Schedules, Deviations from the Schedule, and ACE for an April Day in 2005 along with the Annual ACE, All Based on the Load 


\section{B.10.2 Wind}

The exact same calculations were conducted by using the wind data from 2005 (Figure B-15). The resulting CSP2 score for the wind only would be higher at $99.1 \%$.

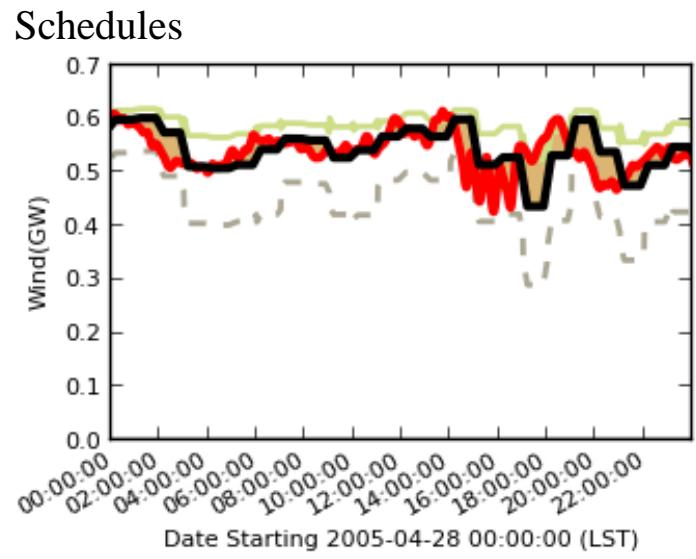

Deviations from the Schedule

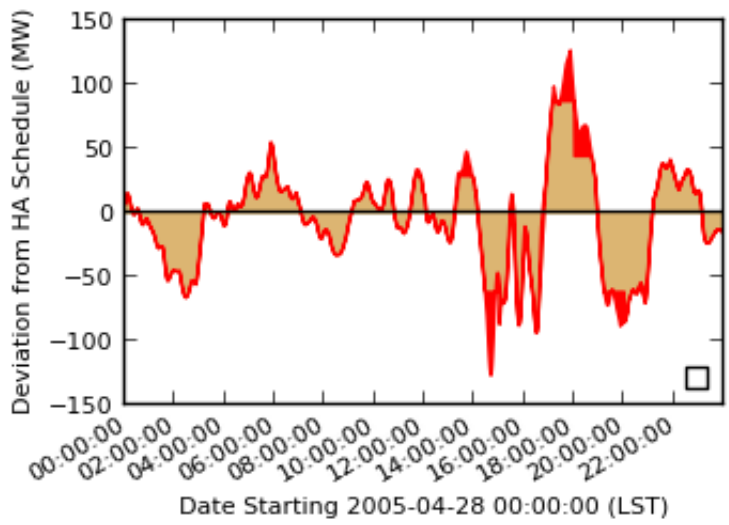

Resulting ACE ( $\mathrm{L}_{10}$ in blue):

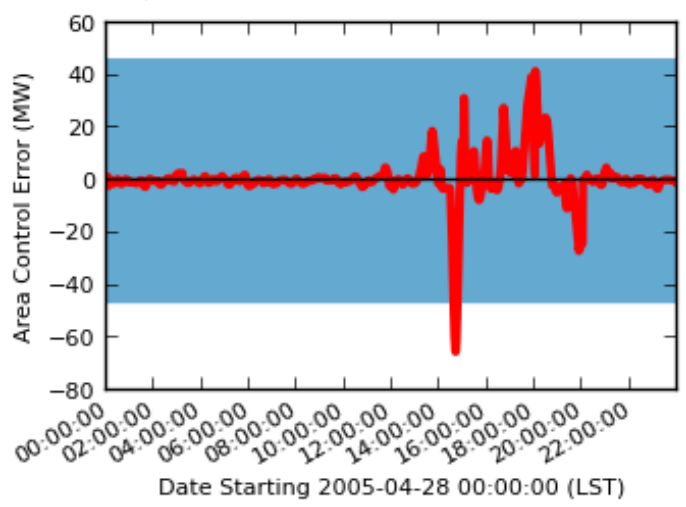

Cumulative ACE over the Full Year

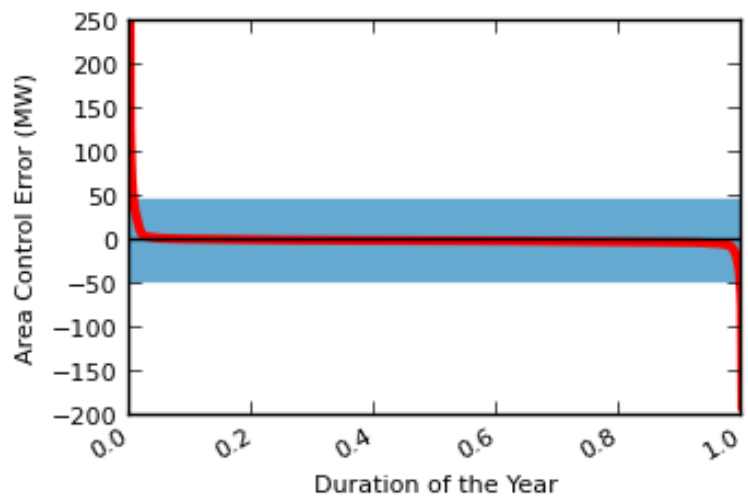

Figure B-15. Schedules, Deviations from the Schedules, and ACE for the Same April 2005 Day along with the Annual ACE, All Based on the Wind

\section{B.10.3 PV}

The same calculations were conducted by using the PV data from 2005 (Figure B-16). The resulting CSP2 score for the PV only would also be higher than the CPS2 score for the load alone at $96.3 \%$. 
Schedules

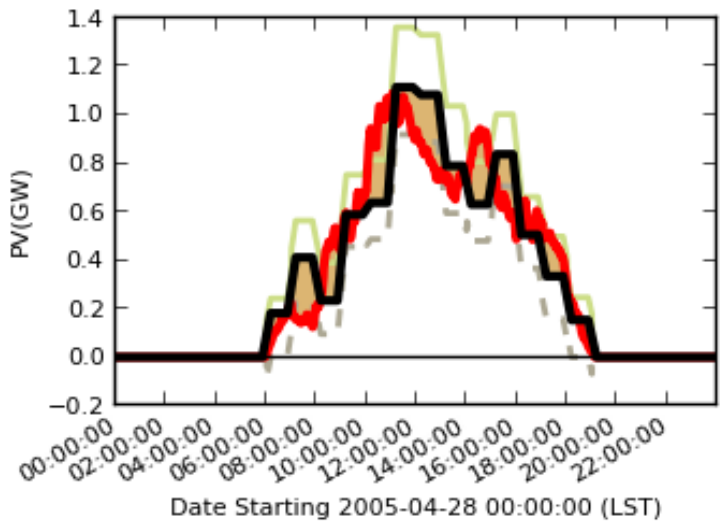

Deviations from the Schedule

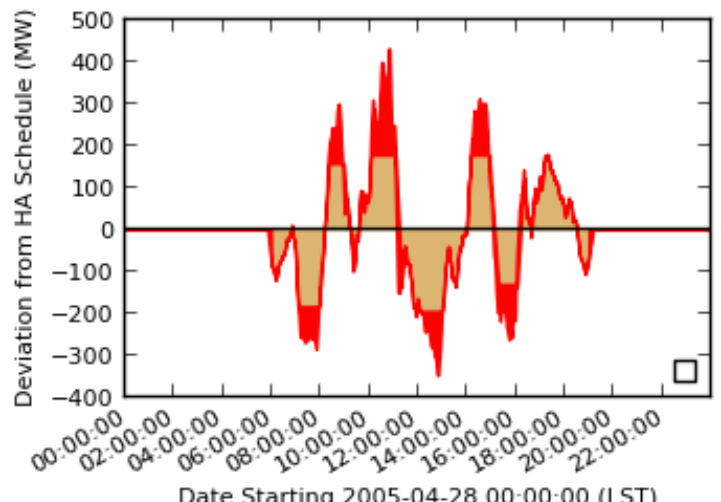

Resulting ACE ( $\mathrm{L}_{10}$ in blue)

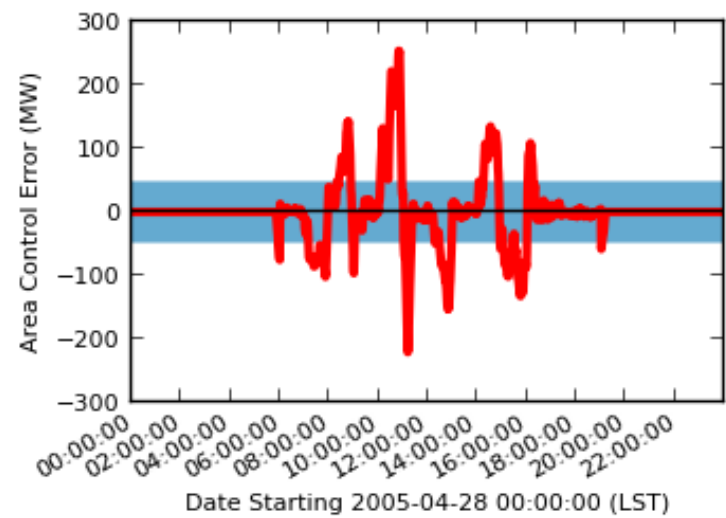

Cumulative ACE over the Full Year

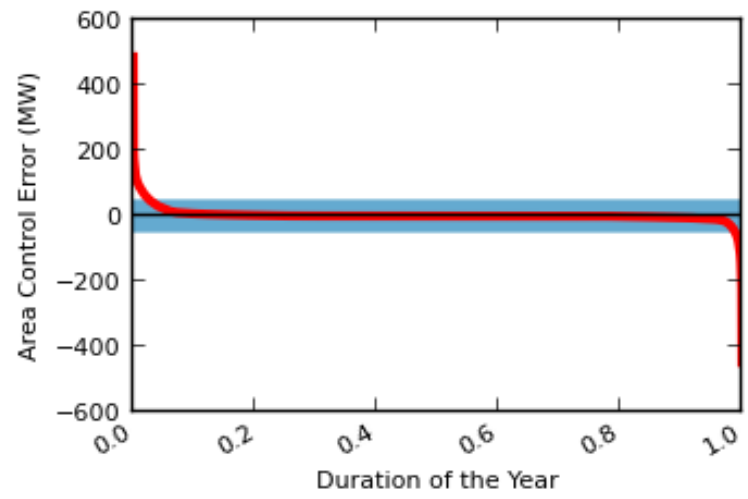

Figure B-16. Schedules, Deviations from the Schedules, and ACE for the Same April 2005 Day along with the ACE, All Based on the PV

\section{B.10.4 Net Load}

The net load was then calculated from the 1-min load data less the 1-min wind and PV data (Figure B-17). The resulting CSP2 score for the net load was at 95.8\%, slightly higher than the CPS2 score for the load alone. This indicates that as long as the balancing reserves are increased when wind and solar are added to the system, then the degree to which the system is kept in balance can remain equivalent to or better than the situation for the load alone. 
Schedules

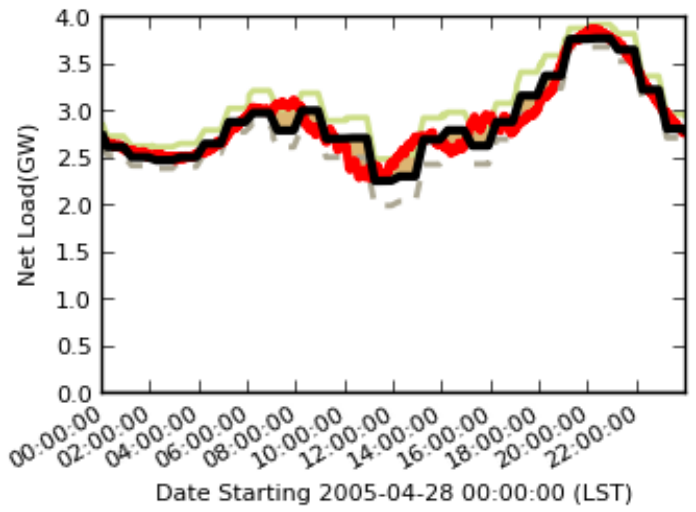

Deviations from the Schedule

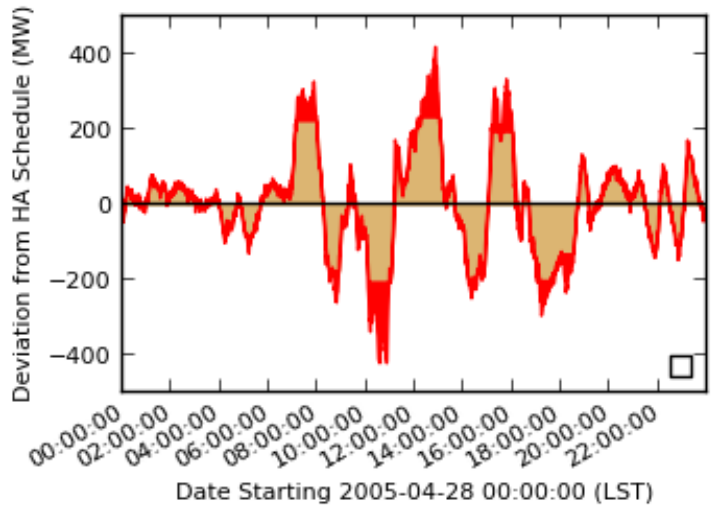

Resulting $\mathrm{ACE}\left(\mathrm{L}_{10}\right.$ in blue)

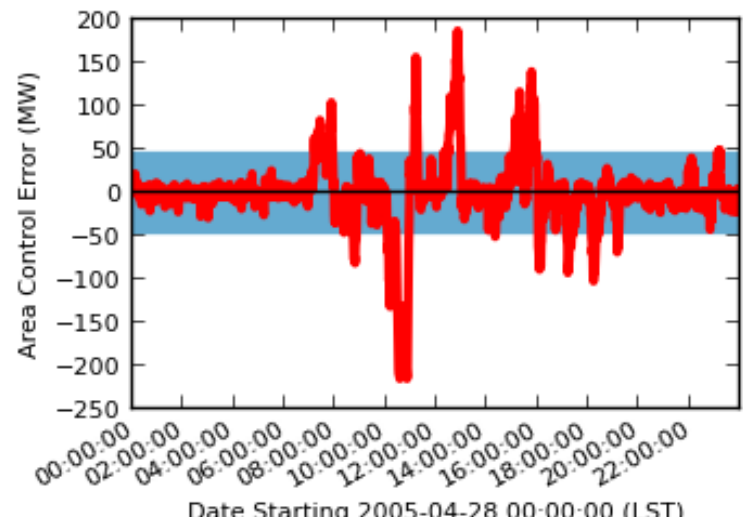

Cumulative ACE over the Full Year

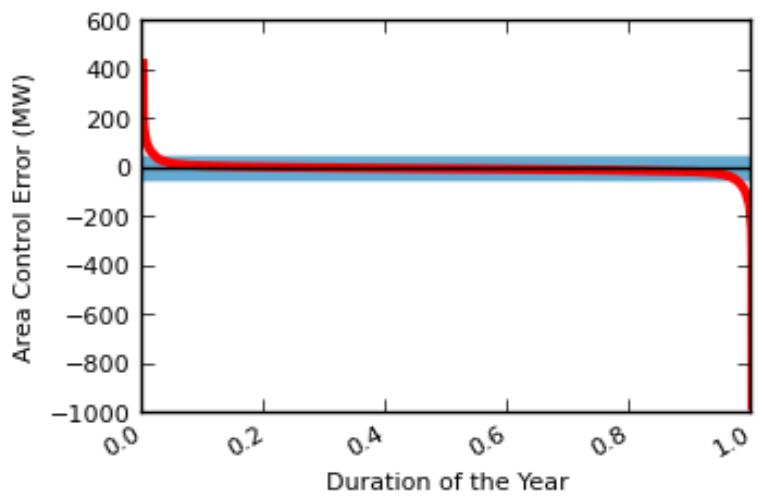

Figure B-17. Schedules, Deviations from the Schedules, and ACE for the same April 2005 Day along with the ACE, All Based on the Net Load

\section{B.11 Sensitivity Analysis}

Several sensitivity cases were run to determine the degree to which assumptions used in the lowPV case affected the BR rules and the resulting CPS2 score. In addition, these sensitivity cases were used to identify steps that the utility could take to mitigate the impact of PV on the need for $\mathrm{BR}$ reserves and the costs associated with holding resources in reserve during the HA scheduling. These sensitivities are explored by estimating the CPS2 score, the average BR up requirement over the year, and the largest BR up and down requirements over the year. These statistics were calculated for the load, load-wind, and the net load defined as load-wind-PV.

One additional calculation in this section is an estimate of the portion of the BR that would need to come from spinning resources. Based on the assumption that non-spinning resources could be started and online within $10 \mathrm{~min}$, then spinning reserves would be needed to meet all the balancing reserves requirements for the first $10 \mathrm{~min}$. Based on the deployment of BR up, we examine the largest amount of BR up needed in 10 min, say, for example, the largest BR deployment in 10 min was $150 \mathrm{MW}$. We then set a requirement that any BR of $150 \mathrm{MW}$ or less needs to come from spinning resources. Anything greater than $150 \mathrm{MW}$ is therefore assumed to 
be able to be met by non-spinning resources that take $10 \mathrm{~min}$ to fully come online. This statistic, showing the largest deployment of BR in 10 min, is called the "minimum BR up from spinning resources" and is shown in the following tables. For the most part the majority of the BR requirements must be met by spinning resources, though we explore some scenarios in which this is not the case.

\section{B.11.1 Comparison of 2005 Results to 2004}

The method employed here for estimating the BR requirements uses the deviations from data based on the 2004 dataset to calculate BR rules for the 2005 dataset (Table B-3). We chose this approach because, in practice, it is not possible to know these deviations ahead of time. To examine the impact of using deviations from a previous year to establish balancing rules, we used 2004 data to generate BR rules for 2004. We then evaluated the performance of the BR rules with the actual 1-min data from 2004 to demonstrate that there is no significant gain in performance for the BR rules derived using 2004 data and applied to 2004 versus applying the same 2004 BR rules to 2005 .

Table B-3. BR Sensitivity Results: 2005 vs. 2004

\begin{tabular}{|c|c|c|c|c|}
\hline Metric & Year & Load & Load-Wind & $\begin{array}{c}\text { Net Load } \\
\text { (Load-Wind-PV) }\end{array}$ \\
\hline CPS2 & $\begin{array}{l}2004 \\
2005\end{array}$ & $\begin{array}{l}95.5 \% \\
93.8 \%\end{array}$ & $\begin{array}{l}96.8 \% \\
96.1 \%\end{array}$ & $\begin{array}{l}96.1 \% \\
95.8 \%\end{array}$ \\
\hline Average BR up & $\begin{array}{l}2004 \\
2005\end{array}$ & $\begin{array}{l}96 \mathrm{MW} \\
96 \mathrm{MW}\end{array}$ & $\begin{array}{l}130 \mathrm{MW} \\
132 \mathrm{MW}\end{array}$ & $\begin{array}{l}170 \mathrm{MW} \\
171 \mathrm{MW}\end{array}$ \\
\hline Maximum BR up & $\begin{array}{l}2004 \\
2005\end{array}$ & $\begin{array}{l}116 \mathrm{MW} \\
\mathbf{1 1 6} \mathbf{M W}\end{array}$ & $\begin{array}{l}187 \mathrm{MW} \\
187 \mathrm{MW}\end{array}$ & $\begin{array}{l}275 \mathrm{MW} \\
278 \mathrm{MW}\end{array}$ \\
\hline $\begin{array}{l}\text { Minimum BR up from spinning } \\
\text { resources }\end{array}$ & $\begin{array}{l}2004 \\
2005\end{array}$ & $\begin{array}{l}102 \mathrm{MW} \\
\mathbf{1 0 3} \mathbf{M W}\end{array}$ & $\begin{array}{l}174 \mathrm{MW} \\
173 \mathrm{MW}\end{array}$ & $\begin{array}{l}250 \mathrm{MW} \\
264 \mathrm{MW}\end{array}$ \\
\hline Maximum BR down & $\begin{array}{l}2004 \\
2005\end{array}$ & $\begin{array}{l}-97 \mathrm{MW} \\
-97 \mathrm{MW}\end{array}$ & $\begin{array}{l}-159 \mathrm{MW} \\
\mathbf{- 1 5 9} \mathrm{MW}\end{array}$ & $\begin{array}{l}-294 \mathrm{MW} \\
-294 \mathrm{MW}\end{array}$ \\
\hline
\end{tabular}

\section{B.11.2 Sensitivity to Choice of Percentiles}

In order to examine the sensitivity of the BR rules and the resulting CPS2 score to the choice of percentiles of 1-min deviations, the percentiles were varied from the choice of the 2.5th and 97.5th percentile for load, wind, and PV used in the reference case to higher and lower values (Table B-4).

The CPS2 score is clearly linked to the choice of percentiles. Another interesting finding is that the minimum amount of reserves that should come from spinning resources increases only slightly with higher percentiles of deviations (by $22 \mathrm{MW}$ for the net load), but the maximum 
total BR in the up direction increases by $90 \mathrm{MW}$ for the net load. This indicates that if the utility desires a CPS2 score greater than $96 \%$, then the utility can primarily use non-spinning resources to meet "tail" events that are outside of the lower percentile range (from the 2.5 th to the 97.5 th).

Table B-4. BR Sensitivity Results: Choice of Percentiles

\begin{tabular}{|c|c|c|c|c|}
\hline Metric & $\begin{array}{c}\text { Percentile of } \\
\text { 1-min Deviations }\end{array}$ & Load & Load-Wind & Net Load \\
\hline CPS2 & $\begin{array}{l}\text { 5th to } 95 \text { th } \\
\text { 2.5th to } 97.5 \text { th } \\
1 \text { st to } 99 \text { th }\end{array}$ & $\begin{array}{l}90.0 \% \\
93.8 \% \\
96.5 \%\end{array}$ & $\begin{array}{c}92.49 \% \\
96.1 \% \\
98.6 \%\end{array}$ & $\begin{array}{l}92.2 \% \\
95.8 \% \\
98.2 \%\end{array}$ \\
\hline Average BR up & $\begin{array}{l}\text { 5th to 95th } \\
2.5 \text { th to } 97.5 \text { th } \\
\text { 1st to 99th }\end{array}$ & $\begin{array}{c}78 \mathrm{MW} \\
96 \mathrm{MW} \\
122 \mathrm{MW}\end{array}$ & $\begin{array}{l}106 \mathrm{MW} \\
132 \mathrm{MW} \\
168 \mathrm{MW}\end{array}$ & $\begin{array}{l}136 \mathrm{MW} \\
171 \mathrm{MW} \\
224 \mathrm{MW}\end{array}$ \\
\hline Maximum BR up & $\begin{array}{l}\text { 5th to 95th } \\
2.5 \text { th to } 97.5 \text { th } \\
\text { 1st to 99th }\end{array}$ & $\begin{array}{l}89 \mathrm{MW} \\
116 \mathrm{MW} \\
156 \mathrm{MW}\end{array}$ & $\begin{array}{l}143 \mathrm{MW} \\
187 \mathrm{MW} \\
253 \mathrm{MW}\end{array}$ & $\begin{array}{l}240 \mathrm{MW} \\
278 \mathrm{MW} \\
368 \mathrm{MW}\end{array}$ \\
\hline $\begin{array}{l}\text { Minimum BR up from spinning } \\
\text { resources }\end{array}$ & $\begin{array}{l}\text { 5th to 95th } \\
2.5 \text { th to } 97.5 \text { th } \\
\text { 1st to } 99 \text { th }\end{array}$ & $\begin{array}{c}87 \mathrm{MW} \\
103 \mathrm{MW} \\
132 \mathrm{MW}\end{array}$ & $\begin{array}{l}137 \mathrm{MW} \\
173 \mathrm{MW} \\
233 \mathrm{MW}\end{array}$ & $\begin{array}{l}225 \mathrm{MW} \\
264 \mathrm{MW} \\
286 \mathrm{MW}\end{array}$ \\
\hline Maximum BR down & $\begin{array}{l}\text { 5th to 95th } \\
\text { 2.5th to } 97.5 \text { th } \\
\text { 1st to 99th }\end{array}$ & $\begin{array}{l}-77 \mathrm{MW} \\
-97 \mathrm{MW} \\
-116 \mathrm{MW}\end{array}$ & $\begin{array}{l}-124 \mathrm{MW} \\
-159 \mathrm{MW} \\
-206 \mathrm{MW}\end{array}$ & $\begin{array}{l}-205 \mathrm{MW} \\
-294 \mathrm{MW} \\
-364 \mathrm{MW}\end{array}$ \\
\hline
\end{tabular}

\section{B.11.3 Sensitivity to Choice of Smoothing Filter for Deployment of ACE}

Adding a smoothing filter to the deviations allows the balancing reserves deployment to avoid chasing small deviations that result in ACE that is lower than the utility $\mathrm{L}_{10}$ value. These ACEs are small enough that they do not affect the CPS2 score. Filtering them out reduces unnecessary wear and tear on generators that are providing balancing reserves. The base choice of a smoothing filter has a time constant of $5 \mathrm{~min}$. A sensitivity case with no filtering (time constant of $0 \mathrm{~min}$ ) shows that there is only a small improvement (an increase of $0.1 \%$ ) in the CPS2 score. On the other hand, increasing the time constant to $10 \mathrm{~min}$ (and therefore filtering out larger deviations) slightly reduces the CPS2 score for both the load and net load. Either way, the results are not found to be sensitive to the particular choice of filtering that was applied in the reference case (a time constant of $5 \mathrm{~min}$ ), as shown in Table B-5. 
Table B-5. BR Sensitivity Results: ACE Smoothing Filter

\begin{tabular}{|c|c|c|c|c|}
\hline Metric & $\begin{array}{c}\text { Time Constant } \\
\text { of Deviation } \\
\text { Filter } \\
\end{array}$ & Load & Load-Wind & Net Load \\
\hline CPS2 & $\begin{array}{l}0 \text { min } \\
\mathbf{5} \text { min } \\
10 \text { min }\end{array}$ & $\begin{array}{l}93.9 \% \\
93.8 \% \\
93.6 \%\end{array}$ & $\begin{array}{l}96.2 \% \\
96.1 \% \\
95.9 \%\end{array}$ & $\begin{array}{l}96.0 \% \\
95.8 \% \\
95.6 \%\end{array}$ \\
\hline Average BR up & $\begin{array}{l}0 \text { min } \\
\mathbf{5} \text { min } \\
10 \text { min }\end{array}$ & $\begin{array}{l}96 \mathrm{MW} \\
96 \mathrm{MW} \\
96 \mathrm{MW}\end{array}$ & $\begin{array}{l}132 \mathrm{MW} \\
\mathbf{1 3 2} \mathrm{MW} \\
132 \mathrm{MW}\end{array}$ & $\begin{array}{l}171 \mathrm{MW} \\
\mathbf{1 7 1} \mathrm{MW} \\
171 \mathrm{MW}\end{array}$ \\
\hline Maximum BR up & $\begin{array}{l}0 \text { min } \\
\mathbf{5} \text { min } \\
10 \text { min }\end{array}$ & $\begin{array}{l}116 \mathrm{MW} \\
116 \mathrm{MW} \\
116 \mathrm{MW}\end{array}$ & $\begin{array}{l}187 \mathrm{MW} \\
187 \mathrm{MW} \\
187 \mathrm{MW}\end{array}$ & $\begin{array}{l}278 \mathrm{MW} \\
278 \mathrm{MW} \\
278 \mathrm{MW}\end{array}$ \\
\hline $\begin{array}{l}\text { Minimum BR up from spinning } \\
\text { resources }\end{array}$ & $\begin{array}{l}0 \text { min } \\
\mathbf{5} \text { min } \\
10 \text { min }\end{array}$ & $\begin{array}{l}110 \mathrm{MW} \\
103 \mathrm{MW} \\
101 \mathrm{MW}\end{array}$ & $\begin{array}{l}176 \mathrm{MW} \\
\mathbf{1 7 3} \mathrm{MW} \\
174 \mathrm{MW}\end{array}$ & $\begin{array}{l}267 \mathrm{MW} \\
264 \mathrm{MW} \\
263 \mathrm{MW}\end{array}$ \\
\hline Maximum BR down & $\begin{array}{l}0 \text { min } \\
5 \text { min } \\
10 \text { min }\end{array}$ & $\begin{array}{l}-97 \mathrm{MW} \\
-97 \mathrm{MW} \\
-97 \mathrm{MW}\end{array}$ & $\begin{array}{l}-159 \mathrm{MW} \\
-159 \mathrm{MW} \\
-159 \mathrm{MW}\end{array}$ & $\begin{array}{l}-294 \mathrm{MW} \\
-294 \mathrm{MW} \\
-294 \mathrm{MW}\end{array}$ \\
\hline
\end{tabular}

\section{B.11.4 Sensitivity to Choice of BR Ramp Rate}

The base assumption was that the balancing reserves could be fully deployable in $10 \mathrm{~min}$ (10\% of BR capacity per minute). Here we test BR with a faster ramp rate that can fully deploy in 5 min (20\% of BR capacity per minute) and a slower ramp rate that can fully deploy in 20 min (5\% of BR capacity per minute) (Table B-6). Balancing reserves that can be fully deployed at a much faster rate has a slight beneficial impact on the CPS2 score relative to the base case. Having much slower reserves, on the other hand, greatly degrades the CPS 2 score, indicating that many deviations from the schedule occur very quickly and that slow reserves would not be able to keep up with many large changes. Interestingly, the impact of slow reserves is slightly worse for the load than the net load, indicating that the wind and PV tend to have slightly slower ramping deviations than the load. 
Table B-6. BR Sensitivity Results: BR Ramp Rates

\begin{tabular}{|c|c|c|c|c|}
\hline Metric & $\begin{array}{l}\text { BR Ramp Rate (fully } \\
\text { deployable in...) }\end{array}$ & Load & Load-Wind & Net Load \\
\hline CPS2 & $\begin{array}{l}5 \mathrm{~min} \\
10 \mathrm{~min} \\
20 \mathrm{~min}\end{array}$ & $\begin{array}{l}97.1 \% \\
93.8 \% \\
84.6 \%\end{array}$ & $\begin{array}{l}97.8 \% \\
96.1 \% \\
88.3 \%\end{array}$ & $\begin{array}{l}97.4 \% \\
95.8 \% \\
87.9 \%\end{array}$ \\
\hline Average BR up & $\begin{array}{c}5 \mathrm{~min} \\
10 \mathrm{~min} \\
20 \mathrm{~min}\end{array}$ & $\begin{array}{l}96 \mathrm{MW} \\
96 \mathrm{MW} \\
96 \mathrm{MW}\end{array}$ & $\begin{array}{l}132 \mathrm{MW} \\
132 \mathrm{MW} \\
132 \mathrm{MW}\end{array}$ & $\begin{array}{l}171 \mathrm{MW} \\
\mathbf{1 7 1} \mathbf{M W} \\
171 \mathrm{MW}\end{array}$ \\
\hline Maximum BR up & $\begin{array}{l}5 \mathrm{~min} \\
10 \mathrm{~min} \\
20 \mathrm{~min}\end{array}$ & $\begin{array}{l}116 \mathrm{MW} \\
116 \mathrm{MW} \\
116 \mathrm{MW}\end{array}$ & $\begin{array}{l}187 \mathrm{MW} \\
187 \mathrm{MW} \\
187 \mathrm{MW}\end{array}$ & $\begin{array}{l}278 \mathrm{MW} \\
278 \mathrm{MW} \\
278 \mathrm{MW}\end{array}$ \\
\hline $\begin{array}{l}\text { Minimum BR up from spinning } \\
\text { resources }\end{array}$ & $\begin{array}{l}5 \mathrm{~min} \\
10 \mathrm{~min} \\
20 \mathrm{~min}\end{array}$ & $\begin{array}{l}103 \mathrm{MW} \\
\mathbf{1 0 3} \mathrm{MW} \\
102 \mathrm{MW}\end{array}$ & $\begin{array}{l}177 \mathrm{MW} \\
\mathbf{1 7 3} \mathrm{MW} \\
173 \mathrm{MW}\end{array}$ & $\begin{array}{l}256 \mathrm{MW} \\
264 \mathrm{MW} \\
259 \mathrm{MW}\end{array}$ \\
\hline Maximum BR down & $\begin{array}{l}5 \mathrm{~min} \\
10 \mathrm{~min} \\
20 \mathrm{~min}\end{array}$ & $\begin{array}{l}-97 \mathrm{MW} \\
-97 \mathrm{MW} \\
-97 \mathrm{MW}\end{array}$ & $\begin{array}{l}-159 \mathrm{MW} \\
-159 \mathrm{MW} \\
-159 \mathrm{MW}\end{array}$ & $\begin{array}{l}-294 \mathrm{MW} \\
-294 \mathrm{MW} \\
-294 \mathrm{MW}\end{array}$ \\
\hline
\end{tabular}

\section{B.11.5 Sensitivity to Choice of Schedule Lead Time for Persistence Forecast}

We assumed that HA schedules needed to be decided based on information available 30 min prior to the start of the operating hour (as illustrated in Figure B-2). With increased automation and use of information technology, it may be possible to shorten the lead time prior to the operating hour for setting schedules. To examine this, we test a 15-min lead time for creating persistence forecasts. We also test a 45-min lead time for utilities that may need more time to set schedules (Table B-7).

The results indicate that with a shorter lead time the BR rules (both average and maximum) can be slightly reduced while the CPS 2 score can be maintained. With a longer lead time, the balancing reserves need to be increased in order to manage the larger forecast error while maintaining the same CPS2 score. 
Table B-7. BR Sensitivity Results: Forecast Lead Time

\begin{tabular}{|c|c|c|c|c|}
\hline Metric & $\begin{array}{l}\text { Lead time for } \\
\text { schedules }\end{array}$ & Load & Load-Wind & Net Load \\
\hline CPS2 & $\begin{array}{l}15 \min \\
30 \min \\
45 \min \end{array}$ & $\begin{array}{l}93.8 \% \\
93.8 \% \\
93.8 \%\end{array}$ & $\begin{array}{l}95.6 \% \\
96.1 \% \\
96.6 \%\end{array}$ & $\begin{array}{l}95.3 \% \\
95.8 \% \\
96.1 \%\end{array}$ \\
\hline Average BR up & $\begin{array}{l}15 \mathrm{~min} \\
30 \mathrm{~min} \\
45 \mathrm{~min}\end{array}$ & $\begin{array}{l}96 \mathrm{MW} \\
96 \mathrm{MW} \\
96 \mathrm{MW}\end{array}$ & $\begin{array}{l}122 \mathrm{MW} \\
\mathbf{1 3 2} \mathrm{MW} \\
140 \mathrm{MW}\end{array}$ & $\begin{array}{l}161 \mathrm{MW} \\
171 \mathrm{MW} \\
181 \mathrm{MW}\end{array}$ \\
\hline Maximum BR up & $\begin{array}{l}15 \mathrm{~min} \\
30 \mathrm{~min} \\
45 \mathrm{~min}\end{array}$ & $\begin{array}{l}116 \mathrm{MW} \\
116 \mathrm{MW} \\
116 \mathrm{MW}\end{array}$ & $\begin{array}{l}163 \mathrm{MW} \\
187 \mathrm{MW} \\
206 \mathrm{MW}\end{array}$ & $\begin{array}{l}268 \mathrm{MW} \\
278 \mathrm{MW} \\
296 \mathrm{MW}\end{array}$ \\
\hline $\begin{array}{l}\text { Minimum BR up from spinning } \\
\text { resources }\end{array}$ & $\begin{array}{l}15 \mathrm{~min} \\
30 \mathrm{~min} \\
45 \mathrm{~min}\end{array}$ & $\begin{array}{l}103 \mathrm{MW} \\
103 \mathrm{MW} \\
103 \mathrm{MW}\end{array}$ & $\begin{array}{l}149 \mathrm{MW} \\
\mathbf{1 7 3} \mathrm{MW} \\
192 \mathrm{MW}\end{array}$ & $\begin{array}{l}239 \mathrm{MW} \\
264 \mathrm{MW} \\
276 \mathrm{MW}\end{array}$ \\
\hline Maximum BR down & $\begin{array}{l}15 \min \\
30 \min \\
45 \mathrm{~min}\end{array}$ & $\begin{array}{l}-97 \mathrm{MW} \\
-97 \mathrm{MW} \\
-97 \mathrm{MW}\end{array}$ & $\begin{array}{l}-142 \mathrm{MW} \\
-159 \mathrm{MW} \\
-172 \mathrm{MW}\end{array}$ & $\begin{array}{l}-312 \mathrm{MW} \\
-294 \mathrm{MW} \\
-309 \mathrm{MW}\end{array}$ \\
\hline
\end{tabular}

\section{B.11.6 Sensitivity to the Choice of Inter-Hour Ramp Start and End Time}

The ramps between operating hours are established by the business practices within the WECC. The duration of the ramps, however, affect the degree to which the hourly schedule deviates from the actual load or net load. Ramps that start and end closer to the operating hour require rapid ramping between hours and leave much of the hour with a flat schedule (as illustrated earlier in Figure B-3). On the other hand, longer ramps between hours provide a gentler slope from hour to hour and less of the hourly schedule is flat.

The shorter ramp times ( 5 min instead of $10 \mathrm{~min}$ ) lead to a lower CPS2 score and larger BR requirements (Table B-8). Extending the ramp times (from 10 to 20-min), on the other hand, increases the CPS2 score and reduces the BR requirements.

We also tested a case with a 30-min hour-to-hour ramp start and end time, which leaves no flat part of the hourly schedule. In this case we also move the lead time for creating these schedules to $50 \mathrm{~min}$ prior to the start of the operating hour. This leaves a lead time of $20 \mathrm{~min}$ prior to the start of the 30-min ramp, which is similar to the lead time before the start of the ramp with 10-min ramps and schedules submitted 30-min prior to the start of the operating hour. The longer lead time increases the forecast error, but the smoother schedules lead to an overall reduction in the $\mathrm{BR}$ requirements and increase in $\mathrm{CPS} 2$ relative to the base case. 
Table B-8. BR Sensitivity Results: Inter-Hour Ramps

\begin{tabular}{|c|c|c|c|c|c|}
\hline Metric & $\begin{array}{l}\text { Hour-to-Hour } \\
\text { Ramp Start and } \\
\text { End Time }\end{array}$ & $\begin{array}{l}\text { Lead Time } \\
\text { for } \\
\text { Schedules } \\
\end{array}$ & Load & Load-Wind & Net Load \\
\hline CPS2 & $\begin{array}{c}5 \mathrm{~min} \\
10 \mathrm{~min} \\
20 \mathrm{~min} \\
30 \mathrm{~min}\end{array}$ & $\begin{array}{l}30 \mathrm{~min} \\
30 \mathrm{~min} \\
30 \mathrm{~min} \\
50 \mathrm{~min}\end{array}$ & $\begin{array}{l}88.3 \% \\
93.8 \% \\
98.0 \% \\
98.6 \%\end{array}$ & $\begin{array}{l}91.1 \% \\
96.1 \% \\
98.5 \% \\
98.7 \%\end{array}$ & $\begin{array}{l}91.4 \% \\
95.8 \% \\
97.8 \% \\
98.1 \%\end{array}$ \\
\hline Average BR up & $\begin{array}{c}5 \mathrm{~min} \\
10 \mathrm{~min} \\
20 \mathrm{~min} \\
30 \mathrm{~min}\end{array}$ & $\begin{array}{l}30 \mathrm{~min} \\
30 \mathrm{~min} \\
30 \mathrm{~min} \\
50 \mathrm{~min}\end{array}$ & $\begin{array}{c}109 \mathrm{MW} \\
96 \mathrm{MW} \\
76 \mathrm{MW} \\
66 \mathrm{MW}\end{array}$ & $\begin{array}{l}143 \mathrm{MW} \\
132 \mathrm{MW} \\
115 \mathrm{MW} \\
119 \mathrm{MW}\end{array}$ & $\begin{array}{l}182 \mathrm{MW} \\
\mathbf{1 7 1} \mathrm{MW} \\
151 \mathrm{MW} \\
157 \mathrm{MW}\end{array}$ \\
\hline Maximum BR up & $\begin{array}{c}5 \mathrm{~min} \\
10 \mathrm{~min} \\
20 \mathrm{~min} \\
30 \mathrm{~min}\end{array}$ & $\begin{array}{l}30 \mathrm{~min} \\
30 \mathrm{~min} \\
30 \mathrm{~min} \\
50 \mathrm{~min}\end{array}$ & $\begin{array}{c}134 \mathrm{MW} \\
116 \mathrm{MW} \\
87 \mathrm{MW} \\
71 \mathrm{MW}\end{array}$ & $\begin{array}{l}202 \mathrm{MW} \\
187 \mathrm{MW} \\
159 \mathrm{MW} \\
168 \mathrm{MW}\end{array}$ & $\begin{array}{l}305 \mathrm{MW} \\
278 \mathrm{MW} \\
243 \mathrm{MW} \\
249 \mathrm{MW}\end{array}$ \\
\hline $\begin{array}{l}\text { Minimum BR up from } \\
\text { spinning resources }\end{array}$ & $\begin{array}{c}5 \mathrm{~min} \\
10 \mathrm{~min} \\
20 \mathrm{~min} \\
30 \mathrm{~min}\end{array}$ & $\begin{array}{l}30 \mathrm{~min} \\
30 \mathrm{~min} \\
30 \mathrm{~min} \\
50 \mathrm{~min}\end{array}$ & $\begin{array}{c}132 \mathrm{MW} \\
103 \mathrm{MW} \\
80 \mathrm{MW} \\
67 \mathrm{MW}\end{array}$ & $\begin{array}{l}186 \mathrm{MW} \\
\mathbf{1 7 3} \mathrm{MW} \\
137 \mathrm{MW} \\
139 \mathrm{MW}\end{array}$ & $\begin{array}{l}295 \mathrm{MW} \\
\mathbf{2 6 4} \mathrm{MW} \\
225 \mathrm{MW} \\
205 \mathrm{MW}\end{array}$ \\
\hline Maximum BR down & $\begin{array}{c}5 \mathrm{~min} \\
10 \mathrm{~min} \\
20 \mathrm{~min} \\
30 \mathrm{~min} \\
\end{array}$ & $\begin{array}{l}30 \mathrm{~min} \\
30 \mathrm{~min} \\
30 \mathrm{~min} \\
50 \mathrm{~min} \\
\end{array}$ & $\begin{array}{l}-122 \mathrm{MW} \\
-97 \mathrm{MW} \\
-72 \mathrm{MW} \\
-59 \mathrm{MW}\end{array}$ & $\begin{array}{l}-178 \mathrm{MW} \\
-159 \mathrm{MW} \\
-140 \mathrm{MW} \\
-157 \mathrm{MW} \\
\end{array}$ & $\begin{array}{l}-296 \mathrm{MW} \\
-294 \mathrm{MW} \\
-277 \mathrm{MW} \\
-293 \mathrm{MW} \\
\end{array}$ \\
\hline
\end{tabular}

\section{B.11.7 Comparison to WWSIS 3 + 5 Reserve Rule}

The Western Wind and Solar Integration Study (WWSIS, Phase 1) study developed simple BR rules that could be used by system operators to manage increasing amounts of variable generation. Because of data limitations at the time of that study, the reserve rules were developed and validated with wind and load data but not with PV. The simple rule suggests operators set the balancing reserves to $3 \%$ of the scheduled load plus $5 \%$ of the scheduled wind and solar in each hour (the $3+5$ rule).

The CPS2 score using this simple rule is almost exactly the same as the CPS2 score from the low-PV case BR rules developed here (Table B-9). The BR requirements are similar, although the maximum reserve requirement in the up and down direction with the simple $3+5$ rule is greater than the maximum reserve required with the rules developed here. This suggests that the $3+5$ rule is a reasonable starting point, even for a case with PV, but more advanced reserve rules can allow the utility to operate with less BR and the same level of reliability. 
Table B-9. BR Sensitivity Results: WWSIS Rule

\begin{tabular}{lcc}
\hline \multicolumn{1}{c}{ Metric } & Methodology & $\begin{array}{c}\text { Net Load } \\
(2005)\end{array}$ \\
\hline CPS2 & Low PV & $95.83 \%$ \\
& WWSIS & $95.85 \%$ \\
Average BR up & Low PV & $\mathbf{1 7 1} \mathbf{~ M W}$ \\
& WWSIS & $170 \mathrm{MW}$ \\
Maximum BR up & Low PV & $\mathbf{2 7 8} \mathbf{~ M W}$ \\
& WWSIS & $340 \mathrm{MW}$ \\
Minimum BR from spinning & Low PV & $\mathbf{2 6 4} \mathbf{M W}$ \\
resources & WWSIS & $277 \mathrm{MW}$ \\
Maximum BR down & Low PV & $-\mathbf{2 9 4} \mathbf{M W}$ \\
& WWSIS & $-340 \mathrm{MW}$ \\
\hline
\end{tabular}

\section{B.11.8 Summary of Sensitivity Studies}

The primary findings from this sensitivity analysis are detailed in Table B-10.

Table B-10. Summary of BR Sensitivity Results

\begin{tabular}{ll}
\hline \multicolumn{1}{c}{ Sensitivity Case } & \multicolumn{1}{c}{ Primary Findings } \\
\hline $\begin{array}{l}\text { Imperfect foresight in } \\
\text { developing BR rules }\end{array}$ & $\begin{array}{l}\text { The } 2004 \text { deviations are used to develop BR rules that are tested using } \\
\text { difference relative to a case in which perfect foresight was instead } \\
\text { assumed. }\end{array}$ \\
\hline $\begin{array}{l}\text { Use of 2.5th and 97.5th } \\
\text { percentiles }\end{array}$ & $\begin{array}{l}\text { The choice of the percentiles of deviations used to establish BR rules led to } \\
\text { a CPS2 score of about } 96 \% \text { for the net load. A higher CPS2 score of more } \\
\text { than 98\% could be achieved by increasing the percentiles to the 1st and } \\
\text { 99th. This would increase the BR by at most about } 90 M W . \text { A large portion } \\
\text { of this increased BR could be met with non-spinning resources. }\end{array}$ \\
\hline $\begin{array}{l}\text { 5-min time constant on } \\
\text { smoothing filter }\end{array}$ & $\begin{array}{l}\text { The deviations were filtered such that not all deviations were met by } \\
\text { deployment of BR. The CPS2 score would not be much higher had this } \\
\text { filter been removed (meaning that BR would need to chase more small } \\
\text { deviations without increasing reliability as measured by the NERC } \\
\text { balancing standards). The time constant of the filter could even be } \\
\text { increased to } 10 \text { min without significantly degrading the CPS2 performance. } \\
\text { Overall, the CPS2 results are not sensitive to the choice of this parameter. }\end{array}$ \\
\hline $\begin{array}{l}\text { 10-min time to full } \\
\text { deployment of BR }\end{array}$ & $\begin{array}{l}\text { The CPS2 score can be improved if BR can be fully deployed in less than } \\
10 \text { min without increasing the BR requirement. This appears to be a } \\
\text { promising approach to increasing the CPS2 performance above } 96 \% \text { with } \\
\text { PV and wind. Decreasing the rate of deployment of BR, on the other hand, } \\
\text { would significantly degrade the CPS2 performance. }\end{array}$ \\
&
\end{tabular}


Table B-10. (Cont.)

\begin{tabular}{|c|c|}
\hline Sensitivity Case & Primary Findings \\
\hline 30-min schedule lead time & $\begin{array}{l}\text { Because HA schedules for wind and PV are based on persistence } \\
\text { forecasting, scheduling close to the start of the operating hour decreases } \\
\text { deviations. Decreasing or increasing the lead time is found to change the } \\
\text { maximum BR requirements by less than about }+/-20 \mathrm{MW} \text {, with the shorter } \\
\text { lead time reducing BR up requirements. The overall impact on CSP2 } \\
\text { performance of a shorter or longer lead time is minor. }\end{array}$ \\
\hline $\begin{array}{l}10 \text { min ramps at the start } \\
\text { and end of the operating } \\
\text { hour }\end{array}$ & $\begin{array}{l}\text { WECC practices are based on 10-min ramps. Decreasing the duration of } \\
\text { these ramps would increase the BR needs and lower CPS } 2 \text { performance. } \\
\text { In contrast, increasing the duration of the ramps increases CPS2 } \\
\text { performance and reduces BR requirements. Extending ramps to } 30 \text { min } \\
\text { prior to the start of the operating hour (and setting schedules } 50 \text { min prior } \\
\text { to the start of the operating hour) shows clear benefits relative to 10-min } \\
\text { ramps. }\end{array}$ \\
\hline WWSIS $3+5$ rule & $\begin{array}{l}\text { Using the } 3+5 \text { reserve rule developed in the WWSIS study provides } \\
\text { sufficient BR to maintain a similar CPS } 2 \text { score, as was found with this more } \\
\text { detailed approach. This provides validation that the } 3+5 \text { rule can be an } \\
\text { effective rule of thumb for a utility with } 9 \% \text { of its energy from PV and } 5 \% \text { of } \\
\text { its energy from wind. The peak reserve requirements will slightly exceed } \\
\text { the peak reserve requirements that would be estimated with a more } \\
\text { detailed approach. }\end{array}$ \\
\hline
\end{tabular}

\section{B.12 NERC CPS1 Performance}

In addition to CPS2, there are two other NERC balancing standards that balancing areas must consider: Disturbance Control Standard (DCS) and Control Performance Standard 1 (CPS1).

DCS ensures that a system can recover from a large contingency event, such as a sudden forced outage of a large conventional power plant. In this study we assume that WECC contingency reserve requirements are adequate to meet DCS. These contingency reserves are included in the model constraints with the assumption that they cannot be used to balance the system under normal operating conditions. The contingency reserves therefore must always be met with or without PV. We do not treat DCS any further in this study.

CPS1, like CPS2, is based on the ACE, but determination of the actual score depends on how well correlated a BA's ACE is with system-wide frequency deviations (or frequency error). Similar to CPS2, a higher CPS1 score is desired as it indicates a better performing BA. If the $\mathrm{ACE}$ at a BA contributes to worsening system-wide frequency errors, then the CPS1 score is lowered. On the other hand, if the ACE is in the direction such that it can reduce system-wide frequency errors, the CPS1 score increases.

Because we do not model system-wide frequency, it is not possible to directly calculate the CPS1 score. We can do a few simple calculations to demonstrate that the CPS1 score with and without wind and PV should not change significantly with the increase in BR. To do this, we first simplify the CPS1 calculation and then develop representative parameter value estimates to come up with a ballpark estimate of the CPS1 score. 
CPS1 can be calculated by using the following formula, based on the assumption that ACE is calculated on a 1-min average and the BA frequency bias, $B$, is constant. NERC CPS1 compliance requires that CPS1 remain above 100 over a 12-month rolling average.

Where

$$
C P S 1=100 *\left(2-\frac{1}{-10 B \cdot \epsilon_{1}^{2}} \mathbb{E}[A C E \cdot \Delta F]\right)
$$

- $B$ is the frequency bias of the utility (assumed to be about $-72.6 \mathrm{MW} / 0.1 \mathrm{~Hz}$ for APS).

- $\epsilon_{1}$ is the target RMS of the 1-min interconnection frequency error (assumed to be $22.8 \mathrm{mHz}$ for WECC).

- $\Delta F$ is the 1-min average frequency deviation from the scheduled frequency within the interconnection (or the frequency error).

- $\quad \mathbb{E}$ is the expectation operator or average over a rolling 12-month period.

If we assume that the average of the ACE over 12 months is zero and that the frequency error over 12 months is also zero, then it is possible to reduce the CPS1 score calculation down to terms related to the standard deviation of the $\mathrm{ACE}$ and frequency error:

Where

$$
C P S 1 \approx 100 *\left(2-k \cdot\left(\sigma_{A C E} \cdot \sigma_{\Delta F} \cdot \rho\right)\right)
$$

- $\quad k$ is equal to $\frac{1}{-10 B \cdot \epsilon_{1}^{2}}$, or about $2.65 / \mathrm{MW}-\mathrm{Hz}$ for APS.

- $\sigma_{A C E}$ is the standard deviation of the ACE.

- $\sigma_{\Delta F}$ is the standard deviation of the frequency error.

- $\quad \rho$ is the correlation between the frequency error of the interconnection and the ACE for the BA.

With this simplification it is clear that the CPS1 performance depends on the variability of the $\mathrm{ACE}$ and the correlation of ACE with system-wide frequency error. If the ACE and frequency error are perfectly uncorrelated, the CPS1 score will be 200 and in compliance with the NERC standard.

On the other hand, if there is some positive correlation between ACE and frequency errors, then the CPS1 score will be less than 200 and possibly less than 100, indicating the BA is out of compliance. 
Statistics from WECC indicate that during the period of 2003 to 2009, the standard deviation of the frequency error was roughly $10 \mathrm{mHz}$ and that many BAs had a CPS1 score of about 180 . Based on the ACE from the load alone in the low-PV case, the standard deviation of the ACE was about 29.4 MW. Using this information, APS would have achieved a CPS1 score for the load alone of about 180 if the correlation of the ACE and the frequency error were roughly 0.25.

In the low-PV case, the standard deviation of the ACE for the load-wind and the net load actually decreases to 24.5 MW and 27.7 MW, respectively. Assuming the correlation of ACE and the frequency error remained roughly 0.25 would lead to a CPS1 score of 184 and 182 for the loadwind and net load, respectively. In all cases the BA would be well within compliance with CPS1. Furthermore, the correlation could increase to 0.68 and 0.60 before the CPS1 score would drop to 100 for the load-wind and net load, respectively.

Based on this analysis, we assume that compliance with CPS1 should not be a problem for the $\mathrm{BA}$ as long as it remains in compliance with CPS2 in the various scenarios we investigate herein.

\section{B.13 Comparison to Other Operating Reserve Methods}

The approach used in this study for estimating balancing reserves builds on approaches developed in previous studies or employed by system operators currently managing variable generation, though it does not always match the approaches in these previous studies. As there is no standard method for estimating balancing reserve requirements, we highlight some of the differences in Table B-11.

Table B-11. Overview of Operating Reserve Methods

\begin{tabular}{|c|c|c|}
\hline Region/Utility & Citation & Important Differences \\
\hline $\begin{array}{l}\text { CAISO, NV } \\
\text { Energy }\end{array}$ & $\begin{array}{l}\text { Makarov et al. } \\
2009 \text {; Navigant } \\
\text { Consulting et al. } \\
2011 \text { (PNNL } \\
\text { method) }\end{array}$ & $\begin{array}{l}\text { The PNNL method is similar to our approach except it separately } \\
\text { quantifies load following and regulation reserves (we quantify only the } \\
\text { balancing reserves that need to be held in the HA and are deployed in RT } \\
\text { via a combination of the RT desk and transmission system operators); the } \\
\text { NV Energy study assumed perfect forecasting in the HA (we use a 30-min } \\
\text { persistence-of-cloudiness forecast); the CAISO study assumed that HA } \\
\text { forecast errors scaled proportionally to wind capacity and selected errors } \\
\text { from a truncated normal distribution. }\end{array}$ \\
\hline $\begin{array}{l}\text { Bonneville } \\
\text { Power } \\
\text { Administration }\end{array}$ & BPA 2009 & $\begin{array}{l}\text { BPA separately quantifies following reserve and regulation reserve (we } \\
\text { quantify only a single balancing reserve amount that should be held in the } \\
\text { HA and deployed in RT through a combination of the RT desk and system } \\
\text { operators). BPA picks a single reserve quantity and holds in it all hours of } \\
\text { the year (we dynamically set balancing reserves based on system } \\
\text { conditions). BPA uses a 1-hr persistence forecast to set HA schedules } \\
\text { (they also examine a } 2 \text {-hr and } 30 \text {-min persistence forecast in a sensitivity } \\
\text { case; we assume } 30 \text {-min persistence of cloudiness in setting HA } \\
\text { schedules). }\end{array}$ \\
\hline
\end{tabular}


Table B-11. (Cont.)

\begin{tabular}{|c|c|c|}
\hline Region/Utility & Citation & Important Differences \\
\hline $\begin{array}{l}\text { Eastern } \\
\text { Interconnection }\end{array}$ & $\begin{array}{l}\text { EnerNex Corp. } \\
2010 \text { (EWITS) }\end{array}$ & $\begin{array}{l}\text { The EWITS method combines short-term 10-min wind forecast errors with } \\
\text { load variability to establish a regulation (short-term) estimate. This reserve } \\
\text { requirement is added to one standard deviation of the HA wind forecast } \\
\text { error (regulation, next hour wind forecast error) to establish the additional } \\
\text { spinning reserve requirement. Two standard deviations of the HA wind } \\
\text { forecast error are then added as non-spinning reserves. The standard } \\
\text { deviations are a function of the wind production level (similar to the } \\
\text { approach used in this study). }\end{array}$ \\
\hline WestConnect & $\begin{array}{l}\text { GE Energy } \\
2010 \text { (WWSIS) }\end{array}$ & $\begin{array}{l}\text { WWSIS adds regulation reserves based on three standard deviations of } \\
10 \text {-min wind variability (we consider deviations from the HA schedule). } \\
\text { From these general rules WWSIS developed a rule of thumb called the } 3 \\
+5 \text { rule: reserves should be set to } 3 \% \text { of the load plus } 5 \% \text { of the hourly } \\
\text { average wind. }\end{array}$ \\
\hline ERCOT & ERCOT 2011 & $\begin{array}{l}\text { The ERCOT regulation requirement is based on the observed 98.8th } \\
\text { percentile of } 5 \text {-min net load (load-wind) changes and deployment of } \\
\text { regulation by hour of the day (we use deviations from HA schedules). The } \\
\text { amount of regulation by hour is set to provide adequate regulation } \\
\text { capability } 98.8 \% \text { of the time. ERCOT sets the DA non-spinning reserves } \\
\text { plus regulation requirement to meet } 95 \text { th percentile of observed DA } \\
\text { forecast error (we do not increase the balancing reserves in the DA; the } \\
\text { requirement is the same in the DA and HA). }\end{array}$ \\
\hline $\begin{array}{l}\text { Southwest } \\
\text { Power Pool }\end{array}$ & CRA 2010 & $\begin{array}{l}\text { CRA uses the } 5 \text { th and } 95 \text { th percentile of } 10 \text {-min wind changes along with } \\
\text { load to establish a regulation reserve requirement (we use deviations from } \\
\text { HA schedules). }\end{array}$ \\
\hline APS & $\begin{array}{l}\text { Black \& Veatch } \\
2012\end{array}$ & $\begin{array}{l}\text { The Black \& Veatch study estimates regulation reserves for daylight hours } \\
\text { required to meet a target CPS2 score based on 10-min load and PV } \\
\text { deviations from HA schedules (the study does not include 10-min ramps } \\
\text { before and after the start of the operating hour, and uses } 70 \text {-min } \\
\text { persistence to set the schedules). The study does not include wind } \\
\text { variability in the assessment of reserves. One other difference is that the } \\
\text { Black \& Veatch study, because it focuses on daylight hours, varies } \\
\text { regulation requirements for each hour of day in each month (we vary } \\
\text { reserve requirements based on conditions of wind or solar). }\end{array}$ \\
\hline
\end{tabular}

\section{B.14 References}

Black \& Veatch, 2012, Integrated Photovoltaic (PV) Integration Cost Study, prepared for Arizona Public Service Company, Nov.

BPA (Bonneville Power Administration), 2009, 2010 BPA Rate Case Wholesale Power Rate Initial Proposal: Generation Inputs Study and Study Documentation [http://www.bpa.gov/ corporate/ratecase/2008/2010_BPA_Rate_Case/docs/WP-10-E-BPA-08.pdf].

CRA (Charles River Associates), 2010, SPP WITF Wind Integration Study, prepared for Southwest Power Pool, Little Rock, Ark. [http://www.spp.org/publications/2010.zip]. 
ERCOT (Electricity Reliability Council of Texas), 2011, 2011-2012 ERCOT Methodologies for Determining Ancillary Service Requirements, VG Operating Reserve Requirements, Western Electricity Coordinating Council, Salt Lake City, Utah [http://www.wecc.biz/committees/ StandingCommittees/JGC/VGS/OWG/ActivityO1].

EnerNex Corp., 2010, Eastern Wind Integration and Transmission Study, National Renewable Energy Laboratory, Golden Colo. [http://www.nrel.gov/wind/systemsintegration/ pdfs/2010/ewits_final_report.pdf].

GE Energy, 2010, Western Wind and Solar Integration Study, National Renewable Energy Laboratory, Golden, Colo. [http://www.nrel.gov/wind/systemsintegration/wwsis.html].

Makarov, Y. V, C. Loutan, J. Ma, and P. de Mello, 2009, "Operational Impacts of Wind Generation on California Power Systems," IEEE Transactions on Power Systems 24(2):10391050 .

Navigant Consulting, Sandia National Laboratories, Pacific Northwest National Laboratories, and NV Energy, 2011, Large-scale Solar Integration Study, NV Energy. Las Vegas, Nev. [http://www.navigant.com/insights/library/energy/large-scale_pv_integration_study/]. 
This page intentionally left blank. 


\section{Appendix C DA/HA Commitment and Dispatch Model Formulation}

The unit commitment and economic dispatch (UC/ED) model used in this analysis is a revised version of the model presented in Wang et al. (2011), Zhou et al. (2013), and Botterud et al. (2013). The model was expanded to include a representation of solar PV as well as balancingdown reserves.

The UC problem schedules the states of a set of available generator units in response to forecasted demand and renewable energy to minimize production cost. The ED problem is then used to determine the scheduled generation of a set of committed units, that is, the ED variables, in response to updated estimates of demand, so that the production cost is minimized for the realized demand. In general, both models are solved on a rolling basis in order to continually ensure that supply can meet demand over time. The UC problem is solved prior to the actual production based on imperfect demand and renewable energy forecasts, because of the minimum time required for every start-up and shutdown of the thermal generators. The ED problem is solved very close to the actual production when the demand forecast is more precise, to control the RT quantity produced to meet the demand. The UC and ED problems essentially use the same optimization model, but the commitment decision variables in the ED model are fixed. In the current formulation, the model has an hourly time resolution and the optimization is done over a 24-hr time period. The main equations in the model are outlined below.

First, we introduce the following general system parameters. $N_{\text {units }}$ is the number of generator units in the system. $N_{\text {segments }}$ is the number of segments of energy blocks. Different generators may have different fuel consumption curves, which are usually nonlinear. To reduce the computational complexity, we discretize unit efficiency curves into energy blocks, assuming a linear production cost increase in energy output within the same block. $N_{\text {hours }}$ is the number of hours for the optimization, assumed to be $24 \mathrm{hr}$ in the case study section. Based on the above parameters, we define the set of units in the power utility system $I=\left\{1, \ldots, N_{\text {units }}\right\}$, the set of energy blocks in each of the generators $K=\left\{1, \ldots, N_{\text {segments }}\right\}$, the set of hours in the simulation rolling horizon $T=\left\{1, \ldots, N_{\text {hours }}\right\}$.

\section{C.1 Operating Cost and Objective Functions}

The operating cost includes production cost, $c_{p g}(i, t)$, the penalty cost for any unmet demand, $c_{\text {ens }}(t)$, and operating reserves, $c_{r n s}(t)$, start-up cost, $c_{s u}(i, t)$, and shutdown costs, $c_{s d}(i, t)$. Specifically,

$$
c_{p g}(i, t)=N L C(i) * u(i, t)+\sum_{k} M C(i, k) * \operatorname{delta}(i, k, t)
$$

where $N L C(i)$ is the no-load cost of unit $i ; u(i, t)$ is the schedule states of unit $i$ at time $t$; $M C(i, k)$ is the $k^{\text {th }}$ step segment of the marginal cost function of unit $i$, and $\operatorname{delta}(i, k, t, s)$ is the amount of generation on the $k^{\text {th }}$ step segment at time $t$ for unit $i$. 


$$
\begin{gathered}
c_{\text {ens }}(t)=C E N S * d_{\text {ens }}(t) \\
c_{r n s}(t)=C R N S *\left(d_{\text {urns }}(t)+d_{d r n s}(t)\right)
\end{gathered}
$$

where $C E N S$ and $C R N S$ are the penalties of unmet energy and reserve, respectively; $d_{\text {ens }}(t)$ is the amount of unmet energy at time $t, d_{\text {urns }}(t)$ and $d_{d r n s}(t)$ are the amount of unmet upward and downward reserve.

Start-up costs, $c_{s d}(i, t)$, refer to costs of either warm or cold start-up, depending on how long the generator has been shut down. Shut-down costs are set to zero in this analysis.

For detailed representation of these costs and corresponding constraints, we refer to Wang et al. (2011), Zhou et al. (2013), and Botterud et al. (2013).

The objective function is to minimize the total operating cost, that is,

$$
\operatorname{Min} \sum_{i} \sum_{t} c_{p g}(i, t)+\sum_{t} \cdot\left[c_{e n s}(t)+c_{r n s}(t)\right]+\sum_{i} \sum_{t}\left[c_{s u}(i, t)+c_{s d}(i, t)\right]
$$

subject to the constraints introduced as follows.

\section{C.2 Demand and Supply Balance Constraints on Energy and Reserve}

Let $\mathrm{p}(i, t)$ the generation of unit $i$ at time $t, \operatorname{sp}(t)$ the solar power supply, $w p(t)$ the wind power supply, $r_{u}(i, t) / r_{d}(i, t)$ the amount of upward/downward reserve provided by unit $i$ at time $t$, $R_{u}(t) / R_{d}(t)$ are the amount of upward/downward reserve demand system wide at time $t$.

The demand balance requires the sum of the total power generation, the utilized solar and wind energy, and the amount of load not served equals the energy demand, $D_{t}$, that is,

$$
\sum_{i} \mathrm{p}(i, t)+s p(t)+w p(t)+d_{e n s}(t) \geq \mathrm{D}(t), \forall t
$$

The reserve balance requires the sum of the total reserve from thermal generators and the reserve not served to equal $R_{u}(t)$, and $R_{d}(t)$, respectively, that is,

$$
\sum_{i} r_{u}(i, t)+d_{u r n s}(t) \geq R_{u}(t), \sum_{i} r_{d}(i, t)+d_{d r n s}(t) \geq R_{d}(t), \forall t
$$


For renewable supply, let $W(t) / S(t)$ be available power supply from wind/solar at time $t$, then,

$$
\begin{gathered}
W(t) \geq w p(t) \\
S(t) \geq s p(t) .
\end{gathered}
$$

The difference is the curtailment of wind/solar power.

\section{C.3 The UC/ED Constraints}

The UC constraints are used to define the following UC variables: $u(i, t)$ is the binary $(0 / 1)$ variable used to denote the state of the generator unit; $z(i, t) / y(i, t)$ is the $0 / 1$ start-up/shut-down action indicator.

$$
\begin{gathered}
u(i, t-1) \geq y(i, t), \forall i, \forall t \\
1-u(i, t-1) \geq z(i, t), \forall i, \forall t \\
u(i, t)-u(i, t-1) \geq z(i, t)-y(i, t), \forall i, \forall t
\end{gathered}
$$

Generator power output is modeled with minimum and maximum output levels, $P_{\min }(i)$ and $P_{\max }(i)$. We use $B(i, k)$ to denote the size of the block, and $\delta(i, k, t) \geq 0$ to denote the power output at block $k$ for generator $i$ at time $t$, which shall not exceed the size of the block, that is,

$$
\delta(i, k, t) \leq B(i, k), \forall i, \forall k, \forall t
$$

For the ED decision, $p(i, t) \geq 0$ is the power output dispatched from generation unit $i$ at time $t$, which is the sum of the minimum power output when the unit is turned on and the cumulative block outputs, that is,

$$
p(i, t)=P_{\min }(i) u(i, t)+\sum_{k} \delta(i, k, t), \forall i, \forall t
$$

Let $p_{u}(i, t)$ be the maximum power for generator $i$ at time $t$, and $p_{d}(i, t)$ be the respective minimum power, then

$$
P_{\min }(i) \cdot u(i, t) \leq p_{d}(i, t) \leq \mathrm{p}(i, t) \leq p_{u}(i, t) \leq P_{\max }(i), \forall i, \forall t
$$

The operating reserves are defined separately for upward reserve and downward reserve. The upward operating reserve supplied by a generator, $r_{u}(i, t) \geq 0$, is the available unused capacity of generator $i$ at time $t$ that can be fully deployed in a short time frame (default assumption is 10 $\mathrm{min}$ ), and the downward reserve supplied by a generator, $r_{d}(i, t) \geq 0$, is the active capacity of generator $i$ at time $t$ that can be fully reduced within the same short time frame. The operating reserve balance for a generator requires the following:

$$
p_{u}(i, t)-r_{u}(i, t) \geq p(i, t), \forall i, \forall t
$$




$$
\begin{gathered}
p(i, t)-r_{d}(i, t) \geq p_{d}(i, t), \forall i, \forall t \\
r_{u}(i, t) \leq \operatorname{SRRESPONSETIME} * \operatorname{MSR}(i) * u(i, t) .
\end{gathered}
$$

where SRRESPONSETIME is the required response time and $\operatorname{MSR}(i)$ is the speed that unit $i$ can ramp up in unit time period.

The generators are dispatched in real time to meet demand variations. The rate that the generator can increase its power output is called ramp-up rate, and the rate that the generator can decrease its power output is called ramp-down rate. The ramp-up/down constraints are as follows:

$$
\begin{aligned}
& p_{u}(i, t) \leq \mathrm{p}(i, t-1)+\operatorname{Ramp}_{u}(\mathrm{i}) \cdot \mathrm{u}(i, t-1)+\operatorname{Ramp}_{s u}(\mathrm{i}) \cdot \mathrm{z}(i, t), \forall i, \forall t \\
& p_{d}(i, t) \geq \mathrm{p}(i, t-1)-\operatorname{Ramp}_{d}(\mathrm{i}) \cdot \mathrm{u}(i, t-1)-\operatorname{Ramp}_{s d}(\mathrm{i}) \cdot \mathrm{y}(i, t), \forall i, \forall t
\end{aligned}
$$

where $\operatorname{Ramp}_{u}(\mathrm{i}) / \operatorname{Ramp}_{d}(\mathrm{i})$ is the maximum hourly power output increase/decrease rate, and $\operatorname{Ramp}_{s u}(\mathrm{i}) / \operatorname{Ramp}_{s d}(\mathrm{i})$ is the maximum hourly increase/decrease rate when a unit is started up/shut down.

In power generation and other production scheduling, technological constraints and maintenance reasons force restrictions on the minimum number of time periods that a machine must stay active once turned on, and stay inactive once turned off, which are commonly referred to as minimum-up/minimum-down constraints. Because there are fixed costs associated with every start-up and shut-down, these constraints play an important role in UC. Rajan and Takriti (2005) characterize the polyhedral structure of a model representing these restrictions. We give the constraint formulation based on their study, which provides complete support for the facets of the minimum-up/down mixed integer programming polytope, reducing the computational complexity substantially.

Given a discrete planning horizon with $T$ periods, it is assumed that the minimum-up time for generator $i$ is $T_{m u}$ and the minimum-down time for generator $i$ is $T_{m d}$. Then we have the following constraints:

$$
\begin{gathered}
\sum_{\tau=t-T_{m u}+1}^{t} z(i, \tau) \leq u(i, t), \forall i, \forall t \\
\sum_{\tau=t-T_{m d}+1}^{t} y(i, \tau) \leq 1-u(i, t), \forall i, \forall t
\end{gathered}
$$




\section{C.5 References}

Botterud, A., Z. Zhou, J. Wang, J. Sumaili, H. Keko, J. Mendes, R.J. Bessa, and V. Miranda, 2013, "Demand Dispatch and Probabilistic Wind Power Forecasting in Unit Commitment and Economic Dispatch: A Case Study of Illinois," IEEE Transactions on Sustainable Energy 4(1):250-261.

Rajan D, Takriti S., 2005, Minimum up/down polytopes of the unit commitment problem with start-up costs. Report RC23628, IBM Research, June.

Wang J., A. Botterud, R. Bessa, H. Keko, L. Carvalho, D. Issicaba, J. Sumaili, and V. Miranda, 2011, "Wind Power Forecasting Uncertainty and Unit Commitment," Applied Energy 88(11):4014-4023.

Zhou, Z., A. Botterud, J. Wang, R.J. Bessa., H. Keko, J. Sumaili, and V. Miranda, “Application of Probabilistic Wind Power Forecasting in Electricity Markets," Wind Energy 16(3):321-338. 
This page intentionally left blank. 


\section{Appendix D Additional HA Scheduling Results}

In the tables below we present more detailed scheduling results for the benchmark low-PV and high-PV scenarios as well as for one of the sensitivity cases with high PV penetration, that is, the case with constant nuclear output.

Table D-1. Summary of HA Energy Scheduling Results for the Low-PV Scenario (2027)

\begin{tabular}{|c|c|c|c|c|c|}
\hline \multirow[b]{2}{*}{ Category } & \multicolumn{2}{|c|}{ Capacity of Plants } & \multicolumn{3}{|c|}{ Energy } \\
\hline & $\begin{array}{l}\mathrm{P}_{\min } \\
{[\mathrm{MW}]}\end{array}$ & $\begin{array}{l}P_{\max } \\
{[\mathrm{MW}]}\end{array}$ & $\begin{array}{c}\text { Average if on } \\
{[\mathrm{MW}]}\end{array}$ & $\begin{array}{c}\text { Energy } \\
\text { [GWh/yr] }\end{array}$ & $\begin{array}{c}\text { Energy } \\
{[\%]}\end{array}$ \\
\hline Nuclear (ST) & 581 & 1,162 & 1,162 & 10,181 & 25.2 \\
\hline Coal (ST) & 957 & 1,982 & 1,783 & 15,550 & 38.5 \\
\hline Gas (ST) & 813 & 3,206 & 60 & 1 & 0.0 \\
\hline Gas (CC) & 1,398 & 2,945 & 2,114 & 8,387 & 20.7 \\
\hline Gas (CT) & 121 & 361 & 1,707 & 933 & 2.3 \\
\hline Oil (CT) & 35 & 70 & N/A & 0 & 0.0 \\
\hline Solar PV & 0 & 1,674 & 793 & 3,474 & 8.6 \\
\hline Wind & 0 & 630 & 220 & 1,893 & 4.7 \\
\hline Total & 3,906 & 12,030 & & 40,418 & 100.0 \\
\hline
\end{tabular}

Table D-2. Summary of HA Energy Scheduling Results for the High-PV (Const. Nucl.) Scenario (2027)

\begin{tabular}{|c|c|c|c|c|c|}
\hline \multirow[b]{2}{*}{ Category } & \multicolumn{2}{|c|}{ Capacity of Plants } & \multicolumn{3}{|c|}{ Energy } \\
\hline & $\begin{array}{c}P_{\min } \\
{[\mathrm{MW}]}\end{array}$ & $\begin{array}{c}P_{\max } \\
{[\mathrm{MW}]}\end{array}$ & $\begin{array}{c}\text { Average if on } \\
{[\mathrm{MW}]}\end{array}$ & $\begin{array}{c}\text { Energy } \\
\text { [GWh/yr] }\end{array}$ & $\begin{array}{c}\text { Energy } \\
{[\%]}\end{array}$ \\
\hline Nuclear (ST) & 581 & 1,162 & 1,162 & 10,181 & 25.2 \\
\hline Coal (ST) & 957 & 1,982 & 1,720 & 14,981 & 37.1 \\
\hline Gas (ST) & 813 & 3,206 & 68 & 1 & 0.0 \\
\hline Gas (CC) & 1,398 & 2,945 & 1,956 & 7,215 & 17.9 \\
\hline Gas (CT) & 121 & 361 & 1,524 & 728 & 1.8 \\
\hline Oil (CT) & 35 & 70 & 8 & 0 & 0.0 \\
\hline Solar PV & 0 & 2,974 & 1,320 & 5,786 & 14.3 \\
\hline Wind & 0 & 630 & 215 & 1,527 & 3.8 \\
\hline Total & 3,906 & 13,330 & & 40,418 & 100.0 \\
\hline
\end{tabular}


Table D-3. Summary of HA Energy Scheduling Results for the High-PV (Flex. Nucl). Scenario (2027)

\begin{tabular}{|c|c|c|c|c|c|}
\hline \multirow[b]{2}{*}{ Category } & \multicolumn{2}{|c|}{ Capacity of Plants } & \multicolumn{3}{|c|}{ Energy } \\
\hline & $\begin{array}{l}\mathrm{P}_{\min } \\
{[\mathrm{MW}]}\end{array}$ & $\begin{array}{c}P_{\max } \\
{[\mathrm{MW}]}\end{array}$ & $\begin{array}{c}\text { Average if on } \\
{[\mathrm{MW}]}\end{array}$ & $\begin{array}{l}\text { Energy } \\
\text { [GWh/yr] }\end{array}$ & $\begin{array}{c}\text { Energy } \\
{[\%]}\end{array}$ \\
\hline Nuclear (ST) & 581 & 1,162 & 1,115 & 9,769 & 24.2 \\
\hline Coal (ST) & 957 & 1,982 & 1,713 & 14,586 & 36.1 \\
\hline Gas (ST) & 813 & 3,206 & 69 & 1 & 0.0 \\
\hline Gas (CC) & 1,398 & 2,945 & 1,941 & 6,866 & 17.0 \\
\hline Gas (CT) & 121 & 361 & 1,594 & 596 & 1.5 \\
\hline Oil (CT) & 35 & 70 & NA & 0 & 0.0 \\
\hline Solar PV & 0 & 2,974 & 1,548 & 6,784 & 16.8 \\
\hline Wind & 0 & 630 & 219 & 1,817 & 4.5 \\
\hline Total & 3,906 & 13,330 & & 40,418 & 100.0 \\
\hline
\end{tabular}

Table D-4. Summary of HA Reserve Scheduling Results for the Low-PV Scenario (2027)

\begin{tabular}{|c|c|c|c|c|c|c|c|c|}
\hline \multirow[b]{2}{*}{ Category } & \multicolumn{2}{|c|}{ Capacity of Plants } & \multicolumn{3}{|c|}{ Spinning Reserve up } & \multicolumn{3}{|c|}{ Spinning Reserve down } \\
\hline & $\begin{array}{c}P_{\min } \\
{[\mathrm{MW}]}\end{array}$ & $\begin{array}{l}P_{\max } \\
\text { [MW] }\end{array}$ & $\begin{array}{c}\text { Average if on } \\
{[\mathrm{MW}]}\end{array}$ & $\begin{array}{l}\text { Reserve } \\
\text { [GW-h/yr] }\end{array}$ & $\begin{array}{c}\text { Reserve } \\
{[\%]}\end{array}$ & $\begin{array}{c}\text { Average if on } \\
{[\mathrm{MW}]}\end{array}$ & $\begin{array}{l}\text { Reserve } \\
\text { [GW-h/yr] }\end{array}$ & $\begin{array}{c}\text { Reserve } \\
{[\%]}\end{array}$ \\
\hline Nuclear (ST) & 581 & 1,162 & 0 & 0 & 0.0 & 0 & 0 & 0.0 \\
\hline Coal (ST) & 957 & 1,982 & 107 & 934 & 28.0 & 175 & 1528 & 54.1 \\
\hline Gas (ST) & 813 & 3,206 & 39 & 1 & 0.0 & 0 & 0 & 0.0 \\
\hline Gas (CC) & 1,398 & 2,945 & 429 & 1863 & 55.8 & 324 & 1296 & 45.9 \\
\hline Gas (CT) & 121 & 361 & 767 & 542 & 16.2 & 8 & 2 & 0.1 \\
\hline Oil (CT) & 35 & 70 & $\mathrm{~N} / \mathrm{A}$ & 0 & 0.0 & 0 & 0 & 0.0 \\
\hline Solar PV & 0 & 1,674 & 0 & 0 & 0.0 & 0 & 0 & 0.0 \\
\hline Wind & 0 & 630 & 0 & 0 & 0.0 & 0 & 0 & 0.0 \\
\hline Total & 3,906 & 12,030 & & 3,341 & 100.0 & & 2,828 & 100.0 \\
\hline
\end{tabular}


Table D-5. Summary of HA Reserve Scheduling Results for the High-PV (Const. Nucl.) Scenario (2027)

\begin{tabular}{|c|c|c|c|c|c|c|c|c|}
\hline \multirow[b]{2}{*}{ Category } & \multicolumn{2}{|c|}{ Capacity of Plants } & \multicolumn{3}{|c|}{ Spinning Reserves up } & \multicolumn{3}{|c|}{ Spinning Reserves down } \\
\hline & $\begin{array}{l}P_{\min } \\
{[\mathrm{MW}]}\end{array}$ & $\begin{array}{l}P_{\max } \\
{[\mathrm{MW}]}\end{array}$ & $\begin{array}{c}\text { Average if on } \\
{[\mathrm{MW}]}\end{array}$ & $\begin{array}{c}\text { Reserve } \\
\text { [GW-h/yr] }\end{array}$ & $\begin{array}{c}\text { Reserve } \\
{[\%]}\end{array}$ & $\begin{array}{c}\text { Average if on } \\
{[\mathrm{MW}]}\end{array}$ & $\begin{array}{l}\text { Reserve } \\
\text { [GW-h/yr] }\end{array}$ & $\begin{array}{c}\text { Reserve } \\
{[\%]}\end{array}$ \\
\hline Nuclear (ST) & 581 & 1,162 & 0 & 0 & 0.0 & 0 & 0 & 0.0 \\
\hline Coal (ST) & 957 & 1,982 & 154 & 1,340 & 33.9 & 209 & 1,824 & 60.8 \\
\hline Gas (ST) & 813 & 3,206 & 35 & 0 & 0.0 & 0 & 0 & 0.0 \\
\hline Gas (CC) & 1,398 & 2,945 & 499 & 2,060 & 52.1 & 312 & 1,173 & 39.1 \\
\hline Gas (CT) & 121 & 361 & 847 & 553 & 14.0 & 5 & 1 & 0.0 \\
\hline Oil (CT) & 35 & 70 & 8 & 0 & 0.0 & 0 & 0 & 0.0 \\
\hline Solar PV & 0 & 2,974 & 0 & 0 & 0.0 & 0 & 0 & 0.0 \\
\hline Wind & 0 & 630 & 0 & 0 & 0.0 & 0 & 0 & 0.0 \\
\hline Total & 3,906 & 13,330 & & 3,953 & 100.0 & & 2,997 & 100.0 \\
\hline
\end{tabular}

Table D-6. Summary of HA Reserve Scheduling Results for the High-PV (Flex. Nucl.) Scenario (2027)

\begin{tabular}{|c|c|c|c|c|c|c|c|c|}
\hline \multirow[b]{2}{*}{ Category } & \multicolumn{2}{|c|}{ Capacity of Plants } & \multicolumn{3}{|c|}{ Spinning Reserves up } & \multicolumn{3}{|c|}{ Spinning Reserves down } \\
\hline & $\begin{array}{c}\mathrm{P}_{\min } \\
{[\mathrm{MW}]}\end{array}$ & $\begin{array}{c}\mathrm{P}_{\max } \\
{[\mathrm{MW}]}\end{array}$ & $\begin{array}{c}\text { Average if on } \\
{[\mathrm{MW}]}\end{array}$ & $\begin{array}{l}\text { Reserve } \\
\text { [GW-h/yr] }\end{array}$ & $\begin{array}{c}\text { Reserve } \\
{[\%]}\end{array}$ & $\begin{array}{c}\text { Average if on } \\
{[\mathrm{MW}]}\end{array}$ & $\begin{array}{l}\text { Reserve } \\
\text { [GW-h/yr] }\end{array}$ & $\begin{array}{c}\text { Reserve } \\
{[\%]}\end{array}$ \\
\hline Nuclear (ST) & 581 & 1,162 & 43 & 373 & 9.3 & 225 & 1,968 & 33.1 \\
\hline Coal (ST) & 957 & 1,982 & 122 & 1,030 & 25.7 & 257 & 2,189 & 36.8 \\
\hline Gas (ST) & 813 & 3,206 & 39 & 0 & 0.0 & 0 & 0 & 0.0 \\
\hline Gas (CC) & 1,398 & 2,945 & 592 & 2,086 & 52.1 & 528 & 1,780 & 30.0 \\
\hline Gas (CT) & 121 & 361 & 855 & 517 & 12.9 & 14 & 2 & 0.0 \\
\hline Oil (CT) & 35 & 70 & $\mathrm{~N} / \mathrm{A}$ & 0 & 0.0 & $\mathrm{~N} / \mathrm{A}$ & 0 & 0.0 \\
\hline Solar PV & 0 & 2,974 & 0 & 0 & 0.0 & 0 & 0 & 0.0 \\
\hline Wind & 0 & 630 & 0 & 0 & 0.0 & 0 & 0 & 0.0 \\
\hline Total & 3,906 & 13,330 & & 4,006 & 100.0 & & 5,939 & 100.0 \\
\hline
\end{tabular}


This page intentionally left blank. 


\section{Appendix E Location of Wind and Solar Sites}

Table E-1. Location and Configuration of PV Systems for APS (Sites 1-25 are used in the 2027 low-PV scenario, and sites 1-32 are used in the 2027 high-PV scenario)

\begin{tabular}{|c|c|c|c|c|c|}
\hline $\begin{array}{l}\text { Site } \\
\text { ID }\end{array}$ & Site Name & Location (in AZ) & $\begin{array}{c}\text { PV } \\
\text { Technology }\end{array}$ & $\begin{array}{c}\text { Tilt } \\
\text { (degrees) }\end{array}$ & $\begin{array}{l}\text { Capacity } \\
\text { (MW ac) }\end{array}$ \\
\hline 1 & APS Solar and ASU $20 \mathrm{MW}$ & Tempe & Fixed & 30 & 24.6 \\
\hline 2 & Small Gen RFP 2: Saddle Mountain 2013 & Near Tonopah & SAT & 0 & 13.1 \\
\hline 3 & Small Gen RFP 1: Ajo 2011 & Ajo & Fixed & 30 & 3.8 \\
\hline 4 & Small Gen RFP 1: Prescott 2011 & Prescott Near Airport & Fixed & 30 & 9.2 \\
\hline 5 & Small Gen RFP: Badger Desert Sky 2013 & $\begin{array}{l}\text { 355th Ave and Indian } \\
\text { School }\end{array}$ & SAT & 0 & 13.8 \\
\hline 6 & $\begin{array}{l}\text { AZ Sun: Cotton Center } 2011 \text { and } \\
\text { Small Gen RFP: Gillespie } 2014\end{array}$ & North of Gila Bend & SAT & 0 & 17.3 \\
\hline 7 & AZ Sun: Paloma 2011 & North of Gila Bend & Fixed & 30 & 16.3 \\
\hline 8 & AZ Sun: Hyder 2011 and 2013 & Hyder & SAT & 0 & 28.5 \\
\hline 9 & AZ Sun: YUMA Foothills 2013 & Yuma & SAT & 0 & 36.1 \\
\hline 10 & AZ Sun: Chino Valley 2012 & Chino Valley & SAT & 0 & 18.9 \\
\hline 11 & $\begin{array}{l}\text { AZ Sun2: PV - Future Project } 2014 \text { and } \\
2015^{\star}\end{array}$ & West of Gila Bend & SAT & 0 & 80.2 \\
\hline 12 & PV - Future Project 2014* & West of Gila Bend & Fixed & 30 & 32 \\
\hline 13 & PV: Future Project 2019* & West of Gila Bend & SAT & 0 & 100 \\
\hline 14 & PV: Future Project 2023* & East of Yuma & SAT & 0 & 100 \\
\hline 15 & PV: Future Project 2024* & East of Yuma & SAT & 0 & 100 \\
\hline 16 & DE Residential (Maricopa) NW & Phoenix & Fixed & 30 & 183.2 \\
\hline 17 & DE Residential (Maricopa) SW & Phoenix & Fixed & 30 & 91.6 \\
\hline 18 & DE Residential (Maricopa) SE & Phoenix & Fixed & 30 & 91.6 \\
\hline 19 & DE Residential (Maricopa) NE & Phoenix & Fixed & 30 & 91.6 \\
\hline 20 & DE Residential (Coconino) & Flagstaff & Fixed & 30 & 114.5 \\
\hline 21 & DE Commercial (Maricopa) NW & Phoenix & Fixed & 0 & 162.56 \\
\hline 22 & DE Commercial (Maricopa) SW & Phoenix & Fixed & 0 & 81.28 \\
\hline 23 & DE Commercial (Maricopa) SE & Phoenix & Fixed & 0 & 81.28 \\
\hline 24 & DE Commercial (Maricopa) NE & Phoenix & Fixed & 0 & 81.28 \\
\hline 25 & DE Commercial (Yavapai) & Prescott & Fixed & 0 & 101.6 \\
\hline 26 & 200 MW 30 percent project 1 & $\begin{array}{l}\text { Yuma - Gila Bend } \\
\text { Corridor }\end{array}$ & SAT & 0 & 200 \\
\hline 27 & 200 MW 30 percent project 2 & $\begin{array}{l}\text { Yuma - Gila Bend } \\
\text { Corridor }\end{array}$ & SAT & 0 & 200 \\
\hline 28 & 200 MW 30 percent project 3 & $\begin{array}{l}\text { Yuma - Gila Bend } \\
\text { Corridor }\end{array}$ & SAT & 0 & 200 \\
\hline 29 & 200 MW 30 percent project 4 & $\begin{array}{l}\text { Yuma - Gila Bend } \\
\text { Corridor }\end{array}$ & SAT & 0 & 200 \\
\hline 30 & 200 MW 30 percent project 5 & $\begin{array}{l}\text { Yuma - Gila Bend } \\
\text { Corridor }\end{array}$ & SAT & 0 & 200 \\
\hline 31 & 200 MW 30 percent project 6 & $\begin{array}{l}\text { Yuma - Gila Bend } \\
\text { Corridor }\end{array}$ & SAT & 0 & 200 \\
\hline 32 & $100 \mathrm{MW} 30$ percent project 1 & $\begin{array}{l}\text { Yuma - Gila Bend } \\
\text { Corridor }\end{array}$ & SAT & 0 & 100 \\
\hline
\end{tabular}


Table E-2. Location of Expected APS Wind Sites (Sites 1-21 are used in both the 2027 low-PV and high-PV scenarios.)

\begin{tabular}{rlcll}
\hline Site ID & APS IRP Site Name & $\begin{array}{c}\text { WWSIS } \\
\text { Site ID }\end{array}$ & $\begin{array}{c}\text { Geographic } \\
\text { Location }\end{array}$ & $\begin{array}{c}\text { Capacity } \\
\text { (MW ac) }\end{array}$ \\
\hline 1 & Aragonne Mesa 1 & 2773 & Eastern NM & 30 \\
2 & Aragonne Mesa 2 & 2738 & Eastern NM & 30 \\
3 & Aragonne Mesa 3 & 2739 & Eastern NM & 30 \\
4 & High Lonesome 1 & 2087 & Central NM & 30 \\
5 & High Lonesome 2 & 2149 & Central NM & 30 \\
6 & High Lonesome 3 & 2133 & Central NM & 30 \\
7 & Perrin Ranch 1 & 3577 & Central N. AZ & 30 \\
8 & Perrin Ranch 2 & 5378 & Central N. AZ & 30 \\
9 & Perrin Ranch 3 & 5455 & Central N. AZ & 30 \\
10 & Wind Owned NM (2022) 1 & 2588 & NM_EA WREZ & 30 \\
11 & Wind Owned NM (2022) 2 & 2587 & NM_EA WREZ & 30 \\
12 & Wind Owned NM (2022) 3 & 2589 & NM_EA WREZ & 30 \\
13 & Wind AZ (2025) 1 & 5051 & AZ_NE WREZ & 30 \\
14 & Wind AZ (2025) 2 & 5052 & AZ_NE WREZ & 30 \\
15 & Wind AZ (2025) 3 & 5053 & AZ_NE WREZ & 30 \\
16 & Wind Owned AZ (2026) 1 & 5212 & AZ_NE WREZ & 30 \\
17 & Wind Owned AZ (2026) 2 & 5213 & AZ_NE WREZ & 30 \\
18 & Wind Owned AZ (2026) 3 & 5215 & AZ_NE WREZ & 30 \\
19 & Wind NM (2027) 1 & 2525 & NM_EA WREZ & 30 \\
20 & Wind NM (2027) 2 & 2526 & NM_EA WREZ & 30 \\
21 & Wind NM (2027) 3 & 2527 & NM_EA WREZ & 30 \\
\hline
\end{tabular}





\section{Argonne}

Decision and Information Sciences Division

Argonne National Laboratory

9700 South Cass Avenue, BIdg. 221

Argonne, IL 60439-4844

www.anl.gov 